\title{
Experimentelle Untersuchung der Wasseraufnahme und der hydraulischen Eigenschaften des Wurzelsystems von sechs heimischen Baumarten
}

\author{
Dissertation \\ zur Erlangung des Doktorgrades \\ der Mathematisch-Naturwissenschaftlichen Fakultäten \\ der Georg-August-Universität zu Göttingen
}

vorgelegt von

Sandra Korn

geboren in Homberg

Göttingen 2004 
D 7

Referent: Prof. Dr. Ch. Leuschner

Korreferentin: Prof. Dr. A. Polle

Tag der mündlichen Prüfung: 25.06.2004 


\section{Inhaltsverzeichnis}

1 Einleitung 4

2 Untersuchungsgebiete $\quad 6$

2.1 Nationalpark Hainich $\ldots \ldots \ldots \ldots \ldots$

$2.1 .1 \quad$ Lage . . . . . . . . . . . . . . . . . . . . . 6

$2.1 .2 \quad$ Klima . . . . . . . . . . . . . . . . . . . . 6

2.1 .3 Geologie und Boden . . . . . . . . . . . . . . . . . . 7

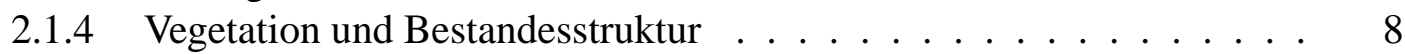

2.2 Lüneburger Heide $\ldots \ldots \ldots \ldots \ldots \ldots$

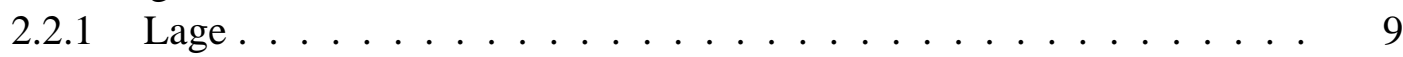

2.2 .2 Klima . . . . . . . . . . . . . . . . . . . . . 10

2.2 .3 Geologie und Boden . . . . . . . . . . . . . . . . . . . . 10

2.2 .4 Vegetation und Bestandesstruktur . . . . . . . . . . . . . . 10

2.3 Beschreibung der untersuchten Baumarten $\ldots \ldots \ldots \ldots \ldots \ldots$

3 Material und Methoden 15

3.1 Oberirdische Bestandesstruktur . . . . . . . . . . . . . . . . . 15

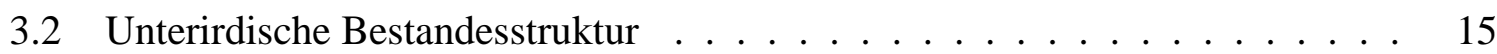

3.2 .1 Grobwurzelverteilung . . . . . . . . . . . . . . . . . . 15

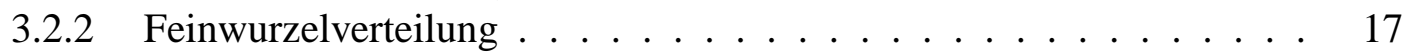

3.3 Xylemsaftflussmessung an Wurzeln $\ldots \ldots \ldots \ldots \ldots \ldots$

$3.3 .1 \quad$ Berechnung der Flussraten . . . . . . . . . . . . . . . . . 18

3.3 .2 Datenerfassung . . . . . . . . . . . . . . . . . . . 19

3.3.3 Auswahl der Wurzeln und Installation der Sensoren. . . . . . . . . 20

3.3 .4 Kalibrierung der Sensoren im Freiland. . . . . . . . . . . . . . 20

3.3 .5 Ernte der Messwurzeln, Lebend-Tot-Trennung . . . . . . . . . . 20

3.3.6 Bestimmung der Wurzeloberfläche, Durchmesser-Entfernungsbeziehung 21

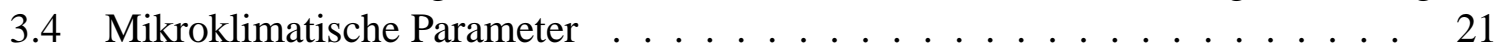

3.5 Registrierung des Bodenfeuchteregimes $\ldots \ldots \ldots \ldots \ldots \ldots 22$

3.5 .1 Volumetrischer Bodenwassergehalt . . . . . . . . . . . . . 22

3.5 .2 Bodenmatrixpotential . . . . . . . . . . . . . . . . 22

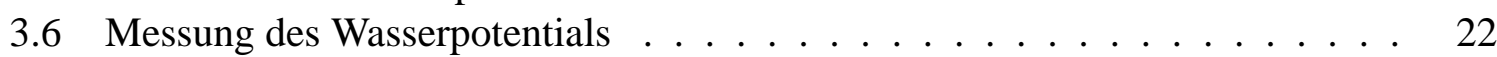

3.7 Anatomie der Messwurzeln $\ldots \ldots \ldots \ldots \ldots \ldots \ldots$

3.7 .1 Bestimmung der Leitfläche . . . . . . . . . . . . . . . . 23 
3.7.2 Untersuchung des Abschlussgewebes der Wurzelspitze . . . . . . . . 23

3.8 Messung der hydraulischen Leitfähigkeit . . . . . . . . . . . . . . . . . 24

3.8.1 Axiale hydraulische Leitfähigkeit . . . . . . . . . . . . . . . . . . . . . 24

3.8 .2 Theoretische Leitfähigkeit . . . . . . . . . . . . . . . . . . . 24

3.8.3 Hydraulische Leitfähigkeit . . . . . . . . . . . . . . . . . . . . 24

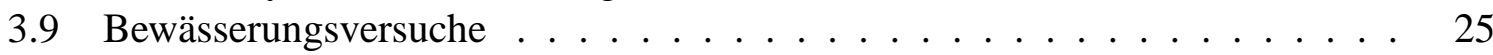

3.10 Statistische Auswertung der Daten . . . . . . . . . . . . . . . . . 25

4 Ergebnisse 27

$4.1 \quad$ Unterirdische Bestandesstruktur des Mischwaldes im Nationalpark Hainich . 27

$4.1 .1 \quad$ Horizontale Verteilung der Feinwurzeln . . . . . . . . . . . . . . 27

$4.1 .2 \quad$ Horizontal- und Vertikalverteilung der Grobwurzeln . . . . . . . . . 31

4.2 Wasseraufnahmeraten von sechs Baumarten und mögliche Einflussgrößen . . 37

$4.2 .1 \quad$ Kalibrierung der Sensoren im Freiland . . . . . . . . . . . . . . . 37

$4.2 .2 \quad$ Biometrische Daten und Morphologie der Wurzeln . . . . . . . . . . . . 38

$4.2 .3 \quad$ Anatomie der Wurzeln . . . . . . . . . . . . . . . . . . 42

$4.2 .4 \quad$ Edaphische und mikrometeorologische Parameter . . . . . . . . . . . 47

$4.2 .5 \quad$ Vergleich der Wasseraufnahmeraten der Baumarten . . . . . . . . . . 50

4.2 .6 Wasserpotentiale . . . . . . . . . . . . . . 61

$4.2 .7 \quad$ Vergleich der hydraulischen Leitfähigkeiten der Wurzeln der verschie-

4.2 .8 Abschätzung der Bestandeswasseraufnahme. . . . . . . . . . . . . 71

4.3 Vergleich der Wasseraufnahme an zwei edaphisch unterschiedlichen Standorten 72

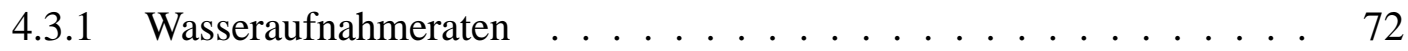

4.3.2 Morphologische und anatomische Eigenschaften . . . . . . . . . . 73

$4.3 .3 \quad$ Mikroklimatische und edaphische Einflüsse . . . . . . . . . . . . . . . . 77

4.3 .4 Wasserpotentiale . . . . . . . . . . . . . . . . . 81

4.4 Wasseraufnahme von Eichen- und Buchenwurzeln bei Wiederbewässerung nach Austrocknung des Bodens . . . . . . . . . . . . . . . . 83

$\begin{array}{llr}5 & \text { Diskussion } & 86\end{array}$

5.1 Wasseraufnahme und Saftfluss in Wurzeln . . . . . . . . . . . . . . . . 86

5.1 .1 Zur Theorie der Wasseraufnahme und des Saftflusses . . . . . . . . . 86

5.1 .2 Variabilität der Wurzel-Wasseraufnahmeraten . . . . . . . . . . . 88

5.2 Interspezifische Variabilität von sechs Baumarten hinsichtlich der Wasserauf-

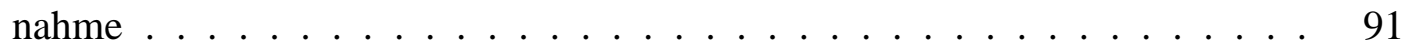

5.2.1 Die Bedeutung biotischer und abiotischer Faktoren für die WurzelWasseraufnahme verschiedener Baumarten . . . . . . . . . 98

5.2.2 Die Bedeutung der unterirdischen Bestandesstruktur für die Wasser-

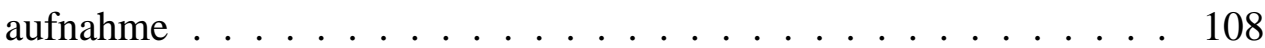

5.2.3 Veränderung der Wasseraufnahme während natürlich auftretender Tro-

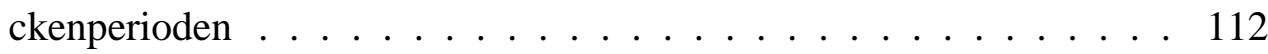


5.3 Wurzelwasseraufnahme von Eiche und Buche auf unterschiedlichen Böden . 125

$\begin{array}{lll}6 & \text { Zusammenfassung } & 128\end{array}$

\begin{tabular}{ll}
\hline Literaturverzeichnis & 130
\end{tabular}

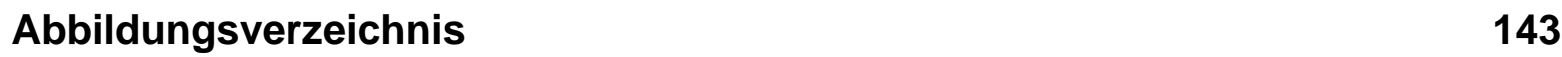

$\begin{array}{ll}\text { Tabellenverzeichnis } & 146\end{array}$

A Anhang I 


\section{Einleitung}

Das Wachstum von Landpflanzen ist zwingend an eine ausreichende Wasseraufnahme über die Wurzeln gebunden, da über die Blätter kontinuierlich Wasser abgegeben wird. Während über den Vorgang der Wasserabgabe in Form der Transpiration schon viel bekannt ist, ist die Physiologie der Wasseraufnahme bisher erst wenig untersucht worden. Insbesondere die Messung der Wasseraufnahme unter natürlichen Gegebenheiten ist aufgrund methodischer Schwierigkeiten bislang nicht intensiv betrieben worden.

So erfolgten bisher Untersuchungen zur hydraulischen Charakterisierung einzelner Wurzeln oder des gesamten Wurzelsystems durch experimentelle Bestimmung der hydraulischen Leitfähigkeit $\mathrm{Lp}_{r}$ im Labor unter Anlegen von Druck an abgeschnittenen Wurzelsystemen ( DINGER et al., 1994, STEUDLE \& MESHCHERYAKOV, 1996). Indirekt kann die Wasseraufnahme durch bodenhydrologische Messungen mittels Tensiometern und WasserhaushaltsModellierung bestimmt werden (z.B. NNYAMAH \& BLACK, 1977, RAMBAL, 1984).

Die direkte Messung des Saftflusses in der Wurzel wurde erst durch die Entwicklung thermischer Messmethoden ermöglicht (VIEWEG \& ZIEGLER, 1960). Bisher wurden jedoch meist Untersuchungen an Grobwurzeln mit Durchmessern über $20 \mathrm{~mm}$ durchgeführt (CABIBEL \& DO, 1991b, ONG \& KHAN, 1993, GREEN et al., 1997). Durch Miniaturisierung dieser Methode (SAKURATANi, 1981, BAKER \& VAN BAVEL, 1987, SENOCK \& HAM, 1993) lässt sich nun der Wasserfluss in wenige Millimeter starken Schwachwurzeln messen. Durch eine Weiterentwicklung in den letzten Jahren von SENOCK \& LEUSCHNER (1999), CONERS (2001) und CONERS \& LEUSCHNER (2002) bietet sie nun die Möglichkeit, die Wasseraufnahme einzelner Wurzelstränge in situ zu bestimmen und die untersuchten Wurzelstränge im Anschluss zu ernten. Dies ermöglicht die Bestimmung einer oberflächenspezifischen Wasseraufnahmerate.

In der vorliegenden Arbeit werden die hydraulischen Eigenschaften und die Wasseraufnahmeraten 3-4 mm starker Wurzeln von sechs mitteleuropäischen Baumarten unter natürlichen Bedingungen untersucht. Buche (Fagus sylvatica L.) und Bergahorn (Acer pseudoplatanus L.) werden als trockenheitsempfindliche Baumarten angesehen (ELLENBERG, 1996). Zu trockenheitstoleranten Baumarten werden dagegen Esche (Fraxinus excelsior L.), Stieleiche (Quercus robur L.), Winterlinde (Tilia cordata Mill.) und Hainbuche (Carpinus betulus L.) gezählt (PIGOTT, 1991, CARLIER et al., 1992, ELLENBERG, 1996).

Vor dem Hintergrund von auch in Mitteleuropa episodisch auftretenden Trockenperioden ist es von praktischer Bedeutung, zu wissen, welche Unterschiede zwischen den Pflanzenarten in der Ausschöpfung der Bodenwasserreserven bestehen und welche Anpassung im Wurzelsystem an zunehmende Austrocknung möglich ist. Aus dendroökologischen Untersuchungen ist bekannt, dass die Wasserverfügbarkeit einen zentralen Standortsfaktor für mitteleuropäische 
Baumarten darstellt und Wassermangel vielerorts den Dicken- und Höhenzuwachs der Bäume limitiert (BROCKMANN et al., 1987).

Die Untersuchung fand in einem artenreichen Mischbestand und einem benachbarten Buchenwald im Nationalpark Hainich (Thüringen) statt. Dieser befindet sich in einem Übergangsbereich vom subozeanischen zum subkontinental geprägten Klima Osteuropas am Rande des Thüringer Beckens. Periodisch auftretende Trockenperioden in den Sommermonaten werden durch ungünstige Eigenschaften des stark tonhaltigen Bodens gefördert ( $\mathrm{KOCH}, 2002)$. Dies ermöglichte es, die Wasseraufnahme-Kapazität der Wurzelsysteme vergleichend zu messen und deren Anpassungsfähigkeit an eine Bodenaustrocknung zu erkennen.

Die zusätzliche Betrachtung der Wasseraufnahmeraten von Buche (Fagus sylvatica L.) und Traubeneiche (Quercus petraea Matt. Liebl.) auf sandigem Boden in einem Bestand in der südlichen Lüneburger Heide erlaubte eine Aussage über den Einfluss der Bodenart auf die Wasseraufnahme über Feinwurzeln. 


\section{Untersuchungsgebiete}

Die Untersuchungen zur Wasseraufnahme von Wurzeln fanden in den Jahren 2000 und 2001 auf einer $6640 \mathrm{~m}^{2}$ großen Fläche in einem Mischwald im Nationalpark Hainich statt. In der Vegetationsperiode 2001 wurde zusätzlich eine $2400 \mathrm{~m}^{2}$ große Untersuchungsfläche in einem benachbarten Buchenreinbestand eingerichtet. Im Rahmen des Projektes „Ökologie artenreicher Mischwälder im Nationalpark Hainich“ wurden ein Mischwald und ein nahgelegener Buchenwald vergleichend untersucht.

In einem Eichen-Buchen-Mischbestand in der Lüneburger Heide fanden während eines achtwöchigen Messzeitraumes weitere Untersuchungen im Jahr 2001 statt.

\subsection{Nationalpark Hainich}

\subsubsection{Lage}

Der Nationalpark Hainich erstreckt sich im westlichen Thüringen über eine Fläche von 7600 ha. Er ist jedoch nur der südliche Teil des Höhenzuges Hainich, der das Thüringer Becken im Westen, Nordwesten und Norden umrandet (KLAUS \& REISINGER, 1995).

Die Untersuchungsfläche im Mischwald liegt in dem Waldgebiet 'Lindig' nahe des Ortes Weberstedt (515’28”60N 10³1'24”29E) auf einer Höhe von 290 m NN. In einer Entfernung von ca. $0.8 \mathrm{~km}$ befindet sich die Untersuchungsfläche in dem Buchenbestand. Diese Fläche liegt im Waldgebiet 'Lichte Hart (Hanfberg)' und ist ein Teil des Langensalzaer Stadtwaldes. Sie hat eine Hangneigung von maximal $4^{\circ}$ und liegt auf einer Höhe von 330 m NN.

\subsubsection{Klima}

Im Hainich lässt sich eine klimatische Zonierung erkennen (KLAUS \& REISINGER, 1995). Diese erstreckt sich von einem subozeanischen Klima im Werratal mit maximal $650 \mathrm{~mm}$ Jahresniederschlag über die Höhenlagen des Hainich, die mit 650-750 mm Niederschlag im Jahr einen submontanen Charakter aufweisen. Am Nordostrand des Hainichs, wo sich die Untersuchungsflächen befinden, geht das Klima zum subkontinentalen Osteuropa mit Niederschlägen von 550 bis $650 \mathrm{~mm}$ über (KLAUS \& REISINGER, 1995).

Die mittlere Jahrestemperatur wird für Weberstedt mit $7.5^{\circ} \mathrm{C}$ angegeben, der mittlere jährliche Niederschlag beträgt $669 \mathrm{~mm}$ (DEUTSCHER WETTERDIENST 2001). Der Niederschlag verteilt sich über das gesamte Jahr relativ gleichmäßig (Abb. 2.1A). Der Vergleich der mittleren monatlichen Niederschläge mit den gemessenen Niederschlägen während der Messperioden zeigte für das Jahr 2000 nur leichte Abweichungen vom langjährigen Mittel. (Abb. 2.1 B). 

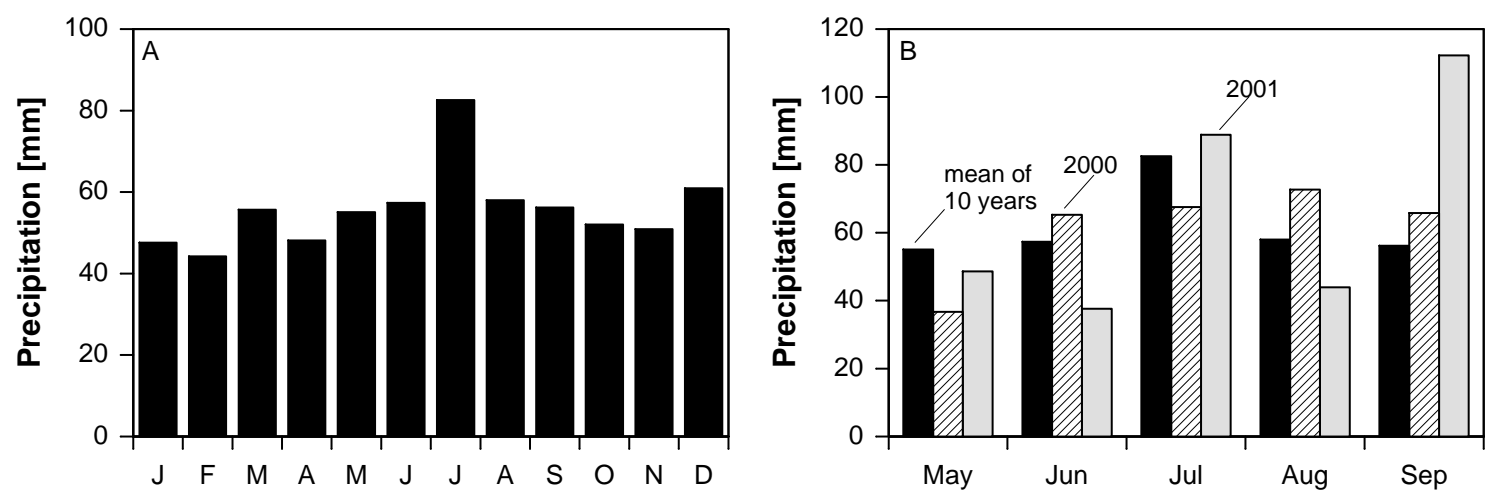

Abb. 2.1: A Mittlere Monatsniederschläge der Jahre 1990-2000 (Wetterstation Weberstedt, Deutscher Wetterdienst 2001). B Vergleich der Monatsniederschläge Mai-September 2000 und 2001 mit den langjährigen Monatsmittelwerten der Wetterstation. Die beiden Abbildungen sind unterschiedlich skaliert.

Auch die Niederschlagssumme des betrachteten Zeitraumes ist mit $308 \mathrm{~mm}$ dem langjährigen Mittel von 309 mm nahezu identisch. Im Jahr 2001 gab es kaum Abweichungen von den 10-jährigen Mittelwerten mit Ausnahme des Monats September, der mit $112 \mathrm{~mm}$ die doppelte Niederschlagsmenge aufwies. Daraus resultierte die etwas erhöhte Niederschlagssumme von $331 \mathrm{~mm}$ gegenüber $309 \mathrm{~mm}$ für die Monate Mai bis September.

\subsubsection{Geologie und Boden}

Auf den Untersuchungsflächen bildet der mittlere Muschelkalk des Trias, wie im gesamten Gebiet des Hainich, das Ausgangsmaterial für die Bodenbildung. Während im Buchenwald teilweise kleinräumige Lößauflagerungen zu finden sind, fehlen diese auf der Fläche im Mischwald. Als Bodentyp hat sich eine tonreiche Terra fusca-Braunerde herausgebildet. Die Bodenart kann als lehmiger Ton bzw. schluffiger Lehm eingestuft werden. Auf beiden Flächen steht das Gestein ab etwa $50 \mathrm{~cm}$ Tiefe an, wobei jedoch kleinräumig sehr starke Variationen möglich sind. Eine dünne organische Auflage lässt sich nur im Buchenwald finden (F-Mull). Im Mischwald dagegen ist nur eine Streuschicht $\left(\mathrm{O}_{L}\right)$ erkennbar.

Der $\mathrm{pH}_{\mathrm{KCl}}$-Wert des Bodens variiert in den oberen $50 \mathrm{~cm}$ zwischen 5.5 und 6.0 auf der Mischwaldfläche. Im Buchenwald zeigen sich ähnliche Verhältnisse, hier rangieren die $\mathrm{pH}_{\mathrm{KCl}}{ }^{-}$ Werte zwischen 5.1 im Oberboden und 5.9 in 30-50 cm Tiefe. Das C/N-Verhältnis ist mit 13$14 \mathrm{~mol} \mathrm{~mol}^{-1} \mathrm{im} \mathrm{Mischwald} \mathrm{etwas} \mathrm{weiter} \mathrm{als} \mathrm{im} \mathrm{Buchenwald} \mathrm{(11-12} \mathrm{mol} \mathrm{mol}^{-1}$ ). Auf beiden Untersuchungsflächen ist die Basensättigung und damit die Nährstoffversorgung mit $99 \%$ der effektiven Austauchkapazität (Mischwald) bzw. 85\% (Buchenwald) sehr hoch.

Die bodenchemischen Analysen wurden im Labor der Abteilung Ökologie der Universität Kassel durchgeführt. 


\subsubsection{Vegetation und Bestandesstruktur}

Die für den Hainich charakteristische Nutzungsform war der Plenterwald. Im Untersuchungsgebiet jedoch wurde eine Mittelwaldwirtschaft betrieben. Da durch diese die stockausschlagbefähigten Laubbaumarten begünstigt werden, kann vermutlich die artenreiche Baumzusammensetzung darauf zurückgeführt werden (ELLENBERG, 1996).

Weiterhin wurde das Gebiet im Hainich kaum forstwirtschaftlich genutzt (ab 1961 Naturschutzgebiet, ab 1964 Truppenübungsplatz der Nationalen Volksarmee der DDR, 1990 Übernahme durch die Deutsche Bundeswehr). 1995 wurde das Gelände an den Bundesforst übergeben, der einige Pflegemaßnahmen durchführen ließ, so wurden Stockausschläge der Linden entfernt, um Eichen und Edellaubhölzer freizustellen. Anfang 1998 trat das Nationalparkgesetz in Kraft, die forstwirtschaftliche Nutzung ist seitdem weitgehend eingestellt.

Der im Hainich vorherrschende Waldtyp ist das Elymo-Fagetum, der Laubwald im Hainich wird zu großen Teilen von Fagus sylvatica L. dominiert. In den östlichen Randbereichen nimmt die Häufigkeit der Buche jedoch ab, sie wird von winterlindenreichen Eichen-Hainbuchenwäldern abgelöst (MÖNNINGHOFF, 1998).

In dem untersuchten Mischwald setzt sich die Baumschicht aus 11 Baumarten zusammen (Tab. 2.1): Fraxinus excelsior L., Acer pseudoplatanus L., Tilia platyphyllos L., T. cordata Mill., Carpinus betulus L., Ulmus glabra Huds., Acer platanoides L., Quercus robur L., Acer campestre L., Fagus sylvatica L. und Prunus avium L. Zusammen erreichten diese Arten eine Stammdichte von 260 Stämmen ha ${ }^{-1}$.

Der Blattflächenindex (LAI) als Maß für die Belaubungsdichte ist im Mischwald mit $5.1 \mathrm{~m}^{2} \mathrm{~m}^{-2}$ nur geringfügig höher als im Buchenwald, in dem ein LAI von $4.9 \mathrm{~m}^{2} \mathrm{~m}^{-2}$ ermittelt wurde. Die Untersuchungsfläche im Buchenwald wird von Buchen beherrscht, Stieleichen, Winterlinden und Bergahorn stellen nur einen geringen Anteil der Arten. Mit 208 Stämmen ha $^{-1}$ ist die Stammdichte geringer als auf der Mischwaldfläche im Lindig.

Auf beiden Untersuchungsflächen beschränkt sich die Strauchschicht auf den Jungwuchs der Baumarten. In der Krautschicht gibt es eine große jahreszeitlich bedingte Variation. Auf der Mischwaldfläche findet man im Frühling (Aufnahme 12.04.2000) einen Deckungsgrad von $100 \%$ mit 13 Arten. Die am häufigsten vertretenen Arten sind Allium ursinum mit $90 \%$ Deckung, Leucojum vernum (50\%), Aconitum vulparia (10\%) und Corydalis carva (2\%). Mitte Juni beträgt der Deckungsgrad noch 90\%, 24 Arten sind vertreten, wobei Aegopodium podagraria (70\% Deckung), Aconitum vulparia (15\%), Ranunculus auricomus (10\%) und Lilium martagon (5\%) vorherrschen.

Auch auf der Untersuchungsfläche im Buchenwald ist der Deckungsgrad der Krautschicht im Frühling (Aufnahme 05.05.2001) mit 75\% hoch. Vorherrschend findet man auch hier Allium ursinum mit 50\% Deckung, Anemone nemorosa, A. ranunculoides, Ranunculus ficaria und Aegopodium podagraria mit jeweils 5 bis 25\% Deckung. Die Krautschicht setzt sich hier aus etwa 12 verschiedenen Arten zusammen. 
Tab. 2.1: Bestandesstrukturdaten der Untersuchungsflächen im Mischwald und dem benachbarten Buchenwald (Daten von $\mathrm{KOCH}, 2002$ ) im Nationalpark Hainich. BHU: Brusthöhenumfang, LAI: Blattflächenindex; für die einzelnen Baumarten ist der jeweilige relative Anteil in \% angegeben.

* Für die Ermittlung des LAI wurden beide Lindenarten zusammengefasst. nd - keine Angaben.

\begin{tabular}{lccccc}
\hline & $\begin{array}{c}\text { Stammdichte } \\
{\left[\mathrm{n} \mathrm{ha}^{-1}\right]}\end{array}$ & $\begin{array}{c}\text { Baumalter } \\
{[\mathrm{a}]}\end{array}$ & $\begin{array}{c}\text { Mittl. BHU } \\
{[\mathrm{cm}]}\end{array}$ & $\begin{array}{c}\text { Mittl. Höhe } \\
{[\mathrm{m}]}\end{array}$ & $\begin{array}{c}\text { LAI } \\
{\left[\mathrm{m}^{2} \mathrm{~m}^{-2}\right]}\end{array}$ \\
\hline Mischwald & $\mathbf{2 6 0}$ & & $\mathbf{1 2 9}$ & $\mathbf{3 5 . 6}$ & $\mathbf{5 . 1}$ \\
F. excelsior & 117 & 80 & 135 & 27.0 & $28 \%$ \\
A. pseudoplatanus & 48 & 80 & 109 & 22.3 & $15 \%$ \\
T. platyphyllos & 18 & 80 & 101 & 21.5 & $19 \%$ \\
T. cordata & 15 & 80 & 124 & 23.4 & $*$ \\
C. betulus & 15 & 80 & 118 & 24.4 & $9 \%$ \\
U. glabra & 15 & 80 & 143 & 24.4 & $4 \%$ \\
A. platanoides & 12 & 80 & 140 & 27.7 & $13 \%$ \\
$Q$. robur & 9 & 180 & 139 & 27.6 & $5 \%$ \\
A. campestre & 6 & 80 & 74 & 18.4 & $2 \%$ \\
F. sylvatica & 3 & 120 & 191 & 28.5 & $5 \%$ \\
P. avium & 2 & 80 & 60 & 12 & $<1 \%$ \\
\hline Buchenwald & $\mathbf{2 0 8}$ & & $\mathbf{1 5 3}$ & $\mathbf{3 0 . 0}$ & $\mathbf{4 . 9}$ \\
F. sylvatica & 171 & 140 & 158 & 30.4 & nd \\
$Q$. robur & 13 & 160 & 151 & 31.7 & $\mathrm{nd}$ \\
T. cordata & 8 & 100 & 65 & 18.4 & nd \\
A. pseudoplatanus & 4 & 100 & 89 & 27.5 & nd \\
\hline
\end{tabular}

\subsection{Lüneburger Heide}

\subsubsection{Lage}

Die Untersuchungen in der Lüneburger Heide wurden in einem Eichen-Buchen-Mischbestand im südlichen Teil der Lüneburger Heide durchgeführt. Der Bestand liegt $3 \mathrm{~km}$ westlich des Ortes Unterlüß (5245’ N, 10³0'E) auf einer Höhe von 115 m NN.

In dem Bestand wurde eine 0.77 ha große Fläche gezäunt (Untersuchungsfläche OB5), auf der seit 1988 Arbeiten zur Erforschung von Walddynamik (Projekt „Ursachen und Mechanismen der Heide-Wald-Sukzession") und Waldökosystemen durchgeführt werden (LEUSCHNER, 1994a, u.a.). 


\subsubsection{Klima}

Das Klima im Untersuchungsgebiet in der Lüneburger Heide ist subozeanisch und kühlgemäßigt. Die langjährige Jahresmitteltemperatur beträgt $8.1^{\circ} \mathrm{C}$. Der jährliche Niederschlag wird mit $801 \mathrm{~mm}$ angegeben, während der Vegetationsperiode Mai bis September wurden 352 mm gemessen (langjähriges Mittel 1961 - 1990 der Station Unterlüß des Deutschen Wetterdienstes).

\subsubsection{Geologie und Boden}

Das Ausgangsmaterial des Bodens besteht aus Schmelzwassersanden der Saale-Eiszeit. Die oberen 40 bis $60 \mathrm{~cm}$ des Bodenprofils bestehen aus periglazialen Geschiebedecksanden der Weichsel-Kaltzeit. Aus diesem Ausgangsmaterial geht ein nährstoffarmer, saurer Mineralboden hervor, der einen $\mathrm{pH}_{K C l^{-}}$Wert von 3.8-4.2 aufweist (BÜTTNER \& LEUSCHNER, 1994).

Als Bodentyp liegt eine podsolige Braunerde vor, der als Humusform ein 8-10 cm starker rohhumusartiger Moder aufliegt. Auch diese ca. $10 \mathrm{~cm}$ mächtige organische Auflage reagiert mit einem $\mathrm{pH}_{\mathrm{KCl}}$ von 2.6-3.0 sauer. Als Bodenart liegt ein Mittelsand vor.

Das C/N-Verhältnis ist mit 22-28 $\mathrm{mol} \mathrm{mol}^{-1}$ in der Auflage und $24 \mathrm{~mol} \mathrm{~mol}^{-1} \mathrm{im} \mathrm{Mineralbo-}^{-}$ den deutlich weiter als im Hainich. Dementsprechend steht die Basensättigung mit nur ca. 5\% der $\mathrm{AK}_{e}$ für eine relativ schlechte Nährstoffversorgung (WEYKAM, 1991).

Das Grundwasser steht erst in 30-40 m Tiefe und damit weit unterhalb des durchwurzelten Bodens an.

\subsubsection{Vegetation und Bestandesstruktur}

Der untersuchte Eichen-Buchen-Mischwald gehörte zu landesherrlichem Jagdgebiet, weshalb er wahrscheinlich nie vollständig entwaldet gewesen ist. Eine intensive Durchforstung fand hier nicht statt, daher kann der Bestand als potentiell natürliche Vegetation angesehen werden (LEUSCHNER, 1994a).

Tab. 2.2: Bestandesstrukturdaten der Untersuchungsfläche OB5 in der Lüneburger Heide (LEUSCHNER, 1994a) BHU: Brusthöhenumfang (BACKES, 1996), LAI: Blattflächenindex

\begin{tabular}{lccccc}
\hline & $\begin{array}{c}\text { Stammdichte } \\
{\left[\mathrm{n} \mathrm{ha}^{-1}\right]}\end{array}$ & $\begin{array}{c}\text { Baumalter } \\
{[\mathrm{a}]}\end{array}$ & $\begin{array}{c}\text { Mittl. BHU } \\
{[\mathrm{cm}]}\end{array}$ & $\begin{array}{c}\text { Mittl. Höhe } \\
{[\mathrm{m}]}\end{array}$ & $\begin{array}{c}\text { LAI } \\
{\left[\mathrm{m}^{2} \mathrm{~m}^{-2}\right]}\end{array}$ \\
\hline Bestand & $\mathbf{5 3 3}$ & & $\mathbf{1 1 9 . 4}$ & $\mathbf{2 8 . 0 0}$ & $\mathbf{5 . 5 4}$ \\
F. sylvatica & 481 & $85-105$ & 55.6 & 17.4 & 3.90 \\
Q. petraea & 52 & $180-200$ & 164.0 & 27.2 & 1.64 \\
\hline
\end{tabular}

Der Bestand setzt sich zu 90\% aus Buchen (Fagus sylvatica L.) und zu 10\% aus Traubeneichen (Quercus petraea (Matt.) Liebl.) zusammen, die eine Stammdichte von 220 Stämmen ha $^{-1}$ er- 
reichen (Tab. 2.2). Eine Strauchschicht ist auf dieser Untersuchungsfläche nicht vorhanden, eine Krautschicht fehlt ebenfalls, lediglich vereinzelt treten Avenella flexuosa und Carex pilulifera auf.

\subsection{Beschreibung der untersuchten Baumarten}

Der Bergahorn (Acer pseudoplatanus L.) ist eine ausgeprägte Mischbaumart, die in den gemäßigten Zonen im ozeanischen Klima vorkommt. Er bevorzugt nährstoffreiche, tiefgründige und feuchten Geröllböden, gilt jedoch als eine Art mit sehr hohen Feuchtigkeitsansprüchen und einer sehr großen Dürreempfindlichkeit. Während der Jungwuchs des Bergahorns noch schattenertragend ist, steigt der Lichtbedarf mit zunehmendem Alter stark an (SPETHMAN \& NAMVAR, 1985).

Als dominante Art tritt der Bergahorn dort auf, wo die Buche aus standörtlichen Gründen fehlt, wie in den Acerion-Gesellschaften (ELLENBERG, 1996).

Holzanatomisch gehört der Bergahorn zu den zerstreutporigen Baumarten mit kleinen, über den gesamten Holzquerschnitt verteilten Gefäßen. Die Wasserleitung findet hier, wie bei allen Zerstreutporern, in einem breiten Splintholzmantel statt. Lediglich in der Kernholzzone ist der Wassertransport eingestellt.

Das Wurzelsystem des Bergahorns ist intensiv verzweigt, aber flach. Die Hauptwurzelmasse wird von oberflächennahen Horizontalwurzeln gebildet. Die Durchwurzelung des Bodenraums durch den Bergahorn kann sehr extensiv sein, jedoch wurde auf ähnlichen Böden auch eine starke Durchwurzelung gefunden (KÖSTLER et al., 1968). Als typisch für den Bergahorn kann ein flaches Herzsenkerwurzelsystem angesehen werden.

Die Esche (Fraxinus excelsior L.) ist eine charakteristische Art der Auenwälder und Schluchtwälder feuchtkühler Lagen. Auch sie zählt, wie der Bergahorn, zu den typischen Mischbaumarten und Edellaubhölzern in Mitteleuropa. Allerdings weist die Esche eine breite ökologische Amplitude auf, sie ist sowohl auf trockenen, flachgründigen Kalkstandorten als auch auf feuchten Standorten zu finden (Eschen-Bachrinnenwälder, Ahorn-Eschen-Hangfußwälder). Eine daraus resultierende Unterscheidung in die zwei Standortsrassen oder Ökotypen Kalkesche und Wasseresche konnte jedoch nicht bestätigt werden (WEISER, 1995).

Dennoch zählt die Esche zu den am stärksten transpirierenden Waldbäumen, weshalb sie auf eine gute Wasserversorgung während der Vegetationszeit angewiesen ist.

Als Sämling kann die Esche noch zu den relativ schattentoleranten Baumarten gezählt werden, allerdings nur unter stark eingeschränktem Wachstum. Starkes Höhenwachstum setzt erst unter guten Lichtbedingungen ein, daher wird die Esche zu den Lichtbaumarten gezählt ( $\mathrm{MA}-$ RIGO et al., 2000).

Die Esche gehört zu den Ringporern, d.h. die Xylemgefäße des Frühholzes haben einen großen Durchmesser und sind regelmäßig an der Jahrringgrenze angeordnet. Die Gefäße des Spätholzes sind englumiger. Der Wassertransport findet nur in wenigen äußeren Jahrringen statt.

Die Esche kann auch tonige, wechsel- oder grundfeuchte und basenreiche Böden intensiv 
durchwurzeln und dort stabile Ökosysteme aufbauen (ASCHE, 1995). Das Wurzelsystem der Esche ist recht einheitlich und regelmäßig. Sie besitzt ein Senkerwurzelsystem, deren horizontal verlaufende Wurzeln kräftig und weitstreichend sind und flach im Oberboden verlaufen. Als charakteristisch für die Esche gilt eine Konzentration der Feinwurzeln auf die obersten Bodenzonen. So konnten auf Lößböden bis zu 57\% der Feinwurzeln in den obersten $20 \mathrm{~cm}$ des Bodens gefunden werden, während die Wurzeln vergesellschafteter Bäume in tiefere Bodenhorizonte gedrängt werden (KÖSTLER et al., 1968, GULDER, 2002).

Die Winterlinde (Tilia cordata Mill.) gehört ebenfalls zu den typischen Mischbaumarten und kommt nur selten in Reinbeständen vor. Sie bevorzugt lichte und sommerwarme Laubmischwälder, Auewald- und Trockenwaldgesellschaften. Sie findet sich als nebenbestandesbildende Art in trockenen Ausbildungen des Eichen-Hainbuchenwaldes. Auf trockenen Standorten gilt die Winterlinde als konkurrenzstärkste Art unter den Edellaubhölzern. Die Linde zählt zu den Schattenbaumarten, sie bevorzugt mittel- bis tiefgründige, lockeren und mineralstoffreiche Böden mit einem ausgeglichenen Wasserhaushalt (NAMVAR \& SPETHMAN, 1986).

Auch die Winterlinde zählt zu den zerstreutporigen Baumarten, wie ein Großteil der in Mitteleuropa verbreiteten Bäume.

Die Winterlinde besitzt ein unregelmäßiges Herzwurzelsystem, aus dem Wurzelausschläge austreiben. Typisch für die Winterlinde sind zahlreiche unmittelbar aus dem Stock und den starken Hauptseitenwurzeln entspringenden Feinwurzeln im Oberboden. Doch scheint die Ausprägung des Wurzelsystems auch von der Vitalität bzw. der soziologischen Stellung des Baumes abzuhängen. So können herrschende Linde mit voller Krone ein sehr intensives Wurzelsystem ausbilden, während bedrängte schwächere Bäume nur eine extensive Durchwurzelung des Bodens erreichen. Insgesamt ist jedoch zu beobachten, dass die Winterlinde nur einen recht kleinen Bodenraum erschließt. Die Feinwurzeln der Winterlinde folgen häufig abgestorbenen Wurzelröhren des gleichen Stockes und dringen am Ende dann kräftig entwickelt in den Boden vor (Selbstaprophytismus) (KÖSTLER et al., 1968).

Die Hainbuche (Carpinus betulus L.) ist eine Baumart des subozeanischen Klimas mit dem Verbreitungsschwerpunkt in Mittel- und Südosteuropa. Da sie eine deutlich geringere Spätfrostempfindlichkeit als die Buche besitzt, dringt die Hainbuche in den stärker kontinental geprägten Klimabereich im Osten vor (ELLENBERG, 1996, TÜRK, 1996). Sie toleriert warme Sommer und findet optimale Wuchsbedingungen auf nährstoffreichen, frischen oder periodisch nassen Böden. Auf grundwasserbeeinflussten, nährstoffreichen Böden findet man Stieleichen-Hainbuchenwälder. Die Hainbuche wird durch Mittel- und Niederwaldwirtschaft gefördert, da sie ein gutes Stockausschlagsvermögen besitzt (TÜRK, 1996).

Im Jungwuchs gilt sie als eine Baumart mit hoher Schattentoleranz, im Alter stark Schatten erzeugend. Durch Wassermangel kann die Hainbuche jedoch leicht geschädigt werden (LEIBUNDGUT, 1991). Nach anderen Autoren gilt die Hainbuche dagegen als relativ dürreunempfindlich (ELLENBERG, 1996, TÜRK, 1996), wodurch sie auch längere Phasen ausgeprägter Sommertrockenheit problemlos überstehen kann. 
Wie schon Winterlinde und Bergahorn gehört auch die Hainbuche zu den zerstreutporigen Baumarten. Jedoch sind bei ihr schon recht deutliche Größenunterschiede zwischen Gefäßen des Früh- und Spätholzes zu erkennen, weshalb sie auch als halb-ringporig angesprochen wird. Das Wurzelsystem der Hainbuche ist sehr einheitlich und regelmäßig. Sie bildet ein Herzwurzelsystem aus, dessen Wurzeln sich strahlenförmig vom Stock her ausbreiten. Daher werden auch unterhalb von 20-30 cm kaum noch horizontal verlaufende Wurzeln gefunden. Auf tiefgründigen Böden ist das Wurzelsystem auch sehr tiefreichend und intensiv, auf feuchten, tonig-lehmigen Substraten wurzelt sie jedoch recht flach (bis $50 \mathrm{~cm}$ Bodentiefe, mit Ausnahme einzelner Vertikalwurzeln). Die Feinwurzelverteilung ist gleichmäßig, ebenso wie die Aufzweigung in Feinwurzeln (KÖSTLER et al., 1968).

Die beiden Eichenarten Stieleiche (Quercus robur L.) und Traubeneiche (Quercus petraea Matt.(Liebl.)) haben ihren Verbreitungsschwerpunkt in West- und Mitteleuropa. Die Stieleiche ist darüber hinaus auch im kontinentalen Osteuropa verbreitet (AAS, 1998).

Beide Arten stehen oft gemeinsam und neigen zur Bastardisierung, dennoch sind sie ökologisch differenziert. Die Stieleiche bevorzugt tiefgründige Böden feuchter bis nasser Standorte auch mit zeitweiliger Überflutung (Auwald). Dies sind oft schwere Ton- oder Lehmböden mit einer guten Wasserversorgung. Die Traubeneiche dagegen reagiert empfindlich auf feuchte Böden, sie stockt auf durchlässigen, frischen bis trockenen Böden wie Sanden (AAS, 1998). Daher ist sie auch weniger sensitiv gegenüber mangelnder Wasserversorgung.

Die Eichen zählen zu den ausgesprochenen Lichtholzarten, sie sind als Jungwuchs nur gering schattenertragend.

Wie die Eschen sind auch die beiden Eichenarten ringporige Hölzer, der Wassertransport im Stamm findet nur in den äußeren Jahrringen statt.

Im Wurzelsystem unterscheiden sich Stiel- und Traubeneiche nicht wesentlich voneinander, z.T. konnten auf gleichen Standorten keine Unterschiede festgestellt werden (KöSTLER et al. 1968). Die Eichen bilden ein extensives Herzwurzelsystem mit weitstreichenden, brettartigen Hauptseitenwurzeln aus. Schwächere Senkerwurzeln, die sich nur wenig verjüngen, entspringen aus diesen Seitenwurzeln. Charakteristisch für die Eiche ist eine spitzwinklige Aufzweigungsform der Wurzeln bis zu einem Durchmesser von 0.5-1.0 cm. Anschließend verjüngen sich auch diese Wurzelstränge nur noch sehr langsam und durchziehen den Boden auf große Entfernungen.

Die Buche (Fagus sylvatica L.) ist eine Baumart des atlantischen bis subkontinentalen Klimas. Sie bildet in vielen mitteleuropäischen Regionen natürliche Reinbestände und stellt oftmals bedeutende Anteile in Mischbeständen. Dort kann sie vergesellschaftet sein mit Edellaubbaumarten wie Esche, Ahorne, Linde und Kirsche. Die Buche gehört zu den Schattbaumarten, die gut schattenertragend sind und im Alter selbst auch einen starken Schatten erzeugen.

Buchenwälder bilden in weiten Teilen Mitteleuropas die potentielle natürliche Vegetation. Die Buche ist in ihren Standortansprüchen sehr variabel. Innerhalb ihrer Verbreitungsgrenzen ist die Buche sehr konkurrenzstark, allerdings ist sie gegen Dürrezeiten im Sommer sehr emp- 
findlich. Daher werden gute Wuchsleistungen nur erzielt, wenn der Boden während der Vegetationszeit gut mit Wasser versorgt ist. Auch gegenüber Spätfrösten im Frühjahr und starkem Winterfrost ist die Buche sehr empfindlich (ELLENBERG, 1996).

In ihrer Holzanatomie kann die Buche den zerstreutporigen Hölzern zugeordnet werden.

Die Buche hat ein typisches Herzwurzelsystem, sie zählt zu den intensiv wurzelnden Baumarten. Entsprechend besitzt sie eine sehr hohe Feinwurzelintensität. Die Durchwurzelung des Bodens ist sehr gleichmäßig, sie entwickelt starke Hauptseitenwurzeln, die sich relativ rasch in schwächere Wurzeln aufzweigen. Mit zunehmendem Alter erhöht sich die Intensität der Durchwurzelung, wodurch ein dichtes Wurzelgeflecht entsteht (KÖSTLER et al., 1968). 


\section{Material und Methoden}

\subsection{Oberirdische Bestandesstruktur}

Auf der $6640 \mathrm{~m}^{2}$ großen Untersuchungsfläche im Hainich wurden verschiedene Strukturparameter aufgenommen, um die Bestandesstruktur der Mischwaldfläche beschreiben zu können. Bestimmt wurden jeweils die Baumart, der Stammumfang in $1.3 \mathrm{~m}$ Höhe (BHU) und die Stammfußpunkte auf der Fläche.

Mit Hilfe eines Höhenmessers (Hypsometer Typ PM-5/1520 PCP, Suunto, Espoo, Finnland) wurden die Baumhöhen und die Kronenansatzhöhen vermessen (KRAMER \& AKÇA, 1987). Von allen Bäumen auf der Untersuchungsfläche wurden die Kronenprojektionsflächen aus dem Abstand zwischen Stammfuß und äußerem Kronenende in 4-Punkt-Messungen (Nord, West, Süd, Ost) berechnet. An den Messbäumen wurden die Kronenprojektionsflächen anhand von 8-Punkt-Messungen errechnet.

Die Aufnahme dieser Parameter auf der Buchenwaldfläche erfolgte durch KOCH (2002).

\subsection{Unterirdische Bestandesstruktur}

Um die Verteilung der Grob- und Feinwurzeln im Bestand aufnehmen zu können, wurden zunächst charakteristische morphologische Merkmale der Wurzeln aller vertretenen Baumarten ermittelt, anhand derer die Wurzel im Feld und im Labor unter dem Binokular den Arten zugeordnet werden konnten (Tab. 3.1).

Durch den Mischbestand wurden drei Transekte gelegt, entlang derer die Probenahmestellen für die Grob- und die Feinwurzeluntersuchungen zufällig ausgewählt wurden. Die jeweils $60 \mathrm{~m}$ langen Transekte lagen mit einem Abstand von $10 \mathrm{~m}$ parallel zueinander. Die Probestellen hatten jeweils einem Abstand von mindestens $1 \mathrm{~m}$.

Die Untersuchung der Grob- und Feinwurzeln auf der Buchenwaldfläche wurde von $\mathrm{KOCH}$ (2002) durchgeführt.

\subsubsection{Grobwurzelverteilung}

Für die Untersuchung der Grobwurzeln wurden auf den drei Transekten zufällig 40 Probenahmestellen ausgewählt, an denen Profilwände $(0.5 \mathrm{~m}$ x $0.5 \mathrm{~m})$ angelegt wurden. In vier Bodentiefen $(0-10 \mathrm{~cm}, 10-20 \mathrm{~cm}, 20-30 \mathrm{~cm}, 30-50 \mathrm{~cm})$ wurden alle Wurzeln mit einem Durchmesser $>2 \mathrm{~mm}$ mit Hilfe einer Schieblehre vermessen und die Baumart bestimmt.

Eine Unterscheidung von toten und lebenden Grobwurzeln war nur eingeschränkt möglich, da zum einen die Wurzeln einer starken mechanischen Belastung beim Anlegen der Profilwände 


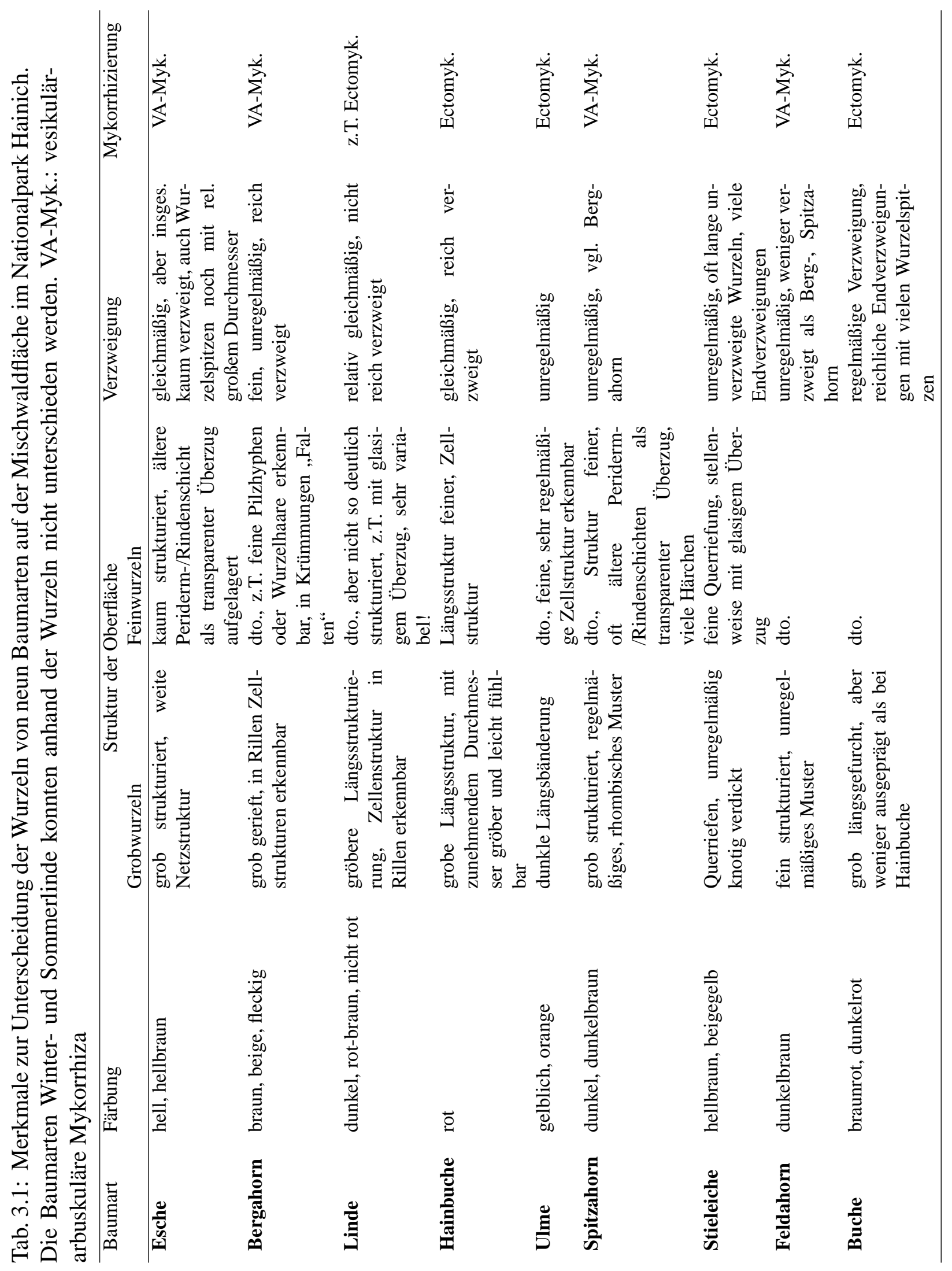


ausgesetzt waren. Wurzeln, die eindeutig tot waren (beginnender Zerfall, Ablösung des Periderms vom Zentralzylinder, sehr eingeschränkte Biegsamkeit), wurden nicht berücksichtigt. Nach BÖHM (1979) wurden die Grobwurzeln in vier Durchmesserklassen eingeteilt (Tab. 3.2).

Tab. 3.2: Einteilung der Grobwurzeln in Durchmesserklassen nach BÖHM $(1979)$.

\begin{tabular}{lc}
\hline & Durchmesser \\
\hline Schwachwurzeln & $2-5 \mathrm{~mm}$ \\
Derbwurzeln & $5-10 \mathrm{~mm}$ \\
Grobwurzeln i. e. S. & $10-20 \mathrm{~mm}$ \\
Starkwurzeln & $>20 \mathrm{~mm}$ \\
\hline
\end{tabular}

Die Entfernung der Probenahmestellen zu den umstehenden Altbäumen wurde mit einem optischen Entfernungsmessgerät (Infrarot-Ultraschall-Entfernungsmessgerät) gemessen.

\subsubsection{Feinwurzelverteilung}

Die Verteilung der Feinwurzeln (Durchmesser $<2 \mathrm{~mm}$ ) im Mischbestand wurde ebenfalls entlang der Transekte untersucht. Dafür wurden pro Transekt jeweils 20 Probestellen zufällig ausgewählt. Dort wurden mit einem Wurzelbohrstock (Durchmesser $35 \mathrm{~mm}$ ) in zwei Tiefen $(0-10 \mathrm{~cm}, 10-20 \mathrm{~cm})$ Proben entnommen. Die Entfernung der Probenahmestellen zu den umstehenden Bäumen wurde ebenfalls mit dem Entfernungsmessgerät bestimmt.

Im Labor wurden aus diesen Proben die Feinwurzeln in einem Sieb (Maschenweite $200 \mu \mathrm{m}$ ) ausgewaschen. Unter dem Binokular wurden von den frisch ausgewaschenen Wurzeln zunächst die toten Anteile aussortiert. Diese lassen sich daran erkennen, dass sie nicht mehr voll turgeszent, luftgefüllt und faserig sind. Die Wurzeln sind bei Druck mit der Pinzette nicht mehr elastisch (HERTEL, 1999).

Die Bestimmung der Baumart erfolgte anhand der morphologischen Unterscheidungsmerkmale in Tab. 3.1.

Wurzeln, Rhizome und Zwiebeln der krautigen Arten, die sich durch ihre sehr helle Oberflächenfärbung sowie eine großzellige Oberflächenstruktur und der fehlenden Verholzung leicht von den Baumwurzeln unterscheiden lassen, wurden mit dem Totanteil der Baumwurzeln verworfen. Ebenfalls nicht berücksichtigt wurden kleinste Feinwurzelfragmente, deren zeitaufwendige Identifizierung im Rahmen dieser Arbeit nicht möglich war.

Die nach Baumarten getrennten lebenden Feinwurzeln wurden im Trockenschrank bei $70^{\circ} \mathrm{C}$ 48 Stunden getrocknet. Anschließend wurde auf einer Feinwaage das Trockengewicht bestimmt. Pro Baumart wurden vor der Trocknung 15-20 Proben jeder Tiefenstufe ausgewählt, deren Wurzeloberfläche mit dem Scannersystem WinRhizo (Version 5.0, Regent Instruments Inc., Quebec, Canada) bestimmt wurde. Erst daran anschließend wurden diese Proben ebenfalls getrocknet und ausgewogen. 
Aus diesen Daten konnte die spezifische Feinwurzeloberfläche (SRA; $\mathrm{m}^{2}$ Wurzeloberfläche pro g Trockengewicht), die Feinwurzelbiomasse und -dichte und der Wurzelflächenindex RAI; $\mathrm{m}^{2}$ Wurzeloberfläche pro $\mathrm{m}^{2}$ Grundfläche) für die einzelnen Baumarten und den gesamten Bestand berechnet werden.

\subsection{Xylemsaftflussmessung an Wurzeln}

Der Fluss von Wasser durch das Xylem einer Pflanze oder eines Pflanzenteils kann mit Hilfe der heat-balance-Methode erfasst werden.

Ein Segment der Pflanze wird konstant erwärmt und die Temperaturdifferenz zwischen dem erwärmten und dem davor liegenden unbeheizten Gewebe erfasst. Je größer der Saftfluss ist, desto mehr Wärme wird der beheizten Zone entzogen, die Temperaturdifferenz verkleinert sich.

Die in dieser Arbeit verwendete Messanordnung basiert auf einem von SAKURATANI (1981) entwickelten System, das durch Modifizierungen nach SENOCK \& HAM (1993) für Messungen an Pflanzensegmenten mit geringem Durchmesser angepasst wurde.

Die Messmanschette besteht aus einem 2 mm starken Kork-Neopren-Gewebe $(3.5$ x $5 \mathrm{~cm})$, auf dem die Heizquelle (Kapton-Heizfilm, Heater Designs, Bloomington, CA, USA), mit einer konstanten Heizleistung von $0.07 \mathrm{~W}$, angebracht ist. Zur Bestimmung der Temperaturdifferenz sind ober- und unterhalb des Heizfilms mit jeweils 3 bzw. 6 mm Abstand zwei Thermoelementpaare angebracht. In Höhe des Heizfilms befindet sich eine Thermosäule, die die Temperaturdifferenz zwischen der Innen- und Außenseite der Isolation registriert.

\subsubsection{Berechnung der Flussraten}

Der Saftfluss errechnet sich nach folgender Formel:

$$
F=\frac{Q}{c_{w}\left(T_{o}-T_{i}\right)}
$$

wobei F die Saftflussrate $\left[\mathrm{kg} \mathrm{s}^{-1}\right.$ ], Q die zugeführte Wärmeenergie [W], $\mathrm{c}_{w}$ die Wärmekapazität des Wassers [4186.8 $\mathrm{J} \mathrm{K}^{-1} \mathrm{~kg}^{-1}$ ] und $\left(T_{o}-T_{i}\right)$ die Temperaturdifferenz des Saftflusses zwischen unterem und oberem Ende der Heizzone darstellt.

Da mit diesem System an Pflanzenteilen mit kleinem Durchmesser und geringen Saftflussmengen gemessen wird, ist es nötig, auch die radialen und axialen Wärmeströme zu erfassen. Die Gesamtenergiebilanz des geheizten Wurzelsegmentes lautet:

$$
Q=Q_{v}+Q_{r}+Q_{f}+S
$$

$\mathrm{Q}$ bezeichnet die zugeführte Wärmeenergie, $\mathrm{Q}_{v}$ die axial abgeführte Energie, $\mathrm{Q}_{r}$ die radial und $\mathrm{Q}_{f}$ die mit dem Saftfluss abgeführte Energie. S gibt die im Gewebe der Wurzel gespeicherte 
Energie wieder. Diese kann jedoch vernachlässigt werden, da sie weniger als $3 \%$ der Gesamtenergiebilanz ausmacht (SENOCK \& HAM, 1993). Alle Komponenten der Energiebilanz haben die Einheit Watt [W].

Aus den Gleichungen 3.1 und 3.2 erhält man folgende Gleichung für den Saftfluss:

$$
F=\frac{Q-Q_{v}-Q_{r}}{c_{w}\left(T_{o}-T_{i}\right)}=\frac{Q_{f}}{c_{w}\left(T_{o}-T_{i}\right)}
$$

Der radiale Wärmeverlust $\mathrm{Q}_{r}$ wird aus einer Materialkonstanten $\mathrm{K}_{g}$ und der Temperaturdifferenz zwischen dem Inneren und dem Äußeren der Messmanschette, die proportional der Thermosäulenspannung $\mathrm{E}[\mu \mathrm{V}]$ ist, errechnet:

$$
Q_{r}=K_{g} \cdot E
$$

Die Materialkonstante $\mathrm{K}_{g}$ wird aus den nächtlichen Messwerten unter der Annahme ermittelt, dass der Saftfluss in der Nacht zum Erliegen kommt und gleich Null gesetzt werden kann. Wird nun in Gleichung $3.2 \mathrm{Q}$ gleich null gesetzt und $\mathrm{Q}_{r}$ gemäß Gleichung 3.4 eingesetzt, erhält man $\mathrm{K}_{g}\left[\mathrm{~W} \mu V^{-1}\right]$ :

$$
K_{g}=\frac{Q-Q_{v}}{E}
$$

Bei der Berechnung des axialen Wärmeverlustes $\mathbf{Q}_{v}$ muss sowohl der Abstand der Thermoelemente mit $0.003 \mathrm{~m}$ als auch die Wärmeleitfähigkeit des verholzten Pflanzengewebes einbezogen werden. Die Wärmeleitfähigkeit von verholzten Geweben ist aus der Summe der Leitfähigkeiten der Gewebekomponenten ermittelt worden. Sie beträgt ca. $0.42 \mathrm{~W} \mathrm{~m}^{-1} \mathrm{~K}^{-1}$ (STEINBERG et al., 1990).

Zur Kalibrierung dieser Messmethode führten CONERS \& LEUSCHNER (2002) Experimente im Freiland und im Labor durch. Dabei ergaben sich gute Übereinstimmungen zwischen den gemessenen Saftflussraten und den gravimetrischen Messungen für einen Xylemsaftfluss $>2 \mathrm{~g} \mathrm{~h}^{-1}$. Geringere Saftflussraten werden jedoch überschätzt. Daher entwickelte CONERS (2001) eine modifizierte Berechnungsmethode für diese kleinen Flüsse, bei der die Temperaturdifferenz $\left(\mathrm{T}_{o}-\mathrm{T}_{i}\right)$ mit dem empirischen Faktor $\beta=0.897 \mathrm{~g} \mathrm{~h}^{-1} \mathrm{~K}^{-1}$ multipliziert wird:

$$
F^{*}=\beta \cdot\left(T_{o}-T_{i}\right)
$$

Die Berechnungen der Saftflussraten wurden mit einem von CONERS (2001) entwickeltem Computerprogramm (Msapcal0.9) durchgeführt.

\subsubsection{Datenerfassung}

Die Steuerung der Messsensoren und die Datenerfassung im Gelände erfolgten über Datalogger (Campbell CR-10X, Campbell Scientific Inc., Logan, Utah, USA) mit Multiplexern 
(Campbell AM416 Relay Multiplexer). Die Aufnahme der Messwerte erfolgte alle 15 Sekunden, gespeichert wurden 15-minütige Mittelwerte.

Die Spannungsversorgung im Gelände erfolgte über eine im Freiland aufgebaute Solaranlage, an die über Laderegler insgesamt 12 Solarbatterien angeschlossen waren. Damit sollte auch in den Nachtstunden die Spannung von $12 \mathrm{~V}$ für die Datalogger und die Heizung der Sensoren gewährleistet sein. Jedoch kam es besonders in dem Messzeitraum $2000 \mathrm{zu}$ Ausfällen der Solaranlage und damit zu Datenverlusten.

\subsubsection{Auswahl der Wurzeln und Installation der Sensoren}

Die Messung des Saftflusses erfolgte jeweils in zwei aufeinanderfolgenden Messperioden an insgesamt 20 Wurzeln pro Baumart. Die Messwurzeln konnten jeweils 2-3 verschiedenen Individuen pro Baumart zugeordnet werden.

Ausgewählt wurden jeweils Wurzeln mit einen Durchmesser von $2.9 \mathrm{~mm}$ bis maximal $4.1 \mathrm{~mm}$ (mit modifizierten Sensoren bis zu $6.3 \mathrm{~mm}$ ). Vorsichtig wurden etwa $10 \mathrm{~cm}$ lange Segmente der Wurzeln in $0.4 \mathrm{~m}$ bis $2.5 \mathrm{~m}$ Entfernung vom Stammfuß und bis zu einer Bodentiefe von $10 \mathrm{~cm}$ freigelegt. Dabei war zu beachten, dass die Wurzeln nicht verletzt oder abgeknickt wurden, um eine möglichst unbeeinflusste Wasseraufnahme zu gewährleisten. An diesen Segmenten wurden die Messmanschetten installiert. Um Umwelteinflüsse auf die Messung zu minimieren, wurden die Messmanschetten mit Isolationsmaterial ummantelt und die Bodenlöcher mit Holzplatten abgedeckt, welche mit Aluminiumfolie als Strahlungsschutz versehen waren.

\subsubsection{Kalibrierung der Sensoren im Freiland}

Vor Abschluss der Messungen im Herbst 2000 und 2001 wurden einige der Messwurzeln mit installierten Sensoren zur Kalibrierung der Sensoren unter Freilandbedingungen verwandt. Dazu wurden je zwei Wurzeln verschiedener Baumarten (Esche, Winterlinde, Buche und Hainbuche) direkt vor dem Sensor unter Wasser abgeschnitten und die Wasseraufnahme aus einem 30 ml-Wasservorrat quantitativ in zunächst 5-minütingen, später 15-minütigen Abständen über 2-3 Stunden bestimmt. Gleichzeitig wurde die von dem Saftflusssensor gemessene Durchflussmenge mit dem Datalogger aufgezeichnet. Die übrigen Wurzeln, an denen Sensoren installiert waren, dienten gleichzeitig als Referenz.

\subsubsection{Ernte der Messwurzeln, Lebend-Tot-Trennung}

Die Wurzeln wurden nach Abschluss der Messungen quantitativ geerntet. Dazu wurden sie von dem Messpunkt bis zu den Wurzelspitzen vorsichtig freigelegt. Aufgrund des sehr tonigen Bodens auf der Untersuchungsfläche im Hainich wurden dort nur Wurzeln geerntet, die in ihrem Verlauf in den oberen $10 \mathrm{~cm}$ des Bodens blieben. Von tiefer verlaufenden Wurzeln wurden nur die Messabschnitte, an denen die Sensoren installiert waren, aufbewahrt. 
Die Messabschnitte aller Wurzeln wurden in 70\%-igem Ethanol zur späteren anatomischen Untersuchung aufbewahrt.

Im Labor wurden die geernteten Wurzelstränge mit Wasser abgespült, um anhaftende Bodenreste zu entfernen. Unter dem Binokular erfolgte anschließend die Trennung von lebenden und toten Anteilen nach der in Kapitel 3.2.2 beschriebenen Methode. Bis zur weiteren Bearbeitung wurden die Wurzeln jeweils gekühlt und feucht aufbewahrt, um ein Schrumpfen durch Austrocknung zu vermeiden.

\subsubsection{Bestimmung der Wurzeloberfläche, Durchmesser-Entfernungsbeziehung}

Von den lebenden Anteilen der geernteten Wurzelstränge wurde mit Hilfe des Computerprogramms WinRhizo (Version 5.0, Regent Instruments Inc., Quebec, Canada) die Oberfläche bestimmt. Neben der Gesamtwurzeloberfläche konnte auch die Verteilung der Oberfläche auf die Durchmesserklassen 0-1 mm, 1-2 mm und $>2$ mm ermittelt werden.

Im Anschluss an die Analyse mit WinRhizo wurden die Wurzeln nach Durchmesserklassen getrennt bei $105^{\circ} \mathrm{C}$ über 48 Stunden getrocknet und gewogen.

An fünf Wurzelsträngen pro Baumart wurden Durchmesser-Entfernungsbeziehungen ermittelt. Die Durchmesser der Wurzelstränge wurden, an der Spitze des Wurzelstranges beginnend, in $2 \mathrm{~cm}$ Abständen bis zum Messabschnitt mit einer Schieblehre gemessen.

\subsection{Mikroklimatische Parameter}

Im Hainich waren auf einer Freifläche vor dem untersuchten Bestand die Messgeräte zur Messung wichtiger klimatologischer Parameter installiert. Kontinuierlich wurden die Strahlungsbilanz (Strahlungsbilanzgeber, Schenk, Wien, Austria), Temperatur und Luftfeuchte (Rotronic, Ettlingen, Germany) in 15-minütigen Mittelwerten aufgezeichnet. Zur Messung des Freilandniederschlags wurden auf der Freifläche fünf Regensammler aufgebaut, die wöchentlich abgelesen wurden.

Aus den Daten der Lufttemperatur und -feuchte konnte über die Magnusgleichung das Wasserdampfsättigungsdefizit der Luft (VPD) berechnet werden.

Im Jahr 2000 wurden durch den Ausfall eines Dataloggers Ende Juli bis Anfang August keine mikroklimatischen Messwerte aufgezeichnet. Daher wurden für diesen Zeitraum das VPD aus Temperatur- und Luftfeuchtedaten der Station Mühlhausen des Deutschen Wetterdienstes berechnet. Als Grundlage der Berechnung diente die Gleichung einer linearen Regression der in dieser Arbeit aufgenommenen VPD-Werte am Bestand und der VPD-Werte der Wetterstation Mühlhausen $(\mathrm{y}=-0.52+2.26 \mathrm{x} ; \mathrm{r}=0.90 ; \mathrm{p} \leq 0.001)$. Für eine Abschätzung des Strahlungsangebotes konnte für den fehlenden Zeitraum nicht auf vergleichbare Daten zurückgegriffen werden. 


\subsection{Registrierung des Bodenfeuchteregimes}

\subsubsection{Volumetrischer Bodenwassergehalt}

Zur Bestimmung des volumetrischen Bodenwassergehaltes $\Theta$ wurden auf der Misch- und der Buchenwaldfläche im Hainich TDR-Sonden (Zylindersonden P2Z mit $10 \mathrm{~cm}$ langen Messstäben) eingesetzt. Von diesen wurden jeweils 2 Stück in den Bodentiefen 5, 15 und $40 \mathrm{~cm}$ parallel zur Oberfläche in den Boden gebracht. Die Steuerung und Datenabfrage erfolgte durch einen Campbell-Datalogger und einen Multiplexer (TRIME-MUX6 TDR-Multiplexer V2, Imko, Ettlingen). Aufgrund des hohen Spannungsbedarfs während der Messung wurden die Sonden nur zweimal am Tag, um 12 Uhr und um 24 Uhr abgefragt.

\subsubsection{Bodenmatrixpotential}

Auf der Mischwaldfläche im Hainich wurden 2000 und 2001 neben den TDR-Sonden automatische Tensiometer eingesetzt, die kontinuierlich die Bodensaugspannung $\psi_{\text {Boden }}$ aufzeichneten. In drei Bodentiefen wurde die Bodensaugspannung von jeweils drei Tensiometern gemessen.

Auf der Fläche im Buchenwald wurde das Bodenmatrixpotential in der Messperiode 2001 von KOCH (2002) mittels Einstichtensiometern gemessen. Hier erfolgte die Datenaufnahme während der Messperiode einmal wöchentlich. In den entsprechenden Bodentiefen waren jeweils 5 Einstichtensiometer zentral auf der Untersuchungsfläche installiert.

\subsection{Messung des Wasserpotentials}

An sieben Terminen wurde das Wasserpotential-Minimum $\Psi_{\min }$ der Wurzeln zur Mittagszeit gemessen. Dieses spiegelt die maximale Anspannung des pflanzlichen Wasserhaushaltes im Tagesgang wider. Zusätzlich wurden von einem Hubwagen im Bestand aus an denselben Terminen auch die Wasserpotential-Minima der Blätter bestimmt.

Eine Möglichkeit zur Bestimmung des Wasserpotentials $\Psi$ ist die Druckkammer-Methode nach SCHOLANDER (SCHOLANDER et al., 1965).

Durch Abschneiden eines Blattes bzw. einer Wurzel entspannt sich der Unterdruck im Xylem, der Xylemsaft zieht sich in die Gefäße zurück. Das abgeschnittene Pflanzenteil wird so in die Druckkammer (PMS-Instruments, Corvallis Oregon) eingebaut, dass die Schnittstelle zur Beobachtung herausragt, während sich der Rest des Blattes oder der Wurzel in der Druckkammer befindet. Dort wird zunehmend Druck ausgeübt, bis der Meniskus des Xylemsaftes an der Schnittfläche sichtbar wird. Dieser positive Druck entspricht dem negativen Druck, der vor dem Abschneiden im Xylem herrschte.

Für die Messung des Wurzel-Wasserpotentials wurden ca. $5 \mathrm{~cm}$ lange Wurzelenden aus den oberen $5 \mathrm{~cm}$ des Bodens vorsichtig und verletzungsfrei freigelegt, abgeschnitten und sofort in die Messkammer eingebracht. 
Im Anschluss daran erfolgte die Wasserpotential-Messung an Blättern, die mit dem Hubwagen aus der Sonnenkrone der Bäume geerntet wurden.

Die Messungen von $\Psi_{\text {min }}$ erfolgten in der Mittagszeit zwischen 12.00 und 14.00 Uhr MESZ.

\subsection{Anatomie der Messwurzeln}

\subsubsection{Bestimmung der Leitfläche}

Von den nach der Ernte der Wurzeln in Ethanol aufbewahrten Messabschnitten wurden im Labor Querschnitte per Hand angefertigt, anhand derer die Leitfläche der jeweiligen Wurzel ermittelt wurde. Diese ist als die Summe der Querschnittsflächen aller wasserleitenden Xylemelemente definiert (LARCHER, 1994). Die Querschnitte wurden mit SudanIII behandelt (färbt Kutin und Suberin) und unter einem Lichtmikroskop (Vergrößerung 40x bzw. 100x) untersucht. Mit einem Messokular und einem Objektmikrometer konnte der Durchmesser der Gefäße gemessen werden. Nach der Übertragung des Querschnittes auf Papier mit Hilfe eines Abbéschen Zeichenapparates wurden die Gefäße gezählt.

Ein Teil der Querschnitte wurde ganz ausgemessen; an den meisten Objekten wurden jedoch pro Querschnitt zwei Ausschnitte (je ca. 1/8 der Gesamtgröße) analysiert und anschließend auf das Gesamtxylem (Gewebe innerhalb des Kambiums abzüglich der Markstrahlen) hochgerechnet.

Aus den so gewonnenen Daten konnte die Leitfläche, die Anzahl, der mittlere Durchmesser und die Verteilung der Gefäßdurchmesser bestimmt werden.

\subsubsection{Untersuchung des Abschlussgewebes der Wurzelspitze}

Von je drei Wurzeln pro Baumart wurden Frischproben entnommen (ca. $20 \mathrm{~cm}$ lange Stränge mit Wurzelspitzen) und in 70\%igem Ethanol für die Weiterverarbeitung im Labor aufbewahrt. Dort wurden Querschnitte in $0.5 \mathrm{~cm}, 10 \mathrm{~cm}$ und $15 \mathrm{~cm}$ Entfernung von der Wurzelspitze angefertigt. Dafür wurden die Wurzelproben mit dem Einbettungsverfahren nach Kulzer (Fa. Heraeus Kulzer, Wehrheim) in Kunststoff eingebettet und mit einem Mikrotom geschnitten. Die Schnitte wurden anschließend mit Toluidinblau und Sudan III angefärbt, um verholzte Zellwände sowie Kutin- und Suberineinlagerungen sichtbar zu machen. Unter einem Lichtmikroskop (Vergrößerung 100x bzw. 400x) wurden die Querschnitte mit Hilfe eines Messokulars und eines Objektmikrometers vermessen, bzw. die Stärke der verschiedenen Gewebeschichten ermittelt und das Vorhandensein einer Endodermis untersucht. Mit Hilfe eines Abbéschen Zeichenapparates wurden die Querschnitte als Handzeichnungen auf Papier übertragen. 


\subsection{Messung der hydraulischen Leitfähigkeit}

\subsubsection{Axiale hydraulische Leitfähigkeit}

Zur Bestimmung der axialen hydraulischen Leitfähigkeit $\mathrm{k}_{m}$ der Wurzeln wurde die Durchflussmethode nach SPERRY et al. (1988) angewandt. Dazu wurden auf der Untersuchungsfläche im Hainich pro Baumart 5 Wurzelsegmente mit einem Durchmesser von ca. 3-4 mm und einer Länge bis zu $10 \mathrm{~cm}$ entnommen. Die Schnittflächen wurden sofort nach dem Abschneiden mit Wachs versiegelt und die Segmente in Wasser aufbewahrt, um eine Austrocknung zu verhindern. Im Labor wurde das Segment unter Wasser auf ca. $5 \mathrm{~cm}$ gekürzt und entsprechend der natürlichen Fliessrichtung in die Apparatur eingebracht. Über eine $60 \mathrm{~cm}$ Wassersäule wurde ein Druck von 0.006 MPa aufgebaut. Das bei diesem Druck durch das Wurzelsegment geflossene Wasser wurde über 5 Minuten aufgefangen, um die aktuelle Leitfähigkeit zu ermitteln. Anschließend wurde ein Wasserdruck von 0.14 MPa angelegt und das Segment damit gespült (flushen), um vorhandene Embolien auszuspülen. Diese Schritte wurden mindestens dreimal wiederholt, bis die aufgefangene und damit durchgeflossene Wassermenge konstant blieb. Aus diesen Werten lässt sich die maximale Leitfähigkeit des Wurzelsegmentes berechnen.

\subsubsection{Theoretische Leitfähigkeit}

Die theoretische Leitfähigkeit $\mathrm{k}_{\text {Stheor }}$ der Wurzeln kann über das Gesetz von Hagen-Poiseuille berechnet werden. Dieses besagt, dass die Flussrate $\left(\frac{\Delta V}{\Delta t}\right)$ durch eine Kapillare proportional zu einem Druckgradienten $\left(\frac{\Delta P}{\Delta l}\right)$ und der hydraulischen Leitfähigkeit ist. Diese hydraulische Leitfähigkeit $\mathrm{k}_{\text {Stheo }}$ wiederum wird bestimmt von dem Radius der Kapillare in der vierten Potenz und der Viskosität der fließenden Flüssigkeit $(\eta)$. Somit kann $\mathrm{k}_{S t h e o}$ aus folgender Gleichung berechnet werden:

$$
k_{\text {Stheo }}=\frac{\Delta V \cdot l}{\Delta P \cdot \Delta t}=\frac{\pi \cdot \Sigma r^{4}}{8 \eta}
$$

Da diese Berechnungen jedoch auf idealen Kapillaren und einer parabelförmigen Verteilung der Fließgeschwindigkeit in der Kapillare basiert, erhält man auf diese Weise eine theoretische hydraulische Leitfähigkeit. Denn beim Fluss durch Wurzeln (und andere Pflanzenteile) sind Übergänge zwischen den einzelnen Gefäßen zu überwinden, ebenso sind die Wände der Xylemgefäße nicht eben wie in einer idealen Kapillare. Dennoch erhält man durch die Berechnung dieser theoretischen hydraulischen Leitfähigkeit die Möglichkeit, den Einfluss artspezifischer Unterschiede in der Holzanatomie auf das Leitungsverhalten zu quantifizieren.

\subsubsection{Hydraulische Leitfähigkeit}

Die hydraulische Leitfähigkeit der Wurzel, $\mathrm{Lp}_{r}$, lässt sich nach SMIT et al. (2000) aus einem Quotienten der Flussrate und dem Wasserpotentialgradienten zwischen Wurzelxylem und - 
oberfläche berechnen:

$$
L p_{r}=\frac{J_{v}}{\Delta \Psi \cdot A}
$$

In die Berechnung der vorliegenden Arbeit gingen die maximalen Saftflussraten zur Mittagszeit des Messtages ein $\left[\mathrm{J}_{v}, \mathrm{~m}^{3} \mathrm{~s}^{-1}\right]$, die jeweilige Gesamtwurzeloberfläche $\left[\mathrm{A}, \mathrm{m}^{2}\right]$ und die Wasserpotentialdifferenz zwischen Boden und Wurzel [ $\Delta \Psi, \mathrm{MPa}]$, gemessen mit Tensiometern und der Druckkammermethode nach Scholander. Da nicht direkt das Wasserpotential der Wurzeloberfläche bestimmt werden konnte, wurde das Bodenmatrixpotential zur Bildung der Potentialdifferenz genutzt, dass mit Tensiometern aufgezeichnet wurde. Aus diesem Grund schließt der so berechnete Wert $\mathrm{Lp}_{r}$ jedoch auch die Leitfähigkeit der Rhizosphäre mit ein. $\mathrm{Lp}_{r}$ wurde für drei Termine während der Vegetationsperiode 2001 berechnet, an denen WurzelWasserpotentialmessungen stattfanden.

\subsection{Bewässerungsversuche}

Zur Untersuchung der Frage, inwieweit sich die Wasseraufnahmeraten der Wurzeln bei einer schnellen Wiederbewässerung nach einer Trockenperiode ändert, ob eventuell unbehebbare Embolien aufgetreten sind, wurden Bewässerungsexperimente an Eichen- und Buchenwurzel durchgeführt.

Dazu wurden während einer Trockenperiode im Juli/August 2001 mehrere Wurzeln, an denen Sensoren installiert waren, ausgewählt. Um diese Wurzeln wurde ein Feld abgesteckt, das ihrem potentiellen weiteren Verlauf angepasst war. Dieses Feld wurde mit einer einem $10 \mathrm{~mm}$ Niederschlag entsprechenden Wassermenge beregnet. Die Saftflussraten dieser Wurzeln waren mindestens in den davor liegenden 7 Tagen sowie in den 4 Tagen nach der Bewässerung gemessen worden.

Nach Abschluss der Messungen wurden auch diese Wurzeln geerntet und dabei notiert, ob sie in dem bewässerten, markierten Feld verliefen bzw. zu welchem Anteil sie darüber hinaus wuchsen.

Zusätzlich wurden sowohl in der Nähe von bewässerten Wurzeln als auch der unbewässerten Kontrollwurzeln bei jedem Bewässerungsversuch insgesamt 5 Sonden eines mini-TDRSystems in den oberen $5 \mathrm{~cm}$ des Bodens installiert. Während der Bewässerung und in bis zu 5 folgenden Tagen wurde der volumetrische Bodenwassergehalt so stündlich aufgenommen.

Die Steuerung und Abfrage der Sonden erfolgte durch einen Campbell-Datalogger und einen Multiplexer (TRIME-MUX6 TDR-Multiplexer V2, Imko, Ettlingen).

\subsection{Statistische Auswertung der Daten}

Die statistische Untersuchung der Daten erfolgte im wesentlichen mit dem Computerprogramm SAS (Statistical Analysis System, SAS-Institute Inc. Cary, NC, USA). Zunächst wur- 
den die Daten mittels des Anpassungstestes von Shapiro \& Wilk auf Normalverteilung getestet. An normalverteilten Daten wurde eine ANOVA sowie der Test von Scheffé für unabhängige Stichproben angewandt, um signifikante Mittelwertunterschiede auf einem Signifikanzniveau von 5\% zu bestimmen. Der Mann-Whitney (Wilcoxon)- two sample-Test wurde auf nicht-normalverteilte Daten angewandt, um dort signifikante Unterschiede zu bestimmen, nachdem noch eine Bonferroni-Korrektur der $\alpha$-Fehler-Kumulierung erfolgte.

Um Zusammenhänge zwischen zwei nicht-normalverteilten Parametern statistisch zu bestimmen und Korrelationskoeffizienten zu errechnen, wurde der Spearman-Rang-Korrelationstest eingesetzt. Regressionsanalysen sowie die Bestimmung der Korrelationskoeffizienten und Funktionsgleichungen zwischen normalverteilten Parametern wurden mit dem Programm Xact (Version 7.20g, SciLab, Hamburg) durchgeführt. 


\section{Ergebnisse}

\subsection{Unterirdische Bestandesstruktur des Mischwaldes im Nationalpark Hainich}

\subsubsection{Horizontale Verteilung der Feinwurzeln}

In den beiden untersuchten Bodentiefen 0-10 $\mathrm{cm}$ und 10-20 cm wurden in allen 60 Proben Feinwurzeln gefunden, der Bestand ist somit vollständig durchwurzelt. Zwischen beiden Tiefenstufen traten in dieser Hinsicht nur leichte Unterschiede auf (Abb. 4.1). Die beiden untersuchten Bodentiefen des Mineralbodens unterschieden sich hinsichtlich der relativen Häufigkeit, mit der Feinwurzeln verschiedener Baumarten in einer Probe gefunden wurden.
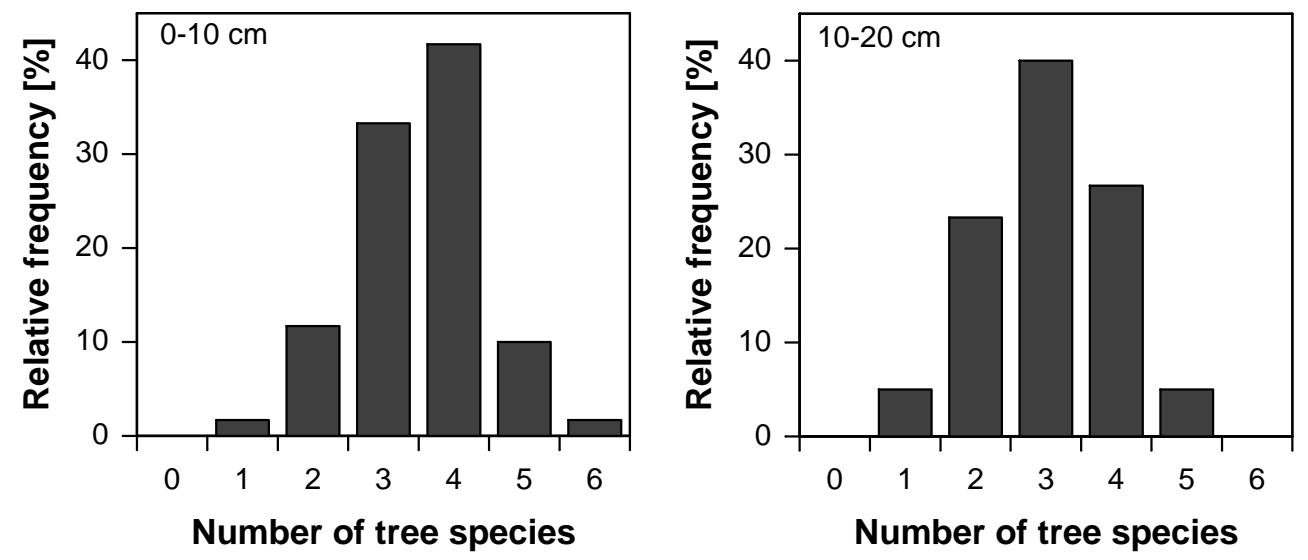

Abb. 4.1: Relative Häufigkeit des gleichzeitigen Vorkommens verschiedener Baumarten in den Feinwurzelproben in 0-10 cm Bodentiefe (links) und 10-20 cm Bodentiefe (rechts), $\mathrm{n}=60$ je Tiefenstufe. Im Mischbestand im Nationalpark Hainich wurden insgesamt 11 Baumarten gefunden; Feinwurzeln von Sommer- und Winterlinde wurden nicht unterschieden.

Mindestens eine Baumart, in diesem Fall die Esche, war in jeder Bodenprobe vorhanden. In über $40 \%$ der Proben kamen Feinwurzeln von vier Baumarten vor. In 10-20 cm Bodentiefe verschob sich diese Häufigkeit, in fast $40 \%$ der Bohrstockproben aus dieser Tiefe kamen lebende Feinwurzeln von drei Baumarten vor. Maximal fünf verschiedene Arten konnten bis in $20 \mathrm{~cm}$ Tiefe gefunden werden, was in 5\% der beprobten Stellen der Fall war. In 0-10 cm Bodentiefe waren mit einer Häufigkeit von $1.7 \%$ Feinwurzeln von maximal sechs Baumarten vertreten. In den Proben ließen sich lebende Feinwurzeln von 10 der 11 vorkommenden Baumarten nachweisen. Lediglich Feinwurzeln von Prunus avium, die nur mit einem Individuum auf der Untersuchungsfläche vertreten ist, traten in keiner Probenstelle auf. 
Die aus der Feinwurzelbiomasse (Tab. 4.1) auf das Bodenvolumen umgerechnete Feinwurzeldichte der neun Baumarten auf der Mischwaldfläche unterschied sich zwischen den einzelnen Arten z.T. signifikant (Tab. 4.2). Den größten Anteil nahmen die Feinwurzeln der Esche ein. Sie machten 58\% der Gesamt-Feinwurzeldichte aus, gefolgt von Bergahorn (14\%) und Wurzeln der beiden Lindenarten (11\%). Obwohl nur zwei Buchen auf der Untersuchungsfläche stehen, trugen Buchenfeinwurzeln noch zu $1.5 \%$ zu der Gesamtfeinwurzeldichte bei.

Tab. 4.1: Feinwurzelbiomassen der neun untersuchten Baumarten der Mischwaldfläche im Nationalpark Hainich. Dargestellt sind Mittelwerte (Mean) und Standardfehler (SE) für die Bodentiefen 0-10 und 10-20 cm; $n=60$. Signifikante Unterschiede zwischen den Arten sind durch unterschiedliche Buchstaben gekennzeichnet $(\mathrm{p}<0.05$, Mann-WhitneyTest).

\begin{tabular}{|c|c|c|c|c|c|c|}
\hline & \multicolumn{6}{|c|}{ Fine root biomass $\left[\mathrm{g} \mathrm{m}^{-2}\right]$} \\
\hline & \multicolumn{3}{|c|}{$0-10 \mathrm{~cm}$} & \multicolumn{3}{|c|}{$10-20 \mathrm{~cm}$} \\
\hline & Mean & & SE & Mean & & SE \\
\hline F. excelsior & 169.57 & $\mathrm{a}$ & 25.37 & 38.59 & $\mathrm{a}$ & 5.87 \\
\hline A. pseudoplatanus & 40.73 & $\mathrm{~b}$ & 9.20 & 10.58 & bc & 2.90 \\
\hline Tilia ssp. & 33.40 & $\mathrm{~b}$ & 6.23 & 18.70 & $\mathrm{~b}$ & 3.64 \\
\hline A. platanoides & 17.20 & $\mathrm{~b}$ & 6.33 & 3.52 & bc & 1.25 \\
\hline C. betulus & 14.85 & $\mathrm{~b}$ & 4.70 & 11.11 & bc & 3.85 \\
\hline A. campestre & 5.43 & $\mathrm{~b}$ & 3.45 & 0.96 & bc & 0.55 \\
\hline Q. robur & 4.65 & $\mathrm{~b}$ & 1.63 & 3.16 & $\mathrm{c}$ & 1.21 \\
\hline F. sylvatica & 4.36 & $\mathrm{~b}$ & 1.82 & 4.21 & bc & 1.75 \\
\hline U. glabra & 2.24 & $\mathrm{~b}$ & 0.72 & 1.62 & $\mathrm{c}$ & 0.92 \\
\hline Stand & 292.42 & & 27.46 & 92.44 & & 6.84 \\
\hline
\end{tabular}

Die Bestandesfeinwurzeldichte beträgt auf der Untersuchungsfläche im Mischwald im Mittel $2.92 \mathrm{~g} \mathrm{~L}^{-1}$ in 0-10 $\mathrm{cm}$ Bodentiefe. Die Feinwurzeldichte aller Baumarten und somit auch die des gesamten Bestandes nimmt mit der Bodentiefe ab, so dass sich in 10-20 cm Bodentiefe im Mittel eine Bestandesfeinwurzeldichte von $0.92 \mathrm{~g} \mathrm{~L}^{-1}$ Feinwurzeln ergab. Die Feinwurzeldichte der Esche betrug in den oberen $10 \mathrm{~cm}$ des Bodens $1.70 \mathrm{~g} \mathrm{~L}^{-1}$. In den folgenden $10 \mathrm{~cm}$ nahm sie auf $0.39 \mathrm{~g} \mathrm{~L}^{-1} \mathrm{ab}$. Eine ebenso starke Reduzierung erfuhr auch die Feinwurzeldichte des Spitzahorns. Feinwurzeln von Berg- und Feldahorn, der Linden und der Hainbuche konnten ebenfalls in einer höheren Dichte in 0-10 cm Bodentiefe gefunden werden. Stieleichen-, Buchen- und Ulmenfeinwurzeln waren dagegen in beiden Bodentiefen in gleicher Dichte vertreten. Diese war jedoch vergleichsweise gering (0.02-0.05 $\left.\mathrm{g} \mathrm{L}^{-1}\right)$.

Signifikante Unterschiede zu den übrigen Baumarten treten im Falle der Esche auf, deren Feinwurzeldichte in 0-10 cm Bodentiefe mehr als vierfach höher war als die des Bergahorns, der mit $0.41 \mathrm{~g} \mathrm{~L}^{-1}$ die nächsthöchste Feinwurzeldichte besaß. Dieses Übergewicht der Esche 
Tab. 4.2: Feinwurzeldichten der neun untersuchten Baumarten der Mischwaldfläche im Nationalpark Hainich. Dargestellt sind Mittelwerte (Mean) und Standardfehler (SE) für die Bodentiefen 0-10 und 10-20 cm; $\mathrm{n}=60$. Signifikante Unterschiede zwischen den Arten sind durch unterschiedliche Buchstaben gekennzeichnet ( $\mathrm{p}<0.05$, Mann-Whitney-Test).

\begin{tabular}{lcccccc}
\hline & \multicolumn{5}{c}{ Fine root density [g L $\left.{ }^{-1}\right]$} \\
& Mean & & SE & Mean & & SE \\
\hline F. excelsior & 1.70 & $\mathrm{a}$ & 0.25 & 0.39 & $\mathrm{a}$ & 0.06 \\
A. pseudoplatanus & 0.41 & $\mathrm{~b}$ & 0.09 & 0.11 & $\mathrm{bc}$ & 0.03 \\
Tilia ssp. & 0.33 & $\mathrm{~b}$ & 0.06 & 0.19 & $\mathrm{~b}$ & 0.04 \\
A. platanoides & 0.17 & $\mathrm{~b}$ & 0.06 & 0.04 & $\mathrm{bc}$ & 0.01 \\
C. betulus & 0.15 & $\mathrm{~b}$ & 0.05 & 0.11 & $\mathrm{bc}$ & 0.04 \\
A. campestre & 0.05 & $\mathrm{~b}$ & 0.03 & 0.01 & $\mathrm{bc}$ & 0.01 \\
Q. robur & 0.05 & $\mathrm{~b}$ & 0.02 & 0.03 & $\mathrm{c}$ & 0.01 \\
F. sylvatica & 0.04 & $\mathrm{~b}$ & 0.02 & 0.04 & $\mathrm{bc}$ & 0.02 \\
U. glabra & 0.02 & $\mathrm{~b}$ & 0.01 & 0.02 & $\mathrm{c}$ & 0.01 \\
Stand & 2.92 & & 0.27 & 0.92 & & 0.07 \\
\hline
\end{tabular}

war in 10-20 cm Bodentiefe weniger stark ausgeprägt; mit einer zweifach höheren Feinwurzeldichte als die Linden $\left(0.39 \mathrm{~g} \mathrm{~L}^{-1}\right.$ gegenüber $\left.0.19 \mathrm{~g} \mathrm{~L}^{-1}\right)$ hatte die Esche jedoch auch in dieser Bodentiefe die signifikant größte Feinwurzeldichte. Die Feinwurzelbiomasse wies in den beiden Bodentiefen und über die verschiedenen Baumarten das gleiche Verteilungsmuster und die gleichen Relationen auf wie die Feinwurzeldichte. Die Esche hatte im Vergleich mit den anderen Baumarten die höchsten Biomassen und dominierte mit $169.57 \mathrm{bzw} .38 .59 \mathrm{~g} \mathrm{~m}^{-2}$ in beiden Bodentiefen. Die geringste Biomasse hatten Feinwurzeln der Ulme $\left(2.24 \mathrm{~g} \mathrm{~m}^{-2}\right)$. Die Biomassen fast aller Baumarten nahmen mit zunehmender Bodentiefe ab.

In Tab. 4.3 sind die spezifischen Feinwurzeloberflächen (SRA, Wurzeloberfläche pro g Trockengewicht) angegeben. Die Feinwurzeln der Ulme wiesen mit $617.6 \mathrm{~cm}^{2} \mathrm{~g}^{-1}$ in $0-10 \mathrm{~cm}$ Bodentiefe eine signifikant größere spezifische Feinwurzeloberfläche auf als die übrigen Arten. In 10-20 cm Bodentiefe dagegen wurden keine signifikanten Unterschiede zwischen den Baumarten gefunden. Die kleinste spezifische Oberfläche hatte die Stieleiche $\left(254.1 \mathrm{~cm}^{2} \mathrm{~g}^{-1}\right)$. Zwischen den beiden Bodentiefen fallen Unterschiede für Feinwurzeln der Linden, der Stieleiche und der Ulme auf. Die spezifische Oberfläche der Linden- und Ulmenfeinwurzeln war in 10-20 cm Tiefe um 55\% bzw. 33\% geringer, die der Stieleiche um etwa 30\% höher. Dadurch war die geringste spezifische Feinwurzeloberfläche in 10-20 cm Tiefe mit $296.3 \mathrm{~cm}^{2} \mathrm{~g}^{-1}$ bei den Linden zu finden. Die übrigen Baumarten wiesen ebenfalls Unterschiede zwischen den beiden Bodentiefen auf, die jedoch geringer waren. 
Tab. 4.3: Spezifische Feinwurzeloberfläche (SRA) der neun untersuchten Baumarten der Mischwaldfläche im Nationalpark Hainich. Dargestellt sind Mittelwerte (Mean) und Standardfehler (SE) für die Bodentiefen 0-10 und 10-20 cm. Signifikante Unterschiede zwischen den Arten sind durch unterschiedliche Buchstaben gekennzeichnet ( $p<0.05$, MannWhitney-Test).

\begin{tabular}{lcccccccc}
\hline & \multicolumn{7}{c}{ SRA $\left[\mathrm{cm}^{2} \mathrm{~g}^{-1}\right]$} \\
& $\mathrm{n}$ & Mean & & SE & $\mathrm{n}$ & Mean & SE \\
\hline F. excelsior & 20 & 435.8 & ab & 50.4 & 20 & 466.4 & a & 97.6 \\
A. pseudoplatanus & 20 & 415.5 & bc & 97.4 & 20 & 313.7 & a & 57.7 \\
Tilia ssp. & 20 & 595.0 & abc & 160.4 & 20 & 296.3 & a & 72.0 \\
A. platanoides & 20 & 499.2 & abc & 49.9 & 20 & 417.0 & a & 70.7 \\
C. betulus & 20 & 300.2 & bc & 36.5 & 20 & 247.9 & a & 47.4 \\
A. campestre & 18 & 423.3 & abc & 49.9 & 15 & 427.0 & a & 101.3 \\
Q. robur & 19 & 254.1 & $\mathrm{c}$ & 22.9 & 20 & 438.4 & a & 69.9 \\
F. sylvatica & 20 & 372.2 & bc & 90.1 & 20 & 316.5 & a & 42.9 \\
U. glabra & 19 & 617.6 & a & 77.7 & 20 & 413.8 & a & 67.4 \\
Stand & & 434.9 & & 28.0 & & 369.2 & & 23.6 \\
\hline
\end{tabular}

Aus der Bestandestrockenmasse und der spezifischen Wurzeloberfläche kann der Wurzeloberflächenindex (RAI, $\mathrm{m}^{2}$ Wurzeloberfläche pro $\mathrm{m}^{2}$ Grundfläche) für die Baumarten und den Bestand berechnet werden (Tab. 4.4). Der Bestandes-RAI betrug $12.72 \mathrm{~m}^{2} \mathrm{~m}^{-2}$ in $0-10 \mathrm{~cm}$ Bodentiefe und nahm in 10-20 $\mathrm{cm}$ auf $3.14 \mathrm{~m}^{2} \mathrm{~m}^{-2} \mathrm{ab}$.

Den höchsten RAI der Baumarten wies wiederum die Esche auf, in beiden Bodentiefen war er mit 7.40 bzw. $1.80 \mathrm{~m}^{2} \mathrm{~m}^{-2}$ signifikant höher als der RAI der anderen acht Baumarten. In Übereinstimmung mit der Höhe der Feinwurzeldichte und -biomasse hatten Stieleiche, Ulme und Buche die geringsten Feinwurzeloberflächen im Bestand $\left(0.12-0.16 \mathrm{~m}^{2} \mathrm{~m}^{-2}\right)$. Nach der Esche hatten in beiden Bodentiefen die beiden Lindenarten mit 1.99 und $0.55 \mathrm{~m}^{2} \mathrm{~m}^{-2}$ die größten RAI-Werte, von denen sich die des Bergahorns nicht signifikant unterschieden (1.96 und $0.33 \mathrm{~m}^{2} \mathrm{~m}^{-2}$ ). Wie schon anhand der starken Feinwurzelbiomassen-Abnahme zwischen den Bodentiefen für den Feldahorn zu erwarten, war der RAI in 10-20 cm Bodentiefe um 70\% geringer als in der obersten Bodenschicht $\left(0.23 \mathrm{~m}^{2} \mathrm{~m}^{-2}\right)$.

Eine Abnahme der Feinwurzeldichte mit zunehmender Entfernung vom nächstgelegenen Baumstamm konnte nur für Spitzahorn und Stieleiche in beiden Bodentiefen beobachtet werden (Abb. 4.2). Eine signifikante Beziehung zwischen Feinwurzeldichte und Stammentfernung zeigte sich auch für die Hainbuche in einer Bodentiefe bis $10 \mathrm{~cm}$. Für die übrigen sechs Arten konnte kein Zusammenhang festgestellt werden. Von allen Baumarten findet man bis in mindestens 10 m Entfernung vom nächstgelegenen Stamm noch Feinwurzeln. Eine maximale Ausbreitung des Feinwurzelsystems bis $20 \mathrm{~m}$ konnte für Bergahorn und Buche nachgewiesen 
Tab. 4.4: Feinwurzeloberflächenindex (RAI) der neun untersuchten Baumarten der Mischwaldfläche im Nationalpark Hainich. Dargestellt sind Mittelwerte (Mean) und Standardfehler (SE) für die Bodentiefen 0-10 und 10-20 cm; n=60. Signifikante Unterschiede zwischen den Arten sind durch unterschiedliche Buchstaben gekennzeichnet $(\mathrm{p}<0.05$, Mann-Whitney-Test).

\begin{tabular}{lcccccc}
\hline & \multicolumn{5}{c}{ RAI $\left[\mathrm{m}^{2} \mathrm{~m}^{-2}\right]$} \\
& Mean & & SE & Mean & SE \\
\hline F. excelsior & 7.40 & a & 1.11 & 1.80 & a & 0.27 \\
A. pseudoplatanus & 1.69 & bc & 0.38 & 0.33 & bc & 0.09 \\
Tilia ssp. & 1.99 & b & 0.37 & 0.55 & b & 0.11 \\
A. platanoides & 0.86 & cd & 0.32 & 0.15 & cd & 0.05 \\
C. betulus & 0.45 & cd & 0.14 & 0.28 & cd & 0.10 \\
A. campestre & 0.23 & d & 0.15 & 0.04 & d & 0.02 \\
Q. robur & 0.12 & d & 0.04 & 0.14 & cd & 0.05 \\
F. sylvatica & 0.16 & d & 0.07 & 0.13 & cd & 0.06 \\
U. glabra & 0.14 & d & 0.04 & 0.07 & d & 0.04 \\
Stand & 12.72 & & & 3.41 & & \\
\hline
\end{tabular}

werden. Während die Esche eine Konzentrierung der Feinwurzeldichte in 5-10 m Entfernung vom Stamm aufwies, waren die Feinwurzeln von Bergahorn und Linden gleichmäßig über die Distanz verteilt. Eine Erstreckung des Wurzelsystems der Esche über $10 \mathrm{~m}$ ließ sich in dieser Untersuchung durch die hohe Stammdichte der Esche im Bestand nicht nachweisen.

In Tab. 4.5 sind die relativen Anteile der neun untersuchten Baumarten an der Feinwurzeldichte und der Stammdichte im Vergleich angegeben.

Über die Hälfte der im Bestand gefundenen Feinwurzeln konnten der Esche zugeordnet werden, was ihre Dominanz in der oberirdischen Bestandesstruktur noch übertraf. Denn der Anteil der Esche an der Gesamtfeinwurzeldichte war mit 54.1\% höher, als ihr Anteil an der Stammdichte (45.0\%). Die relativen Anteile der zweiten häufig vertretenen Baumart, dem Bergahorn, traten dahinter deutlich zurück, ebenso wie die der anderen neun Baumarten. Wie die Esche, hatten auch die Linden, Spitzahorn, Hainbuche und Buche höhere Anteile im Wurzelbereich gegenüber der Stammdichte. Dagegen war besonders die Ulme mit nur 1.0\% Anteil an der Feinwurzeldichte gegenüber ihrem Anteil an der Stammanzahl mit 5.8\% unterrepräsentiert.

\subsubsection{Horizontal- und Vertikalverteilung der Grobwurzeln}

In Abb. 4.3 sind die relativen Häufigkeiten dargestellt, mit der Wurzeln $>2 \mathrm{~mm}$ verschiedener Arten in den untersuchten Profilwänden vorkommen. Auch in dieser Wurzelklasse gab es im Bestand keine Probestelle ohne Wurzeln. Am häufigsten (in 32.5\% der Probestellen) wurden 

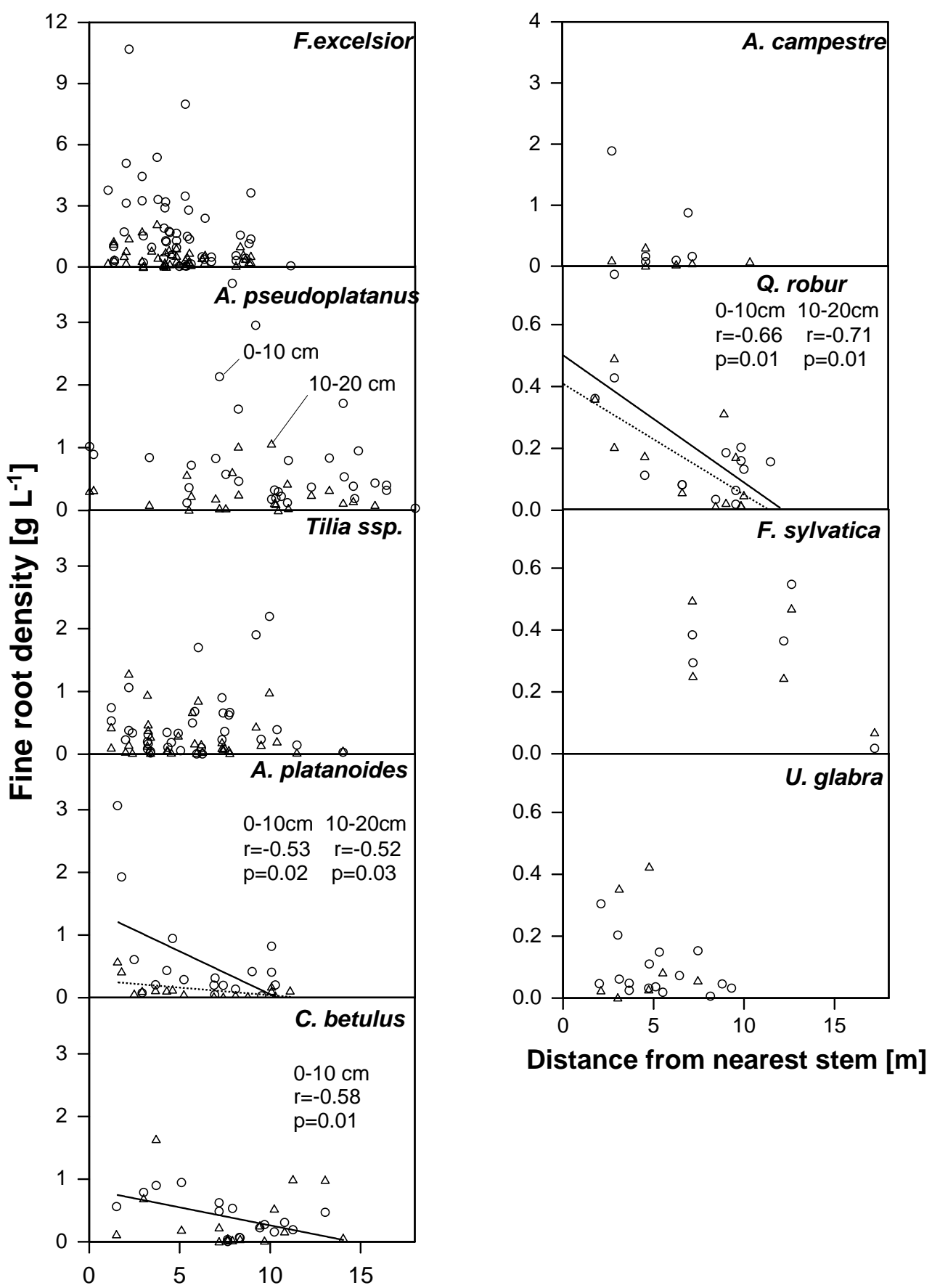

Distance from nearest stem [m]

Abb. 4.2: Abhängigkeit der Feinwurzeldichte vom Abstand zum nächsten Stamm der jeweiligen Baumart auf der Untersuchungsfläche im Nationalpark Hainich. Dargestellt sind die Feinwurzeldichten in den Bodentiefen 0-10 cm und 10-20 cm für die neun gefundenen Baumarten. Die Graphen sind unterschiedlich skaliert. 
Tab. 4.5: Relativer Anteil der neun Baumarten an der Feinwurzeldichte in 0-20 cm Bodentiefe (1.92 $\mathrm{g} \mathrm{L}^{-1}$ ) und an der Stammdichte (260 Stämme ha ${ }^{-1}$ ) auf der Untersuchungsfläche im Nationalpark Hainich.

\begin{tabular}{lcc}
\hline & $\begin{array}{c}\text { Fine root density } \\
{[\%]}\end{array}$ & $\begin{array}{c}\text { Stem density } \\
{[\%]}\end{array}$ \\
\hline F. excelsior & 54.08 & 45.00 \\
A. pseudoplatanus & 13.33 & 18.46 \\
Tilia ssp. & 13.54 & 8.46 \\
A. platanoides & 5.38 & 4.62 \\
C. betulus & 6.74 & 5.77 \\
A. campestre & 1.66 & 2.31 \\
Q. robur & 2.03 & 3.46 \\
F. sylvatica & 2.23 & 1.15 \\
U. glabra & 1.00 & 5.77 \\
\hline
\end{tabular}

Grobwurzeln von zwei oder drei verschiedenen Baumarten in einer Profilwand gefunden. In 2.5\% der untersuchten Bodenprofile waren Grobwurzeln nur einer Baumart vertreten, auch in diesem Fall waren dies Eschenwurzeln. Wurzeln von fünf Baumarten wurden in $7.5 \%$ der Probestelle gefunden. Wie schon bei der Feinwurzelverteilung beobachtet, konnten Grobwurzeln von zehn der elf vorkommenden Baumarten in dieser Untersuchung gefunden werden, wobei eine Unterscheidung von Sommer- und Winterlinde an den Profilwänden nicht möglich war. Grobwurzeln von Prunus avium wurden nicht gefunden.

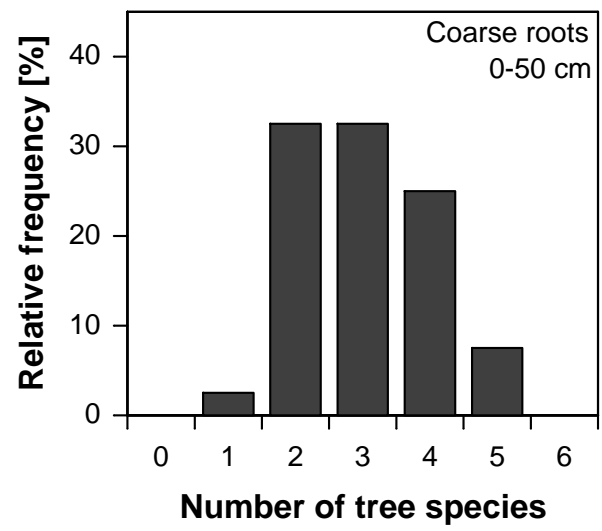

Abb. 4.3: Relative Häufigkeit des Vorkommens von Grobwurzeln (Durchmesser $>2 \mathrm{~mm}$ ) verschiedener Baumarten in den Profilwänden in 0-50 cm Bodentiefe; $n=40$. Im Mischbestand im Nationalpark Hainich wurden insgesamt 11 Baumarten gefunden. Wurzeln von Sommer- und Winterlinde wurden nicht unterschieden. 
Die Grobwurzeldichte wird definiert als Anzahl der Wurzeln pro $\mathrm{m}^{2}$ Profilwand, die größer als $2 \mathrm{~mm}$ im Durchmesser sind. Die mittlere Bestandesgrobwurzeldichte betrug 105.7 Wurzeln $\mathrm{m}^{-2}$ über 0-50 $\mathrm{cm}$ Bodentiefe.

Vergleichbar mit der Feinwurzeldichte erreichte die Esche die höchste Grobwurzeldichte mit 53.4 Wurzeln $\mathrm{m}^{-2}$ (Abb. 4.4), gefolgt von den Linden mit 13.5 Wurzeln $\mathrm{m}^{-2}$. Ebenso viele Wurzeln hatte der Bergahorn $\left(12.9 \mathrm{~m}^{-2}\right)$. Nur an einer Probestelle wurden Wurzeln der Stieleiche gefunden, woraus sich die geringste Dichte von 0.3 Wurzeln $\mathrm{m}^{-2}$ ergibt. Buche und Hainbuche hatten jeweils eine Grobwurzeldichte von 6.7 Wurzeln $\mathrm{m}^{-2}$.

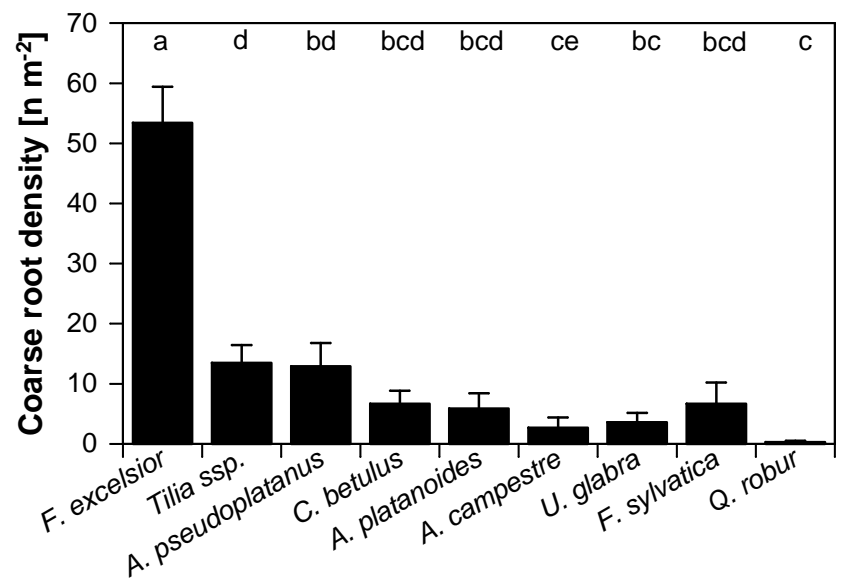

Abb. 4.4: Grobwurzeldichten der neun untersuchten Baumarten der Mischwaldfläche im Nationalpark Hainich. Dargestellt sind Mittelwerte und Standardfehler für die Bodentiefe 0$50 \mathrm{~cm} ; \mathrm{n}=40$. Signifikante Unterschiede zwischen den Arten sind durch unterschiedliche Buchstaben gekennzeichnet $(\mathrm{p}<0.05$, Mann-Whitney-Test).

In Abb. 4.5 ist die Grobwurzeldichte in 0-50 cm Tiefe gegen die Entfernung zum nächsten Stamm der jeweiligen Baumart aufgetragen. Die Ausdehnung der Grobwurzelsysteme der Linden und der Buche erreichte maximal $20 \mathrm{~m}$. Grobwurzeln von Bergahorn, Hainbuche und Esche wurden bis in $15 \mathrm{~m}$ Entfernung zum Stamm gefunden. Besonders für die Esche muss hier jedoch die hohe Stammdichte berücksichtigt werden, die den Nachweis einer weiteren Ausdehnung mit dieser Methode unmöglich machte. Speziell Feldahorn-, Ulmen- und Stieleichengrobwurzeln wurden nur in wenigen Probestellen gefunden, so dass dort eine Aussage über die Ausdehnung der Wurzeln kaum möglich ist. Eine signifikante lineare Abhängigkeit kann daher nur für die Grobwurzeln der Buche gefunden werden. Spitz- und Bergahorn zeigen ebenfalls eine tendenzielle Abnahme der Grobwurzeldichte mit zunehmender Stammentfernung, dies ist jedoch nicht statistisch signifikant ( $\mathrm{p}>0.05$ ).

Die Grobwurzeldichte der meisten Baumarten erreichte in den oberen $20 \mathrm{~cm}$ des Bodens ein Maximum (Abb.4.6A). Die Abnahme der Grobwurzeldichte in einer Bodentiefe von 30-50 cm ist für die meisten Baumarten signifikant.

Die Grobwurzeldichte der Esche verringerte sich von maximal 94.5 (10-20 cm Tiefe) auf 

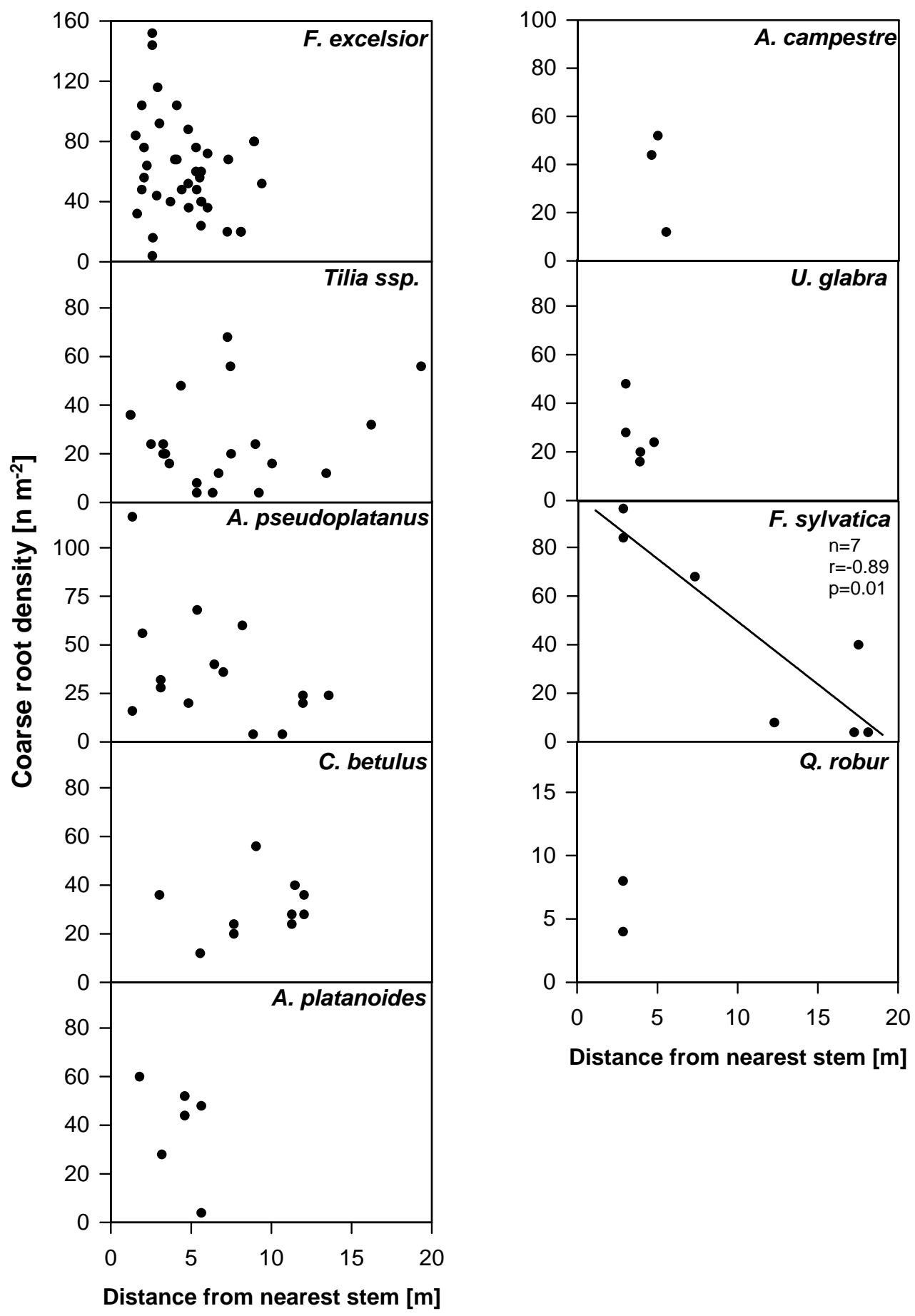

Abb. 4.5: Abhängigkeit der Grobwurzeldichte vom Abstand zum nächsten Stamm der jeweiligen Baumart auf der Untersuchungsfläche im Nationalpark Hainich. Dargestellt sind die Grobwurzeldichten auf einer Profilwand von 0-50 cm Bodentiefen für die neun Baumarten. Die Graphen sind unterschiedlich skaliert. 

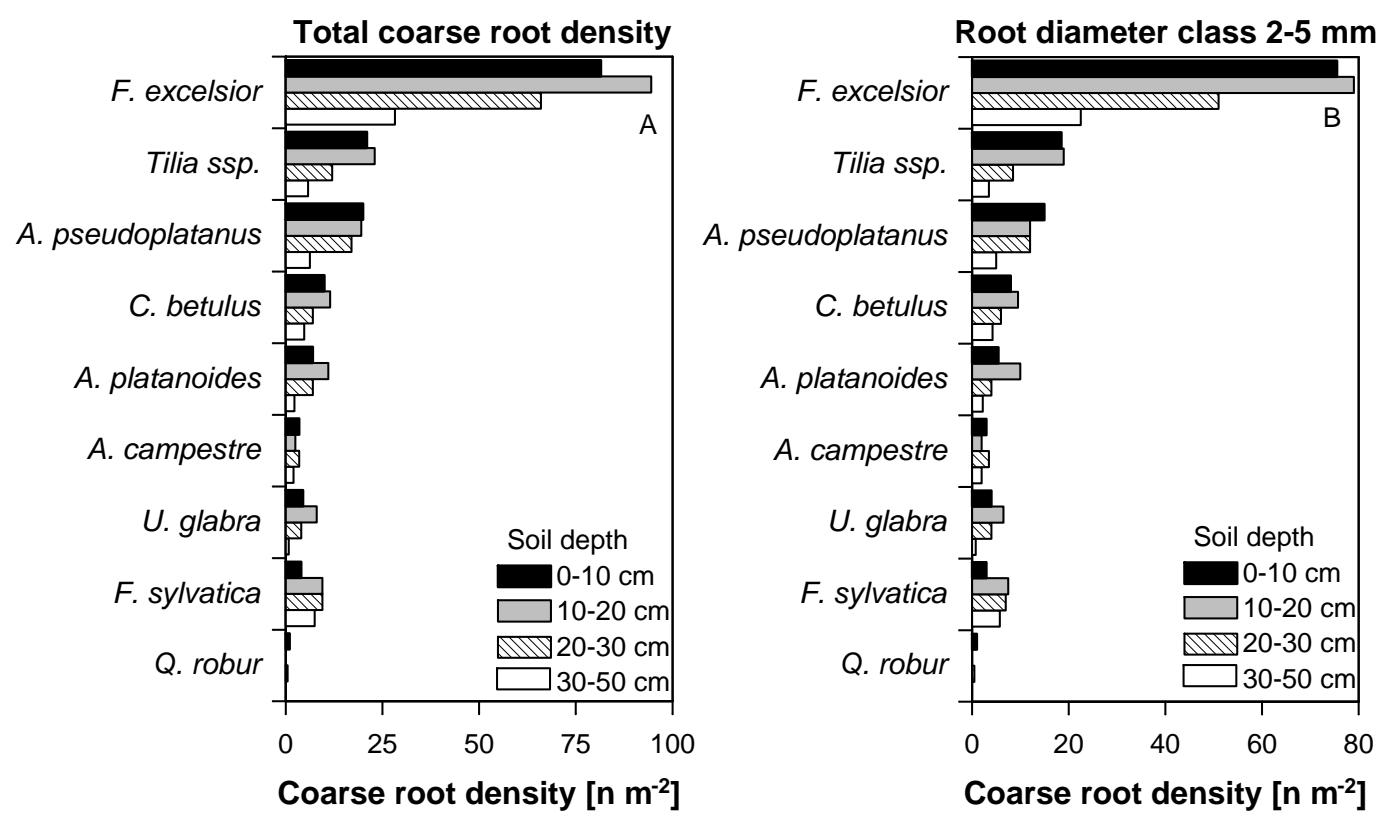

Abb. 4.6: A Grobwurzeldichte in den vier Tiefenstufen 0-10 cm, 10-20 cm, 20-30 cm und 30-50 cm Bodentiefe der neun Baumarten auf der Mischwaldfläche im Nationalpark Hainich. Dargestellt sind die Mittelwerte aller Grobwurzeln für die Tiefenstufen; n=40. B Grobwurzeldichte für die Durchmesserklasse der Schwachwurzeln $(2-5 \mathrm{~mm})$ in den vier Tiefenstufen. Dargestellt sind jeweils die Mittelwerte für die Tiefenstufen; $n=40$.

28.25 Wurzeln $\mathrm{m}^{-2}$. Die Abnahme der Grobwurzeldichte war für Linden, Bergahorn, Hainbuche, Spitzahorn und Ulme ebenso stark, die Anzahl der Wurzeln verringerte sich um 70$90 \%$. An allen Bodentiefen konnten 2 bis 3.5 Wurzeln des Feldahorn pro $\mathrm{m}^{2}$ gefunden werden, auch die Buchengrobwurzeln waren über drei Bodentiefen gleichverteilt (7.5-9.5 Wurzeln $\mathrm{m}^{-2}$ ). Alle Baumarten hatten in 0-10 cm Tiefe weniger Grobwurzeln als in $10-20 \mathrm{~cm}$ Tiefe. Betrachtet man die für die Untersuchung der Wasseraufnahme relevante Durchmesserklasse von 2-5 mm (Schwachwurzeln), so ergibt sich eine Verteilung auf die Tiefenstufen entsprechend der Gesamtgrobwurzelverteilung (Abb. 4.6B). Dies war zu erwarten, da Schwachwurzeln an der Gesamtgrobwurzelmenge einen Anteil von 81.7\% hatten, während Derbwurzeln (8.9\%), Grobwurzeln i.e.S. (5.6\%) und Starkwurzeln (3.8\%) nur einen geringen Mengenanteil ausmachten. Der Verteilungsschwerpunkt dieser Durchmesserklasse war daher ebenfalls in einer Bodentiefe bis $20 \mathrm{~cm}$ zu finden. In dieser Durchmesserklasse hatte die Esche 154.50 Wurzeln $\mathrm{m}^{-2}$ bis in $20 \mathrm{~cm}$ Tiefe, gefolgt von den Linden (37.50 Wurzeln $\mathrm{m}^{-2}$ ), Bergahorn (27.00 Wurzeln $\mathrm{m}^{-2}$ ) und Hainbuche (17.50 Wurzeln $\mathrm{m}^{-2}$ ). Buchen hatten in diesen Bodentiefen 10.5 Schwachwurzeln pro $\mathrm{m}^{2}$, während nur eine Wurzel der Stieleiche vertreten war. 


\subsection{Wasseraufnahmeraten von sechs Baumarten und mögliche Einflussgrößen}

\subsubsection{Kalibrierung der Sensoren im Freiland}

Die Kalibrierung der Saftflusssensoren erfolgte nach dem Abschluss der Messungen im August/September 2000 und 2001 an jeweils zwei Wurzeln von Esche, Winterlinde, Hainbuche und Buche. An diesen Wurzeln fanden zuvor Saftflussmessungen statt, so dass der Nullpunkt des Saftflusses bestimmt werden konnte. In Abb. 4.7 sind die gravimetrisch ermittelten Flussraten den thermoelektrisch gemessenen Flussraten der Sensoren gegenübergestellt. Die mit diesen beiden Methoden gemessenen Flussraten stimmten sehr gut überein $\left(\mathrm{R}^{2}=0.98\right)$.

Die Flussraten dieser Wurzeln erreichten Werte zwischen 0.5 und $20 \mathrm{~g} \mathrm{~h}^{-1}$. Dies entsprach der Höhe der Flussraten, die während des Untersuchungszeitraums gemessen wurden.

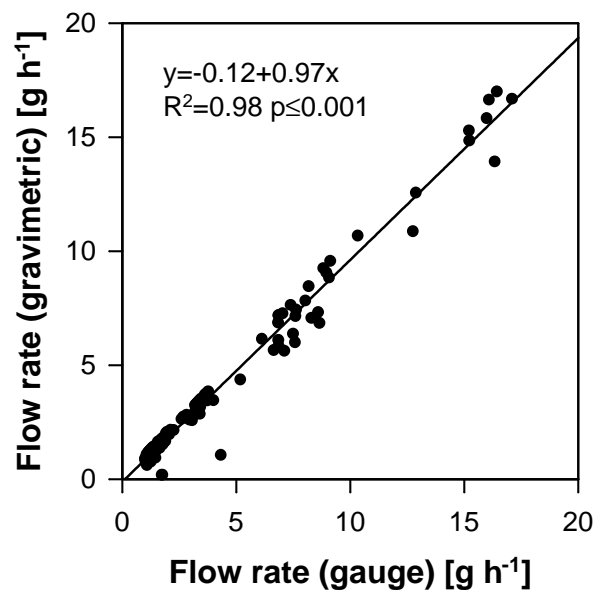

Abb. 4.7: Korrelation zwischen gravimetrisch bestimmten und mit den Saftflusssensoren gemessenen Flussraten von je zwei Wurzeln verschiedener Baumarten (Esche, Winterlinde, Hainbuche und Buche). Die Messungen fanden im August/September 2000 und 2001 an 3$4 \mathrm{~mm}$ starken Wurzeln auf der Untersuchungsfläche im Hainich statt. Die gravimetrische Bestimmung der Flussrate erfolgte über die Wasserentnahme aus einem $30 \mathrm{ml}$ Reservoir über 2 bis 3 Stunden bei gleichzeitiger Erfassung der Flussrate über die Saftflusssensoren.

Auch bei der Unterscheidung der vier zu dieser Kalibrierung herangezogenen Baumarten ergab sich jeweils eine sehr gute Korrelation zwischen der Messung mit Saftflusssensoren und der gravimetrisch bestimmter Wasserentnahme aus einem Reservoir. Dies drückte sich in den Werten des Bestimmtheitsmaßes $\mathrm{R}^{2}$ von 0.94 (Esche), 0.98 (Winterlinde), 0.96 (Hainbuche) und 0.98 (Buche) aus; die Irrtumswahrscheinlichkeiten lagen jeweils bei $\leq 0.001$. 


\subsubsection{Biometrische Daten und Morphologie der Wurzeln}

Nach dem Abschluss der Saftflussmessungen an den Feinwurzeln der Bäume wurden diese Wurzeln quantitativ geerntet und verschiedene biometrische Daten aufgenommen. Alle Wurzeln hatten einen Wurzeldurchmesser zwischen 2.9 und $4.1 \mathrm{~mm}$ am Messabschnitt des Saftflusssensors.

Zunächst wurde die Wurzeloberfläche der geernteten Messwurzeln ermittelt (Abb. 4.8). Die Hainbuche hatte unter den sechs Baumarten im Hainich im Mittel die größte Wurzeloberfläche mit $489.54 \pm 692 \mathrm{~cm}^{2}$, gefolgt von Stieleiche, Buche und Bergahorn. Diese wiesen zwar geringere Wurzeloberflächen auf $\left(233.07,225.07\right.$ bzw. $\left.162.57 \mathrm{~cm}^{2}\right)$, unterschieden sich jedoch nicht signifikant von der Hainbuche. Die Esche hatte mit $88.74 \pm 76 \mathrm{~cm}^{2}$ ebenso wie die Winterlinde mit $76.82 \pm 48 \mathrm{~cm}^{2}$ signifikant kleinere Wurzeloberflächen.

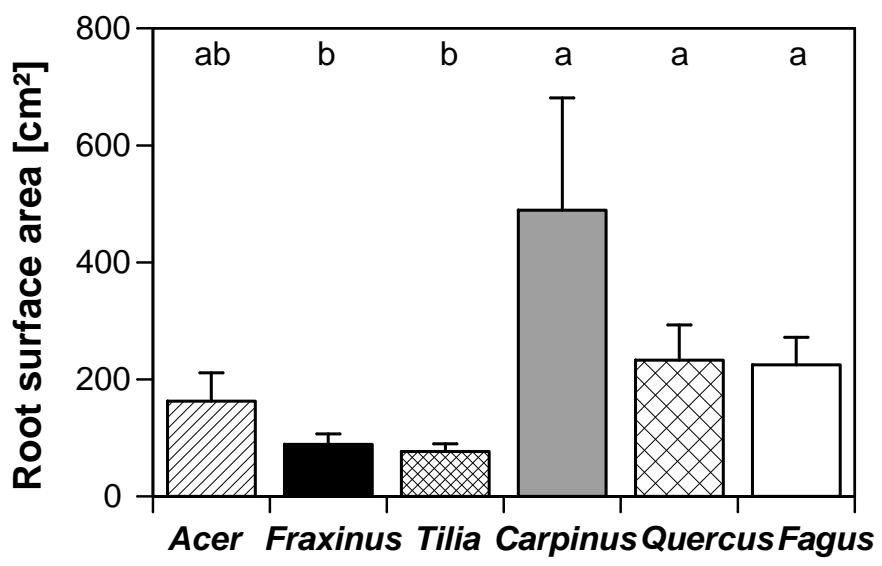

Abb. 4.8: Gesamtwurzeloberfläche von sechs Baumarten auf der Untersuchungsfläche im Hainich. Dargestellt sind die Mittelwerte und Standardfehler von 10-15 Wurzelsträngen mit einem Durchmesser von 2.9 - $4.1 \mathrm{~mm}$, an denen zuvor Saftflussmessungen stattfanden. Unterschiedliche Buchstaben kennzeichnen signifikante Unterschiede zwischen den Baumarten $(\mathrm{p}<0.05$, Mann-Whitney-Test).

Die Aufteilung der gesamten Wurzeloberfläche in Feinst- (0-1 mm Durchmesser), Fein- (1$2 \mathrm{~mm}$ ) und Schwachwurzeln $(>2 \mathrm{~mm})$ der geernteten Wurzeln ist in Abb. 4.9A dargestellt. In der Klasse der Feinstwurzeln und der Feinwurzeln hatten die Baumarten hinsichtlich ihrer Wurzeloberfläche die gleichen Relationen zueinander wie in der Gesamtwurzeloberfläche. Die Wurzeln der Hainbuchen wiesen auch in diesen beiden Durchmesserklassen die größten Wurzeloberflächen auf, während bei Eschen und Lindenwurzeln signifikant kleinere Oberflächen gefunden wurden. Dies änderte sich jedoch bei der Betrachtung der Schwachwurzeloberfläche. Hier trat die Hainbuche hinter die Eiche zurück, signifikante Unterschiede zwischen den Baumarten konnten nicht ermittelt werden. Betrachtet man in Abb. 4.9B den prozentualen Anteil der Oberfläche in den drei Durchmesserklassen an der Gesamtwurzeloberfläche, können nur geringe Unterschiede zwischen den Baumarten festgestellt werden. Unabhängig von 

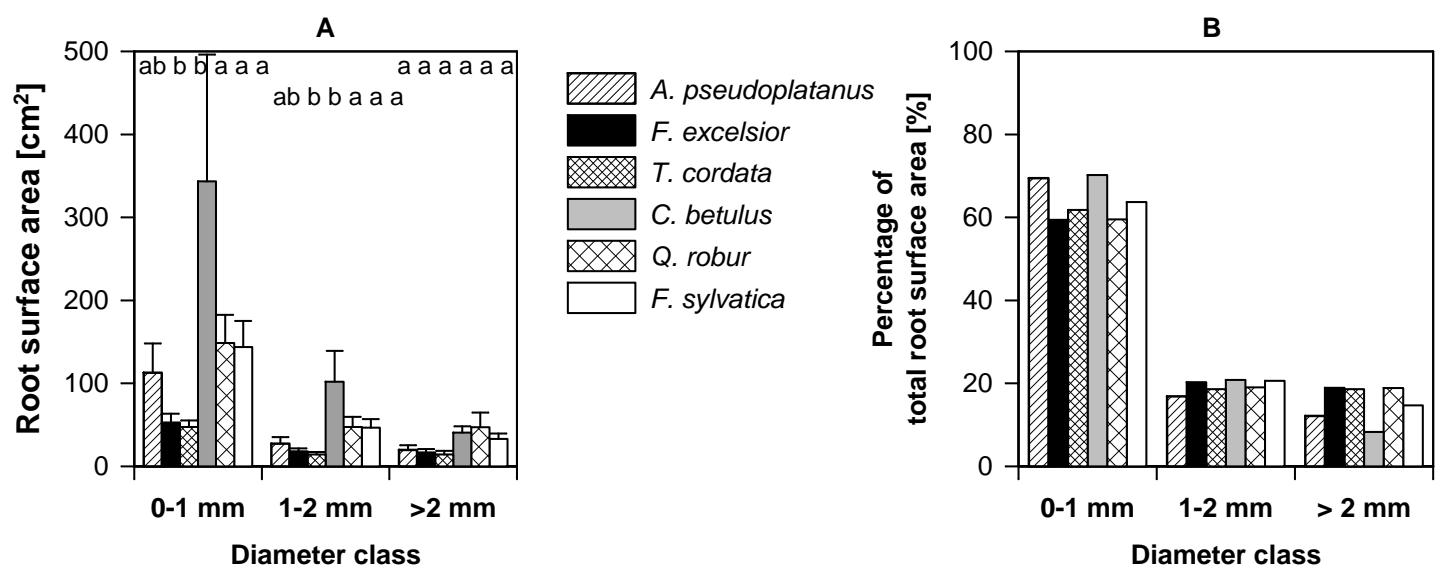

Abb. 4.9: Verteilung der Wurzeloberfläche auf die Durchmesserklassen 0-1 mm, 1-2 mm und $>2 \mathrm{~mm}$. A Mittelwerte mit Standardfehlern von 12-14 im Hainich geernteten Wurzelsträngen pro Baumart mit einem Durchmesser von 2.9 - $4.1 \mathrm{~mm}$. Signifikante Unterschiede zwischen den Baumarten sind durch unterschiedliche Buchstaben gekennzeichnet $(\mathrm{p}<0.05$, Mann-Whitney-Test). B Prozentualer Anteil der Oberfläche jeder Durchmesserklasse an der Gesamtwurzeloberfläche.

der Gesamtwurzeloberfläche trugen die Feinstwurzeln ca. 60\%, Fein- und Schwachwurzeln jeweils ca. 20\% zur Wurzeloberfläche bei. Eine Ausnahme bildete die Hainbuche, die einen geringeren prozentualen Anteil an Schwachwurzeln besaß (8\%).

Die Verteilung der Wurzeloberfläche auf die Durchmesserklassen Feinst-, Fein- und Schwachwurzeln in Beziehung zur Gesamtwurzeloberfläche ist in Abb. 4.10 dargestellt. Für alle Arten und Durchmesserklassen ergaben sich strikt lineare Beziehungen mit Korrelationskoeffizienten von 0.81 bis 0.99. Aus den unterschiedlichen Steigungen der Regressionsgeraden kann abgelesen werden, dass die Feinstwurzeln (0-1 mm) mit den steilsten Steigungen bei allen Baumarten auch die Gruppe mit der größten Wurzeloberfläche stellten. Mit zunehmender Gesamtwurzeloberfläche vergrößerte sich auch der Anteil der Wurzeloberfläche der drei Durchmesserklassen bei allen Baumarten. Nur für die Schwachwurzeln der Hainbuche konnte keine Steigung nachgewiesen werden. Dies bedeutet, dass mit zunehmender Gesamtwurzeloberfläche keine weitere Zunahme der Schwachwurzeln erfolgt und somit den Feinst- und Feinwurzeln eine größere Bedeutung zukommt.

An jeweils fünf Wurzelsträngen pro Baumart wurde der Durchmesser entlang des Hauptstranges in Abhängigkeit von der Entfernung zu dessen Wurzelspitze gemessen. Die lineare Beziehung zwischen diesen beiden Parametern ist in Abb. 4.11 aufgetragen.

Für alle sechs Baumarten kann eine signifikante Korrelation zwischen dem Abstand vom Wurzelende und dem Durchmesser nachgewiesen werden, die Korrelationskoeffizienten variieren zwischen 0.64 (Buche) und 0.92 (Bergahorn). Unterschiede zwischen den Baumarten ergaben sich auch in der Steigung der Regressionsgeraden, d.h. in dem Maß der Durchmesserzunahme mit der Entfernung zum Wurzelende. Die längsten und dünnsten Wurzeln wurden an der 


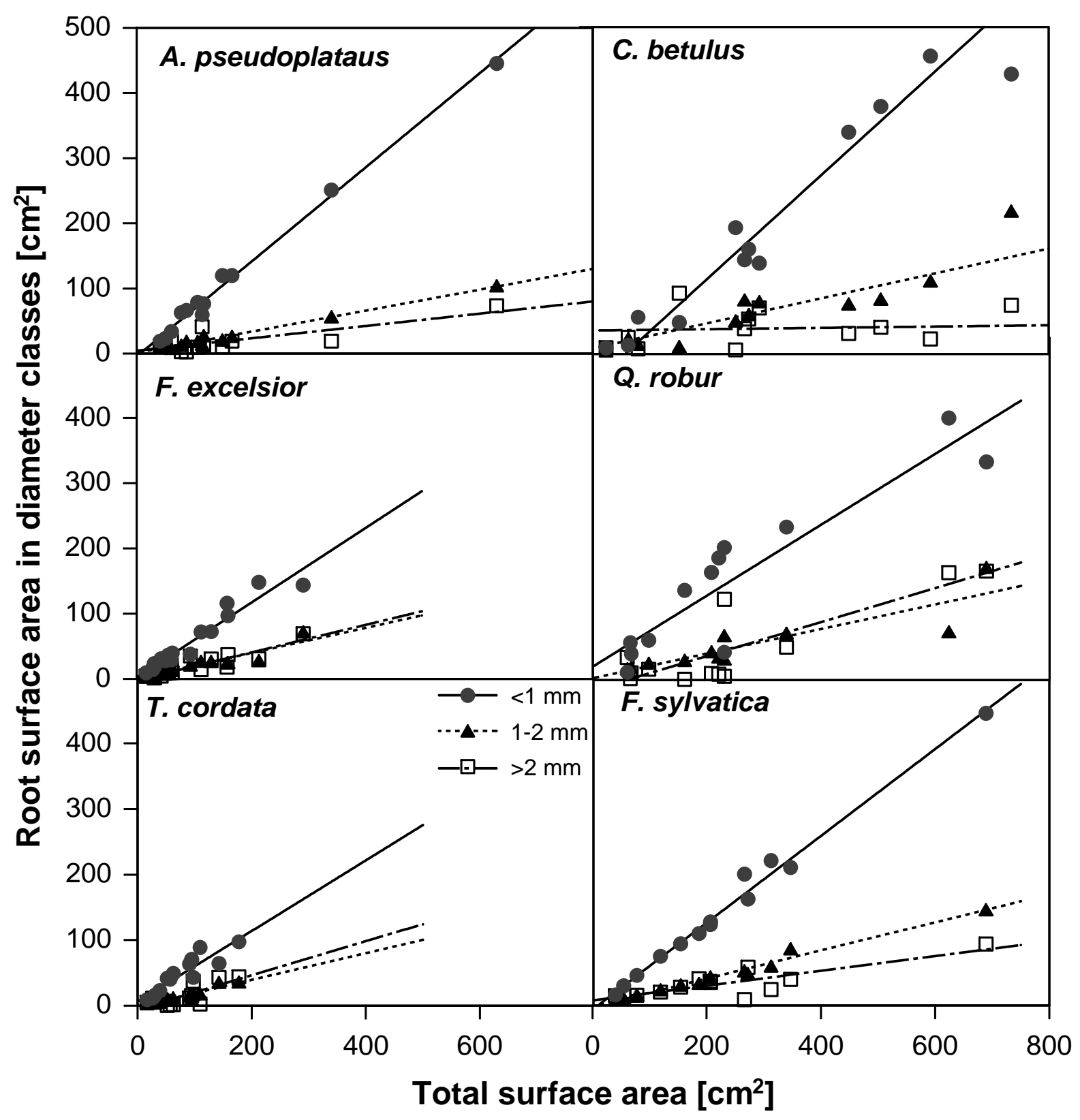

Abb. 4.10: Abhängigkeit der Wurzeloberfläche in den Durchmesserklassen 0-1 mm (Feinst-), 1-2 mm (Fein-) und $>2 \mathrm{~mm}$ (Schwachwurzeln) von der Gesamtwurzeloberfläche des jeweiligen Wurzelstranges. Aufgetragen sind die Werte aller im Nationalpark Hainich geernteten 2.9 - $4.1 \mathrm{~mm}$ starken Wurzelstränge, an denen zuvor Saftflussmessungen durchgeführt worden sind. 


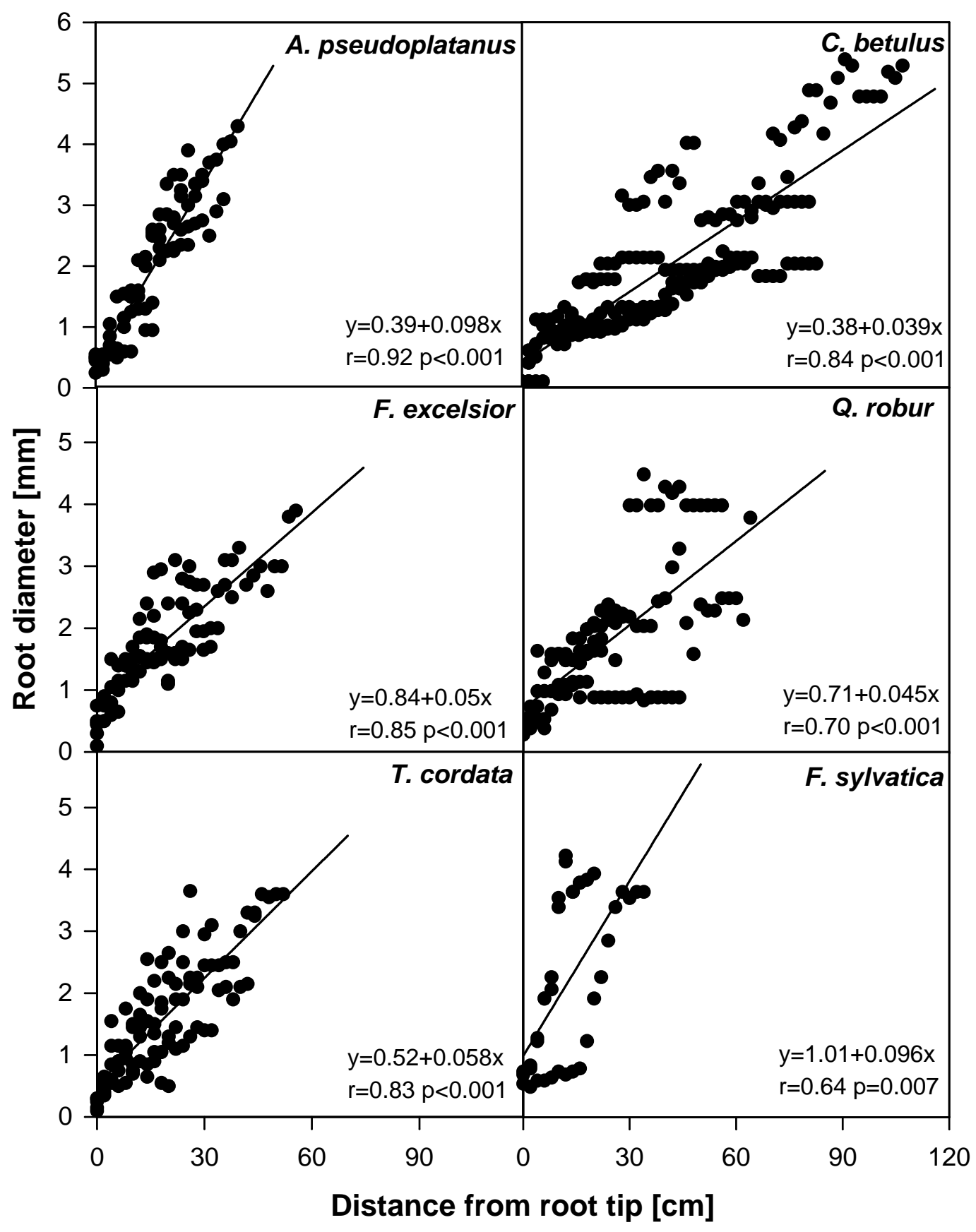

Abb. 4.11: Abhängigkeit des Wurzeldurchmessers von der Entfernung zum Wurzelende. Vermessen wurden pro Baumart fünf Wurzelstränge, geerntet im Hainich in den Jahren 2000 und 2001 nach dem Abschluss der Saftflussmessungen. Der Abstand wurde entlang des Hauptwurzelstranges von dessen Wurzelspitze bis zum Messabschnitt ermittelt. 
Hainbuche gefunden, deren Wurzeln nur $0.039 \mathrm{~mm} \mathrm{~cm}^{-1}$ im Durchmesser zunahmen. Die Hainbuche wies mit 0.05 bis $0.1 \mathrm{~mm}$ auch die geringsten Durchmesser der Wurzelspitzen auf. Die Steigungen der Regressionsgeraden von Esche, Linde und Eiche sind einander sehr ähnlich, sie liegen zwischen 0.045 (Eiche) und $0.058 \mathrm{~mm} \mathrm{~cm}^{-1}$ (Linde). Diese drei Baumarten wiesen direkt an der Wurzelspitze des Hauptwurzelstranges Durchmesser zwischen 0.1 und $0.3 \mathrm{~mm}$ auf.

Bergahorn und Buche hatten die kürzesten und stärksten Wurzelstränge. Kein vermessener Wurzelstrang war länger als 25-35 cm. Die Durchmesserzunahme war mit 0.096 und $0.098 \mathrm{~mm}$ $\mathrm{cm}^{-1}$ bei Buche und Bergahorn am stärksten. An Wurzelsträngen dieser beiden Baumarten konnten auch direkt hinter der Wurzelspitze Durchmesser von 0.5-0.7 mm gemessen werden.

\subsubsection{Anatomie der Wurzeln}

\section{Anatomie am Messabschnitt}

Die in den beiden Messjahren 2000 und 2001 hinsichtlich ihrer Anatomie vergleichend untersuchten Wurzeln der sechs Baumarten hatten alle einen Durchmesser zwischen 3 und $4 \mathrm{~mm}$ an dem Messabschnitt, an dem der Saftflusssensor angebracht war. Sie sind daher in der Stärke gut untereinander vergleichbar. Von den Messabschnitten wurden Querschnitte angefertigt, an denen die anatomische Struktur der Wurzeln untersucht wurde. In Abb. 4.12 sind die Mittelwerte der Leitflächen der Messwurzeln dargestellt. Die Leitfläche ist die Summe aller Gefäßquerschnittsflächen.

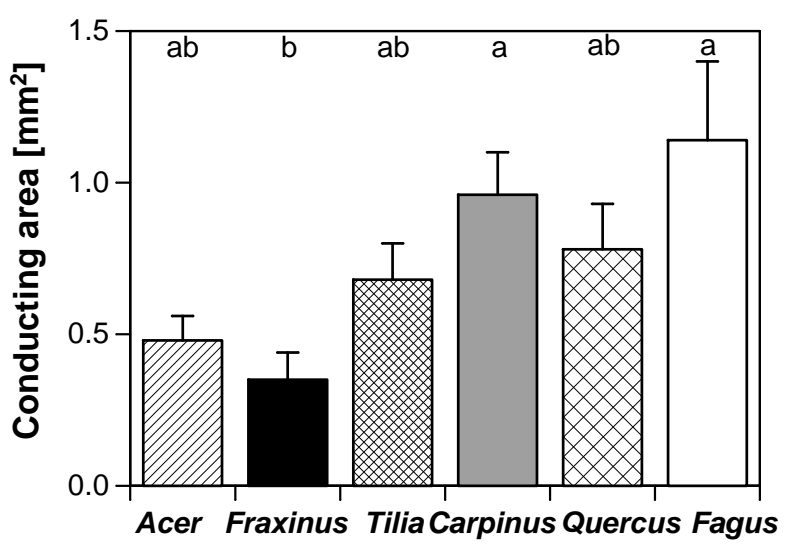

Abb. 4.12: Leitflächen der Wurzeln der sechs untersuchten Baumarten im Hainich. Die Leitflächen wurden an den Messabschnitten der Wurzelstränge ermittelt, an denen zuvor Saftflussmessungen durchgeführt wurden, der Wurzeldurchmesser betrug 3-4 mm. Dargestellt sind Mittelwerte und Standardfehler von 18-23 Wurzeln je Baumart. Unterschiedliche Buchstaben kennzeichnen signifikante Unterschiede zwischen den Baumarten $(\mathrm{p}<0.05$, Mann-WhitneyTest). 
Die Leitfläche der Eschenwurzeln war mit $0.35 \mathrm{~mm}^{2}$ im Mittel am geringsten und unterschied sich signifikant von den Buchenwurzeln, die mit $1.14 \mathrm{~mm}^{2}$ im Mittel die größten Leitflächen aufwiesen. Der Anteil der Leitfläche an der Wurzelquerschnittsfläche machte bei der Esche nur $4.0 \%$ aus. Auch anteilig wies die Buche mit $12.0 \%$ die größte Leitfläche auf. Eine nur wenig kleinere Leitflächen hatten die Hainbuchenwurzeln mit $0.96 \mathrm{~mm}^{2}(9.7 \%$ des Wurzelquerschnittes). Die Größe der Leitfläche unterschied sich zwischen den anderen Baumarten nicht signifikant. Bergahorn hatte eine Leitfläche von $0.48 \mathrm{~mm}^{2}$, was $5.0 \%$ der Wurzelquerschnittsfläche entsprach. Relativ gering waren auch die Unterschiede zwischen den Leitflächen von Winterlinde und Stieleiche, die einen relativen Anteil von $7.3 \%$ und $8.1 \%$ ausmachten $(0.68$ bzw. $0.78 \mathrm{~mm}^{2}$ ).

In der Anzahl von Gefäßen pro $\mathrm{mm}^{2}$ Xylemquerschnittsfläche konnten zwischen den untersuchten Baumarten keine signifikanten Unterschiede festgestellt werden (Abb. 4.13).

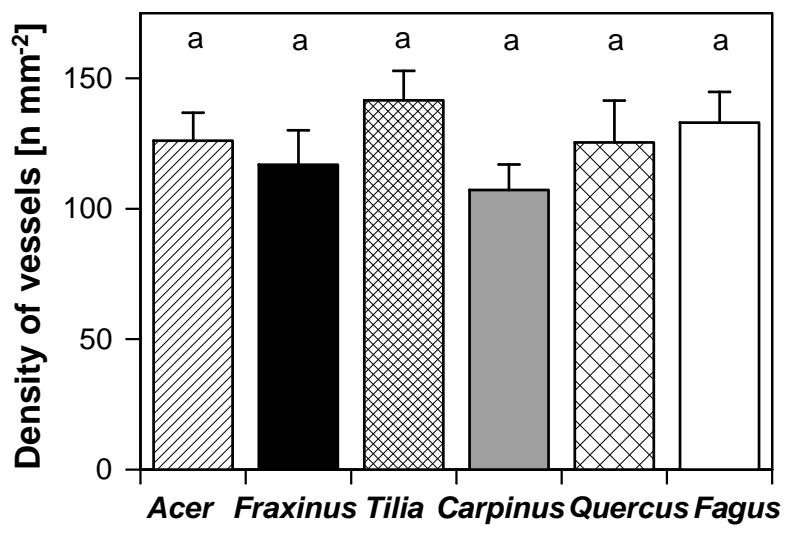

Abb. 4.13: Dichte der Gefäße pro $\mathrm{mm}^{2}$ Xylemquerschnittsfläche in Querschnitten von 3-4 mm starken Wurzeln von Bergahorn, Esche, Winterlinde, Hainbuche, Stieleiche und Esche von der Untersuchungsfläche im Nationalpark Hainich. Pro Baumart wurden 15-20 Wurzeln untersucht. Unterschiedliche Buchstaben kennzeichnen signifikante Unterschiede zwischen den Baumarten $(\mathrm{p}<0.05$, Mann-Whitney-Test).

Im Mittel hatten Wurzeln der Winterlinde mit einem Durchmesser von 3-4 mm mit 141.6 Gefäßen die meisten Leitelemente auf einem $\mathrm{mm}^{2}$ Xylemfläche, gefolgt von Buchenwurzeln mit 133.1 Gefäßen. Tendenziell wiesen Wurzeln der Hainbuche mit 107.2 Gefäßen pro mm² Xylemfläche die wenigsten Leitbahnen auf.

In der Häufigkeitsverteilung der Gefäße über die Gefäßdurchmesser wurden srtspezifische Unterschiede festgestellt (Abb. 4.14). Eine Gauß-Funktion der Form $y=a+b \cdot e^{-\left(\frac{x-c}{d}\right)^{2}}$ beschreibt die Verteilungskurven. Bergahorn, Esche und Winterlinde haben eine sehr ähnliche Verteilung. Die Maxima lagen mit 22.5, 22.8 bzw. 21.3 Leitelementen pro $\mathrm{mm}^{2}$ Xylemquerschnitt bei einem Durchmesser von 15-20 $\mu \mathrm{m}$. Damit ist die Verteilungskurve dieser Arten im Vergleich zu Hainbuche, Stieleiche und Buche zugunsten englumiger Gefäße nach links verschoben. Die Verteilungskurven von Hainbuche und Stieleiche sind flacher, das Maximum 
wird jeweils bei einem Gefäßdurchmesser von 30-35 $\mu \mathrm{m}$ erreicht. Das Maximum der Verteilungskurve der Buche liegt mit 23 Gefäßen $\mathrm{mm}^{-2}$ in der Durchmesserklasse 35-40 $\mu \mathrm{m}$.
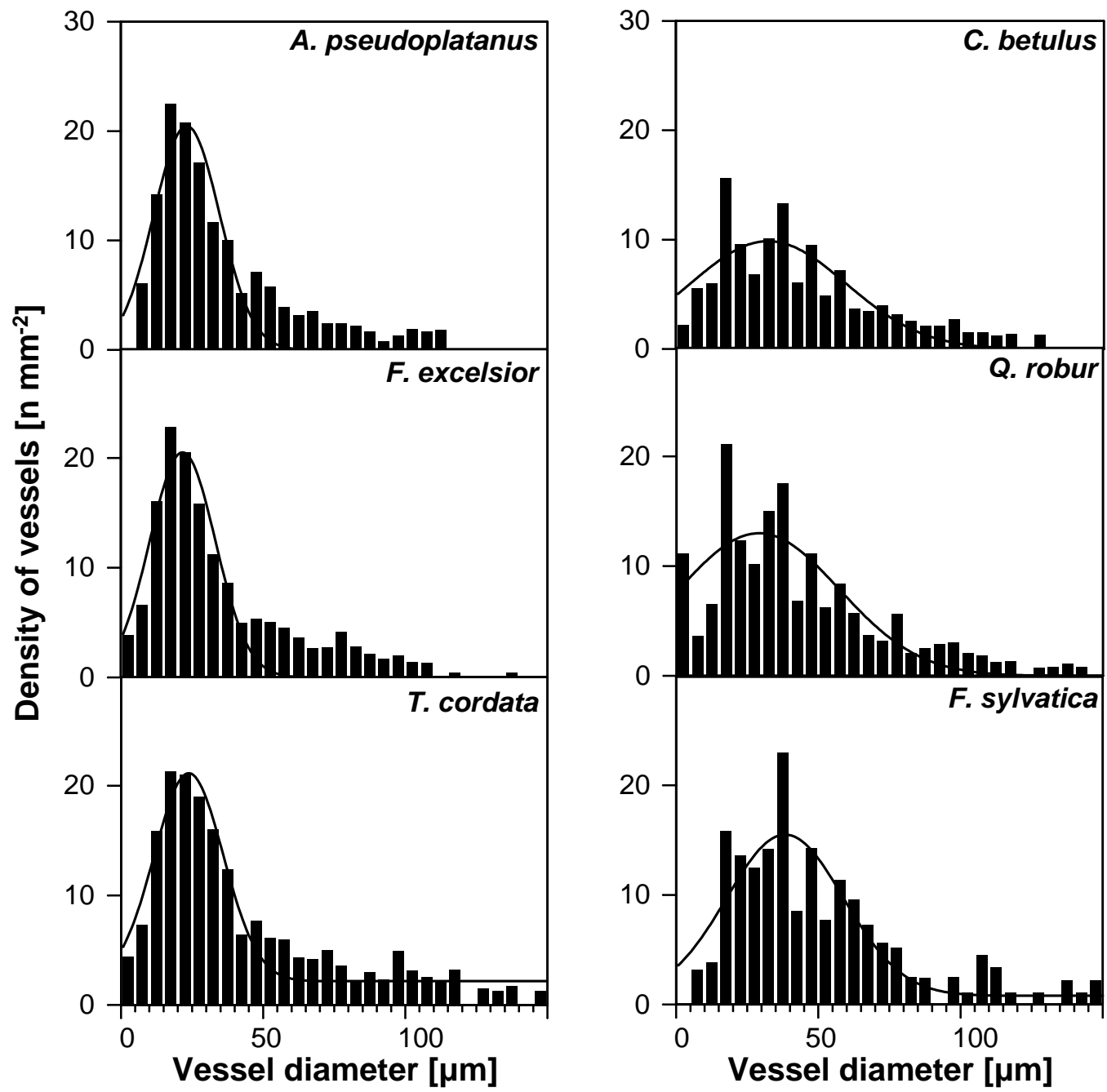

Abb. 4.14: Häufigkeitsverteilung von Xylemgefäßen in Querschnitten von 3-4 mm starken Wurzeln von Bergahorn, Esche, Winterlinde, Hainbuche, Stieleiche und Buche im Nationalpark Hainich. Pro Baumart wurden 15-20 Wurzeln untersucht. Die Verteilungskurven werden durch die Gleichung $y=a+b \cdot e^{-\left(\frac{x-c}{d}\right)^{2}}$ beschrieben.

\section{Anatomie des Wurzelstranges}

Im Folgenden sind die Ergebnisse der anatomischen Untersuchung der ersten $15 \mathrm{~cm}$ des Wurzelstranges hinter der Wurzelspitze dargestellt. Hier soll vor allem eine Ausdifferenzierung der Wurzel durch sekundäres Dickenwachstum in dieser Region untersucht werden. 
Es kann beobachtet werden, dass sich die Wurzeldurchmesser, die direkt hinter der mykorrhizierten Wurzelspitze gemessen wurden, zwischen den Baumarten unterschieden (Abb. 4.15).

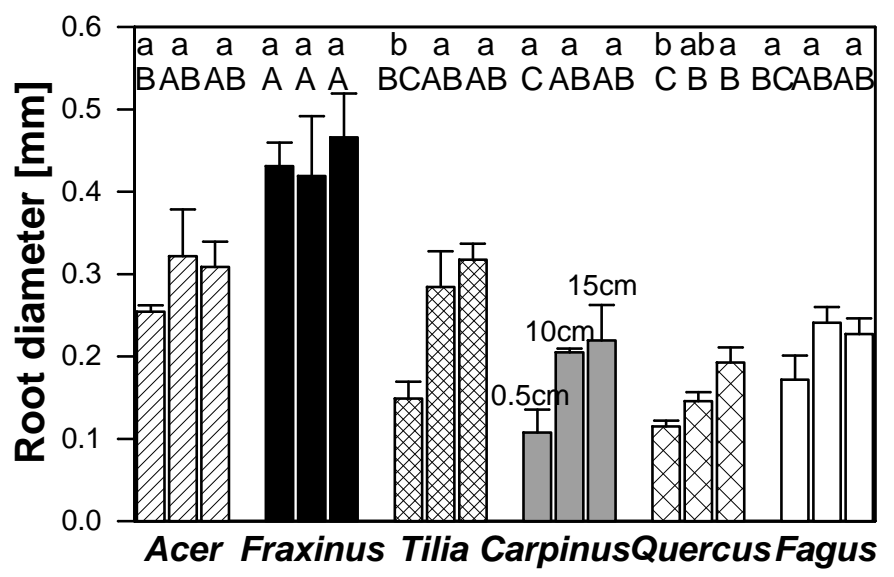

Abb. 4.15: Wurzeldurchmesser in $0.5 \mathrm{~cm}, 10 \mathrm{~cm}$ und $15 \mathrm{~cm}$ Abstand von der Wurzelspitze der sechs Baumarten im Nationalpark Hainich. Aufgetragen sind jeweils die Mittelwerte und Standardfehler von drei mikroskopisch untersuchten Wurzelenden. Unterschiedliche Großbuchstaben geben signifikante Unterschiede zwischen den Baumarten an, Kleinbuchstaben solche innerhalb einer Baumart ( $\mathrm{p}<0.05$, Mann-Whitney-Test).

Während Eschenwurzeln schon $0.5 \mathrm{~cm}$ hinter der Wurzelspitze einen Durchmesser von $0.43 \mathrm{~mm}$ aufwiesen, hatten Linde, Hainbuche und Eiche mit 0.15, 0.11, 0.12 und $0.17 \mathrm{~mm}$ in der Wurzelspitzenregion einen geringeren Durchmesser. Mit 0.17 bzw. $0.25 \mathrm{~mm}$ lagen auch die Durchmesser der Buchen- und Bergahornwurzeln in dieser Größenordnung. Die Wurzeln erfuhren im Verlauf der untersuchten $15 \mathrm{~cm}$ ein relativ starkes Dickenwachstum. So verdoppelte sich bei Linde und Hainbuche der Ausgangsdurchmesser. Eine solche Steigerung des Wurzeldurchmessers konnte bei Bergahorn und Esche nicht beobachtet werden; mit $0.31 \mathrm{~mm}$ (Bergahorn) und $0.47 \mathrm{~mm}$ (Esche) waren diese Wurzeln dennoch stärker im Durchmesser als die übrigen Baumarten.

Die Stärke des Periderms und die Anzahl an Zellschichten, aus denen es aufgebaut ist, sind in Abb. 4.16 und Abb. 4.17 dargestellt. Beim Bergahorn wurden hinter der Wurzelspitze jeweils 3-4 Peridermzellschichten gefunden, die in ihrer Stärke zwischen 28.13 und $34.98 \mu \mathrm{m}$ schwankten. Bei der Esche fiel eine starke Zunahme der Peridermdicke in $15 \mathrm{~cm}$ Entfernung zur Wurzelspitze auf. Eschenwurzeln wiesen mit $74.88 \mu \mathrm{m}$ im Vergleich mit den anderen fünf Baumarten die dickste Peridermschicht in $0.5 \mathrm{~cm}$ Abstand zur Wurzelspitze auf. Auch in $15 \mathrm{~cm}$ Entfernung war der Unterschied zu den anderen Baumarten signifikant. Eine Peridermdicke von $183.97 \mu \mathrm{m}$ wurde von keiner weiteren Baumart erreicht.

Hainbuche, Eiche und Buche glichen sich in der Stärke des Periderms. Bei der Hainbuche verdoppelte sich die Peridermschicht von 24.15 auf $46.16 \mu \mathrm{m}$. Die Eiche hatte $0.5 \mathrm{~cm}$ hinter der Wurzelspitze ein sekundäres Abschlussgewebe von $24.89 \mu \mathrm{m}$ Stärke, das in den weiteren 


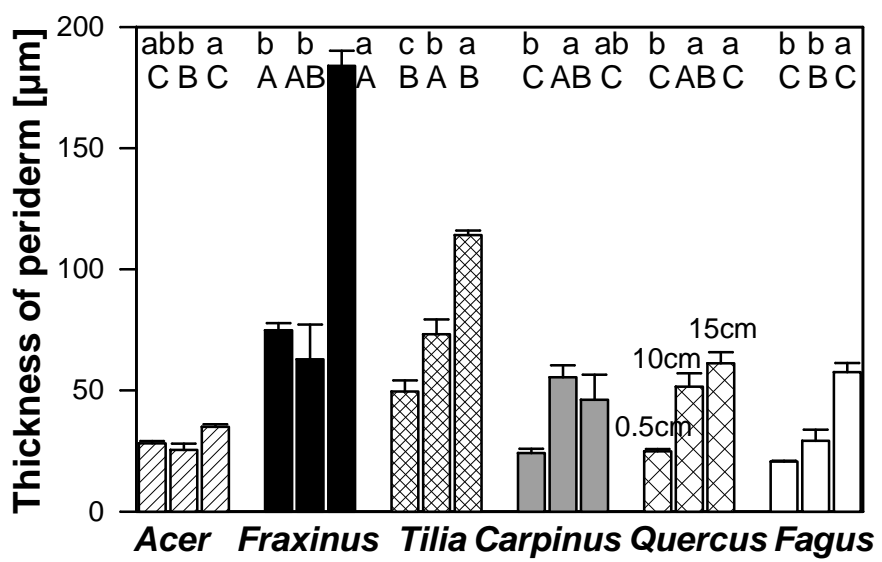

Abb. 4.16: Stärke des Periderms in $0.5 \mathrm{~cm}, 10 \mathrm{~cm}$ und $15 \mathrm{~cm}$ Abstand von der Wurzelspitze der sechs Baumarten im Nationalpark Hainich. Aufgetragen sind jeweils die Mittelwerte und Standardfehler von drei mikroskopisch untersuchten Wurzelenden. Unterschiedliche Großbuchstaben geben signifikante Unterschiede zwischen den Baumarten an, Kleinbuchstaben solche innerhalb einer Baumart. ( $\mathrm{p}<0.05$, Mann-Whitney-Test).

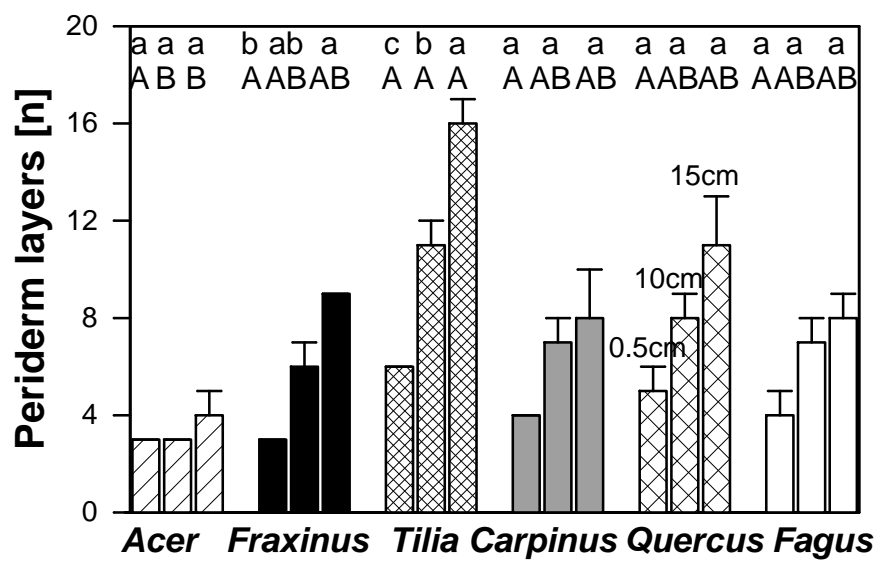

Abb. 4.17: Anzahl der Zelllagen des Periderms in $0.5 \mathrm{~cm}, 10 \mathrm{~cm}$ und $15 \mathrm{~cm}$ Abstand von der Wurzelspitze der sechs Baumarten im Nationalpark Hainich. Aufgetragen sind jeweils die Mittelwerte und Standardfehler von drei mikroskopisch untersuchten Wurzelenden. Unterschiedliche Großbuchstaben geben signifikante Unterschiede zwischen den Baumarten an, Kleinbuchstaben solche innerhalb einer Baumart. $(\mathrm{p}<0.05$, Mann-Whitney-Test). 
$15 \mathrm{~cm}$ der Wurzelachse auf $61.17 \mu \mathrm{m}$ anstieg. Die Peridermschicht der Buche verstärkte sich in diesen $15 \mathrm{~cm}$ von 20.63 auf $57.64 \mu \mathrm{m}$.

In der Anzahl der Periderm-Zelllagen glichen sich die sechs Baumarten mehr als in der Stärke der Peridermschicht. Signifikante Unterschiede konnten nur zwischen Bergahorn und Esche festgestellt werden. Schon $0.5 \mathrm{~cm}$ hinter der Wurzelspitze war das Periderm 3-6 Zellschichten mächtig. Mit Ausnahme des Bergahorns steigerte sich die Anzahl der Zellschichten bis in $15 \mathrm{~cm}$ Entfernung auf 8 (Hainbuche, Stieleiche) bis maximal 16 Zellreihen (Esche). Der Bergahorn dagegen steigerte die Anzahl der Zelllagen mit zunehmender Entfernung ebenso wie die Stärke des Periderms und den Wurzeldurchmesser nur wenig. Bei den anderen Baumarten war

die Änderung der Peridermstärke dagegen größer als die Zunahme des Wurzeldurchmessers, woraus sich eine starke Zunahme des Anteils des Periderms am Wurzelquerschnitt ergab.

\subsubsection{Edaphische und mikrometeorologische Parameter Strahlungsbilanz und VPD im Verlauf des Untersuchungszeitraums}

Als wichtige klimatische Einflussgrößen wurden die Strahlungsbilanz und das Wasserdampfsättigungsdefizit der Luft (VPD) aufgenommen. In Abb. 4.18 sind die Tageshellphasensumme der Strahlungsbilanz und die Mittelwerte des VPD über die Tageshellphase im Verlauf der Vegetationsperiode Mai bis Mitte Oktober 2000 und 2001 aufgetragen. Die Mittelwerte der Tageshellphasensumme der Strahlungsbilanz lagen im Jahr 2000 bei einem Wert von 17.49 $\mathrm{MJ} \mathrm{m}^{-2} \mathrm{~d}^{-1}$ und in der Vegetationsperiode 2001 bei $18.39 \mathrm{MJ} \mathrm{m}^{-2} \mathrm{~d}^{-1}$. Das Wasserdampfsättigungsdefizit (VPD) der Vegetationsperiode 2000 war ebenfalls niedriger als im folgenden Jahr, was in einem Mittelwert von $9.56 \mathrm{hPa}$ gegenüber $10.04 \mathrm{hPa}$ für 2001 resultierte. Perioden mit einer täglichen Strahlungsbilanz von über $20 \mathrm{MJ} \mathrm{m}^{-2} \mathrm{~d}^{-1}$ wurden im Jahr 2000 Ende Mai und vorwiegend im Juni erreicht, wobei auch das VPD jeweils hohe Werte annahm. Im Verlauf der Messungen im Jahr 2001 wurden solche Perioden sowohl Mitte und Ende Mai als auch im Juni und nahezu den ganzen Juli erreicht. Auch hier zeigte das VPD einen synchronen Verlauf mit Werten über $15 \mathrm{hPa}$ bis zu $32 \mathrm{hPa}$. In beiden Jahren konnte ein Absinken der Strahlungsbilanz und des VPD ab September beobachtet werden. Insgesamt waren sowohl Strahlung als auch VPD großen Schwankungen von Tag zu Tag unterworfen. Im Verlauf der Vegetationsperiode 2000 wurden Mitte Juni maximale Werte von Strahlungsbilanz und VPD gemessen (30.78 $\mathrm{MJ} \mathrm{m}^{-2} \mathrm{~d}^{-1}$ bzw. $22.49 \mathrm{hPa}$ ). Im Jahr 2001 erreichte die Strahlungsbilanz Ende Juni ein Maximum mit 30.04 $\mathrm{MJ} \mathrm{m}^{-2} \mathrm{~d}^{-1}$, während maximale VPD-Werte mit $32.14 \mathrm{hPa}$ Ende August gemessen wurden.

\section{Saisonaler Verlauf des volumetrischen Bodenwassergehaltes}

Die in beiden Untersuchungsjahren während der Vegetationsperiode gemessenen volumetrischen Bodenwassergehalte sind in Abb. 4.19 dargestellt.

Die Untersuchungsfläche im Mischwald hatte sowohl während der Vegetationsperiode 2000 als auch 2001 die niedrigsten volumetrischen Wassergehalte in $5 \mathrm{~cm}$ Tiefe. Im Jahr 2000 


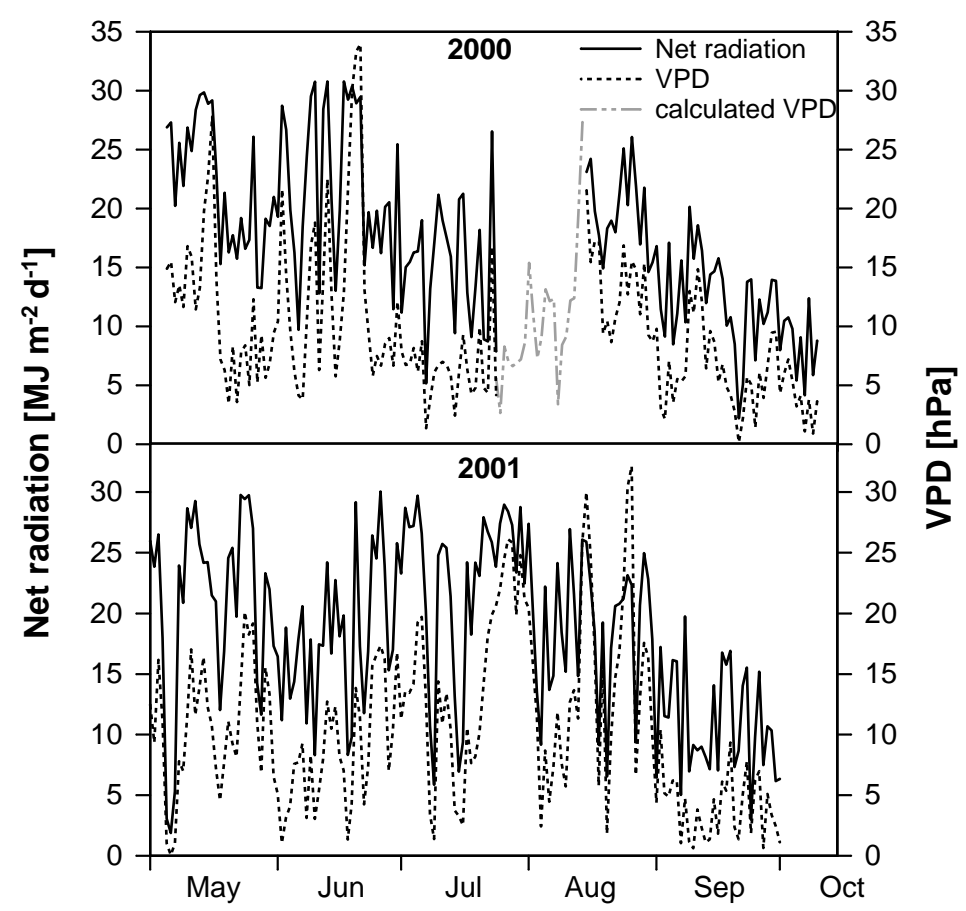

Abb. 4.18: Tageshellphasensummen der Strahlungsbilanz und Mittelwerte des Wasserdampfsättigungsdefizites der Luft (VPD) der Tageshellphasen während der Vegetationsperioden 2000 und 2001 im Hainich, gemessen auf einer Freifläche in direkter Nachbarschaft des untersuchten Bestandes. (Tageshellphase: Globalstrahlung $<5 \mathrm{~J} \mathrm{~m}^{-2} \mathrm{~s}^{-1}$ ). Im Jahr 2000 konnten fehlende Werte des VPD aus Daten des Deutschen Wetterdienstes (Station Mühlhausen) berechnet werden.

zeichneten sich Austrocknungsperioden in dieser Bodentiefe Mitte bis Ende Juni und Mitte Juli bis Mitte August ab. In diesen Perioden sank der volumetrische Bodenwassergehalt in $5 \mathrm{~cm}$ Tiefe auf $23.8 \mathrm{Vol} \%$. Auch in $15 \mathrm{~cm}$ und $40 \mathrm{~cm}$ Bodentiefe konnte diese Austrocknung beobachtet werden. Die Abnahme des Wassergehaltes war in diesen Bodenhorizonten jedoch weniger stark, der Bodenwassergehalt sank nicht unter 30.3 bzw. 33.3 Vol.\%.

Die Unterschiede im Wassergehalt zwischen den Bodentiefen waren im klimatisch trockeneren Jahr 2001 viel geringer. Eine Austrocknungsperiode zeichnete sich in 15 bzw. 40 cm Bodentiefe ab. Hier war ein Absinken des Bodenwassergehaltes von über 40 Vol.\% auf 30 Vol.\% im Verlauf von sechs Wochen (Mitte Juli bis Ende August) zu beobachten. In $5 \mathrm{~cm}$ Tiefe unterlag der Bodenwassergehalt dagegen nur geringen Schwankungen.

Ein abweichendes Bodenwasserregime zeigte sich in dem benachbarten Buchenwald in der Vegetationsperiode 2001. Der Bodenwassergehalt in 5 und $15 \mathrm{~cm}$ Tiefe sank während der Austrocknungsperiode Ende Juli bis August von über 40 Vol.\% auf 26 Vol.\%. In $40 \mathrm{~cm}$ Bodentiefe wirkten sich weder Austrocknungs- noch Wiederbefeuchtungsphase aus; der Bodenwassergehalt schwankte während der gesamten Vegetationsperiode zwischen 33.3 und 36.7 Vol\%. 


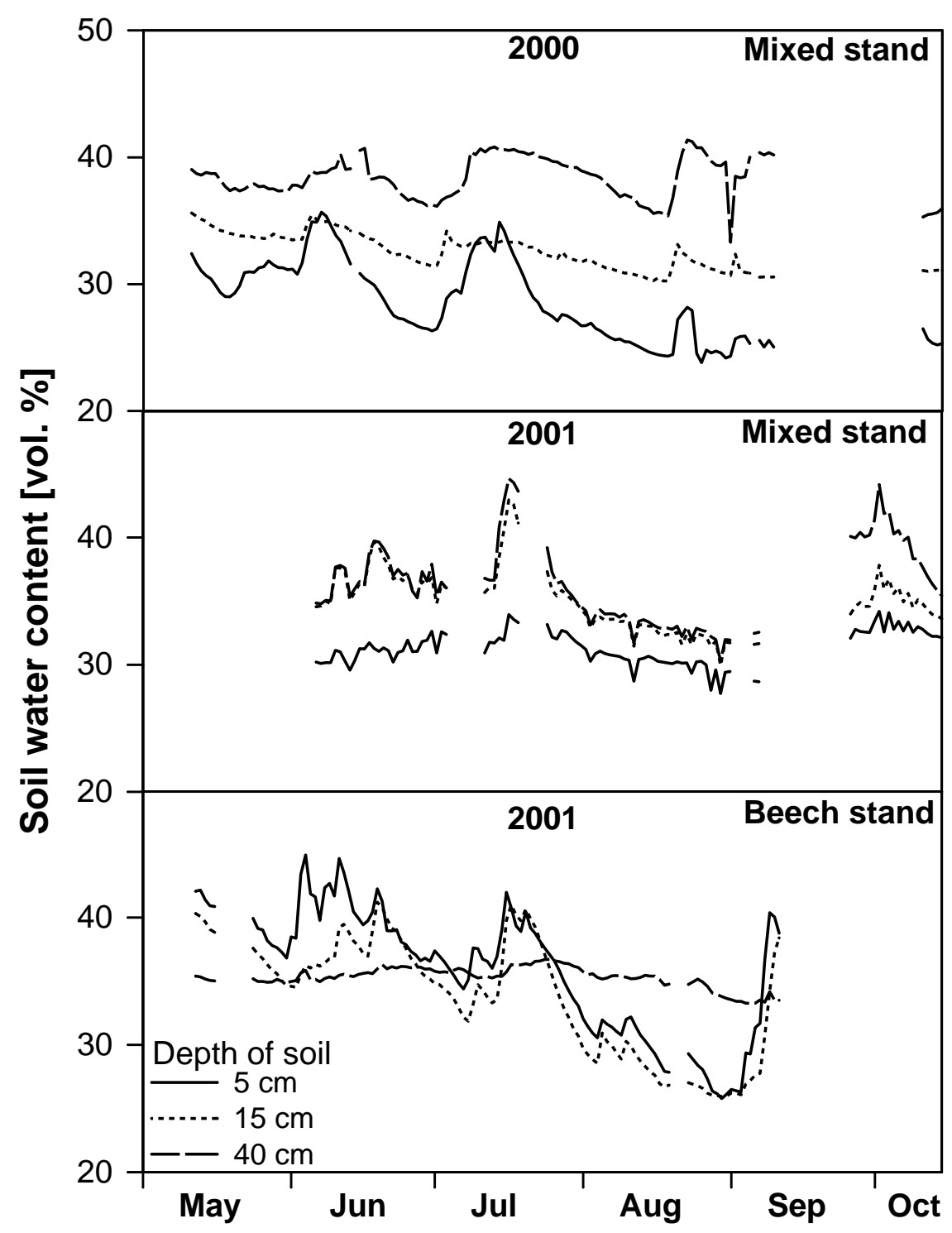

Abb. 4.19: Volumetrischer Bodenwassergehalt der Vegetationsperioden Mai bis Oktober der Jahre 2000 und 2001 im Hainich in 5, 15 und $40 \mathrm{~cm}$ Bodentiefe. Die Bodenwassergehalte wurden gemessen mittels automatischer TDR-Sonden auf den Untersuchungsflächen im Mischund Buchenwald. Dargestellt sind jeweils die Tagesmittelwerte zweier Sonden pro Tiefenstufe. 


\subsubsection{Vergleich der Wasseraufnahmeraten der Baumarten}

\section{Die Saftflussdichten der sechs Baumarten}

Die Wasseraufnahmeraten wurden auf die Querschnittsfläche der jeweiligen Wurzel bezogen, um die Saftflussdichte zu erhalten.

Für den Vergleich der Baumarten wurden die mittleren Saftflussdichten der Tageswerte über den gesamten Untersuchungszeitraum gebildet (Abb. 4.20). Es ergaben sich zwei Gruppen, die sich signifikant voneinander unterschieden. Die Hainbuche hatte mit $4.27 \mathrm{~g} \mathrm{~mm}^{-2} \mathrm{~d}^{-1} \mathrm{im}$ Mittel die höchsten Saftflussdichten, gefolgt von Stieleiche und Buche. Signifikant geringere Saftflussdichten wiesen Bergahorn, Linde und Esche auf, die mit 2.75, 1.97 und $1.93 \mathrm{~g} \mathrm{~mm}^{-2}$ $\mathrm{d}^{-1}$ um ein Drittel geringer waren als die der Hainbuche.

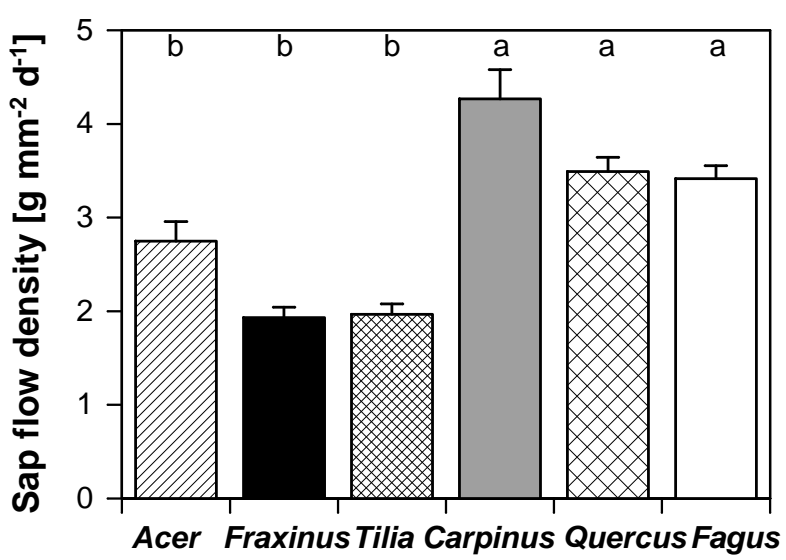

Abb. 4.20: Gemittelte Tageswerte der Saftflussdichten der Wurzeln von sechs untersuchten Baumarten im Nationalpark Hainich, gemittelt aus Messungen an 10-18 Wurzeln pro Baumart über die gesamten Messperioden 2000 und 2001. Die Saftflussmessungen wurden mit dem Miniatur-Saftflusssystem nach Senock \& Ham an 3-4 mm starken Wurzeln durchgeführt. Unterschiedliche Buchstaben kennzeichnen signifikante Unterschiede zwischen den Baumarten $(\mathrm{p}<0.05$, Mann-Whitney-Test).

In Abb. 4.21 sind die Tageswerte der Saftflussdichten von Bergahorn, Esche und Winterlinde aus der Vegetationsperiode 2000 und von Hainbuche, Stieleiche und Buche aus der Vegetationsperiode 2001 dargestellt. Da im Jahr 2000 besonders für die Esche nur wenige kontinuierliche Daten aufgenommen werden konnten, wurden über vier Wochen im Jahr 2001 nochmals Wurzeln der Esche, der Winterlinde und des Bergahorns untersucht (dargestellt im Insert Abb. 4.21). Dabei bestätigten sich die im Vergleich zwischen den Messperioden niedrigen Saftflussdichten aus dem Jahr 2000. Eine witterungsbedingte geringere Saftflussdichte konnte somit ausgeschlossen werden.

Nur wenige Wurzeln von Esche, Bergahorn und Winterlinde wiesen Saftflussdichten über $5 \mathrm{~g} \mathrm{~mm}^{-2} \mathrm{~d}^{-1}$ auf. Hier fielen zwei Wurzeln des Bergahorns auf, die vielfach höhere Saftflussdichten hatten. An diesen Wurzeln konnten Saftflussdichten bis $21.75 \mathrm{~g} \mathrm{~mm}^{-2} \mathrm{~d}^{-1}$ gemessen 

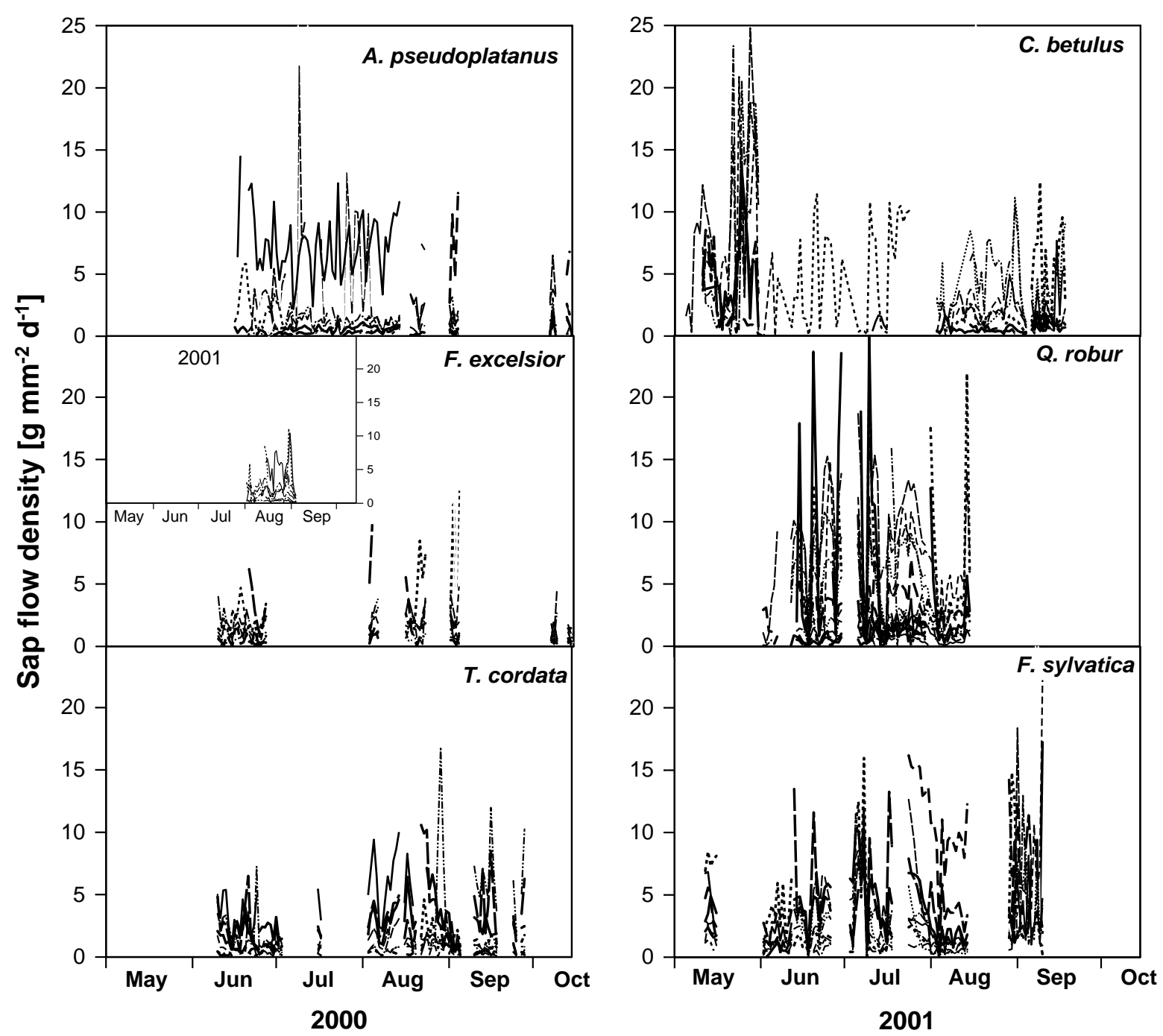

Abb. 4.21: Tageswerte der Saftflussdichten der Wurzeln von sechs Baumarten im Nationalpark Hainich im Verlauf der Vegetationsperioden 2000 (links) und 2001 (rechts). Pro Baumart und Messdurchgang wurden 5-10 Wurzeln parallel untersucht, die Messungen erfolgten mit dem Miniatur-Saftflussmesssystem an 3-4 mm starken Wurzeln. Verkleinert sind Werte der Messungen an 3-4 Wurzeln von Bergahorn, Esche und Winterlinde im Jahr 2001 dargestellt (Insert). 
werden. Von den parallel untersuchten Wurzeln wurden maximal $5.84 \mathrm{~g} \mathrm{~mm}^{-2} \mathrm{~d}^{-1}$ erreicht. Die Saftflussdichten von Hainbuche, Stieleiche und Buche hatten dagegen über die gesamte Messperiode höhere Saftflussdichten. Lediglich in einzelnen Wurzeln wurden Saftflussdichten von weniger als $5 \mathrm{~g} \mathrm{~mm}^{-2} \mathrm{~d}^{-1}$ gemessen. Mit $24.80 \mathrm{~g} \mathrm{~mm}^{-2} \mathrm{~d}^{-1}$ erreichte die Hainbuche kurzfristig Maximalwerte der Saftflussdichte im Mai. Allen Baumarten gemein war eine hohe innerartliche Variabilität der Höhe der Saftflussdichte zwischen den einzelnen Wurzeln. Die zugehörigen Variationskoeffizienten sind in Tab. 4.6 angegeben. Sie lagen für jede Baumart über $100 \%$.

Tab. 4.6: Variationskoeffizienten der Tageswerte der Saftflussdichten von 10-18 Wurzeln pro Baumart im Nationalpark Hainich, gemessen über die gesamten Messperioden 2000 und 2001. Die Saftflussmessungen wurden mit dem Miniatur-Saftflusssystem nach Senock \& Ham an 3-4 mm starken Wurzeln durchgeführt

\begin{tabular}{lc}
\hline & Coefficient of variation \\
\hline A. pseudoplatanus & $168 \%$ \\
F. excelsior & $111 \%$ \\
T. cordata & $131 \%$ \\
C. betulus & $110 \%$ \\
Q. robur & $115 \%$ \\
F. sylvatica & $109 \%$ \\
\hline
\end{tabular}

Um den Einfluss der zuvor vorgestellten Parameter Strahlungsbilanz, Wasserdampfsättigungsdefizit der Luft (VPD) und Bodenwassergehalt auf die Wasseraufnahme der Wurzeln beschreiben zu können, wurden die Korrelationskoeffizienten für eine Beziehung zwischen den Umweltparametern und der Saftflussdichte berechnet. Diese unterschieden sich zwischen den einzelnen Wurzeln z.T. sehr stark, so dass die Mittelwerte aus den signifikanten Korrelationskoeffizienten $(\mathrm{p}<0.05)$ für die Baumarten gebildet wurden (Tab. 4.7).

Bei der großen Mehrzahl der jeweils 15 untersuchten Wurzeln wurde keine signifikante Abhängigkeit der Wasseraufnahme vom Bodenwassergehalt gefunden. Bei der Strahlungsbilanz und dem VPD war der Einfluss dagegen größer (4 bis 12 von 15 Wurzeln mit signifikanten Beziehungen).

Für die Esche konnte eine starke Abhängigkeit vom VPD beobachtet werden. Eine Beziehung zwischen der Saftflussdichte und dem Bodenwassergehalt ließ sich dagegen nur für eine Wurzel feststellen. Die Linde hatte die niedrigsten Korrelationskoeffizienten der sechs Baumarten. Nur sechs bzw. fünf der untersuchten 15 Wurzeln wiesen eine positive Korrelation mit der Strahlungsbilanz oder dem VPD auf.

Eine Abhängigkeit zwischen Saftflussdichte und Strahlung fand sich für sechs Wurzeln der Hainbuche ( $\mathrm{r}=0.75)$. Wie bei der Esche konnte nur für eine Wurzel eine signifikante Korrelation mit dem Bodenwassergehalt errechnet werden. 
Tab. 4.7: Mittlere Korrelationskoeffizienten zur Abhängigkeit der Saftflussdichte der Wurzeln der sechs im Hainich untersuchten Baumarten von Strahlungsangebot (Strahlungsbilanz, Tageshellphasensumme), Wasserdampfsättigungsdefizit der Luft (VPD, Tagesmittelwerte der Hellphase) sowie dem Bodenwassergehalt (Tagesmittelwerte) in der jeweiligen Bodentiefe ( 5 bzw. $15 \mathrm{~cm}$ ). Pro Baumart wurden 15 Wurzeln auf die Abhängigkeit der Saftflussdichte von den Umgebungsparametern untersucht. In die Ermittlung des mittleren Korrelationskoeffizienten gingen nur signifikante Korrelationen ein $(\mathrm{p}<0.05)$. Die Anzahl der Wurzeln mit signifikanten Beziehungen ist als $\mathrm{n}$ angegeben.

\begin{tabular}{l|cc|cc|cc}
\hline & Net radiation & $\mathrm{n}$ & $\mathrm{VPD}$ & $\mathrm{n}$ & Soil water content & $\mathrm{n}$ \\
\hline A. pseudoplatanus & 0.61 & 5 & 0.63 & 5 & 0.63 & 4 \\
F. excelsior & 0.62 & 8 & 0.76 & 6 & 0.55 & 1 \\
T. cordata & 0.52 & 6 & 0.60 & 5 & 0.54 & 3 \\
C. betulus & 0.59 & 4 & 0.75 & 6 & 0.72 & 1 \\
Q. robur & 0.65 & 12 & 0.56 & 11 & 0.44 & 6 \\
F. sylvatica & 0.60 & 12 & 0.70 & 12 & 0.47 & 5 \\
\hline
\end{tabular}

Für eine größere Anzahl Wurzeln konnten bei Stieleiche und Buche signifikante Korrelationskoeffizienten berechnet werden. Diese sprachen bei der Stieleiche für eine engere Beziehung zwischen Strahlung und Saftfluss ( $r=0.65)$ als zwischen VPD und Saftfluss ( $r=0.56)$. Fast alle untersuchten Wurzeln der Buche wiesen eine erhöhte Saftflussdichte mit steigendem VPD $(\mathrm{r}=0.70)$ und steigender Strahlungsbilanz auf $(\mathrm{r}=0.60)$.

Bei allen Baumarten war die Korrelation der Saftflussdichte mit dem Bodenwassergehalt gering, was sich durch niedrige signifikante Korrelationskoeffizienten und durch eine geringe Anzahl Wurzeln, die diesen signifikanten Korrelationskoeffizienten aufweisen, ausdrückte.

Zur Ermittlung der Bedeutung der verschiedenen Einflussgrößen für die Saftflussdichten wurde eine multiple Regression mit Variablenselektion durchgeführt. Dabei wurden in einem Regressionsmodell schrittweise die Parameter (Strahlungsangebot, Wasserdampfsättigungsdefizit und Bodenwassergehalt) aus dem Modell entfernt, die das Bestimmtheitsmaß des Modells nicht signifikant erhöhten.

In Tab. 4.8 ist für jede untersuchte Einflussgröße die Anzahl der Wurzeln angegeben, für die dieser Faktor in dem Modell selektiert wurde und einen signifikanten Einfluss auf die Wasseraufnahme hatte. Der Anteil der durch das Modell erklärten Varianz ist ebenfalls angegeben. Nicht für alle untersuchte Wurzeln konnte eine beeinflussende Größe bestimmt werden. 17.7\% der Bergahornwurzeln, 40.9\% der Eschen- und die Hälfte der Lindenwurzeln (50.4\%) zeigten sich in ihrem Saftfluss durch keinen der betrachteten Parameter signifikant beeinflusst. Dies traf auch auf 10.5\% der Eichen- und 37.5\% der Buchenwurzeln zu. Dagegen wurde die Höhe der Saftflussdichte der Hainbuche in jeder Wurzel zumindest durch den Parameter Strahlung beeinflusst. 
Tab. 4.8: Ergebnisse der multiplen Regression mit Variablenselektion (backwards elemination, $\mathrm{p}<0.05)$ für die Abhängigkeit der Wurzel-Saftflussdichte von den Faktoren Strahlung, VPD und Bodenwassergehalt $(\Theta)$ während der Vegetationsperioden 2000 und 2001. Angegeben ist die Anzahl der Wurzeln (n), die in die Regression aufgenommen wurden, die Anzahl der Wurzeln, für die der jeweilige Faktor bei der Selektion erhalten blieb $\left(\mathrm{n}_{\text {selection }}\right)$, sowie ein Mittelwert für den Anteil der Varianz (explained variance), die durch den jeweiligen Faktor erklärt wird.

\begin{tabular}{l|c|ccc|ccc|c}
\hline & & \multicolumn{3}{|c|}{$\mathrm{n}_{\text {selection }}$} & \multicolumn{3}{|c|}{ explained variance (\%) } & \\
& $\mathrm{n}$ & net radiation & VPD & $\Theta$ & net radiation & VPD & $\Theta$ & $\mathrm{R}^{2}$ \\
\hline A. pseudoplatanus & 17 & 7 & 9 & 9 & 29.3 & 42.2 & 42.6 & 0.60 \\
F. excelsior & 22 & 7 & 5 & 7 & 49.0 & 62.2 & 33.5 & 0.66 \\
T. cordata & 21 & 2 & 7 & 5 & 63.7 & 42.2 & 32.0 & 0.47 \\
C. betulus & 17 & 17 & 8 & 1 & 58.3 & 66.4 & 18.2 & 0.95 \\
Q. robur & 19 & 8 & 12 & 11 & 36.6 & 37.4 & 17.3 & 0.59 \\
F. sylvatica & 24 & 6 & 9 & 9 & 38.9 & 60.0 & 28.0 & 0.59 \\
\hline
\end{tabular}

Die Hälfte der Bergahornwurzeln zeigte eine Beeinflussung der Saftflussdichte durch das VPD und den Bodenwassergehalt. Durch diese beiden Faktoren ließen sich jeweils 42.2\% der Varianz in der Saftflussdichte erklären. Für jeweils etwa ein Drittel der Eschenwurzeln ließ sich ein großer Teil der Variation der Saftflussdichte durch Strahlung, VPD oder Bodenwassergehalt beschreiben. Nur zwei der Lindenwurzeln reagierten mit ihrer Saftflussdichte signifikant auf die Strahlungsbilanz. Die Parameter Strahlung und VPD beeinflussten zu 58.3\% bzw. 66.4\% die Varianz der Saftflussdichte der Hainbuche. Nur eine Hainbuchenwurzel zeigte eine Änderung des Saftflusses mit sich änderndem Bodenwassergehalt (18.2\% erklärte Varianz). Mit Ausnahme von Bergahorn und Stieleiche zeigten sich die Saftflussdichten von einer Änderung des Bodenwassergehaltes relativ unbeeinflusst.

Für den größten Teil der Stieleichen- und Buchenwurzeln war das VPD eine wichtige Einflussgröße für die Wasseraufnahme. Auch die Strahlungsbilanz trug zu einer signifikanten Erhöhung der erklärten Varianz bei.

\section{Oberflächenspezifische Wurzelwasseraufnahme}

Durch die Ernte der Wurzelstränge nach dem Abschluss der Saftflussmessung konnte der Saftfluss auf die Wurzeloberfläche bezogen werden, so dass oberflächenspezifische Saftflussraten erhalten wurden. In Abb. 4.22 sind die Tageswerte der oberflächenspezifischen Wasseraufnahmeraten von Bergahorn, Esche und Winterlinde aus der Vegetationsperiode 2000 und von Hainbuche, Stieleiche und Buche aus der Vegetationsperiode 2001 dargestellt. Esche und Linde hatten im Vergleich mit Stieleiche und Hainbuche sehr hohe oberflächenspezifische Wasseraufnahmeraten. 

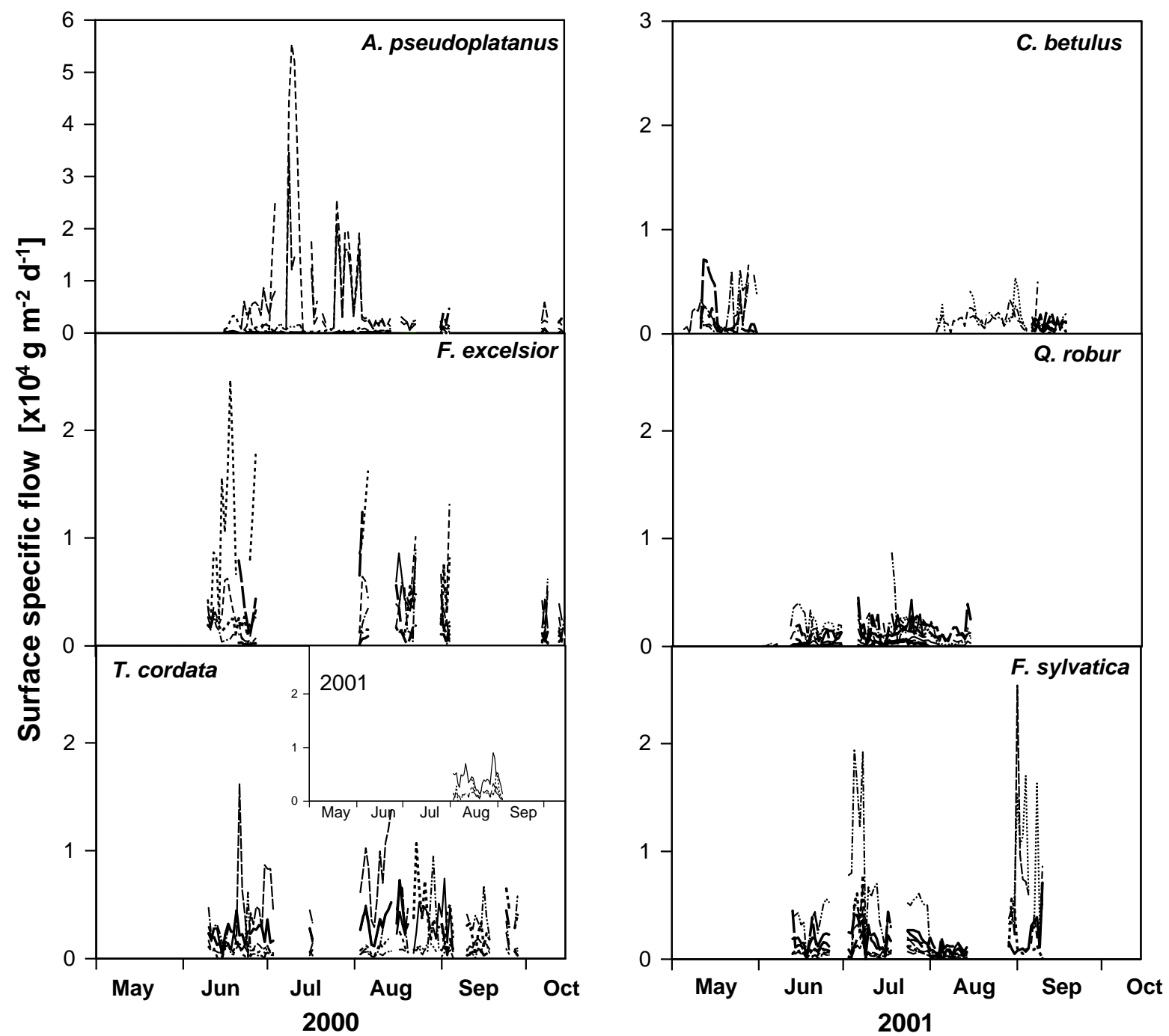

Abb. 4.22: Tageswerte der oberflächenspezifischen Wasseraufnahmeraten der Wurzeln von sechs Baumarten im Nationalpark Hainich im Verlauf der Vegetationsperioden 2000 (links) und 2001 (rechts). Pro Baumart und Messdurchgang wurden 5-10 Wurzeln parallel untersucht. Die Messungen wurden an 3-4 mm starken Wurzeln mit dem Miniatur-Saftflussmesssystem durchgeführt. Als Bezugsgröße dient die Gesamtwurzeloberfläche, die nach Abschluss der Messungen bestimmt wurde. Die Ordinatenachse der Grafik des Bergahorns ist abweichend von den anderen skaliert. Verkleinert sind Werte der Messungen an 3-4 Wurzeln von Bergahorn, Esche und Winterlinde im Jahr 2001 dargestellt (Insert). 
Die Esche erreichte zu Beginn der Messungen Maximalwerte von $24600 \mathrm{~g} \mathrm{~m}^{-2} \mathrm{~d}^{-1}$. Zwei Wurzeln des Bergahorn zeigten eine sehr hohe oberflächenspezifische Aufnahmeleistung. An ihnen wurden Saftflussraten bis zu $55400 \mathrm{~g} \mathrm{~m}^{-2} \mathrm{~d}^{-1}$ gemessen, was bis zu 50 fach die Wasseraufnahme der anderen Wurzeln zu diesem Zeitpunkt übertraf. Diese hohe Aufnahmeleistung stand in Verbindung mit einer vergleichsweise kleinen Wurzeloberfläche. Auch Esche und Buche wiesen einzelne Wurzeln auf, die mit einer kleinen Wurzeloberfläche eine sehr hohe Wasseraufnahmerate erreichten. Diese Wurzeln hatten eine oberflächenspezifische Aufnahmerate von 19500 bis $25400 \mathrm{~g} \mathrm{~m}^{-2} \mathrm{~d}^{-1}$. Die oberflächenspezifische Aufnahmeleistung der Stieleiche erreichte die Höhe der Aufnahmeraten der anderen Baumarten nicht. Vergleichbare Tageswerte erreichte nur die Hainbuche. Allerdings war bei diesen beiden Arten die intraspezifische Variabilität der Wurzeln geringer als die der anderen Baumarten.

Das für die Saftflussdichte beobachtete Verhältnis der Arten zueinander kehrte sich bei der Betrachtung der wurzeloberflächenspezifischen Saftflussrate um (Abb.4.23). Die Esche wies mit $3423.3 \mathrm{~g} \mathrm{~m}^{-2} \mathrm{~d}^{-1}$ die höchste oberflächenspezifische Saftflussrate auf, gefolgt von Bergahorn (3189.1 $\left.\mathrm{g} \mathrm{m}^{-2} \mathrm{~d}^{-1}\right)$ und Winterlinde (2284.7 $\mathrm{g} \mathrm{m}^{-2} \mathrm{~d}^{-1}$ ). Eine geringere Wasseraufnahmerate hatte die Stieleiche mit nur $1041.3 \mathrm{~g} \mathrm{~m}^{-2} \mathrm{~d}^{-1}$. Trotz der beobachteten einzelnen Wurzeln mit erhöhter Aufnahmekapazität war auch die oberflächenspezifische Saftflussrate der Buche geringer als von Esche und Bergahorn. Sie lag mit $1967.2 \mathrm{~g} \mathrm{~m}^{-2} \mathrm{~d}^{-1}$ unter jener der Hainbuche.

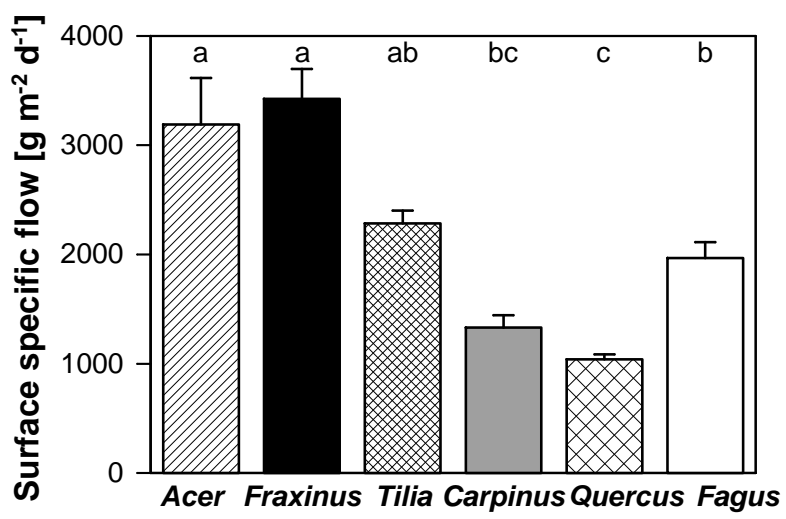

Abb. 4.23: Gemittelte Tageswerte der oberflächenspezifischen Wasseraufnahmeraten der Wurzeln der sechs untersuchten Baumarten im Hainich. In die Mittelwertberechnung gingen 10-15 Wurzeln pro Baumart ein, an denen während der Vegetationsperioden 2000 und 2001 Saftflussmessungen stattfanden. Unterschiedliche Buchstaben kennzeichnen signifikante Unterschiede zwischen den Baumarten ( $\mathrm{p}<0.05$, Mann-Whitney-Test).

In Abb. 4.24 ist die oberflächenspezifische Wasseraufnahmerate bezogen auf die Oberfläche der Feinstwurzeln $(<1 \mathrm{~mm})$ der gemessenen Wurzelstränge dargestellt.

Die spezifischen Wasseraufnahmeraten, berechnet auf die Oberfläche der Feinstwurzeln $<1 \mathrm{~mm}$ Durchmesser im Wurzelstrang lag naturgemäß höher als die auf die Gesamt-Wurzeloberfläche bezogenen Raten. Der Anteil der Feinstwurzeloberfläche des Bergahorns lag bei $69.5 \%$. Die 
entsprechende Wasseraufnahmerate dieser Feinstwurzeloberfläche war mit $6551.9 \mathrm{~g} \mathrm{~m}^{-2} \mathrm{~d}^{-1}$ doppelt so hoch wie die der Gesamtwurzeloberfläche. Die Erhöhung der Wasseraufnahmerate der Feinstwurzeln gegenüber der Gesamtwurzel lag für Esche, Linde, Hainbuche und Buche bei $68.8 \%$ (5777.1 $\mathrm{g} \mathrm{m}^{-2} \mathrm{~d}^{-1}$, Esche) bis $74.2 \%$ (3426.8 $\mathrm{g} \mathrm{m}^{-2} \mathrm{~d}^{-1}$, Buche).

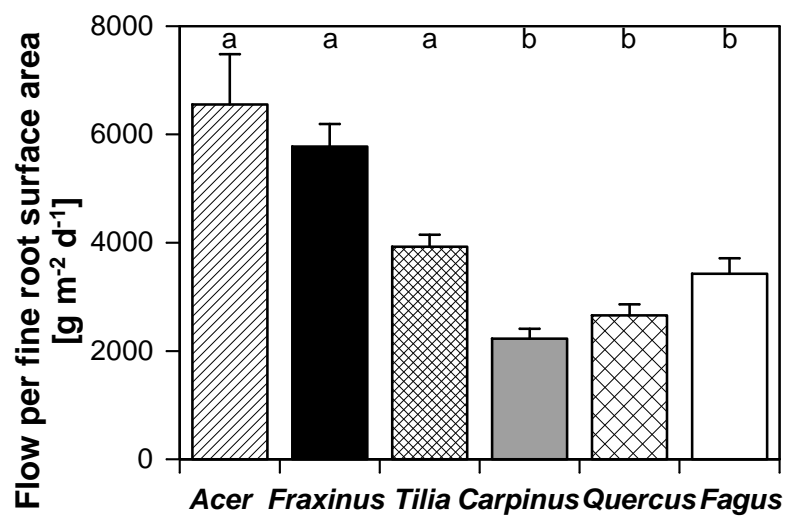

Abb. 4.24: Wasseraufnahmeraten der sechs untersuchten Baumarten im Hainich bezogen auf die Feinstwurzeloberfläche $(<1 \mathrm{~mm})$. Die mittleren Aufnahmeraten wurden gebildet aus 1015 Wurzeln pro Baumart, an denen in den Vegetationsperioden der Jahre 2000 und 2001 Saftflussmessungen stattfanden. Unterschiedliche Buchstaben kennzeichnen signifikante Unterschiede zwischen den Baumarten ( $\mathrm{p}<0.05$, Mann-Whitney-Test).

Diese Baumarten wiesen entsprechende Feinstwurzelanteile von 59.5\%, 61.8\%, 70.2\% bzw. 63.7\% am untersuchten Wurzelstrang auf. Die Wasseraufnahmerate der Stieleiche über die Feinstwurzeloberfläche lag bei $2658.5 \mathrm{~g} \mathrm{~m}^{-2} \mathrm{~d}^{-1}$. Die höchsten Tageswerte wiesen Bergahorn und Esche auf. Die Linde hatte eine wenig geringere oberflächenspezifische Wasseraufnahmerate. Der Unterschied zu Buche, Hainbuche und Eiche war signifikant.

\section{Wasseraufnahmeraten der Wurzeln während natürlich auftretender Trockenperioden}

Während einer Austrocknungsperiode im Juni 2000 sank der Bodenwassergehalt von 34.9 auf 26.7 Vol.\% (Abb.4.25) in der Bodentiefe von $5 \mathrm{~cm}$. Im gleichen Zeitraum erreichten die Tageshellphasensummen der Strahlungsbilanz und die entsprechenden Mittelwerte des VPD die in dieser Vegetationsperiode gemessenen Maximalwerte von $30.78 \mathrm{MJ} \mathrm{m}^{-2} \mathrm{~d}^{-1} \mathrm{bzw} .33 .94 \mathrm{hPa}$. Im Jahr 2001 war vom 21. Juli bis 3. August 2001 eine Austrocknungsperiode zu beobachten, während der der Bodenwassergehalt in einer Bodentiefe von $15 \mathrm{~cm}$ von 37.3 auf 33.9 Vol.\% fiel. Auf der Untersuchungsfläche im Buchenwald sank der Bodenwassergehalt deutlicher von 39.2 auf 31.5 Vol.\%. Die Transpirationsrate der Bäume war während dieser Periode hoch, da die Hellphasensummen der Strahlungsbilanz Werte bis zu $28.76 \mathrm{MJ} \mathrm{m}^{-2} \mathrm{~d}^{-1}$ annahmen und das Sättigungsdefizit der Luft zwischen 14.15 und $26.1 \mathrm{hPa}$ betrug. 

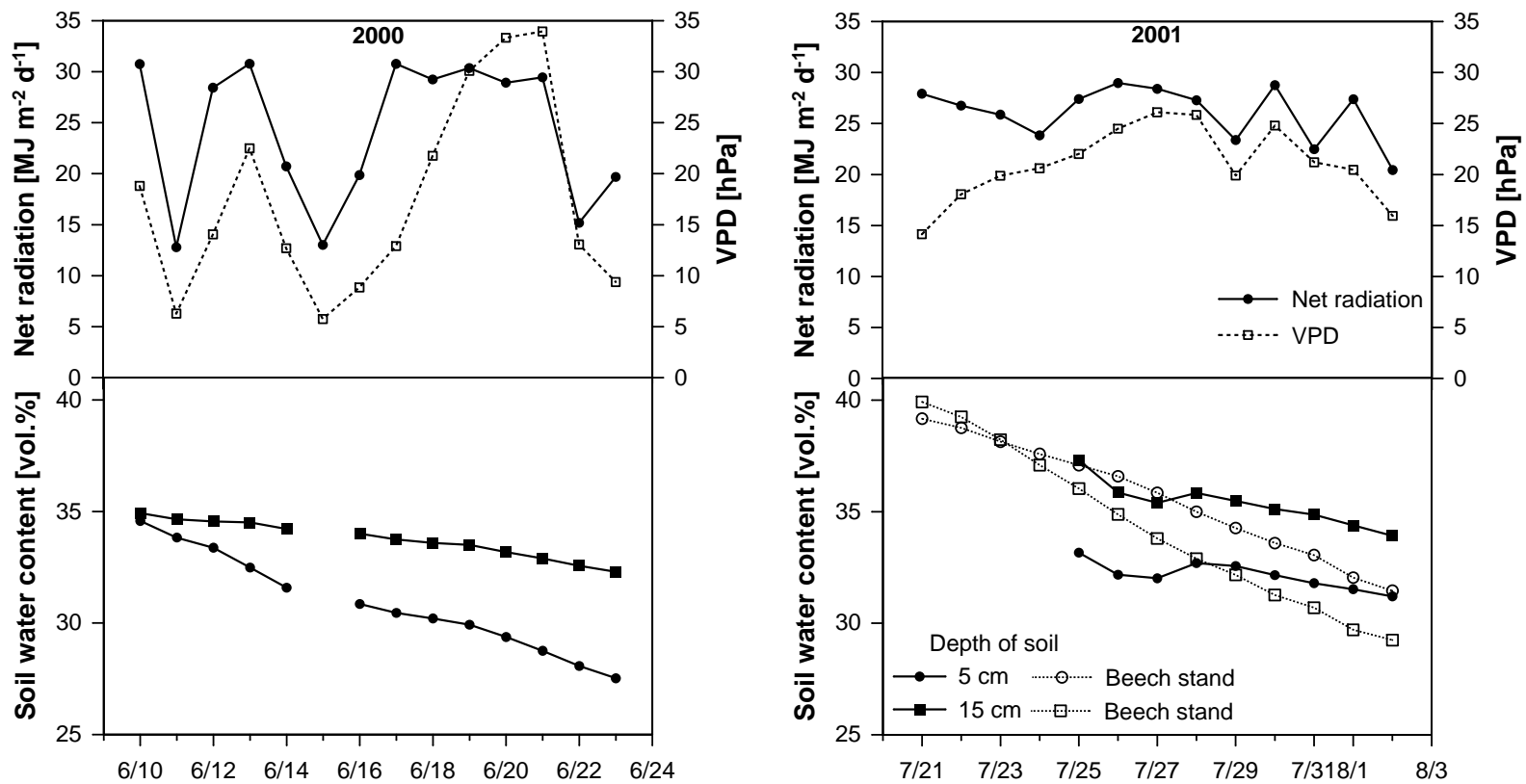

Abb. 4.25: Strahlungsbilanz (Tageshellphasensummen), VPD (Mittelwerte der Tageshellphasen) und Bodenwassergehalte (Tagesmittelwerte) während zweier Austrocknungsperioden in den Vegetationsperioden 2000 und 2001 auf den Untersuchungsflächen im Nationalpark Hainich. Strahlungsbilanz und VPD wurden auf einer Freifläche neben dem Bestand gemessen, die Bodenwassergehalte mittels TDR auf den Untersuchungsflächen.

Die Saftflussdichten der Wurzeln der sechs Baumarten während dieser beiden Austrocknungsperioden unterschieden sich in der Höhe und in der Reaktion auf die Reduzierung des Bodenwassergehaltes (Abb. 4.26).

Für Bergahorn, Esche und Winterlinde lagen Daten aus beiden Vegetationsperioden vor. Esche und Winterlinde wiesen auch in diesen beiden Perioden die geringsten Saftflussdichten auf. Während der Austrocknungsperiode 2000 nahm die Saftflussdichte des Bergahorns nur geringfügig ab, sieht man von einer 50\%igen Abnahme zu Beginn der Austrocknungsphase ab. Die Maximalwerte der Strahlungsbilanz und des VPD überdeckten eine mögliche Auswirkung des sinkenden Bodenwassergehaltes, die im Jahr 2001 für die letzten Tage der Austrocknungsperiode deutlich wurde. Durch die konstanten klimatischen Bedingungen konnte die Reaktion auf eine Abnahme des Bodenwassergehaltes deutlicher beobachtet werden. Die Wurzeln zeigten eine signifikante Reduzierung der Saftflussdichte um $73.2 \%$ von 6.67 auf $1.79 \mathrm{~g} \mathrm{~mm}^{-2}$ $\mathrm{d}^{-1}$, bevor am letzten betrachteten Tag die Saftflussdichte wieder anstieg.

Für die Esche konnte in der Austrocknungsphase 2000 keine Reduzierung der Saftflussdichte festgestellt werden. Auch im Jahr 2001 wurden die Saftflussdichten nicht signifikant gesenkt, die Reduzierung betrug lediglich 28.4\%. Während im Jahr 2000 im Verlauf der Austrocknungsperiode bei Wurzeln der Linde nur tendenziell eine Abnahme der Saftflussdichte zu erkennen war, sank die aus drei Wurzeln gemittelte Saftflussdichte im August 2001 um 71.5\%. 

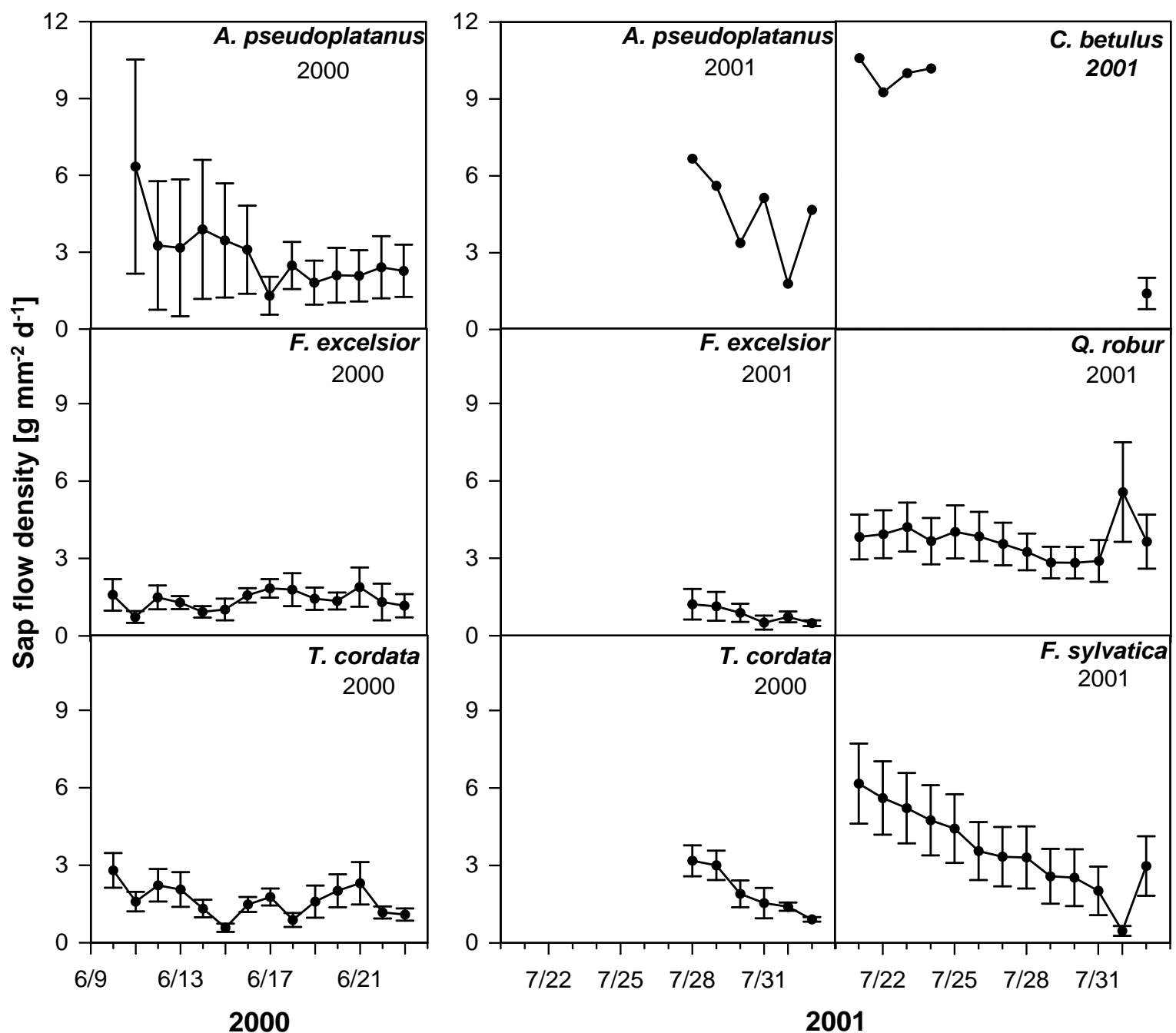

Abb. 4.26: Tageswerte der Saftflussdichte der Baumarten Bergahorn, Esche, Winterlinde, Hainbuche, Stieleiche und Buche während zweier Austrocknungsperioden (10.6.-23.6.2000 und 21.7.-2.8.2001) auf den Untersuchungsflächen im Nationalpark Hainich. Aufgetragen sind die mittleren Tageswerte aus Messungen an 3-15 Wurzeln pro Baumart sowie die Standardfehler. Für die Hainbuche sind nur Werte von einer bzw. drei untersuchten Wurzeln angegeben. 
Für die Hainbuche lagen zu Beginn der Austrocknungsperiode Daten aus Saftflussmessungen an nur einer Wurzel vor; für den letzten Tag des hier untersuchten Zeitraumes konnte ein Mittelwert der Saftflussdichten aus drei Wurzeln angegeben werden. Diese Werte deuten auf eine starke Abnahme der Saftflussdichte in diesem Zeitraum hin, da die Saftflussdichte offenbar von 10.48 auf $1.37 \mathrm{~g} \mathrm{~mm}^{-2} \mathrm{~d}^{-1}$ sank. Vergleicht man diese Werte mit vorher und nachher gemessenen Daten (Abb. 4.21), so scheint sich diese Tendenz jedoch zu bestätigen.

Die Saftflussdichten von 15 parallel untersuchten Wurzeln der Stieleiche wiesen eine nur geringe Änderung über die 13 Tage auf. Zu Beginn der Austrocknungsphase lag die mittlere Saftflussdichte bei $3.86 \mathrm{~g} \mathrm{~mm}^{-2} \mathrm{~d}^{-1}$. Sie nahm mit zunehmender Austrocknung nur leicht $\mathrm{ab}$, der niedrigste Wert lag bei $2.86 \mathrm{~g} \mathrm{~mm}^{-2} \mathrm{~d}^{-1}$. Am folgenden Tag stieg die Saftflussdichte wieder an.

Eine kontinuierliche Abnahme der Saftflussdichte konnte an zehn Wurzeln der Buche beobachtet werden. Die mittlere Saftflussdichte lag am 21.7.2001 bei $6.17 \mathrm{~g} \mathrm{~mm}^{-2} \mathrm{~d}^{-1}$. Innerhalb von zehn Tagen nahm sie auf $2.02 \mathrm{~g} \mathrm{~mm}^{-2} \mathrm{~d}^{-1}$ ab. Während die Saftflussdichten von Stieleiche und Esche am 1.8.2001 mit einer Zunahme der Strahlungsbilanz wieder anstiegen, erreichte die Buche ähnlich dem Bergahorn an diesem Tag den niedrigsten Wert $\left(0.47 \mathrm{~g} \mathrm{~mm}^{-2}\right.$ $\left.\mathrm{d}^{-1}\right)$.

Die Durchführung einer multiplen Regressionsanalyse zeigte eine Zunahme der Bedeutung des Bodenwassergehaltes während der Austrocknungsperiode (Tab. 4.9). Für alle Baumarten stieg der durch den Bodenwassergehalt erklärbare Anteil der Varianz an, während der Einfluss der Strahlung und des VPD abnahm. Besonders deutlich wurde dies bei der Buche; die Varianz der Saftflussdichte jeder untersuchten Wurzel wurde etwa zur Hälfte von der Bodenfeuchte bestimmt.

Tab. 4.9: Ergebnisse der multiplen Regression mit Variablenselektion (backwards elemination, $\mathrm{p}<0.05)$ für die Abhängigkeit der Wurzel-Saftflussdichte von den Faktoren Strahlung (Tageshellphasensummen der Strahlungsbilanz), VPD und Bodenwassergehalt $(\Theta)$ während einer Austrocknungsperiode im Jahr 2001. Angegeben ist die Anzahl der Wurzeln (n), die in die Regression aufgenommen wurden, die Anzahl der Wurzeln, für die der jeweilige Faktor bei der Selektion erhalten blieb $\left(\mathrm{n}_{\text {selection }}\right)$, sowie ein Mittelwert für den Anteil der Varianz (explained variance), die durch den jeweiligen Faktor erklärt wird.

\begin{tabular}{l|c|ccc|ccc|c}
\hline & & \multicolumn{3}{|c|}{$\mathrm{n}_{\text {selection }}$} & \multicolumn{3}{|c|}{ explained variance (\%) } & \\
& $\mathrm{n}$ & net radiation & VPD & $\Theta$ & net radiation & VPD & $\Theta$ & $\mathrm{R}^{2}$ \\
\hline A. pseudoplatanus & 5 & 4 & 3 & 2 & 39.4 & 57.0 & 66.6 & 0.83 \\
F. excelsior & 6 & 0 & 0 & 3 & 0 & 0 & 56.8 & 0.58 \\
T. cordata & 8 & 1 & 1 & 4 & 44.6 & 38.8 & 44.1 & 0.52 \\
C. betulus & 1 & - & - & - & - & - & - & - \\
Q. robur & 15 & 4 & 5 & 11 & 56.0 & 19.5 & 60.6 & 0.82 \\
F. sylvatica & 10 & 5 & 5 & 10 & 29.9 & 40.4 & 50.4 & 0.91 \\
\hline
\end{tabular}


Nur 50\% der untersuchten Eschenwurzeln konnte ein beeinflussender Faktor (Bodenwassergehalt) zugeordnet werden, so dass die Wasseraufnahme der Esche während der Austrocknungsperiode nur in geringem Maße von den drei Umweltfaktoren beeinflusst wurde. Ähnliches konnte auch bei der Linde beobachtet werden. Nur für jeweils eine der Lindenwurzeln blieben Strahlungsbilanz oder VPD als Variable im Regressionsmodell erhalten. Die durch diese beiden Faktoren erklärte Varianz lag bei $44.6 \%$ bzw. 38.8\%. Nur die Hälfte der Wurzeln erfuhr mit einer Änderung des Bodenwassergehaltes auch eine Änderung der Saftflussdichte. Trotz der nur geringen Änderung der Saftflussdichte der Stieleiche während der Austrocknungsperiode war der Bodenwassergehalt für $73.3 \%$ der Wurzeln eine signifikante Einflussgröße. Die durch den Bodenwassergehalt erklärte Varianz war mit $60.6 \%$ hoch. Eine weitere wichtige Einflussgröße für die Saftflussdichte von vier Wurzeln war die Strahlungsbilanz (erklärte Varianz 56.0\%). Die wenigen Daten der Hainbuche wurden nicht in die Regressionsanalyse aufgenommen.

\subsubsection{Wasserpotentiale}

\section{Wasserpotentiale der Feinwurzeln}

Im Verlauf der Vegetationsperiode 2001 wurden die Tagesminima der Wurzel-Wasserpotentiale der sechs Baumarten mit der Druckkammermethode nach Scholander an sieben Terminen zur Mittagszeit (MESZ 12-14 Uhr) bestimmt. Das Wasserpotential der Feinwurzeln zeigte für alle sechs Baumarten einen gleichartigen saisonalen Verlauf (Abb. 4.27). Die Werte der ersten Messung (20.6.2001) lagen zwischen -0.42 MPa (Esche) und -0.71 MPa (Linde). Dies war der einzige Termin, für den ein signifikanter Unterschied $(\mathrm{p}<0.05)$ zwischen den Baumarten nachgewiesen werden konnte. Das Wurzel-Wasserpotential der Linde war in diesem Fall signifikant niedriger als das der Esche und der Stieleiche. Bis zum nächsten Messtermin Mitte Juli änderte sich das Wurzel-Wasserpotential nur wenig. Mit Einsetzen der Austrocknungsperiode (siehe Abb. 4.25) sank das Wurzel-Wasserpotential aller Baumarten signifikant. Nach einer kurzen Erholungsphase mit einem leichten Anstieg des Wasserpotentials wurden Mitte August die niedrigsten Werte erreicht. Am letzten Messtermin (24.9.2001) hatte sich nach Beendigung der Trockenperiode durch wiedereinsetzende vermehrte Niederschläge das WurzelWasserpotential erholt. Die Werte lagen auf dem Niveau der ersten Messungen zu Beginn der Vegetationsperiode.

Die Buche erreichte mit -1.53 MPa das niedrigste Wasserpotential der sechs Baumarten während der Trockenperiode am 31.7.2001. Erst zwei Wochen später konnten Minimalwerte des Wurzel-Wasserpotentials der anderen Baumarten gemessen werden (15.8.2001). Die Esche hatte das zu diesem Zeitpunkt niedrigste Wasserpotential mit -1.46 MPa, Linde und Stieleiche erreichten nahezu identische Werte mit -1.35 bzw. -1.34 MPa. Der Bergahorn hielt das Wasserpotential während der Trockenperiode relativ konstant, der niedrigste Wert lag mit -1.25 MPa höher als bei Esche, Buche, Winterlinde und Stieleiche. Nur die Hainbuche hatte ein ebenso gering abgesenktes Wasserpotential (-1.25 MPa). 

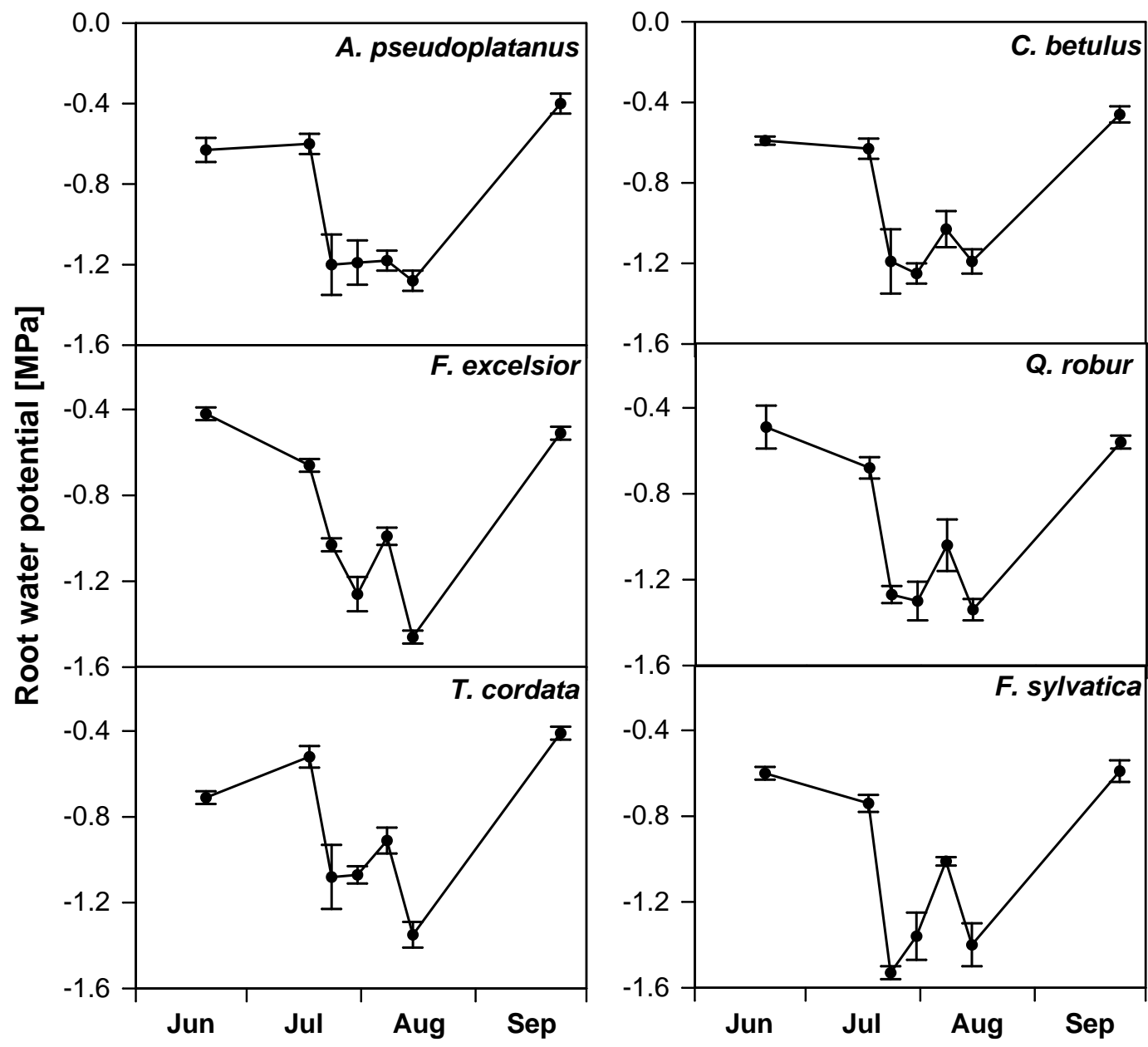

Abb. 4.27: Wurzel-Wasserpotentiale der sechs untersuchten Baumarten auf der MischwaldUntersuchungsfläche im Nationalpark Hainich. Aufgetragen sind die Mittelwerte und Standardfehler der Tagesminima, die an jeweils fünf Feinwurzelenden mit der Druckkammermethode nach Scholander an sieben Terminen zur Mittagszeit (12-14 Uhr MESZ) während der Vegetationsperiode 2001 gemessen wurden. 
In Abb. 4.28 sind die Wurzel-Wasserpotentiale gegen die gemittelten Tageswerte der WurzelSaftflussdichte für die sechs Baumarten aufgetragen. Aus den korrespondierenden Datenpaaren einzelner Messtermine während der Vegetationsperiode 2001 lässt sich eine Aussage über die Tendenz der Interaktion zwischen Saftflussdichte und Wurzel-Wasserpotential treffen.

Für Bergahorn und Esche konnte keine Beziehung zwischen dem Wurzel-Wasserpotential und der Saftflussdichte des gleichen Tages ermittelt werden. Unabhängig von der Höhe des Wasserpotentials lag die Saftflussdichte des Bergahorns bei Werten zwischen 3.97 bis $5.21 \mathrm{~g} \mathrm{~mm}^{-2}$ $\mathrm{d}^{-1}$. Noch geringere Schwankungen bei verschiedenen Wurzel-Wasserpotentialen wies die Saftflussdichte der Eschenwurzeln auf. Auch für die Hainbuche war kein Zusammenhang zwischen der Saftflussdichte und dem Wurzel-Wasserpotential erkennbar. An Tagen mit vergleichbaren Wasserpotentialen $(-0.46$ bis $-0.63 \mathrm{MPa})$ wies die Saftflussdichte sehr variable Werte auf, die von 3.54 bis $10.02 \mathrm{~g} \mathrm{~mm}^{-2} \mathrm{~d}^{-1}$ reichten.

Im Gegensatz dazu konnte für die Linde eine tendenzielle Zunahme der Wasseraufnahme mit absinkendem Wurzel-Wasserpotential festgestellt werden. Die Saftflussdichte stieg kontinuierlich von 1.68 auf $2.92 \mathrm{~g} \mathrm{~mm}^{-2} \mathrm{~d}^{-1}$ an, während das Wasserpotential der Wurzeln im gleichen Zeitraum von -0.41 MPa auf -1.35 MPa sank. Eine lineare Regression der beiden Parameter liefert einen signifikanten Korrelationskoeffizienten von -0.9 ( $\mathrm{p}=0.002)$. Für die Buche deutet sich ein ähnlicher Zusammenhang zwischen Flussdichte und Wasserpotential der Wurzeln an. Zum Zeitpunkt des niedrigsten Wasserpotentials (-1.53 MPa) konnte eine hohe Saftflussdichte gemessen werden $\left(6.17 \mathrm{~g} \mathrm{~mm}^{-2} \mathrm{~d}^{-1}\right)$. Dieser Zusammenhang schwächte sich jedoch bei höheren Wasserpotentialen ab bzw. kehrte sich dort tendenziell sogar um.

Die Saftflussdichte der Stieleiche war an Tagen mit einem niedrigen Wasserpotential gering. An den Terminen, an denen hohe Potentiale gemessen wurden (-0.49 MPa), konnte auch eine hohe Saftflussdichte ermittelt werden $\left(6.76 \mathrm{~g} \mathrm{~mm}^{-2} \mathrm{~d}^{-1}\right)$. Daher deutete sich für die Stieleiche eine positive Beziehung zwischen diesen beiden Parametern an. 

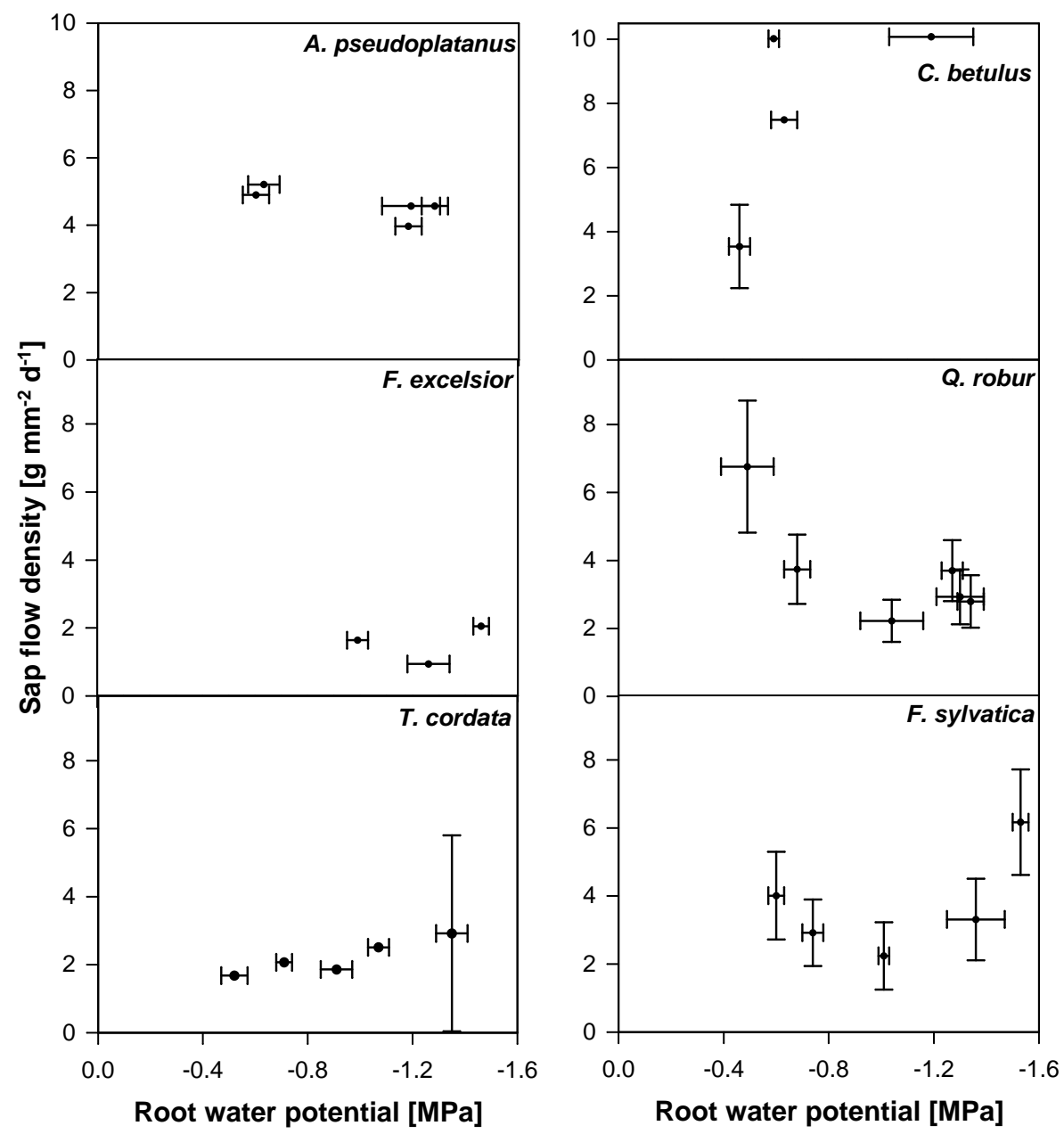

Abb. 4.28: Mittlere Tageswerte der Saftflussdichte der sechs Baumarten in Abhängigkeit von den Tagesminima des Wurzel-Wasserpotentials. Das Wasserpotential wurde an jeweils fünf Feinwurzelenden mit der Druckkammermethode nach Scholander bestimmt, die Saftflussdichten wurden an 9-14 Wurzeln pro Baumart mit 3-4 mm Durchmesser mit dem MiniaturSaftflussmesssystem ermittelt. Aufgetragen sind jeweils die Mittelwerte und Standardfehler. 


\section{Wasserpotentiale in Blättern und Potentialgradient im Baum}

Zeitgleich mit den Wurzel-Wasserpotentialen wurden auch die Wasserpotentiale von exponierten Sonnenblättern gemessen (Ausnahme: Buche, hier konnte mit dem Hubwagen keine Krone erreicht werden). In Abb. 4.29 sind vergleichend zu den schon beschriebenen Tagesminima der Wurzel-Wasserpotentiale die Blatt-Wasserpotentiale dargestellt.

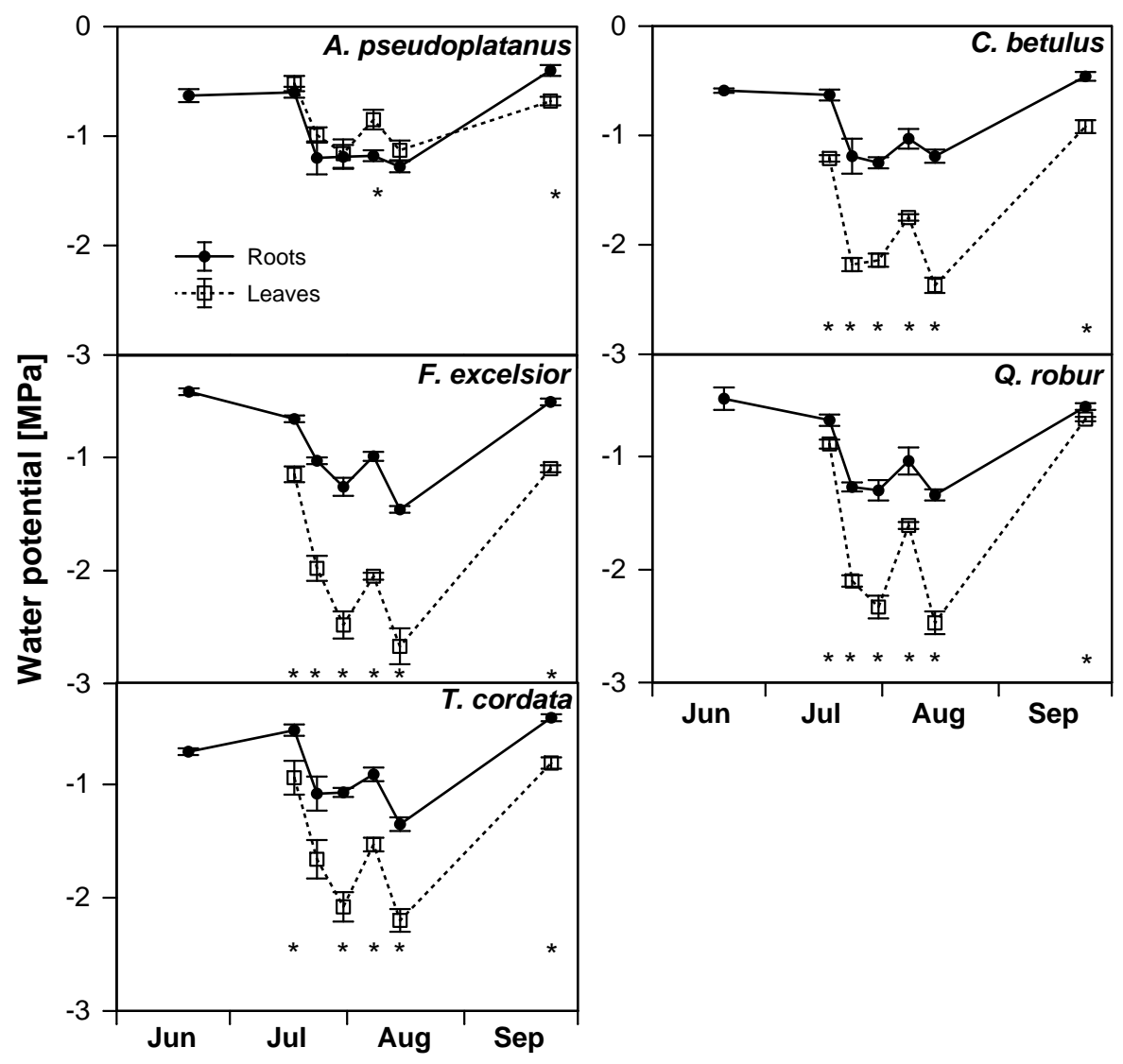

Abb. 4.29: Tagesminima der Blatt- und Wurzel-Wasserpotentiale der sechs Baumarten auf der Mischwald-Untersuchungsfläche im Nationalpark Hainich. Die Wurzel-Wasserpotentiale wurden an jeweils fünf Feinwurzelenden zur Mittagszeit (12-14 Uhr MESZ) mit der Druckkammermethode nach Scholander gemessen. Zeitgleich wurden die Blatt-Wasserpotentiale von jeweils fünf Blättern aus der Sonnenkrone bestimmt. Aufgetragen sind die Mittelwerte und Standardfehler. Sterne kennzeichnen signifikante Unterschiede zwischen Blatt- und Wurzel-Wasserpotential ( $\mathrm{p}<0.05$, ANOVA).

Der saisonale Verlauf der Blatt-Wasserpotentiale von Juni bis September glich dem des WurzelWasserpotentials, jedoch wurden signifikant niedrigere Wasserpotentiale in den Blättern gemessen. Allerdings war kein paralleler Verlauf von Wurzel- und Blatt-Wasserpotential zu beobachten, da eine Absenkung der Blatt-Wasserpotentiale bei Trockenheit viel stärker ausfiel 
als bei Wurzeln. Dadurch ergab sich mit einer Absenkung der Wasserpotentiale ein zunehmender Potentialgradient zwischen Blatt und Wurzel.

$\mathrm{Zu}$ Beginn der Messungen Mitte Juli lag die Potentialdifferenz zwischen Wurzeln und Blatt zwischen 0.21 MPa (Eiche) und 0.58 MPa (Hainbuche). Die größte Potentialdifferenz wurde bei Esche, Linde, Hainbuche und Stieleiche Mitte August erreicht. Dieser betrug zwischen Blättern und Wurzeln der Esche 1.21 MPa, für die Hainbuche lag er bei $1.18 \mathrm{MPa}$. Nur wenig geringer war die Potentialdifferenz der Eiche (1.13 MPa) und der Linde (1.01 MPa). Im September reduzierte sich die Potentialdifferenz zwischen Blatt und Wurzel mit den sich erholenden Wasserpotentialen wieder auf die zu Beginn gemessenen Werte.

Die Blatt-Wasserpotentiale des Bergahorns lagen an den meisten Messterminen auf gleicher Höhe mit den Wurzel-Wasserpotentialen, Anfang August sogar signifikant höher. Erst am letzten Messtermin Ende September war das Wasserpotential der Blätter signifikant negativer als das der Wurzeln und eine Potentialdifferenz von $0.28 \mathrm{MPa}$ erkennbar.

Die niedrigsten Blatt-Wasserpotentiale konnten am 15.8.2001 gemessen werden. Die Esche senkte ihr Blatt-Wasserpotential auf -2.67 MPa, nur wenig höher lag das Wasserpotential der Stieleiche (-2.47 MPa) und der Hainbuche (-2.37 MPa). Lindenblätter aus der Sonnenkrone hatten ein Minimum-Wasserpotential von -1.66 MPa. Signifikant höher war an diesem Messtermin das Blatt-Wasserpotential des Bergahorns, das bei -1.16 MPa lag.

\subsubsection{Vergleich der hydraulischen Leitfähigkeiten der Wurzeln der verschiedenen Baumarten}

\section{Theoretische hydraulische Leitfähigkeit der Wurzeln}

Nach dem Gesetz von Hagen-Poiseuille kann eine theoretische axiale Leitfähigkeit $\left(\mathrm{k}_{S}\right.$ theo $)$ aus der Summe der Gefäßdurchmesser im Wurzelquerschnitt berechnet werden. Als Bezugsgröße wird die Xylemfläche verwendet. Baumartbezogene Mittelwerte der theoretischen axialen Leitfähigkeit der Wurzeln am Messabschnitt sind in Abb. 4.30 dargestellt.

Die größte Differenz zu den anderen Baumarten wies die Esche auf, für die die geringste theoretische Leitfähigkeit mit $0.11 \mathrm{~m}^{2} \mathrm{MPa}^{-1} \mathrm{~s}^{-1}$ berechnet wurde. Nur wenig höher war die Leitfähigkeit des Bergahorns $\left(0.14 \mathrm{~m}^{2} \mathrm{MPa}^{-1} \mathrm{~s}^{-1}\right)$. Die höchsten Werte der Leitfähigkeit wurden für die Buchenwurzeln gefunden, die mit $0.36 \mathrm{~m}^{2} \mathrm{MPa}^{-1} \mathrm{~s}^{-1} \mathrm{mehr}$ als doppelt so hoch waren wie bei der Esche. Die gleiche theoretische Leitfähigkeit wie die Buche konnte auch für die Stieleiche errechnet werden $\left(0.35 \mathrm{~m}^{2} \mathrm{MPa}^{-1} \mathrm{~s}^{-1}\right)$. Aus der Anzahl und der Durchmesser der Gefäße von Winterlindenwurzeln konnte eine theoretische Leitfähigkeit von $0.32 \mathrm{~m}^{2} \mathrm{MPa}^{-1} \mathrm{~s}^{-1}$ bestimmt werden. Signifikante Unterschiede zwischen den Baumarten ließen sich jedoch nicht feststellen. Unterschiede in der Leitfähigkeit von Ringporern (Esche, Stieleiche) und von Zerstreutporern (Bergahorn, Linde, Hainbuche und Buche) ließen sich nicht feststellen. 


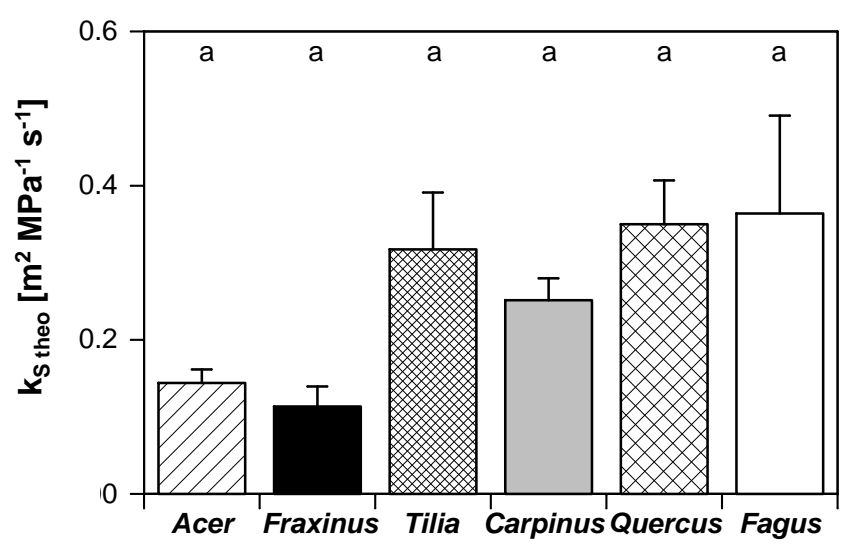

Abb. 4.30: Theoretische hydraulische Leitfähigkeit $\mathrm{k}_{\text {Stheo }}$ der Wurzeln von sechs Baumarten, berechnet nach dem Gesetz von Hagen-Poiseuille aus den Durchmessern der Xylemgefäße am 3-4 mm starken Messabschnitt der Wurzeln. Dargestellt sind die Mittelwerte und Standardfehler für 8-10 Wurzeln pro Baumart aus dem Hainich. Unterschiedliche Buchstaben kennzeichnen signifikante Unterschiede zwischen den Arten ( $\mathrm{p}<0.05$, Mann-Whitney-Test).

\section{Hydraulische Leitfähigkeit unter in situ-Bedingungen}

Die hydraulische Leitfähigkeit $\mathrm{Lp}_{r}$, die in der vorliegenden Arbeit aus dem Wasserpotentialgradienten zwischen Wurzel und Boden und der maximal gemessenen oberflächenspezifischen Saftflussrate berechnet wurde, schließt neben der gesamten hydraulischen Leitfähigkeit der Wurzel auch die Leitfähigkeit der Rhizosphäre mit ein.

In Abb. 4.31 sind die artbezogenen Mittelwerte der hydraulischen Leitfähigkeit $\mathrm{Lp}_{r}$ von Messungen an drei Terminen im Hainich dargestellt. An jedem Messtermin wurden 4-7 Wurzeln in die Berechnung einbezogen.

Über diese drei Messtermine gemittelt hatte die Winterlinde die höchste hydraulische Leitfähigkeit mit $2.76 \cdot 10^{-7} \mathrm{~m} \mathrm{MPa}^{-1} \mathrm{~s}^{-1}$. Wurzeln von Bergahorn und Hainbuche hatten eine geringere hydraulische Leitfähigkeit als die Linde; sie lagen mit $1.10 \mathrm{bzw} .0 .96 \cdot 10^{-7} \mathrm{~m} \mathrm{MPa}^{-1} \mathrm{~s}^{-1}$ in derselben Größenordnung. Eine hydraulische Leitfähigkeit von $0.79 \cdot 10^{-7} \mathrm{~m} \mathrm{MPa}^{-1} \mathrm{~s}^{-1}$ konnte für die Esche ermittelt werden. Die geringste in situ Leitfähigkeit wiesen Buchen- und Eichenwurzeln auf (0.47 bzw. $\left.0.38 \cdot 10^{-7} \mathrm{~m} \mathrm{MPa}^{-1} \mathrm{~s}^{-1}\right)$.

In Tab. 4.10 sind die Werte der hydraulischen Leitfähigkeit sowie die Potentialdifferenzen zwischen Wurzel und Boden an drei Messterminen dargestellt. Letztere fußen auf Druckkammermessungen und Tensiometerdaten.Das Bodenmatrixpotential sank von $-0.011 \mathrm{MPa}$ (20.6.2001) auf -0.052 MPa am zweiten Termin und erreichte am 15.8.2001 den negativsten Wert dieser drei Messtermine (-0.077 MPa). Anhand des Bodenmatrixpotentials konnte die zunehmende Austrocknung des Bodens abgelesen werden. Damit einher ging für alle sechs Baumarten eine ansteigende Potentialdifferenz zwischen Wurzel und Boden. Am ersten Messtermin war diese am steilsten für die Winterlinde (0.70 MPa). Die größte Steigerung der Potentialdifferenz an diesen drei Messterminen wies die Esche auf, die Differenz zwischen 


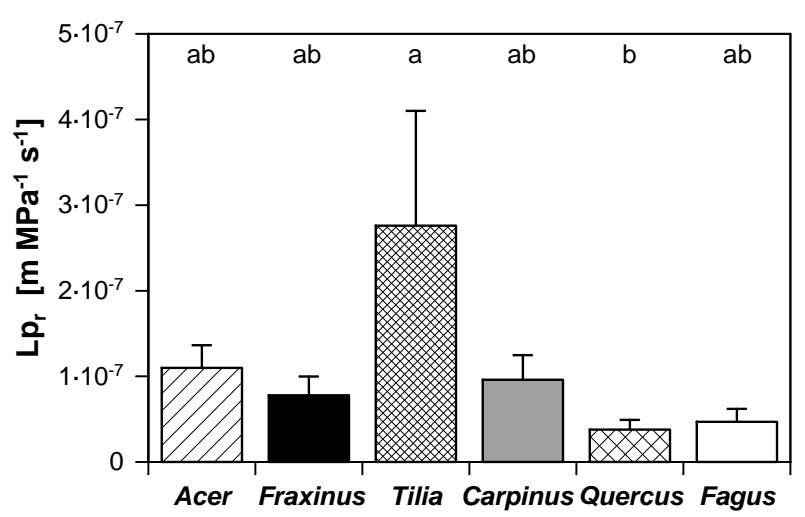

Abb. 4.31: Hydraulische Leitfähigkeit $\mathrm{Lp}_{r}$ der Wurzeln der untersuchten Baumarten unter in situ-Bedingungen auf den Untersuchungsflächen im Nationalpark Hainich. Dargestellt sind die Mittelwerte und Standardfehler aus Messungen von 4-7 Wurzeln pro Baumart. Ermittelt wurde $\mathrm{Lp}_{r}$ aus den Wasseraufnahmeraten, den Wurzeloberflächen und dem Wasserpotentialgradienten zwischen Boden und Wurzel an drei Tagen während der Vegetationsperiode 2001. Unterschiedliche Buchstaben kennzeichnen signifikante Unterschiede zwischen den Arten $(\mathrm{p}<0.05$, Mann-Whitney-Test).

Bodenmatrixpotential und Wurzel-Wasserpotential nahm von 0.41 auf $1.38 \mathrm{MPa}$ zu. Eine gleichartige Erhöhung der Wasserpotentialdifferenz $(\Delta \Psi)$ fand sich ebenfalls bei Buchen- und Eichenwurzeln.

Mit der Zunahme der Potentialdifferenz ging eine Abnahme der hydraulischen Leitfähigkeit $\mathrm{Lp}_{r}$ einher. Nur für Wurzeln der Eiche ließ sich eine Zunahme der in situ gemessenen Werte von $\mathrm{Lp}_{r}$ zwischen dem zweiten und dritten Messtermin beobachten. An zwei Messtagen (20.6. und 8.8.2001) erreichte die Eiche die geringste Leitfähigkeit. Für die Linde wurde an den beiden Messterminen, von denen Daten vorliegen, die höchste hydraulische Leitfähigkeit aller Arten berechnet. Ein signifikanter Unterschied zwischen den Baumarten war jedoch nur am letzten Messtermin (15.8.) vorhanden. Innerhalb einer Baumart war die Abnahme der hydraulischen Leitfähigkeit mit zunehmender Austrocknung bei der Esche am wenigsten stark, die größte Abnahme konnte für Wurzeln der Winterlinde berechnet werden. Nur für die Buche waren die Unterschiede zwischen den hydraulischen Leitfähigkeiten der drei Termine statistisch signifikant.

\section{Axiale hydraulische Leitfähigkeit}

Im Labor wurde die maximale axiale hydraulische Leitfähigkeit $\mathrm{k}_{m}$ von 3-4 mm starken Wurzelsegmenten der sechs Baumarten mit der Durchflussmethode nach SPERRY et al. (1988) bestimmt. Diese war für die Wurzeln des Bergahorns mit einem Mittelwert von $2.87 \times 10^{-4} \mathrm{~m}^{4}$ $\mathrm{MPa}^{-1} \mathrm{~s}^{-1}$ am höchsten (Abb. 4.32). Die maximale axiale Leitfähigkeit der anderen fünf Baumarten lag in einer Größenordnung zwischen 0.19 bis $0.54 \times 10^{-4} \mathrm{~m}^{4} \mathrm{MPa}^{-1} \mathrm{~s}^{-1}$.

Ein etwa zehnfach geringeres axiales Leitungsvermögen als der Bergahorn hatten die Wur- 
Tab. 4.10: Hydraulische Leitfähigkeit $\left(\mathrm{Lp}_{r}\right)$ der sechs Baumarten im Nationalpark Hainich unter in situ-Bedingungen. Die hydraulische Leitfähigkeit wurde berechnet aus der maximalen oberflächenspezifischen Saftflussrate einer Wurzel(n=3-5) zur Mittagszeit (12-14 Uhr MESZ) und der Wasserpotentialdifferenz zwischen Boden und Wurzel $(\Delta \Psi)$ an drei Tagen während der Vegetationsperiode 2001. $\Delta \Psi$ wurde durch $\Psi_{\text {Boden }}$ (aus Tensiometermessungen - $\Psi_{\text {Wurzel }}$ (aus Druckkammermessungen) bestimmt. Unterschiedliche Buchstaben kennzeichnen signifikante Artunterschiede am jeweiligen Messtermin $(\mathrm{p}<0.05$, Mann-Whitney-Test).

\begin{tabular}{l|cc|cc|cc}
\hline & \multicolumn{2}{|c|}{$\mathbf{2 0 . 6 . 2 0 0 1}$} & \multicolumn{2}{c|}{$\mathbf{8 . 8 . 2 0 0 1}$} & \multicolumn{2}{c}{$\mathbf{1 5 . 8 . 2 0 0 1}$} \\
& $\begin{array}{l}\Delta \Psi \\
{[\mathrm{MPa}]}\end{array}$ & $\begin{array}{c}\mathrm{Lp} \mathrm{m}_{r} \times 10^{7} \\
{\left[\mathrm{MPa}^{-1} \mathrm{~s}^{-1}\right]}\end{array}$ & $\begin{array}{c}\Delta \Psi \\
{[\mathrm{MPa}]}\end{array}$ & $\begin{array}{c}\mathrm{Lp} \mathrm{p}_{r} \times 10^{7} \\
{\left[\mathrm{~m} \mathrm{MPa}^{-1} \mathrm{~s}^{-1}\right]}\end{array}$ & $\begin{array}{c}\Delta \Psi \\
{[\mathrm{MPa}]}\end{array}$ & $\begin{array}{c}\mathrm{Lp}_{r} \times 10^{7} \\
{\left[\mathrm{~m} \mathrm{Ma}^{-1} \mathrm{~s}^{-1}\right]}\end{array}$ \\
\hline A. pseudoplatanus & 0.62 & $\mathbf{1 . 5 9} \pm \mathbf{0 . 5 2} \mathrm{a}$ & 1.13 & $\mathbf{1 . 4 9} \pm \mathbf{0 . 2 6} \mathrm{a}$ & 1.20 & $\mathbf{0 . 5 5} \pm \mathbf{0 . 2 7} \mathrm{ab}$ \\
F. excelsior & 0.41 & nd & 0.94 & $\mathbf{0 . 8 3} \pm \mathbf{0 . 6 2} \mathrm{a}$ & 1.38 & $\mathbf{0 . 7 4} \pm \mathbf{0 . 1 7} \mathrm{ab}$ \\
T. cordata & 0.70 & nd & 0.86 & $\mathbf{3 . 7 4} \pm \mathbf{2 . 3 0} \mathrm{a}$ & 1.27 & $\mathbf{1 . 4 4} \pm \mathbf{0 . 6 2} \mathrm{a}$ \\
C. betulus & 0.58 & $\mathbf{0 . 9 6} \pm \mathbf{0 . 8 6} \mathrm{a}$ & 0.98 & nd & 1.11 & nd \\
Q. robur & 0.48 & $\mathbf{0 . 6 4} \pm \mathbf{0 . 3 0} \mathrm{a}$ & 0.99 & $\mathbf{0 . 1 9} \pm \mathbf{0 . 0 7} \mathrm{a}$ & 1.26 & $\mathbf{0 . 3 0} \pm \mathbf{0 . 1 0} \mathrm{ab}$ \\
F. sylvatica & 0.59 & $\mathbf{0 . 8 8} \pm \mathbf{0 . 2 2} \mathrm{a}$ & 0.96 & $\mathbf{0 . 2 6} \pm \mathbf{0 . 1 0} \mathrm{a}$ & 1.32 & $\mathbf{0 . 1 7} \pm \mathbf{0 . 1 0} \mathrm{b}$ \\
\hline
\end{tabular}

zeln von Esche und Hainbuche (0.23 bzw. $\left.0.19 \times 10^{-4} \mathrm{~m}^{4} \mathrm{MPa}^{-1} \mathrm{~s}^{-1}\right)$. In der Reihung Winterlinde, Stieleiche, Buche nahm die maximale axiale Leitfähigkeit von 0.45 über 0.47 auf $0.54 \times 10^{-4} \mathrm{~m}^{4} \mathrm{MPa}^{-1} \mathrm{~s}^{-1} \mathrm{zu}$. Somit ergaben sich im Verhältnis der Baumarten zueinander nur geringe Unterschiede $\mathrm{zu}$ der theoretischen axialen Leitfähigkeit $\mathrm{k}_{\text {Stheo }}$. Eine Ausnahme bildeten die untersuchten Wurzelsegmente des Bergahorns, dessen theoretische axiale Leitfähigkeit in derselben Größenordnung mit den übrigen Baumarten lag, jedoch eine viel höhere maximale axiale Leitfähigkeit aufwies. Andere Relationen wiesen die Baumarten dagegen bei der Betrachtung der Wurzelleitfähigkeit $\mathrm{Lp}_{r}$ auf.

Die spezifische axiale Leitfähigkeit erhält man durch die Einbeziehung der Querschnittsfläche des Wurzelsegments. In Abb. 4.33 ist die spezifische Leitfähigkeit der Wurzelsegmente der sechs untersuchten Baumarten dargestellt. Mit $0.37 \mathrm{~m}^{2} \mathrm{MPa}^{-1} \mathrm{~s}^{-1}$ lag die Leitfähigkeit der Bergahorn-Wurzelsegmente wiederum zwei- bis vierfach höher als die spezifische axiale Leitfähigkeit der Wurzelsegmente der anderen fünf Baumarten. Buchen- und Eichenwurzeln unterschieden sich kaum (0.15 bzw. $\left.0.14 \mathrm{~m}^{2} \mathrm{MPa}^{-1} \mathrm{~s}^{-1}\right)$. Die Hainbuchenwurzeln wiesen mit einer Leitfähigkeit von $0.06 \mathrm{~m}^{2} \mathrm{MPa}^{-1} \mathrm{~s}^{-1}$ die geringsten Werte auf. Eine nur wenig höhere spezifische Leitfähigkeit hatten die untersuchten Wurzelsegmente der Winterlinde $\left(0.08 \mathrm{~m}^{2} \mathrm{MPa}^{-1} \mathrm{~s}^{-1}\right)$. Es traten jedoch keine signifikanten Unterschiede zwischen den Baumarten auf. 


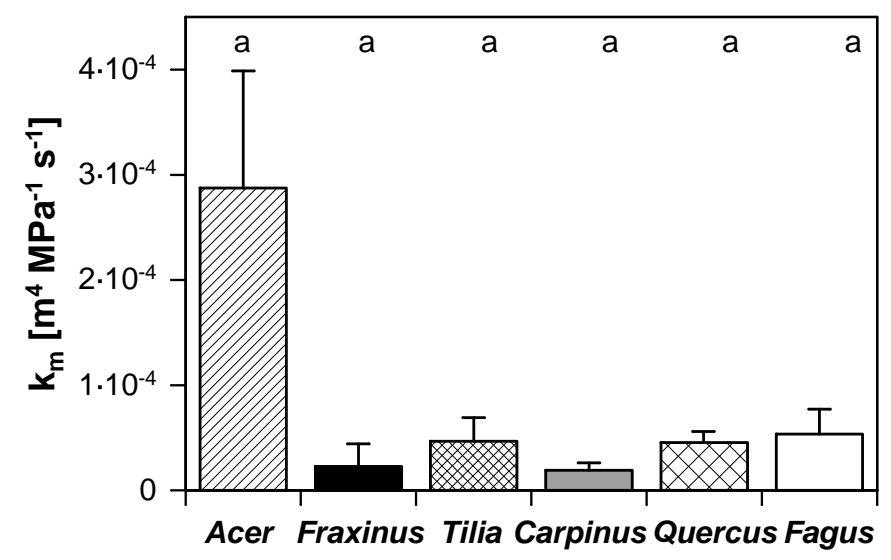

Abb. 4.32: Maximale hydraulische Leitfähigkeit $\mathrm{k}_{m}$ von 3-4 mm starken Wurzeln von sechs Baumarten im Nationalpark Hainich, gemessen mit der Durchflussmethode nach SPERRY et al. (1988). Dargestellt sind die Mittelwerte und Standardfehler aus Messungen an 4-8 ca. $5 \mathrm{~cm}$ langen Segmenten pro Baumart. Unterschiedliche Buchstaben kennzeichnen signifikante Unterschiede zwischen den Arten $(\mathrm{p}<0.05$, GLM).

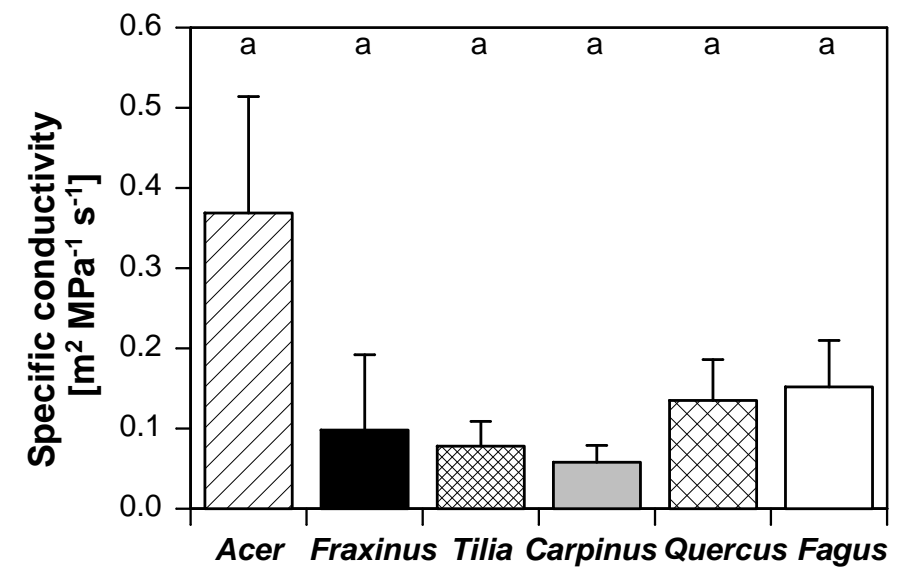

Abb. 4.33: Spezifische Leitfähigkeit ( $\mathrm{k}_{m}$ bezogen auf die Querschnittsfläche der Segmente) der Wurzeln von sechs Baumarten im Hainich. Die Leitfähigkeiten wurden mit der Durchflussmethode nach SPERRY et al. (1988) gemessen. Dargestellt sind die Mittelwerte und Standardfehler von jeweils 4-8 Messungen pro Baumart. Unterschiedliche Buchstaben kennzeichnen signifikante Unterschiede zwischen den Arten $(\mathrm{p}<0.05, \mathrm{GLM})$. 


\subsubsection{Abschätzung der Bestandeswasseraufnahme}

Aus den für den Bestand berechneten RAI-Werten und der über die Saftflussmessungen ermittelten oberflächenspezifischen Wurzelwasseraufnahme kann der Bestandeswasserverbrauch abgeschätzt werden. In Tab. 4.11 ist die mittlere Wasseraufnahmemenge der sechs Baumarten über die Vegetationsperioden 2000 und 2001 angegeben. Die Berechnung der Wasseraufnahme der Buche bezieht sich auf den benachbarten Buchenbestand, die Strukturparameter (RAI, LAI, Stammdichte) dieses Bestandes wurden der Arbeit von KOCH (2002) entnommen.

Tab. 4.11: Bestandeswasseraufnahme von sechs Baumarten im Nationalpark Hainich. Die Werte der Bestandeswasseraufnahme wurden aus den oberflächenspezifischen Wasseraufnahmeraten der sechs untersuchten Baumarten und deren Wurzeloberflächenindex (RAI) berechnet. Angegeben sind die Mittelwerte über die Monate Juni - September 2000 und 2001. Die Angaben für die Buche beziehen sich auf den Buchenreinbestand. Die Strukturparameter des Buchenreinbestandes wurden von $\mathrm{KOCH}$ (2002) aufgenommen. LAI: Blattflächenindex

\begin{tabular}{lcccc}
\hline & $\begin{array}{c}\text { Stem density } \\
{\left[\mathrm{n} \mathrm{ha}^{-1}\right]}\end{array}$ & $\begin{array}{c}\text { LAI } \\
{\left[\mathrm{m}^{2} \mathrm{~m}^{-2}\right]}\end{array}$ & $\begin{array}{c}\text { RAI } \\
{\left[\mathrm{m}^{2} \mathrm{~m}^{-2}\right]}\end{array}$ & $\begin{array}{c}\text { Water consumption } \\
{\left[\mathrm{mm} \mathrm{d}^{-1}\right]}\end{array}$ \\
\hline A. pseudoplatanus & 48 & 0.77 & 1.69 & 1.12 \\
F. excelsior & 117 & 1.43 & 7.40 & 2.53 \\
T. cordata & 15 & 0.97 & 1.99 & 0.53 \\
C. betulus & 15 & 0.46 & 0.45 & 0.34 \\
Q. robur & 9 & 0.23 & 0.12 & 0.01 \\
F. sylvatica & 171 & 4.90 & 4.40 & 1.86 \\
\hline
\end{tabular}

Die höchste Bestandeswasseraufnahme ergab sich für die Esche, was zum einen aus einer hohen oberflächenspezifischen Wasseraufnahmerate und zum anderen aus der ober- und unterirdischen Dominanz der Esche (117 Individuen pro ha, höchster RAI) resultierte. Der Bergahorn war mit 48 Stämmen pro ha auf der Mischwaldfläche die zweithäufigste Baumart. Der RAI war mit 1.69 geringer als der der Linde, dennoch hatte der Bergahorn den zweithöchsten mittleren Bestandeswasserverbrauch. Der RAI der Linde setzt sich aus den Feinwurzeloberflächen von Sommer- und Winterlinde zusammen, so dass die Bestandeswasseraufnahme der Winterlinde eventuell überschätzt wurde. So hatte sie bei gleicher Individuenanzahl im Bestand eine höhere Wasseraufnahme als die Hainbuche. Die Stieleiche hatte die niedrigste Stammdichte der hier aufgeführten Baumarten und den kleinsten RAI. Auch der Wasserverbrauch auf Bestandesebene war mit $0.01 \mathrm{~mm} \mathrm{~d}^{-1}$ sehr gering. Die Angaben der Buche beziehen sich auf den Buchenreinbestand, in dem sie eine höhere Stammdichte als die Esche im Mischwald erreichte. Mit einem RAI von 4.40 kann für den Buchenbestand auf einen mittlerer Wasserverbrauch hochgerechnet werden, der unter dem des Mischwaldes liegt. Bei den hier hochgerechneten Werten ist zu berücksichtigen, dass nur die Feinwurzeln bis in $20 \mathrm{~cm}$ Tiefe erhoben wurden, der tatsächliche Bestandes-RAI also sicher größer ist. 


\subsection{Vergleich der Wasseraufnahme an zwei edaphisch unterschiedlichen Standorten}

\subsubsection{Wasseraufnahmeraten}

Während eines achtwöchigen Untersuchungszeitraums im Sommer 2001 wurden die Wasseraufnahmeraten von Buche und Eiche vergleichend im Nationalpark Hainich und in der Lüneburger Heide gemessen. Die in der Lüneburger Heide untersuchten Wurzeln lagen - vergleichbar mit den Durchmessern der Wurzeln aus dem Hainich - zwischen 3.0 und $4.1 \mathrm{~mm}$. Die Saftflusssensoren wurden in einer Tiefe zwischen 5 und $20 \mathrm{~cm}$ an je 10 Wurzeln pro Baumart installiert. Bei der Ernte der Wurzeln nach dem Abschluss der Messungen konnten jedoch nur drei Wurzeln der Eiche bzw. zwei Wurzeln der Buche dem Mineralboden zugeordnet werden. Von den übrigen Wurzeln waren die überwiegenden Anteile in der organischen Auflage bzw. den oberen $5 \mathrm{~cm}$ des Oberbodens lokalisiert. Daher wird im Folgenden zwischen Wurzeln der organischen Auflage und des Mineralbodens unterschieden. Im Hainich ist keine organische Auflage vorhanden, so dass nur Wurzeln des Mineralbodens (meist im $\mathrm{A}_{h}$-Horizont) untersucht wurden.

Die auf den Wurzelquerschnitt bezogene Saftflussdichte ist als Mittelwert über den Untersuchungszeitraum in Abb. 4.34A dargestellt.
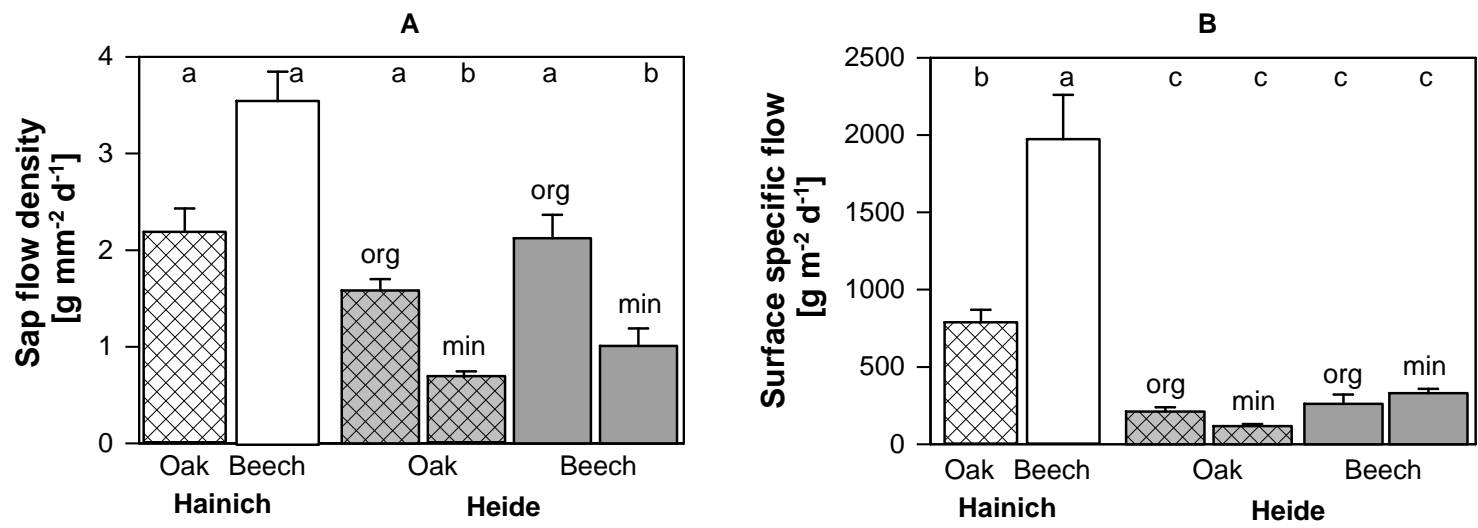

Abb. 4.34: A Tageswerte der Saftflussdichten und B Tageswerte der oberflächenspezifischen Saftflussraten von Eiche und Buche in den Untersuchungsgebieten Hainich und Lüneburger Heide. Dargestellt sind in beiden Graphen die Mittelwerte und Standardfehler aus Messungen an 10-15 Wurzeln pro Baumart im Hainich, 6-8 Wurzeln der organischen Auflage (org) und 2-3 Wurzeln des Mineralbodens (min) in der Lüneburger Heide für die Monate August-September 2001. Im Hainich war keine organische Auflage vorhanden. Unterschiedliche Buchstaben kennzeichnen signifikante Unterschiede zwischen den Baumarten $(\mathrm{p}<0.05$, Mann-Whitney-Test). 
Innerhalb eines Standortes traten signifikante Unterschiede nur zwischen Wurzeln der organischen Auflage und des Mineralbodens auf. Für die Lüneburger Heide lässt sich festhalten, dass die Saftflussdichte der organischen Auflage mit $1.58 \mathrm{~g} \mathrm{~mm}^{-2} \mathrm{~d}^{-1}$ (Traubeneiche) bzw. $2.12 \mathrm{~g} \mathrm{~mm}^{-2} \mathrm{~d}^{-1}$ (Buche) höher war als im Mineralboden. Die beiden Mineralbodenwurzeln der Traubeneiche in der Lüneburger Heide hatten eine mittlere Saftflussdichte, die mit $0.68 \mathrm{~g} \mathrm{~mm}^{-2} \mathrm{~d}^{-1}$ dreifach geringer war als die Saftflussdichte der Eichenwurzeln im Hainich $\left(2.18 \mathrm{~g} \mathrm{~mm}^{-2} \mathrm{~d}^{-1}\right)$. Zwischen den Mineralbodenwurzeln der Buche im Hainich und der Lüneburger Heide bestand ebenfalls ein signifikanter Unterschied. Buchenwurzeln im Hainich erreichten eine Saftflussdichte von $3.56 \mathrm{~g} \mathrm{~mm}^{-2} \mathrm{~d}^{-1}$, in der Lüneburger Heide von nur $1.01 \mathrm{~g} \mathrm{~mm}^{-2} \mathrm{~d}^{-1}$.

Durch die Einbeziehung der Wurzeloberfläche des gesamten Wurzelstranges erhält man die oberflächenspezifische Wasseraufnahmerate (Abb. 4.34B). Während Stieleiche und Buche im Hainich einen signifikanten Unterschied der oberflächenspezifischen Wasseraufnahmerate aufwiesen, minimierten sich sowohl art- als auch bodenschichtspezifische Unterschiede in der Lüneburger Heide. Mineralbodenwurzeln der Stieleiche im Hainich nahmen $784.78 \mathrm{~g} \mathrm{~m}^{-2}$ $\mathrm{d}^{-1}$ Wasser auf. Der Unterschied zu den Mineralbodenwurzeln der Traubeneiche in der Lüneburger Heide, die eine oberflächenspezifische Flussrate von $117.16 \mathrm{~g} \mathrm{~m}^{-2} \mathrm{~d}^{-1}$ hatten, war mit einem Faktor von sieben signifikant. Die Buchen hatten im Hainich eine oberflächenbezogene Wasseraufnahmerate von $1969.31 \mathrm{~g} \mathrm{~m}^{-2} \mathrm{~d}^{-1}$, die zum einen fast doppelt so hoch war wie die der Stieleiche, aber auch die Aufnahmerate der Buchen-Mineralbodenwurzeln in der Lüneburger Heide um das sechsfache übertraf (331.09 $\left.\mathrm{g} \mathrm{m}^{-2} \mathrm{~d}^{-1}\right)$. Die oberflächenspezifischen Aufnahmeraten der Auflagen-Wurzeln der Traubeneiche waren höher als die ihrer Mineralbodenwurzeln. Die Traubeneiche hatte eine Aufnahmeleistung von $211.82 \mathrm{~g} \mathrm{~m}^{-2} \mathrm{~d}^{-1}$, die von der Buche im Mineralboden und in der organischen Auflage übertroffen wurde $\left(261.38 \mathrm{~g} \mathrm{~m}^{-2}\right.$ $\left.\mathrm{d}^{-1}\right)$.

\subsubsection{Morphologische und anatomische Eigenschaften}

\section{Wurzeloberfläche}

In Abb. 4.35 sind die Wurzeloberflächen der zur Saftflussmessung verwendeten Eichen- und Buchenwurzeln beider Standorte aufgetragen. Innerhalb eines Standortes ließen sich signifikante Unterschiede zwischen den Auflage- und Mineralbodenwurzeln der Buche feststellen. Die Wurzeln aus der organischen Auflage hatten mit $736.59 \mathrm{~cm}^{2}$ (Traubeneiche) und $838.55 \mathrm{~cm}^{2}$ (Buche) im Mittel die größten Wurzeloberflächen, waren also stärker verzweigt. Zwischen den beiden Untersuchungsgebieten dagegen traten damit trotz gleicher Durchmesser der Wurzeln am Messabschnitt (3-4 mm) signifikante Unterschiede auf. Im Hainich besaßen die Stieleichenwurzeln eine Wurzeloberfläche von $233.07 \mathrm{~cm}^{2}$, die Oberfläche der vergleichbaren Mineralbodenwurzeln der Traubeneiche waren mit $395.32 \mathrm{~cm}^{2}$ tendenziell größer. Ein nur geringer Unterschied bestand dagegen zwischen den Buchenwurzeln im Mineralboden beider Standorte. Im Hainich betrug die Wurzeloberfläche $225.67 \mathrm{~cm}^{2}$, wohingegen in der Lüneburger Heide $273.06 \mathrm{~cm}^{2}$ gemessen werden konnten. 


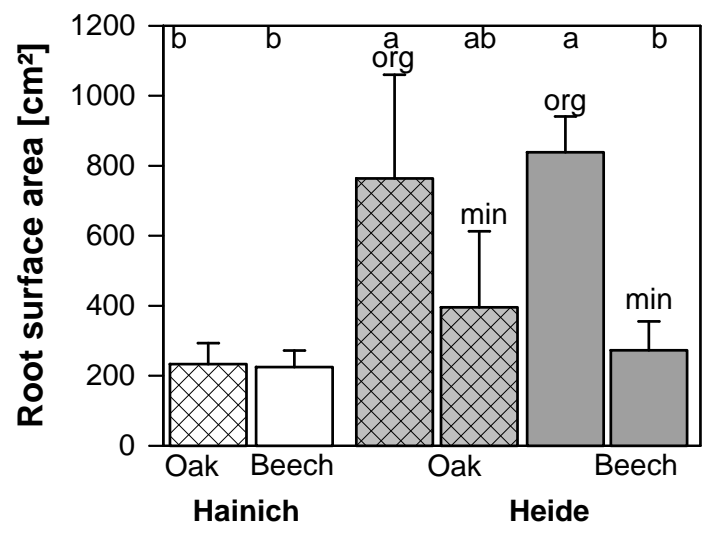

Abb. 4.35: Gesamtoberfläche der 3-4 mm starken Messwurzelstränge von Eichen und Buchen im Hainich und der Lüneburger Heide. Dargestellt sind die Mittelwerte und Standardfehler von 8-13 Wurzeln aus dem Hainich, 4-6 Wurzeln der organischen Auflage (org) und 2-3 Wurzeln des Mineralbodens (min) in der Lüneburger Heide aus der Vegetationsperiode 2001. Der Bestand im Hainich wies keine organische Auflage auf. Unterschiedliche Buchstaben kennzeichnen signifikante Unterschiede zwischen den Baumarten $(\mathrm{p}<0.05$, Mann-Whitney-Test).

Betrachtet man die Verteilung der Wurzeloberfläche auf die drei Durchmesserklassen 0-1 mm, 1-2 $\mathrm{mm}$ und $<2 \mathrm{~mm}$ (Abb. 4.36A), so wird deutlich, dass der Unterschied zwischen den Standorten durch eine größere Feinstwurzeloberfläche $(0-1 \mathrm{~mm})$ vor allem der Auflagewurzeln in der Lüneburger Heide zu Stande kam. Die Messwurzeln von Stieleiche und Buche im Hainich hatten eine Feinstwurzeloberfläche von 148.70 bzw. $143.89 \mathrm{~cm}^{2}$; auf Feinstwurzeln entfielen im Mineralboden der Lüneburger Heide doppelt so große Oberflächen von 300.42 bzw. $220.67 \mathrm{~cm}^{2}$. Deutlich größer war die Feinstwurzeloberfläche der Messwurzeln aus der organischen Auflage, die bei $601.39 \mathrm{~cm}^{2}$ für die Traubeneiche und $672.15 \mathrm{~cm}^{2}$ für die $\mathrm{Bu}-$ che lag. Auch in der Durchmesserklasse 1-2 mm (Feinwurzeln) blieb ein signifikanter Unterschied zwischen Wurzeln aus dem Hainich und der organischen Auflage der Lüneburger Heide bestehen. Stieleiche und Buche im Hainich hatten nahezu identische Feinwurzeloberflächen (47.52 und $46.59 \mathrm{~cm}^{2}$ ). Ebenfalls sehr ähnlich waren die Oberflächen der Auflagewurzeln, die bei $135.12 \mathrm{~cm}^{2}$ (Traubeneiche) und $147.80 \mathrm{~cm}^{2}$ (Buche) lagen. Der Vergleich der Mineralbodenwurzeln zeigte höhere Werte für die Traubeneiche der Lüneburger Heide $\left(80.08 \mathrm{~cm}^{2}\right)$, nicht jedoch für die Buche $\left(46.36 \mathrm{~cm}^{2}\right)$ gegenüber dem Hainich. In der Durchmesserklasse der Schwachwurzeln $(<2 \mathrm{~mm})$ traten keine signifikanten Unterschiede auf. Die Oberflächen hatten Größen zwischen $6.03 \mathrm{~cm}^{2}$ (Buche, Mineralboden Lüneburger Heide) und $47.23 \mathrm{~cm}^{2}$ (Stieleiche, Mineralboden Hainich), wobei die Baumarten im Hainich tendenziell größere Schwachwurzeloberflächen hatten.

Die standortsbezogenen Unterschiede in der Größe der Wurzeloberfläche verschiedener Durchmesserklassen spiegeln sich in dem relativen Anteil der Durchmesserklassen an der Gesamtwurzeloberfläche lediglich für die Feinstwurzeln wider (Abb. 4.36B). Unabhängig von der 

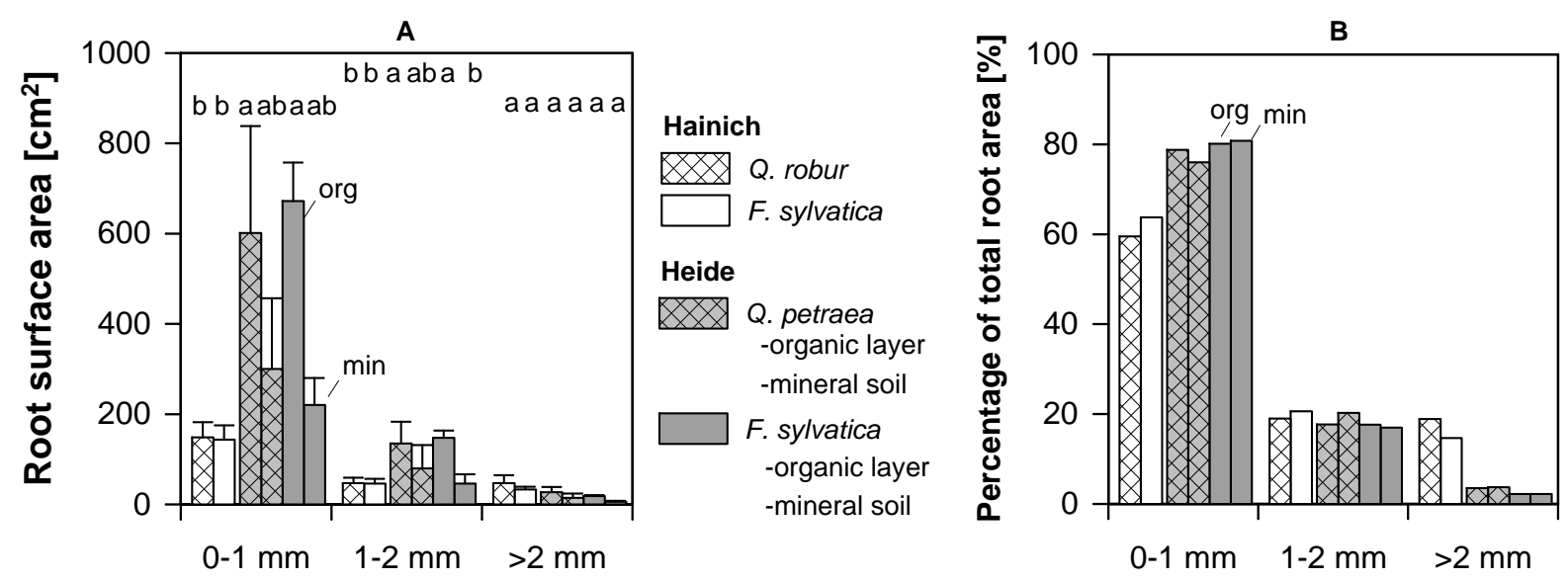

Abb. 4.36: Verteilung der Wurzeloberfläche der 3-4 mm starken Messwurzeln auf die Durchmesserklassen 0-1 mm, 1-2 mm und $>2 \mathrm{~mm}$. A Dargestellt sind die Mittelwerte und Standardfehler der im Hainich und der Lüneburger Heide geernteten Messwurzelstränge von Buche und Eiche, in der Lüneburger Heide unterschieden zwischen Wurzeln der organischen Auflage $(n=4-6)$ und des Mineralbodens $(n=2-4)$, an denen zuvor Saftflussmessungen durchgeführt wurden. Der Bestand im Hainich wies keine organische Auflage auf. Im Hainich konnten 8-13 Wurzeln pro Baumart geerntet werden. Unterschiedliche Buchstaben kennzeichnen signifikante Unterschiede zwischen den Baumarten ( $\mathrm{p}<0.05$, Mann-Whitney-Test). B Darstellung der Werte als relativer Anteil an der Gesamtwurzeloberfläche.

Verteilung auf organische Auflage oder Mineralboden hatten Feinstwurzeln von Traubeneiche und Buche in der Lüneburger Heide einen Anteil von 76.0\% (Traubeneiche, Mineralboden) bis zu 80.8\% (Buche, Mineralboden) an der Gesamtoberfläche der Messwurzeln. Im Hainich dagegen wurden durchschnittlich 59.6\% der Wurzeloberfläche der Stieleichen und 63.8\% der Oberfläche der Buchen von den Feinstwurzeln gebildet. Die Durchmesserklasse der Feinwurzeln (1-2 mm) dagegen war unabhängig von Gesamtwurzelgröße und Standort zu 19.0\% (Stieleiche Hainich) bis zu 20.3\% (Traubeneiche, Mineralboden Lüneburger Heide) an der Gesamtwurzeloberfläche beteiligt. Wurzeln im Hainich hatten geringere Anteile an Schwachwurzeln als die Wurzeln in der Lüneburger Heide. Die Oberflächen der Schwachwurzeln im Hainich hatten einen Anteil von 14.7 bis $18.9 \%$ an der Gesamtwurzeloberfläche, während Schwachwurzeln der Lüneburger Heide zwischen 2.2 und 3.8\% der Oberfläche der Wurzelstränge ausmachten.

\section{Anatomie der Eichen- und Buchenwurzeln}

Von den Messwurzeln aus dem Hainich und der Lüneburger Heide wurden Querschnitte erstellt, an denen mikroskopisch die Anzahl, die Größe und die Verteilung der Xylemgefäße bestimmt wurde.

In Abb. 4.37 sind die Mittelwerte der Leitflächen aufgetragen. Die Leitfläche gibt die Summe aller Gefäßquerschnittsflächen an. 


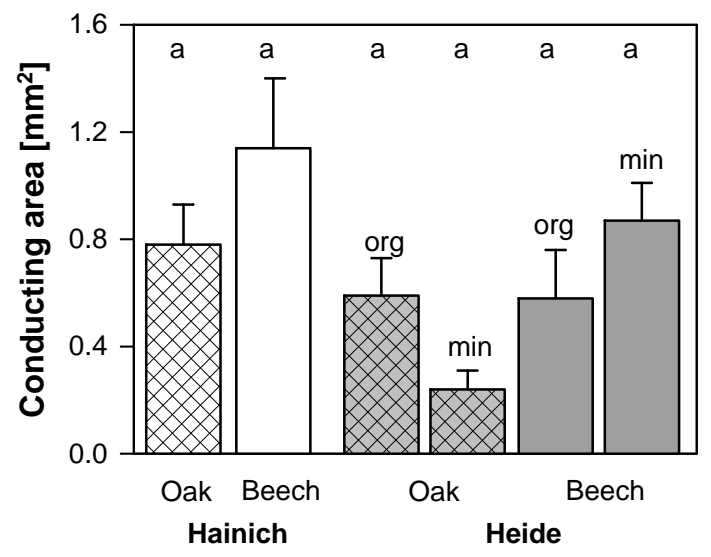

Abb. 4.37: Leitflächen der Wurzelquerschnitte von Eiche und Buche aus den Untersuchungsgebieten Hainich und Lüneburger Heide. Dargestellt sind die Mittelwerte und Standardfehler von 12-18 Wurzeln pro Baumart im Hainich und 4-6 Wurzeln pro Baumart aus der organischen Auflage (org) bzw. 2-4 Wurzeln aus dem Mineralboden (min) der Lüneburger Heide. Die Querschnitte wurden an den Messabschnitten der Wurzeln erstellt, an denen zuvor die Saftflussmessungen stattfanden (Durchmesser 3-4 mm). Unterschiedliche Buchstaben kennzeichnen signifikante Unterschiede zwischen den Baumarten $(\mathrm{p}<0.05$, Mann-Whitney-Test).

Die 3-4 mm starken Wurzeln von Stieleiche und Buche hatten ähnlich große Leitflächen wie die Wurzeln von Traubeneiche und Buche in der Lüneburger Heide. Die Eichen hatten dabei jeweils kleinere Leitflächen als die Buchen. Im Hainich betrug die Summe der Gefäßquerschnittsflächen der Eichen im Mittel $0.78 \mathrm{~mm}^{2}$, in der Lüneburger Heide hatten Traubeneichen der organischen Auflage eine Leitfläche von $0.59 \mathrm{~mm}^{2}$; im Mineralboden fanden sich die kleinsten Leitflächen mit 0.24 mm² . 3-4 mm starke Wurzeln der Buchen im Hainich wiesen eine Leitfläche von $1.14 \mathrm{~mm}^{2}$ auf, vergleichbare Wurzeln der Buche in der Lüneburger Heide hatten dagegen $0.58 \mathrm{~mm}^{2}$ (organische Auflage) bzw. $0.87 \mathrm{~mm}^{2}$ (Mineralboden).

Neben den Leitflächen kann die Anzahl der Xylemgefäße einen Einfluss auf die durchfließende Wassermenge haben. Daher wird in Abb. 4.38 die Anzahl der Xylemgefäße pro mm² Xylemquerschnittsfläche für die Wurzeln von Eichen und Buchen aufgetragen, die ebenfalls an den Messabschnitten gezählt wurden.

Weder zwischen den Baumarten noch zwischen den beiden Untersuchungsgebieten Hainich und Lüneburger Heide konnten Unterschiede in der mittleren Gefäßanzahl festgestellt werden. Die Werte der Eichen lagen zwischen 125.44 und 142.70 Gefäßen pro mm $^{2}$ Xylemfläche, die der Buchen nur geringfügig höher zwischen 133.07 und 185.60 Gefäßen $\mathrm{mm}^{-2}$.

Die Verteilung der Xylemgefäße verschiedener Größen auf die Xylemquerschnittsfläche ist in Abb. 4.39 dargestellt.

Die Unterschiede zwischen den Standorten waren geringer als die Unterschiede zwischen Eichen und Buchen. So ließ sich feststellen, dass beide Baumarten in der Lüneburger Heide 


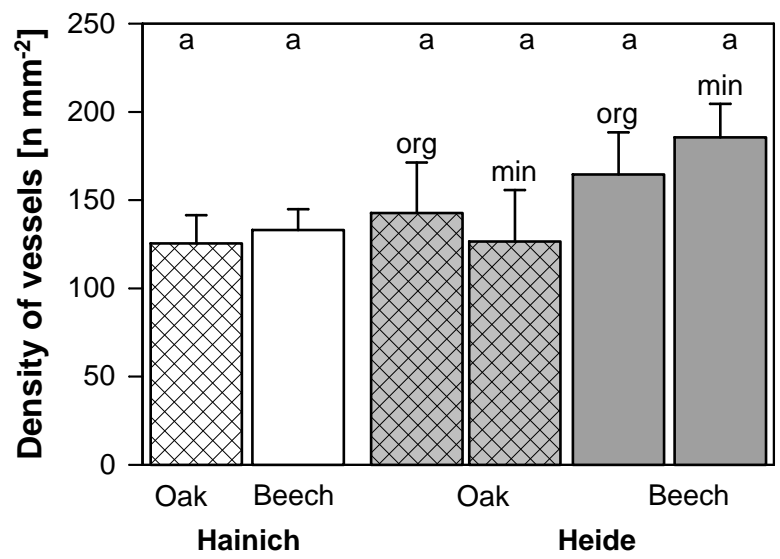

Abb. 4.38: Anzahl der Xylemgefäße im Wurzelquerschnitt von Buchen und Eichen. Dargestellt sind die Mittelwerte und Standardfehler von 12-18 Wurzeln pro Baumart aus dem Hainich und von 4-6 Wurzeln der organischen Auflage (org) bzw. 2-4 Wurzeln des Mineralbodens (min) der Lüneburger Heide. Eine organische Auflage war im Hainich nicht vorhanden. Die Querschnitte wurden an den Messabschnitten der Wurzeln erstellt, an denen zuvor die Saftflussmessungen stattfanden (Durchmesser 3-4 mm). Unterschiedliche Buchstaben kennzeichnen signifikante Unterschiede zwischen den Baumarten ( $\mathrm{p}<0.05$, Mann-Whitney-Test).

keine Gefäße mit einem Durchmesser über $135 \mu$ m aufwiesen. Im Fall der Buche lagen die Durchmesser aller Gefäße unter $100 \mu \mathrm{m}$. Im Hainich wurden bis zu $160 \mu \mathrm{m}$ weite Gefäße gefunden (Stieleiche). Die größten Gefäße der Buche erreichten an diesem Standort maximal $180 \mu \mathrm{m}$. Die Stieleiche im Hainich erreichte ein Häufigkeitsmaximum bei einem Gefäßdurchmesser von 30-35 $\mu \mathrm{m}$ mit 15 Gefäßen $\mathrm{mm}^{-2}$. In der Heide lag das Maximum der Wurzeln der organischen Auflage und des Mineralbodens bei Gefäßen mit einem Durchmesser von 35$40 \mu \mathrm{m}$ (26.6 bzw. 20.4 Gefäße mm ${ }^{-2}$ ). Die Maxima der Verteilungskurven der Buchenwurzeln aus der Lüneburger Heide lagen ebenfalls in der Durchmesserklasse 35-40 $\mu \mathrm{m}$, die allerdings mit 40.1 (organische Auflage) bzw. 34.2 Gefäßen pro $\mathrm{mm}^{2}$ (Mineralboden) häufiger vertreten war als bei den Eichen. Die Buchenwurzeln aus dem Hainich hatten im Xylemquerschnitt maximal 23 Gefäße $\mathrm{mm}^{-2}$ in der Durchmesserklasse 35-40 $\mu \mathrm{m}$.

\subsubsection{Mikroklimatische und edaphische Einflüsse}

Die Tageshellphasensummen der Strahlungsbilanz und die Tagesmittelwerte des Wasserdampfsättigungsdefizits der Luft (VPD) sind in Abb. 4.40 für die Untersuchungsflächen im Hainich und der Lüneburger Heide dargestellt. Maximalwerte der Strahlungsbilanz wurden sowohl im Hainich (29.70 $\mathrm{MJ} \mathrm{m}^{-2} \mathrm{~d}^{-1}$ ) als auch in der Lüneburger Heide $\left(28.71 \mathrm{MJ} \mathrm{m}^{-2} \mathrm{~d}^{-1}\right)$ Ende Juli erreicht. Im August lagen die Werte der Strahlungsbilanz in der Lüneburger Heide unter $20 \mathrm{MJ} \mathrm{m}^{-2} \mathrm{~d}^{-1}$, während im Hainich noch nahezu Maximalwerte erreicht wurden. Auf 

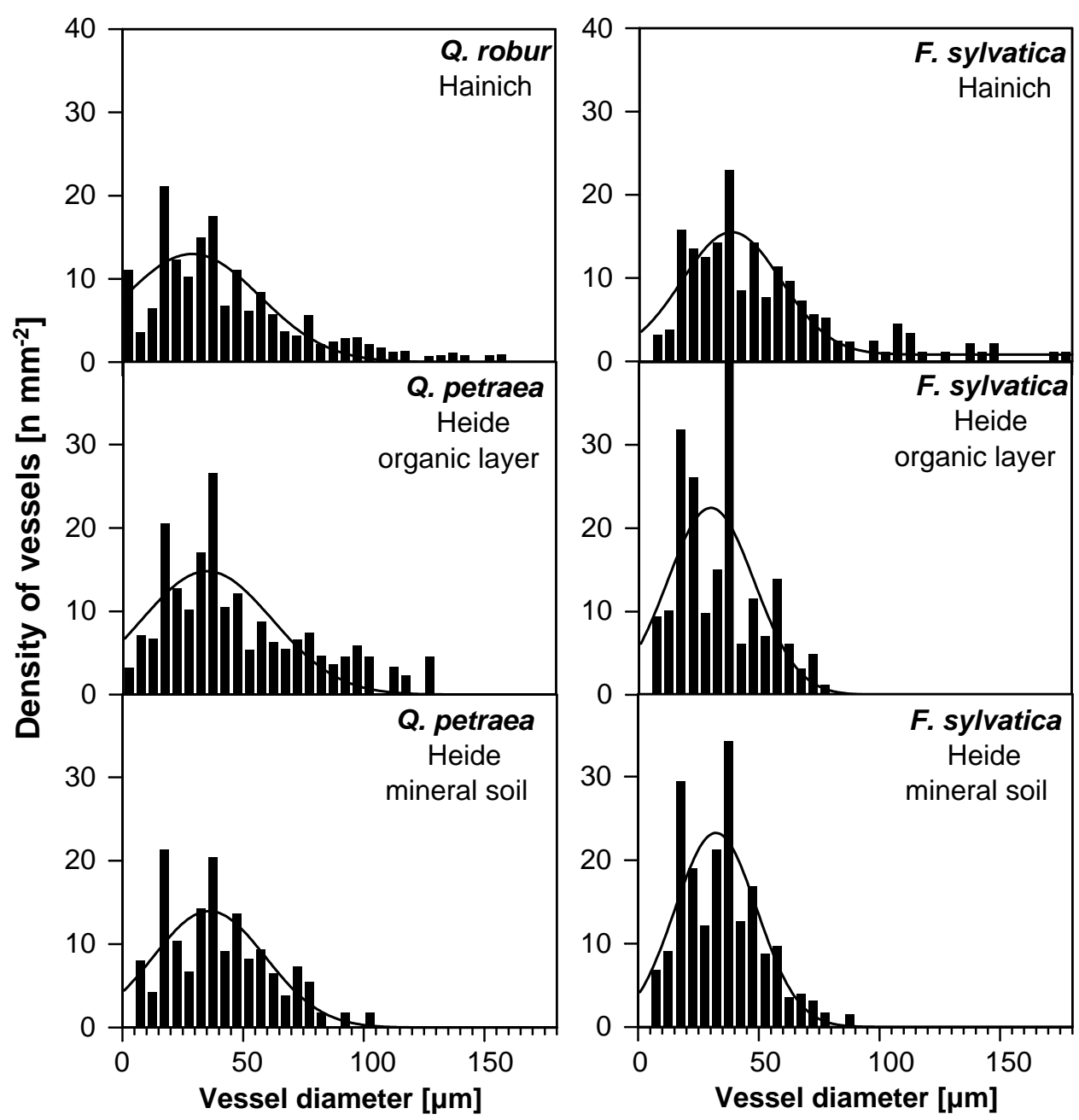

Abb. 4.39: Häufigkeitsverteilung der Xylemgefäße in Querschnitten von 3-4 mm starken Wurzeln von Eiche und Buche aus den Untersuchungsgebieten Hainich und Lüneburger Heide. Pro Baumart wurden 12-18 Wurzeln aus dem Hainich und 4-6 Wurzeln der organischen Auflage bzw. 2-4 Wurzeln des Mineralbodens der Lüneburger Heide untersucht, die nach Abschluss der Saftflussmessungen 2001 geerntet worden waren. 
beiden Untersuchungsflächen konnte eine Abnahme der Tageshellphasensumme ab Anfang September beobachtet werden.

Das VPD dagegen zeigte in den beiden Untersuchungsgebieten einen unterschiedlichen saisonalen Verlauf. Während im Hainich Ende Juli und Mitte August Perioden mit Maximalwerten über $25 \mathrm{hPa}$ erreicht wurden, konnte in der Lüneburger Heide nur Mitte Juli ein Maximum von $23.35 \mathrm{hPa}$ gemessen werden. Erst Anfang September überschritten die in der Lüneburger Heide gemessenen VPD-Werte diejenigen im Hainich.

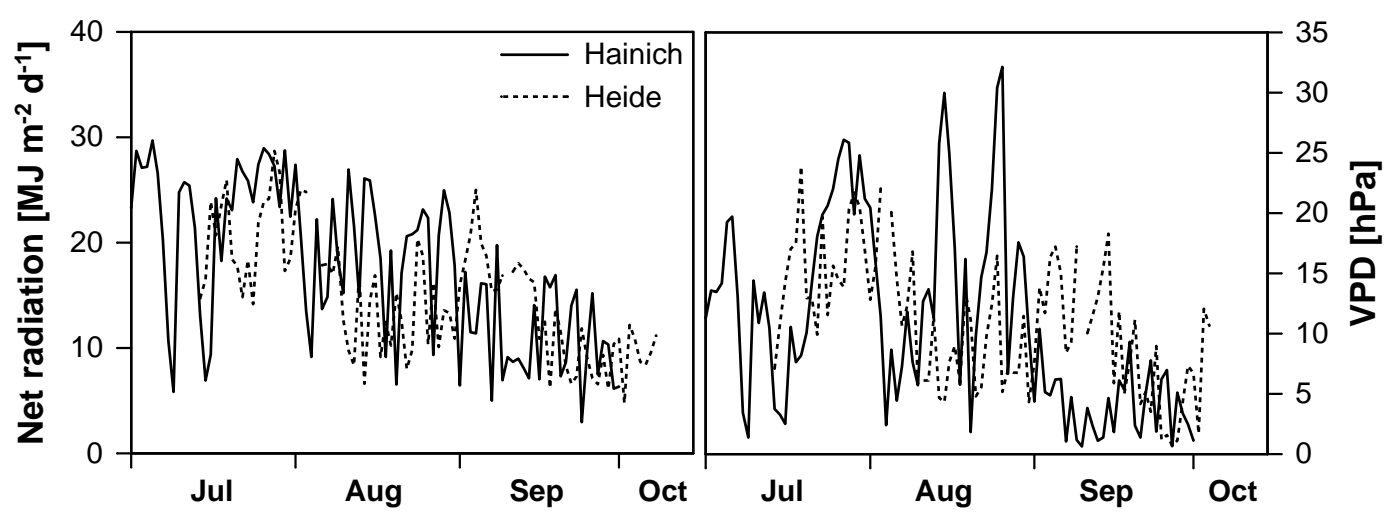

Abb. 4.40: Tageshellphasensummen der Strahlungsbilanz und Tageshellphasenmittelwerte des Wasserdampfsättigungsdefizit der Luft (VPD) während der Monate Juli bis Oktober 2001 im Hainich und in der Lüneburger Heide. Aufgenommen wurden die Werte auf einer Freifläche neben dem untersuchten Bestand im Hainich bzw. auf einem Messturm über dem Bestand in der Lüneburger Heide (Tageshellphase $=$ Globalstrahlung $>5 \mathrm{~J} \mathrm{~m}^{-2} \mathrm{~s}^{-1}$ ).

Die in der Lüneburger Heide aufgezeichneten Bodenwassergehalte der organischen Auflage und des Mineralbodens waren geringer als die Bodenwassergehalte des Hainich in $5 \mathrm{~cm}$ Bodentiefe (Abb. 4.41). Auf der Mischwaldfläche im Hainich schwankte während der hier betrachteten Messperiode der volumetrische Bodenwassergehalt nur wenig. Mitte Juli konnten 34.0 Vol.\% gemessen werden, in den folgenden Wochen sank der Bodenwassergehalt auf 27.7 Vol.\%. Im Buchenwald im Hainich wurde ab Ende Juli eine zunehmende Austrocknung aufgezeichnet. Der Bodenwassergehalt sank von 42.0 Vol.\% auf 25.8 Vol.\% Ende August. Mit einsetzenden Niederschlägen erfolgte im Anschluss eine Durchfeuchtung des Bodens mit ansteigenden Bodenwassergehalten.

In der Lüneburger Heide bestand beim Start der Messungen ein großer Unterschied zwischen den Bodenwassergehalten der organischen Auflage und des Mineralbodens. Im Verlaufe des August sank der Wassergehalt in der organischen Auflage von 28.8 auf 11.0 Vol.\%, im September stieg der Wassergehalt wieder auf die Ausgangswerte an. Im Mineralboden $(5 \mathrm{~cm}$ Bodentiefe) dagegen wurden im August schon viel niedrigere Bodenwassergehalte als im Hainich und in der organischen Auflage gemessen. Diese sanken von $12.0 \mathrm{Vol} . \%$ auf 9.1 Vol.\%; Ende August zeichnete sich ein erneuter Anstieg ab. 


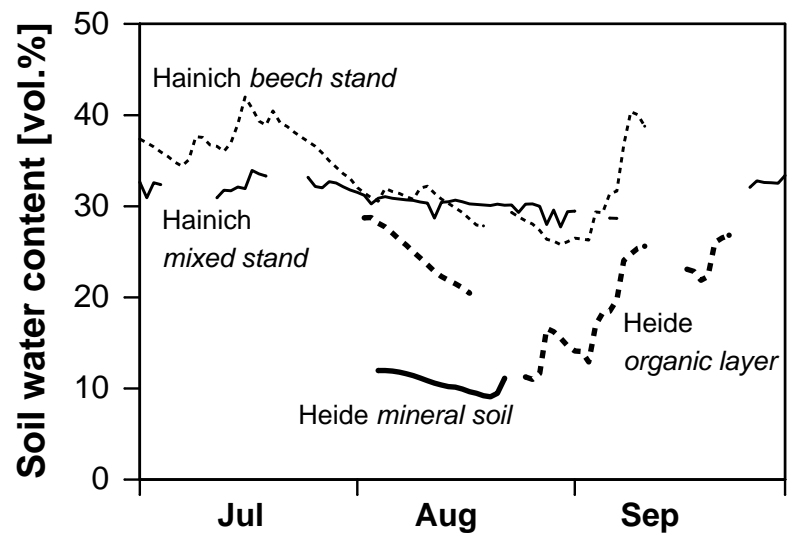

Abb. 4.41: Bodenwassergehalt auf den Untersuchungsflächen im Hainich (Misch- und Buchenwald) und der Lüneburger Heide (organische Auflage und Mineralboden) während des Untersuchungszeitraums im Jahr 2001. Die Werte wurden mittels TDR-Sonden in einer Bodentiefe von $5 \mathrm{~cm}$ aufgenommen. Dargestellt sind jeweils die Tagesmittelwerte zweier Sonden.

Für die Beziehung der Saftflussdichte der Baumarten Eiche und Buche in den beiden Beständen zu den Parametern Strahlungsbilanz, VPD und Bodenwassergehalt wurde für jede Wurzel der zugehörige Korrelationskoeffizient berechnet. In Tab. 4.12 sind jeweils die mittleren signifikanten Korrelationskoeffizienten $(\mathrm{p}<0.05)$ sowie die Anzahl der Wurzeln mit einer signifikanten Beziehung angegeben.

Tab. 4.12: Mittlere signifikante Korrelationskoeffizienten $(\mathrm{p}<0.05)$ der Abhängigkeit der Saftflussdichte der Wurzeln von Eiche und Buche im Hainich und in der Lüneburger Heide von der Strahlungsbilanz, dem Wasserdampfsättigungsdefizit der Luft (VPD) sowie dem volumetrischen Bodenwassergehalt. In die Analyse gingen je 15 Wurzeln pro Baumart aus dem Hainich ein, sowie 8 Wurzeln pro Baumart aus der Lüneburger Heide. Es wurden nur signifikante Beziehungen bei der Mittelung berücksichtigt.

\begin{tabular}{lc|cc|cc|cc}
\hline & & Net radiation & $\mathrm{n}$ & VPD & $\mathrm{n}$ & Soil water content & $\mathrm{n}$ \\
\hline Q. robur & Hainich & 0.65 & 12 & 0.56 & 11 & 0.44 & 6 \\
F. sylvatica & Hainich & 0.60 & 12 & 0.70 & 12 & 0.47 & 5 \\
Q. petraea & Heide & 0.70 & 6 & 0.79 & 6 & 0.72 & 3 \\
F. sylvatica & Heide & 0.69 & 7 & 0.74 & 7 & 0.71 & 3 \\
\hline
\end{tabular}

An beiden Standorten wurden Wurzeln gefunden, deren Saftflussdichte unabhängig von Strahlungsangebot, VPD oder Bodenwassergehalt variierte. Für maximal 12 von 15 Wurzeln im Hainich bzw. 6-7 von 8 Wurzeln in der Lüneburger Heide konnten signifikante Korrelationskoeffizienten für die Beziehung zu mindestens einem Parameter angegeben werden. Weniger als die Hälfte der Wurzeln wiesen jeweils eine signifikante Abhängigkeit von dem Boden- 
wassergehalt auf. Auch die meist niedrigeren Korrelationskoeffizienten wiesen auf einen nur geringen Einfluss des Bodenwassergehaltes hin. Nur für drei Wurzeln der Buche in der Lüneburger Heide war die Korrelation mit dem Bodenwassergehalt enger als mit der Strahlungsbilanz. Mit Ausnahme der Stieleiche war der mittlere Korrelationskoeffizient für die Beziehung der Saftflussdichte zum VPD höher als der Korrelationskoeffizient für die Strahlungsbilanz. Die Beziehung der in der Lüneburger Heide untersuchten Wurzeln zu den drei hier betrachteten Parametern war enger als die der vergleichbaren Arten im Hainich. Dies galt insbesondere für den Bodenwassergehalt.

\subsubsection{Wasserpotentiale}

Die Wasserpotentiale der Wurzeln wurden in der Lüneburger Heide an vier Terminen zur Mittagszeit (12-14 Uhr MESZ) an in der Auflage wachsenden Feinwurzelenden mit der Druckkammer-Methode nach Scholander bestimmt. In Abb. 4.42 sind die Wurzel-Wasserpotentiale von Eiche und Buche in den beiden Untersuchungsgebieten aufgetragen.
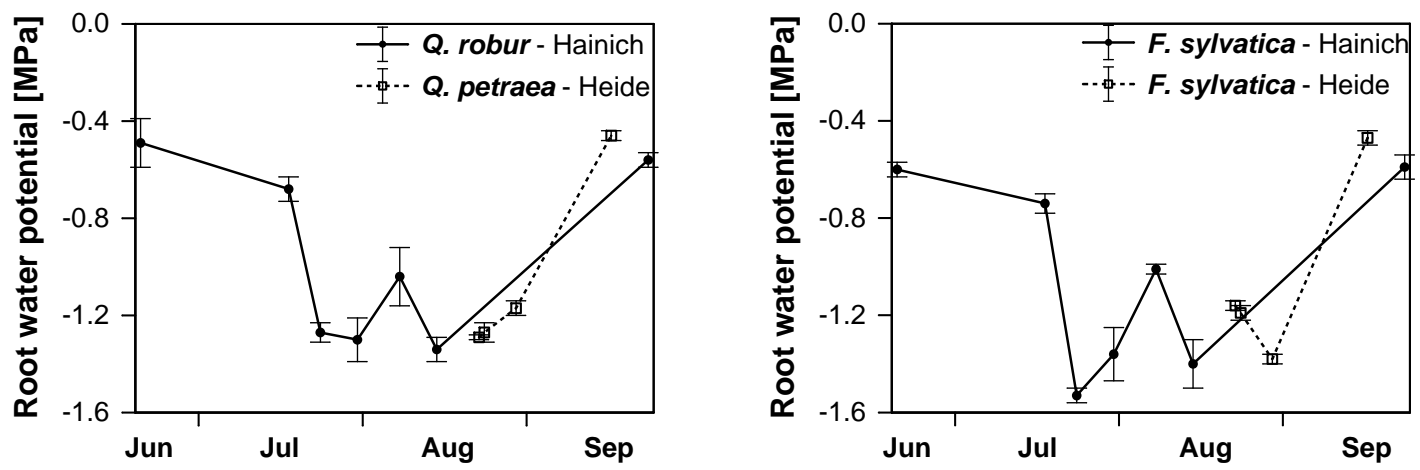

Abb. 4.42: Wurzel-Wasserpotentiale der Eiche (links) und Buche (rechts) im Hainich und der Lüneburger Heide. Gemessen wurden die Tagesminima an jeweils fünf Feinwurzelenden mit der Druckkammermethode nach Scholander an 7 Terminen im Hainich und 4 Terminen in der Lüneburger Heide zur Mittagszeit (12-14 Uhr MESZ) während der Vegetationsperiode 2001. Aufgetragen sind die Mittelwerte und Standardfehler.

Erst gegen Ende des Messzeitraumes liegen Daten aus der Lüneburger Heide vor, daher kann ein sommerliches Absinken des Wasserpotentials mit diesem Datensatz nicht belegt werden. Es lässt sich jedoch erkennen, dass die Wasserpotentiale in der Lüneburger Heide in derselben Größenordnung lagen wie die im Hainich. Die Stieleiche im Hainich erreichte als negativsten Wert -1.34 MPa am 15.8.2001. Bis Ende September stieg das Wasserpotential wieder auf $0.56 \mathrm{MPa}$ an. Im gleichen Zeitraum stieg das Wurzel-Wasserpotential der Traubeneiche in der Lüneburger Heide von -1.29 MPa (23.8.2001) auf -0.46 MPa. Damit war es höher als im Hainich, obwohl sehr viel geringere Bodenwassergehalte vorlagen. Ähnliches ließ sich für die Buche beobachten. Diese erreichte schon im Juli im Hainich ihr negativstes Wasserpotential 
mit -1.53 MPa. Während eines zweites Minimums Mitte August erniedrigte sich das WurzelWasserpotential auf -1.40 MPa. Bis Ende September stieg das Wasserpotential auf -0.59 MPa an. In der Lüneburger Heide sank das Wurzel-Wasserpotential der Buche Ende August von -1.19 MPa auf -1.38 MPa. Der Anstieg im September verlief etwas steiler als im Hainich auf -0.47 MPa. Zwischen den Baumarten eines Standortes ließ sich auch hier kein signifikanter Unterschied ermitteln.

In Abb. 4.43 sind die Wasserpotentiale und die Saftflussdichten der Wurzeln von Eiche und Buche im Hainich und der Lüneburger Heide gegeneinander aufgetragen. Besonders für die Eichen in der linken Abbildung ist deutlich zu erkennen, dass bei gleichem Wasserpotential die Saftflussdichte der Wurzeln in der Lüneburger Heide sehr viel geringer war als Hainich. Die Traubeneiche in der Lüneburger Heide erreichte bei einem Wasserpotential von -1.29 MPa im Mittel eine Saftflussdichte von $1.79 \mathrm{~g} \mathrm{~mm}^{-2} \mathrm{~d}^{-1}$. Im Vergleich dazu wurde an der Stieleiche im Hainich bei einem Wasserpotential von -1.30 MPa eine etwa 60\% höhere mittlere Saftflussdichte von $2.93 \mathrm{~g} \mathrm{~mm}^{-2} \mathrm{~d}^{-1}$ gemessen. Deutlich größer war die Differenz zwischen den Eichen in den beiden Untersuchungsgebieten bei weniger negativen Wasserpotentialen. Die Stieleiche im Hainich wies bei -0.49 MPa eine mittlere Saftflussdichte von $6.76 \mathrm{~g} \mathrm{~mm}^{-2} \mathrm{~d}^{-1}$ auf. In der Lüneburger Heide erreichten die Wurzeln der Traubeneiche bei einem Wasserpotential von -0.46 MPa dagegen lediglich $0.87 \mathrm{~g} \mathrm{~mm}^{-2} \mathrm{~d}^{-1}$. Während sich für die Stieleiche aus diesen Werten eine positive Beziehung zwischen Saftflussdichte und Wurzel-Wasserpotential andeutete, konnte für die Traubeneiche keine Beziehung aufgestellt werden.

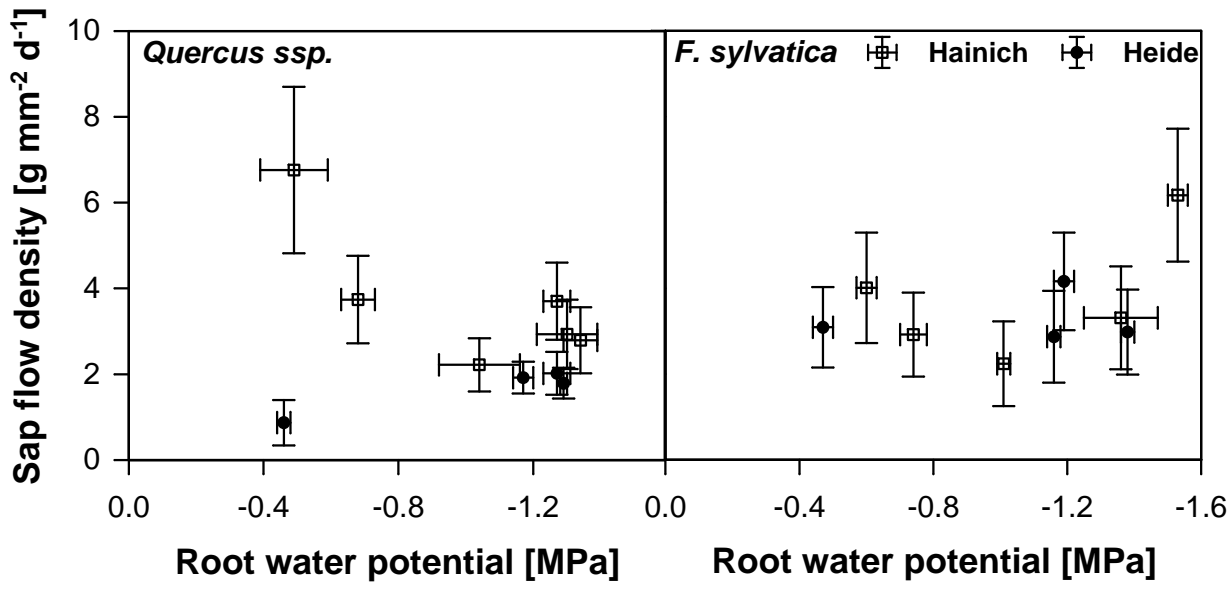

Abb. 4.43: Mittlere Tageswerte der Saftflussdichten von Eiche (links) und Buche (rechts) in Abhängigkeit von den Tagesminima des Wurzel-Wasserpotentials im Vergleich der beiden Untersuchungsflächen im Hainich (offene Symbole) und der Lüneburger Heide (gefüllte Symbole). Das Wasserpotential wurde an jeweils fünf Feinwurzelenden mit der Druckkammermethode nach Scholander bestimmt, die Saftflussdichten wurden an 9-14 Wurzeln aus dem Hainich und je 8 Wurzeln pro Baumart aus der Lüneburger Heide mit 3-4 mm Durchmesser mit dem Miniatur-Saftflussmesssystem ermittelt. Aufgetragen sind jeweils die Mittelwerte und Standardfehler. 
Die Saftflussdichten der Buche lagen auf beiden Untersuchungsflächen bei ähnlichen Wasserpotentialen in vergleichbarer Höhe. Das niedrigste Wurzel-Wasserpotential in der Lüneburger Heide lag bei $-1.38 \mathrm{MPa}$, die Saftflussdichte zu diesem Zeitpunkt bei $2.98 \mathrm{~g} \mathrm{~mm}^{-2} \mathrm{~d}^{-1}$. Im Hainich wurden bei einem Wasserpotential von -1.36 MPa Saftflussdichten von $3.31 \mathrm{~g} \mathrm{~mm}^{-2}$ $\mathrm{d}^{-1}$ gemessen. Auch bei einer entspannten Wasserhaushaltssituation, also weniger negativen Wasserpotentialen von -0.47 MPa in der Lüneburger Heide bzw. -0.60 MPa im Hainich, gab es keine Unterschiede zwischen den Saftflussdichten, die im Hainich bei $4.01 \mathrm{~g} \mathrm{~mm}^{-2} \mathrm{~d}^{-1}$ und in der Lüneburger Heide bei $3.09 \mathrm{~g} \mathrm{~mm}^{-2} \mathrm{~d}^{-1}$ lagen. Während für die Buche im Hainich ein sich andeutender negativer Zusammenhang zwischen Saftflussdichte und Wurzel-Wasserpotential angenommen werden kann, ist keine Beziehung dieser beiden Parameter für die Buchenwurzeln der Lüneburger Heide feststellbar.

\subsection{Wasseraufnahme von Eichen- und Buchenwurzeln bei Wiederbewässerung nach Austrocknung des Bodens}

Während einer niederschlagsfreien Periode von 5-12 Tagen (je nach Bewässerungszeitpunkt) mit einem Wasserdampfsättigungsdefizit der Luft von bis zu $15 \mathrm{hPa}$ wurden vier Wurzeln der Stieleiche und drei Wurzeln der Buche im Hainich künstlich mit $10 \mathrm{~mm}$ Niederschlag bewässert. Die Tagesgänge der Stieleichen sind in der Abb. 4.44 dargestellt, die der Buchen in Abb. 4.45. Aufgetragen sind jeweils die Saftflussdichten an drei Tagen während der Austrocknungsphase, der Tagesgang während der Bewässerung sowie der folgenden drei Tage. Zusätzlich sind die entsprechenden Tagesgänge von unbewässerten Kontrollwurzeln der gleichen Baumindividuen aufgetragen.

Zeitgleich wurde in unmittelbarer Nähe der bewässerten Wurzeln und der Kontrollwurzeln mit mini-TDR-Sonden der Bodenwassergehalt aufgezeichnet. Dieser ist ebenfalls in den Abbildungen aufgetragen. Die neben bewässerten Wurzeln installierten TDR-Sonden zeigten nach dem Beginn der Bewässerung eine Zunahme des Bodenwassergehaltes um 20\% bis zu 72\% gegenüber den Vortagen. Die in der Nähe unbewässerter Wurzeln aufgenommenen Bodenwassergehalte dagegen zeigten meist konstante oder abnehmende Werte.

Die Bewässerung hatte auf die einzelnen Wurzeln unterschiedliche Auswirkungen. Besonders deutlich zeigte sich ein sofortiger Anstieg der Saftflussdichte in den Wurzeln Ei45.8 und Ei45.9 der Stieleiche. Die Saftflussdichte erhöhte sich nach dem Beginn der Bewässerung um $58 \%$ bis 134\%, gemessen an den Maxima der Saftflussdichten der vorausgehenden Tage.

Eine Auswirkung auf die Saftflussdichten der folgenden Tage hatte die künstliche Bewässerung nur in wenigen Fällen, da die ausgebrachte Wassermenge zu gering war, um eine erneute Austrocknung des Bodens zu verhindern. Dies zeigten die Bodenwassergehalte der bewässerten Plots, die meist am folgenden Tag wieder das Niveau vor der Bewässerung erreichten.

Auch die Wurzeln der Buche reagierten mit einem kaum verzögerten Anstieg der Saftfluss- 

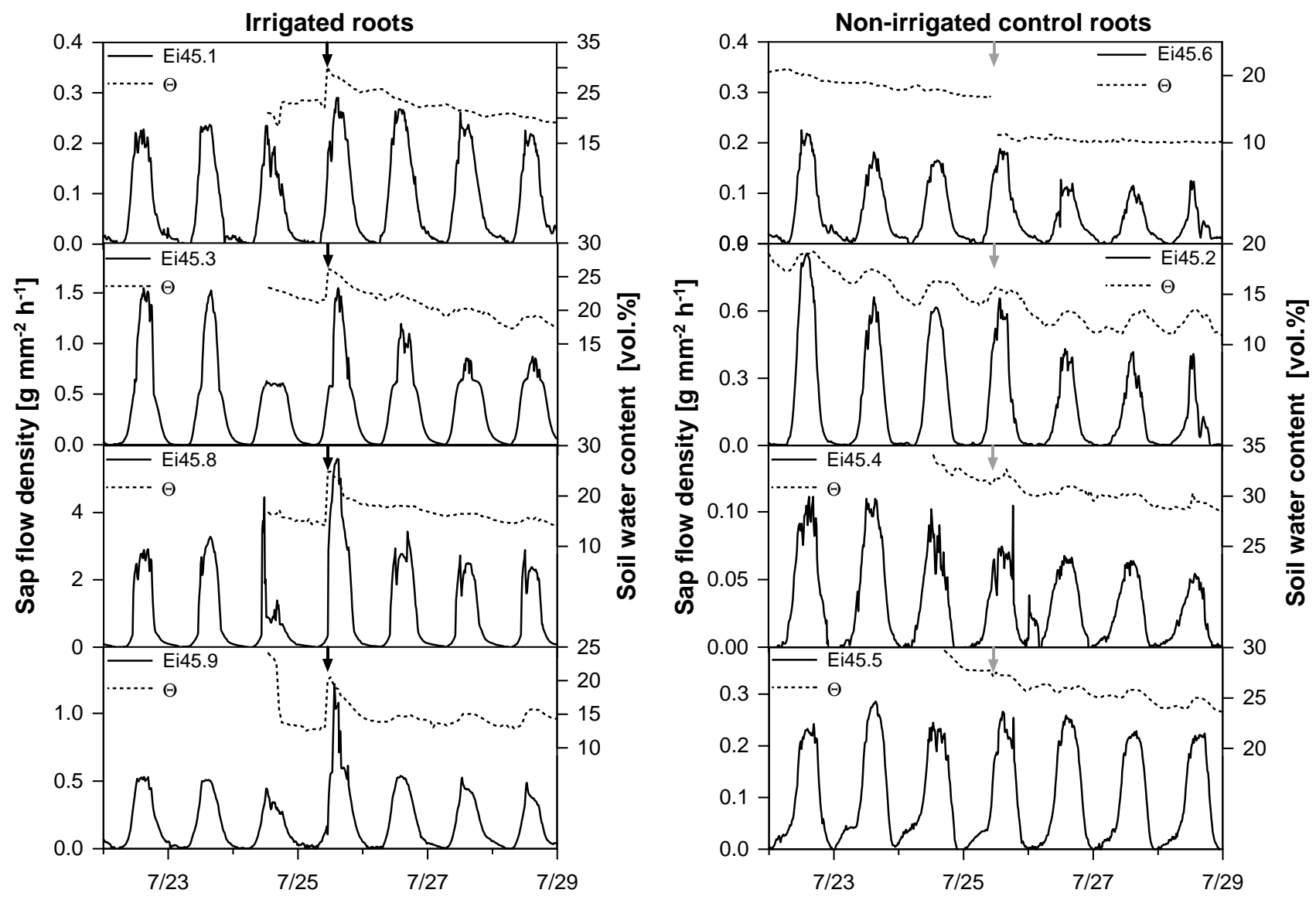

Abb. 4.44: Tagesgänge der Saftflussdichten vor und nach der Bewässerung von Wurzeln der Stieleiche im Nationalpark Hainich. Bewässert wurde mit $10 \mathrm{~mm}$ Niederschlag über ca. 30 Minuten am 25.07.2001. Die Saftflussdichten wurden mit der Miniatur-Saftflussmethode gemessen. Der Bodenwassergehalt wurde mit mini-TDR-Sonden stündlich automatisch aufgezeichnet. Rechts sind die Tagesgänge der Saftflussdichten unbewässerter Kontrollwurzeln aufgetragen. Die Graphen sind unterschiedlich skaliert. 

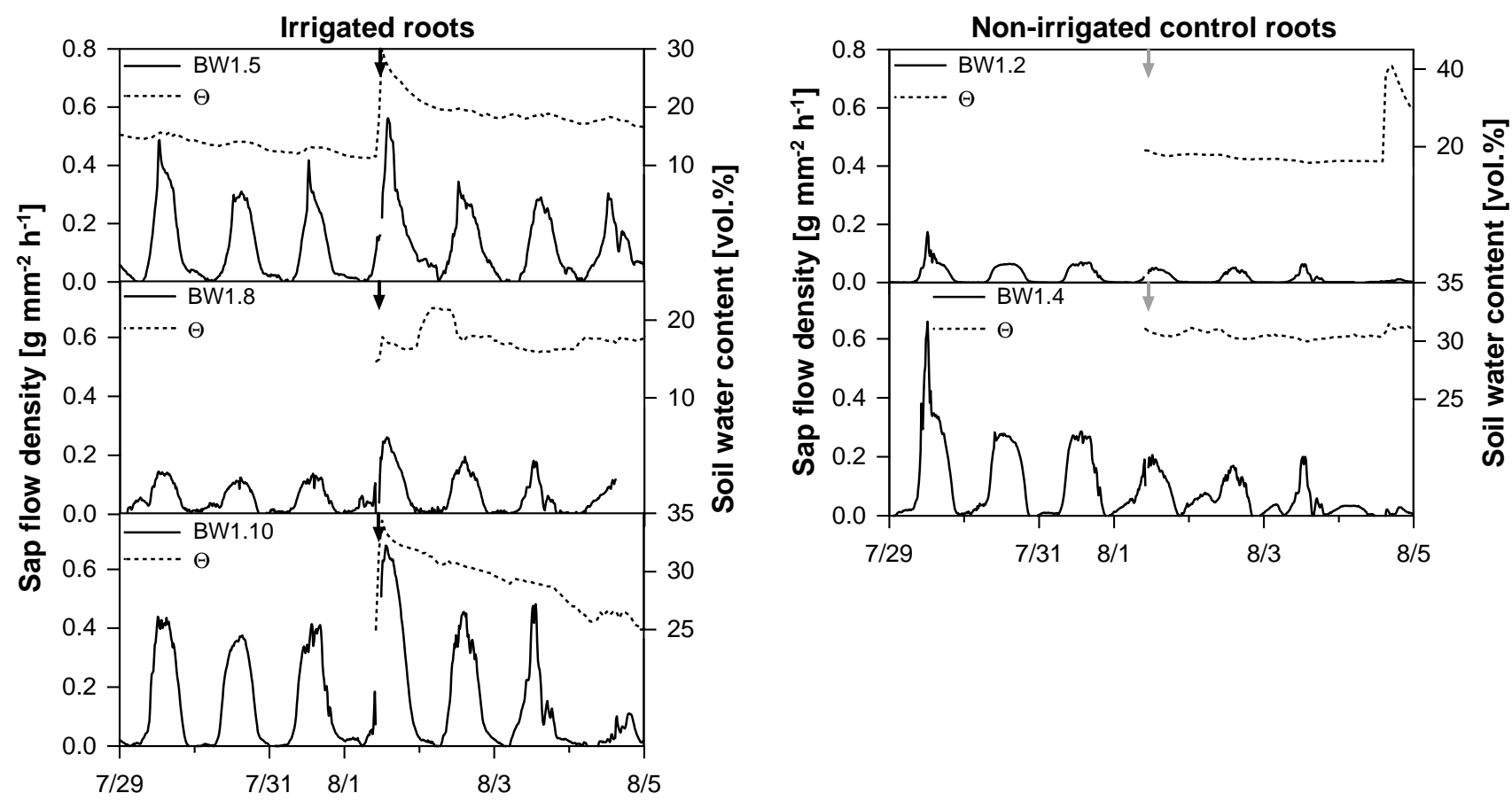

Abb. 4.45: Tagesgänge der Saftflussdichten vor und nach der Bewässerung von Wurzeln der Buche im Nationalpark Hainich. Bewässert wurde mit $10 \mathrm{~mm}$ Niederschlag über ca. 30 Minuten am 01.08.2001. Die Saftflussdichten wurden mit der Miniatur-Saftflussmethode gemessen. Der Bodenwassergehalt wurde mit mini-TDR-Sonden stündlich automatisch aufgezeichnet. Rechts sind die Tagesgänge der Saftflussdichten unbewässerter Kontrollwurzeln aufgetragen. Die Graphen sind unterschiedlich skaliert.

dichte auf die Bewässerung. Der Wurzelstrang BW1.5 verlief zu einem Teil außerhalb der bewässerten Fläche, so dass trotz eines starken Anstiegs des Bodenwassergehaltes nur eine Steigerung der Saftflussdichte um 39\% gemessen wurde. Die Saftflussdichte der Wurzeln BW1.8 und BW1.10 dagegen nahm um 93\% bzw. 66\% gegenüber den Vortagen zu. Die Bewässerung wirkte sich auch in den folgenden Tage durch erhöhte Saftflussdichten aus. Während sich die Saftflussdichten der unbewässerten Kontrollwurzeln weiter verringerten (Absinken um bis zu 30\%), hielten sich die Flussdichten der bewässerten Wurzeln etwa auf demselben Niveau. 


\section{Diskussion}

\subsection{Wasseraufnahme und Saftfluss in Wurzeln}

\subsubsection{Zur Theorie der Wasseraufnahme und des Saftflusses}

Die Wasseraufnahme über die Wurzeln einer Pflanze ist nur ein Teilaspekt des Wasserstroms durch die ganze Pflanze. Dabei wird Wasser vom Boden bis zur umgebenden Luft durch das Gefäßsystem der Pflanze transportiert. In diesem Zusammenhang wird von einem "soilplant-atmosphere-continuum" (SPAC) gesprochen (z.B. LÖSCH, 2001). Der Fluss des Wassers durch die Pflanze kann durch eine allgemeine Flussgleichung beschrieben werden, die analog zu dem Ohmschen Gesetz des elektrischen Stromflusses formuliert werden kann:

$$
\text { Fluss }=\frac{\text { Potentialgradient } \Delta \Psi}{\sum \text { Transportwiderstände } R}
$$

Zwischen Boden und Atmosphäre besteht ein steiler Potentialgradient, entlang dessen das Wasser zum jeweils niedrigeren Wasserpotential geleitet wird. Mit der Verdunstung des Wassers von der Mesophyllzellenoberfläche im Blatt entwickelt sich ein Wasserdefizit, das sich bis in das Wurzelsystem fortsetzt. Liegt auch dort schließlich ein ausreichend hoher Potentialgradient gegenüber der Rhizosphäre vor, wird Wasser aus dem Boden aufgenommen.

Im Boden beeinflussen die Nachleitfähigkeit und der Widerstand an der Grenzfläche zur Wurzel (Rhizosphäre) die Wasseraufnahme.

Gegenüber den Befürwortern dieser Theorie (z.B. MILBURN, 1996, STEUdLE, 1995, ZIMMERMANN \& TYREE, 2002) stehen jedoch Kritiker. So diskutieren z.B. ZIMMERMANN et al. (2002) verschiedene Mechanismen, die neben der Spannung durch den Wasserpotentialgradienten den Fluss des Wassers durch die Pflanze antreiben. Die Autoren beschreiben als solche alternativen Mechanismen einen durch osmotischen Druck angetriebenen Wassertransport vergleichbar dem Wurzeldruck. Dieser osmotische Druck wird hervorgerufen durch eine Segmentierung des axialen Wassertransportweges hervorgerufen, in dem die Querwände der Xylemelemente als semipermeable Barrieren fungieren. Weiterhin wird die MaragoniStrömung angeführt, die die Restleitfähigkeit cavitierter Xylemelemente beschreibt. Ferner werden elektrische treibende Kräfte des Wassertransportes angesprochen, die sich aus dem trans-root Potential ergeben. Das trans-root Potential beschreibt eine elektrische Potentialdifferenz zwischen dem Xylem und einem externen Medium (auch WEGNER \& ZIMMERMANN, 1998). 
Der hydraulische Gesamtwiderstand der Pflanze im SPAC setzt sich aus einer Reihe unterschiedlich großer Teilwiderstände zusammen. Die in dieser Arbeit hauptsächlich betrachteten Kompartimente betreffen den Übergang des Wassers vom Boden in die Wurzel und die Weiterleitung im Xylem.

Die hydraulische Leitfähigkeit in der Wurzel setzt sich aus einem radialen und einem axialen Anteil zusammen (MELCHIOR \& STEUDLE, 1993). Die axiale hydraulische Leitfähigkeit beschreibt die Wasserleitung im Xylem der Wurzel. Diese nimmt entlang der Wurzelachse in Richtung auf dickere Wurzeln zu (ZIMMERMANN \& TYREE, 2002). Im primären Xylem der Wurzelspitze ist der Wasserfluss durch Querwände in den Gefäßen behindert (MELCHIOR \& STEUDLE, 1993), wodurch sich der Fließwiderstand erhöht.

Die radiale Leitfähigkeit der Wurzeln bestimmt den Wasserfluss von der Wurzelrinde bzw. -oberfläche durch Cortex, Endodermis oder Periderm in das Xylem. Hier scheint der entscheidende limitierende Faktor für die Wasseraufnahme der Wurzel zu liegen (z.B. STEUDLE, 1994, PASSIOURA, 1988, ZIMMERMANN \& TYREE, 2002). Durch welche Faktoren die radiale Leitfähigkeit gesteuert wird, ist noch nicht abschließend geklärt. Hierbei spielt die Identifizierung des radialen Transportweges des Wassers eine entscheidende Rolle.

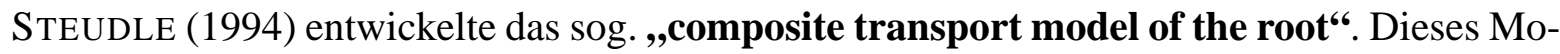
dell berücksichtigt, dass der Wassertransport von der Wurzeloberfläche zum Xylem parallel auf einem apoplastischen und einem zellulären Transportweg erfolgen kann.

Entsteht durch die Transpiration ein hydrostatischer Druckgradient zwischen Boden und Wurzelxylem, kann die Wasseraufnahme über den apoplastischen Weg erhöht werden, mit einer entsprechenden Steigerung der hydraulischen Leitfähigkeit. Bei geringem Fluss ist der hydraulische Widerstand hoch, der zelluläre Weg dominiert, angetrieben durch einen osmotischen Druckgradienten. Dadurch wird ein Wasserverlust an den trockenen Boden verhindert. Demnach ist die Wurzel in der Lage, die Wasseraufnahme an den Wasserbedarf des Sprosses anzupassen.

Neben der Anpassung der hydraulischen Wurzelleitfähigkeit an langanhaltende Veränderungen der Umweltbedingungen in Form von Veränderungen in der Wurzelanatomie durch Suberinisierung der Zellen, sind Pflanzenwurzeln in der Lage, innerhalb von wenigen Tagen die hydraulische Leitfähigkeit zu ändern (JAVOT \& MAUREL, 2002). In diesem Zusammenhang steht die Entdeckung von integralen Membranproteinen sowohl in pflanzlichen als auch in tierischen Zellen, die die Passage von Wasser regulieren. Diese Proteine werden als Aquaporine bezeichnet. Sie stellen wasserspezifische transmembrane Transportkanäle dar, die hochselektiv den Wassertransport von Zelle zu Zelle regulieren (CHRISPEELS \& MAUREL, 1994). In Pflanzen können Aquaporine in vielen verschiedenen Formen exprimiert werden. In nahezu allen Zelltypen wurden Aquaporine gefunden (JAVOT \& MAUREL, 2002). Vermehrt kommen Aquaporine jedoch dort vor, wo entweder eine rasche Zellteilung und -streckung ermöglicht werden muss oder wo ein starker Wasserfluss stattfindet (TYERMAN et al., 2002). Somit bilden die Aquaporine einen wichtigen Faktor in der Regulation und Kontrolle des radialen Wasser- 
flusses in der Wurzel.

Aufgrund der Vielzahl an Formen, in denen Aquaporine in pflanzlichen Geweben auftreten können, ist das Verständnis der genauen Funktion dieser Wassertransportkanäle in Bezug auf die hydraulische Leitfähigkeit der Pflanze bisher noch unvollständig. Bisher liegen von verschiedenen Autoren Hinweise auf die Funktion einiger Aquaporin-Isoformen vor, die Rückschlüsse darauf zulassen, dass diese multifunktionalen Kanäle für bis zu 30\% der hydraulischen Leitfähigkeit von Opuntienwurzeln und sogar bis zu 90\% der Leitfähigkeit von Gerstenwurzeln verantwortlich sind (JAVOT \& MAUREL, 2002).

\subsubsection{Variabilität der Wurzel-Wasseraufnahmeraten}

Während Messungen der Stamm-Saftflussraten von Bäumen schon seit langem durchgeführt werden, liegen über Flussraten in Wurzeln bisher nur wenige Zahlen vor. In Tab. 5.1 ist eine Auswahl bisher publizierter Daten aufgelistet.

Bis auf wenige Ausnahmen fanden die meisten Untersuchungen an Grob- oder Starkwurzeln mit Durchmessern über $10 \mathrm{~mm}$ statt. Sie beschränken sich zudem meist auf wirtschaftlich genutzte Baumarten (Apfel, Ölbaum, Kiwi), die in Plantagen angepflanzt und über Beregnungssysteme künstlich bewässert wurden.

Die angegebenen maximalen Saftflussdichten variieren zwischen 0.004 und $3.36 \mathrm{~g} \mathrm{~mm}^{-2}$ $\mathrm{h}^{-1}$. Allerdings lässt sich feststellen, dass die Saftflussdichten der Starkwurzeln (Durchmesser $>20 \mathrm{~mm}$ ) trotz großer Unterschiede in den Durchmessern (von 21 bis $76 \mathrm{~mm}$ ) und verschiedener Baumarten relativ ähnlich waren. Eine Ausnahme bilden Wurzeln mit einem Durchmesser über $90 \mathrm{~mm}$ von Juglans major und Pyrus communis, die um ein vielfaches geringere maximale Saftflussdichten aufwiesen.

Dagegen wurde bei Messungen an Schwachwurzeln (Durchmesser $<5 \mathrm{~mm}$ ) trotz der geringeren Durchmesservariation eine weite Spanne an maximalen Saftflussdichten angegeben, die zwischen 0.25 und $3.36 \mathrm{~g} \mathrm{~mm}^{-2} \mathrm{~h}^{-1}$ schwanken. Selbst bei ausschließlicher Berücksichtigung von mitteleuropäischen Baumarten finden sich bis zu einen Faktor fünf voneinander abweichende Wasseraufnahmeraten.

In Abb. 5.1 sind die Wurzeldurchmesser und die maximalen stündlichen Saftflussraten der verschiedenen Baumarten aus Tab. 5.1 gegeneinander aufgetragen.

Zwischen diesen beiden Parametern ergibt sich eine signifikant negative Korrelation ( $\mathrm{r}=-0.52$, $\mathrm{p}=0.006$ ). Mit zunehmendem Wurzeldurchmesser verringert sich die Saftflussdichte in diesen Wurzeln. Betrachtet man jedoch allein die Klasse der Schwach- und Derbwurzeln mit Durchmessern unter $5 \mathrm{~mm}$, ergibt sich kein Zusammenhang zwischen Wurzeldurchmesser und maximaler Saftflussdichte $(\mathrm{r}=0.23, \mathrm{p}=0.50)$. $\mathrm{Zu}$ beachten ist besonders bei den Wurzeln mit großen Durchmessern, dass sich der Anteil an hydropassivem also nicht-wasserleitendem Gewebe (Periderm, Bast) erhöht, daher wurde bei allen Angaben, sofern möglich, die Saftflussdichte auf die Xylemfläche bezogen.

Die Saftflussdichte verschiedener Wurzeln einer Baumart und sogar eines Individuums kann in sehr hohem Maße variieren. Dies zeigen die in der vorliegenden Arbeit gemessenen Saftflussraten von Wurzeln, die unmittelbar benachbart verliefen und damit keinen oder nur sehr 
Tab. 5.1: Vergleich der von verschiedenen Autoren gemessenen maximalen Saftflussdichten (auf die Querschnittsfläche am Messpunkt bezogene Saftflussrate) in Grob- und Schwachwurzeln von Bäumen.

\begin{tabular}{|c|c|c|c|}
\hline Author & Tree species & $\begin{array}{l}\text { Root diameter } \\
{[\mathrm{mm}]}\end{array}$ & $\begin{array}{l}\text { Max. sap flow density } \\
{\left[\mathrm{g} \mathrm{mm}^{-2} \mathrm{~h}^{-1}\right]}\end{array}$ \\
\hline CABIBEL \& DO $(\overline{1991 a})$ & Malus spec. & 23 & 0.22 \\
\hline $\begin{array}{lll}\text { GREEN \& } & \text { CLOTHIER } \\
(1995) & & \end{array}$ & Acinidia deliciosa & $23-32$ & 0.31 \\
\hline $\begin{array}{|lll|}\text { GREEN } & \& & \text { CLOTHIER } \\
(1999) & & \\
\end{array}$ & Malus domestica & $21 / 38$ & $0.36 / 0.11$ \\
\hline GREEN et al. (2003) & Malus domestica & $43 / 56$ & $0.41 / 0.29$ \\
\hline HulTiNE et al. (2003) & Juglans major & $90 / 67 / 91$ & $0.004 / 0.014 / 0.008$ \\
\hline KANG et al. $(2003)$ & Pyrus communis & 111.3/105.9 & $0.064 / 0.062$ \\
\hline MORENO et al. (1996) & Olea europaea & 68.8 & 0.32 \\
\hline ONG \& KHAN (1993) & Croton melagocarpus & 76 & 0.33 \\
\hline GREEN et al. (1997) & Malus domestica & $19 / 21$ & $\begin{array}{c}0.25 / 0.23 \\
0.42 / 0.29 \text { (bewässert) }\end{array}$ \\
\hline $\mathrm{KoCH}(2002)$ & Fagus sylvatica & 8.8 & 1.1 \\
\hline 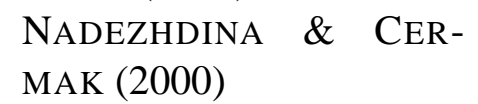 & Picea abies & k.A. & 0.03 \\
\hline & Tilia cordata & k.A. & 0.05 \\
\hline $\begin{array}{l}\text { SENOCK \& LEUSCHNER } \\
(1999)\end{array}$ & Eucalyptus saligna & $2-5$ & 3.36 \\
\hline $\begin{array}{l}\text { CONERS \& LEUSCHNER } \\
(2002)\end{array}$ & Fagus sylvatica & $3-4$ & $0.48-0.64$ \\
\hline ICKE $(2000)$ & $\begin{array}{l}\text { Fagus sylvatica } \\
\text { Quercus petraea }\end{array}$ & $\begin{array}{l}2.9-4.3 \\
3.0-4.7\end{array}$ & $\begin{array}{l}0.35 \\
0.25\end{array}$ \\
\hline This study & $\begin{array}{c}\text { Acer pseudoplatanus } \\
\text { Fraxinus excelsior } \\
\text { Tilia cordata } \\
\text { Carpinus betulus } \\
\text { Quercus robur } \\
\text { Fagus sylvatica }\end{array}$ & $\begin{array}{l}2.6 \\
3.0 \\
2.9 \\
3.0 \\
2.8 \\
3.4\end{array}$ & $\begin{array}{l}0.80 \\
0.97 \\
1.15 \\
0.84 \\
1.30 \\
0.95\end{array}$ \\
\hline
\end{tabular}




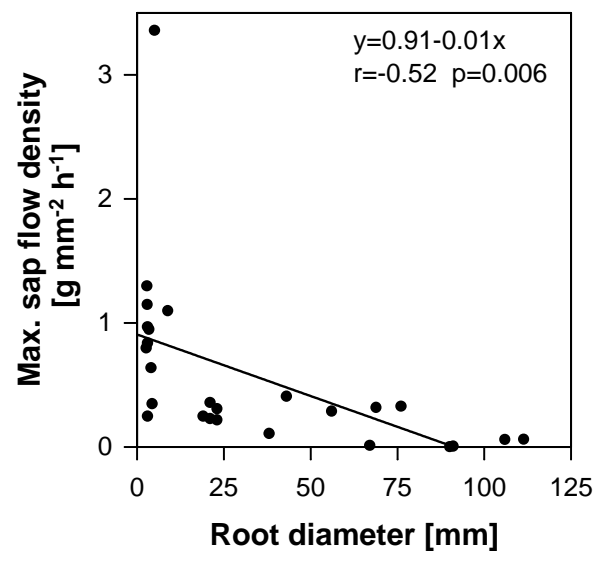

Abb. 5.1: Beziehung zwischen dem Wurzeldurchmesser und der maximalen Saftflussdichte (stündlich), entnommen aus verschiedenen Literaturstellen (siehe Tab. 5.1).

geringfügigen Unterschieden in der Bodenstruktur und der Bodenfeuchte ausgesetzt waren. Es ergaben sich sowohl für die Saftflussdichte als auch die oberflächenspezifische Wasseraufnahmerate sehr hohe Variationskoeffizienten (Bergahorn 168\%, Esche 111\%, Linde 131\%, Hainbuche 110\%, Buche 109\% und Stieleiche 115\%). Die Höhe der Variation war unabhängig von der Höhe der Wasseraufnahme.

Eine solch hohe Variabilität ist auch von anderen Untersuchungen des Wurzelsaftflusses bekannt. Mit derselben Miniatur-Saftflussmethode konnten LEUSCHNER et al. (2004) für die Wasseraufnahme von jeweils 4-6 Buchen- und Eichenwurzeln Variationskoeffizienten bis zu 150\% feststellen, die Saftflussdichte konnte bei zeitgleicher Messung bis zu zehnfach zwischen den einzelnen Wurzeln variieren. Durch aufwändige Tensiometermessungen (LEUSCHNER, 1994b) konnten kleinräumige Variationen der Bodenfeuchte als Ursache ausgeschlossen werden.

Auch GREEN \& CLOTHIER (1999) berichten von stark unterschiedlichen Saftflussraten in einander ähnlichen Wurzeln. Die von ihnen genannten Parameter Wurzeldurchmesser, Lokalisierung der Wurzeln im Boden und Wurzeldichte, die diese Differenzen erklären sollen, treffen für die Ergebnisse der vorliegenden Untersuchung nur bedingt zu. Alle Wurzeln hatten am Messabschnitt denselben Durchmesser, lagen in sehr enger Nachbarschaft und unterschieden sich im Alter nicht voneinander.

Da jedoch viele der Untersuchungen nur mit einer geringen Parallelenzahl durchgeführt wurden, fehlen nähere Angaben zur intraspezifischen Variabilität der Saftflussraten in anderen Wäldern.

Bei gleichmäßig feuchtem Boden findet die Wasseraufnahme der Bäume oberflächennah (bis in $100 \mathrm{~cm}$ Tiefe) statt. Sowohl GREEN \& CLOTHIER (1995) als auch GREEN et al. (1997) stellten an Apfelbäumen fest, dass oberflächennahe Wurzeln eine bevorzugte Rolle bei der Wasseraufnahme spielen. Sie beobachteten, dass Wurzeln aus tieferen Horizonten die Wasseraufnahme einstellten, sobald oberflächennahe Wurzeln aufgrund von wiedereinsetzender Be- 
wässerung die Wasseraufnahmerate steigerten. Obwohl in den tieferen Bodenhorizonten das Bodenmatrixpotential mit Bewässerung des Bodens wieder anstieg, konnte dort keine Steigerung der Wasseraufnahmerate festgestellt werden. RAMBAL (1984) fand bei der Untersuchung der Wasseraufnahme immergrüner Eichen (Quercus coccifera) ebenfalls mit einer zunehmenden Bodenaustrocknung eine Zunahme der Wasseraufnahme in tieferen Bodenschichten, allerdings erst in 300-400 cm Tiefe. CONERS (2001) konnte ebenfalls bei der Untersuchung der Wasseraufnahme von Feinwurzeln im Mitteldeutschen Trockengebiet eine Verschiebung des Wasseraufnahme zu tiefreichenden Wurzeln bei der Austrocknung des Oberbodens beobachten.

In der vorliegenden Arbeit wurden für die Untersuchung der Wasseraufnahme oberflächennah verlaufende Wurzelstränge ausgewählt, um Differenzen durch unterschiedliche Aufnahmemuster zwischen Tiefen- und Oberflächenwurzeln auszuschließen.

\subsection{Interspezifische Variabilität von sechs Baumarten hinsichtlich der Wasseraufnahme}

Für die Untersuchung wurden Baumarten ausgewählt, die sich in ihren Standort- und Wasserversorgungsansprüchen unterscheiden. Daher können zwischen den Baumarten differierende Wasseraufnahmeraten sowie differierende Reaktionen auf natürlich auftretende Trockenperioden vermutet werden.

In zahlreichen Untersuchungen werden die Baumarten hinsichtlich ihres Wasserhaushaltes in trockenheitstolerante und dürreempfindliche Baumarten eingeteilt. Diese Unterscheidung beruht meist auf Messungen der Transpiration, Stamm-Saftflussdichte oder Blattleitfähigkeit. Nur wenige Studien an mitteleuropäischen Baumarten beziehen direkt gemessene WurzelWasseraufnahmeraten in die Betrachtung der Trockenheitstoleranz mit ein.

Im folgenden sollen die untersuchten Baumarten kurz nach Literaturangaben hinsichtlich Trockenheitstoleranz, Saftflussraten bzw. Transpirationsraten charakterisiert werden.

Der Bergahorn wird mit der Hainbuche und der Buche zu den Baumarten gezählt, die nur gering dürreertragend sind (ELLENBERG, 1996). Die hohen Feuchtigkeitsansprüche des Bergahorns resultieren nach WIERSUM \& HARMANNY (1983) in einer eingeschränkten Permeabilität der Wurzeln für Wasser durch eine fortschreitende Suberinisierung der Wurzelspitze. Dies konnte durch die anatomischen Untersuchungen in der vorliegenden Arbeit nicht bestätigt werden. Das Periderm war in der Nähe der Wurzelspitze ähnlich, in größerer Entfernung sogar deutlich geringmächtiger ausgebildet als bei den anderen untersuchten Arten. Auf Flächen mit uneingeschränkter Wasserverfügbarkeit kann der Bergahorn sehr hohe Transpirationsraten erreichen (LEMOINE et al. 2001). Als maximale Transpirationsrate wird für den Bergahorn dagegen von LADEFOGED (1963) an Strahlungstagen und bei guter Wasserversorgung lediglich $0.5 \mathrm{ld}^{-1} \mathrm{~m}^{-2}$ Blattfläche angegeben. Im gleichen Bestand konnten für die Esche und die Eiche die dreifache Transpirationsrate gemessen werden. Der Bergahorn zeigte in einer Untersuchung von SCHMITT (1999) starke Beeinträchtigungen durch Trockenstress, 
sowohl in morphologischen als auch physiologischen Parametern wie Photosyntheseleistung und Blattleitfähigkeit.

Im Hainich wurde an denselben Bäumen, an denen die Wurzel-Wasseraufnahme gemessen wurde auch der Stammsaftfluss registriert (HÖLSCHER et al., 2004). Für Bergahorn betrug die mittlere Flussdichte im Stamm $102 \mathrm{~g} \mathrm{~cm}^{-2} \mathrm{~d}^{-1}$, während sie in den Wurzeln mit $275 \mathrm{~g} \mathrm{~cm}^{-2}$ $\mathrm{d}^{-1}$ fast das dreifache betrug.

Die Esche gilt im Gegensatz zum Bergahorn als tolerant in Bezug auf Trockenstress (CARLIER et al., 1992, RUST \& S AVILL, 2000, AUSSENAC \& LEVY, 1983). Eschenwurzeln zeigten bei Trockenheit nur eine geringe Einschränkungen in der Wasseraufnahmekapazität. Nach der Wiederbewässerung konnte eine schnelle Erholung des Wasseraufnahmevermögens beobachtet werden (WIERSUM \& HARMANNY, 1983). Nach Untersuchungen von SCHMITT (1999) zeigte die Esche keine Stressantworten auf physiologischer und morphologischer Ebene, was ebenfalls auf hohe Trockenstresstoleranz hindeutet.

Von vielen Autoren wird die Esche als eine stark transpirierende Baumart beschrieben (LEMOINE et al., 2001, STÖHR \& LÖSCH, 2004, ROBERTS \& ROSIER, 1994). In einem Mischbestand in Dänemark erreichte die Esche mit einer maximalen Transpirationsrate von $2.51 \mathrm{~d}^{-1} \mathrm{~m}^{-2}$ im Vergleich mit Bergahorn, Buche und Eiche die höchsten Werte (LADEFOGED, 1963). Im Gegensatz dazu ergaben sowohl die Messung der Stamm-Saftflussdichte von HöLSCHER et al. (2004) als auch die Wurzel-Saftflussdichten der vorliegenden Arbeit in diesem Bestand die niedrigsten Werte für die Esche über die gesamte Dauer der Vegetationsperiode. Im Mittel konnte eine Saftflussdichte im Stamm von $67 \mathrm{~g} \mathrm{~cm}^{-2} \mathrm{~d}^{-1}$ gemessen werden, in der Wurzel erreichte sie dagegen $193 \mathrm{~g} \mathrm{~cm}^{-2} \mathrm{~d}^{-1}$. Betrachtet man die Wasseraufnahmerate der Esche jedoch auf Bestandesebene, weist sie in der vorliegenden Untersuchung die höchsten Werte auf (Tab. 4.11). Dennoch kann sie nach der vorliegenden Studie nicht grundsätzlich zu den stark transpirierenden Baumarten gezählt werden. Die hohen Transpirations- bzw. Stammsaftflussraten wurden in Beständen oder zu Zeiten einer guten Wasserversorgung gemessen. CARLIER et al. (1992) dagegen weisen auf standortsbedingte Unterschiede in der Höhe der Transpiration hin. Eschen in einem Auwald wiesen hohe Transpirationsleistungen auf, Eschen eines trockenen Bergstandortes hingegen hatten selbst bei hoher Bodenfeuchte geringere Transpirationsleistungen, begleitet von weiteren physiologischen Unterschieden (stomatäre Leitfähigkeit, Wasserpotential).

Die Winterlinde reagiert auf Wassermangel mit einer Herabsetzung der Transpiration. Wird sie anschließend bewässert, setzt diese wieder stark ein (LAZARESCU \& FIDANOF, 1968). Im Vergleich mit der Sommerlinde ist die Einschränkung der Transpiration bei der Winterlinde wesentlich ausgeprägter. Daraus schließen die Autoren, dass die Winterlinde besser in der Lage ist, eine Dürreperiode zu überstehen. SCHMITT (1999) stufte die Sommerlinde nach ihren Reaktionen auf Trockenstress ebenfalls als trockentolerant ein. PIGOTT (1991) ordnet die Winterlinde ebenfalls den Baumarten zu, die nur selten von Trockenstress betroffen sind, was er auf ein tiefreichendes Wurzelsystem zurückführt. Im Gegensatz zu der Buche zeigte die Linde keine permanente Schädigung nach einer mehrwöchigen Trockenperiode. 
Eine der wenigen Wurzelsaftflussmessungen an in der vorliegenden Arbeit untersuchten Baumarten wurde von NADEZHDINA \& CERMAK (2000) an Winterlinden in einem Bestand in Tschechien durchgeführt. Die untersuchten Grobwurzeln hatten im Gegensatz zu den in dieser Arbeit untersuchten Wurzeln einen Durchmesser von mindestens $2.5 \mathrm{~cm}$. Die Saftflussdichte war mit 0.03-0.05 $\mathrm{g} \mathrm{mm}^{-2} \mathrm{~h}^{-1}$ im Mittel deutlich geringer. An Feinwurzeln im Hainich lagen sie bei $1.15 \mathrm{~g} \mathrm{~mm}^{-2} \mathrm{~h}^{-1}$.

HÖLSCHER et al. (2004) ermittelte für die Winterlinden im Mischbestand im Hainich eine mittlere Saftflussdichte von $86 \mathrm{~g} \mathrm{~cm}^{-2} \mathrm{~d}^{-1}$. Die in dieser Arbeit untersuchten Wurzeln hatten im Mittel eine Saftflussdichte von $197 \mathrm{~g} \mathrm{~cm}^{-2} \mathrm{~d}^{-1}$.

Für die Hainbuche konnten keine vergleichbare Angaben über Stammsaftfluss oder Transpirationsraten gefunden werden, so dass hier lediglich die Daten von HÖLSCHER et al. (2004) aus demselben Bestand zum Vergleich zur Verfügung stehen. Die Autoren geben für die Hainbuche eine mittlere Stamm-Saftflussdichte von $77 \mathrm{~g} \mathrm{~cm}^{-2} \mathrm{~d}^{-1}$ an. Dagegen weisen die Wurzeln eine Saftflussdichte von $427 \mathrm{~g} \mathrm{~cm}^{-2} \mathrm{~d}^{-1}$ im Mittel auf. Während LEIBUNDGUT (1991) die Hainbuche als empfindlich gegenüber Trockenheit einstuft und RÖHRIG \& GUSSONE (1990) angeben, dass sie durch Wassermangel schnell geschädigt werden kann, wird sie von TÜRK (1996) als trockenheitstolerant eingeschätzt. ELLENBERG (1996) stellt für die Hainbuche, im Vergleich zur Buche, die als stark trockenheitsempfindlich angegeben ist, eine mittelmäßige Dürreempfindlichkeit fest.

Stiel- und Traubeneiche unterscheiden sich hauptsächlich in ihrer Toleranz gegenüber Trockenheit, auch wenn beide Arten als sehr trockenstress-tolerant angesehen werden. Die Traubeneiche ist unempfindlicher gegenüber periodisch auftretendem Wassermangel. Unter natürlichen Bedingungen konnten BREDA et al.(1993a) keine signifikanten Unterschiede in der Stamm-Saftflussdichte nachweisen, auch wenn die Stieleiche stets leicht niedrigere Werte aufwies.

Neben der Winterlinde wird der Stieleiche nur eine geringe Dürreempfindlichkeit zugesprochen (ELLENBERG, 1996). WIERSUM \& HARMANNY (1983) konnten nur eine geringe Einschränkung der Wurzel-Wasseraufnahme sowie eine schnelle Erholung nach Trockenheit feststellen. Die mittlere Wurzel-Saftflussdichte der Stieleiche im Hainich beträgt $349 \mathrm{~g} \mathrm{~cm}^{-2} \mathrm{~d}^{-1}$. In dem von LADEFOGED (1963) untersuchten Mischbestand in Dänemark erreichte die Traubeneiche fast ebenso hohe Maximalwerte der Transpiration $\left(2.3 \mathrm{ld}^{-1} \mathrm{~m}^{-2}\right)$ wie die Esche. BREDA et al. (1993b) geben für einen Traubeneichen-Bestand in Frankreich eine Transpirationsrate von $3.8 \mathrm{~mm} \mathrm{~d}^{-1}$ (entspricht $3.81 \mathrm{~m}^{-2} \mathrm{~d}^{-1}$ ) an, die höher liegt als die von LADEFOGED (1963) gemessenen Werte. Eine gleichzeitige Messung der Blatt-Wasserpotentiale und des Stammsaftflusses ergab hohe Transpirationsraten bei gleichzeitig niedrigen BlattWasserpotentialen, was auf eine hohe Trockenheitstoleranz der Eiche während Trockenperioden hinweist (TOGNETTI et al., 1996).

CONERS (2001) konnte an Strahlungstagen eine Stamm-Saftflussdichte von $900 \mathrm{~g} \mathrm{~cm}^{-2} \mathrm{~d}^{-1}$ an Traubeneichen in der Lüneburger Heide messen. Für den Wurzelsaftfluss liegen ebenfalls Daten aus dem Mischbestand in der Lüneburger Heide vor. So erreichten Traubenei- 
chenwurzeln in der organischen Auflage bei guter Wasserversorgung eine Saftflussdichte von $1148 \mathrm{~g} \mathrm{~cm}^{-2} \mathrm{~d}^{-1}$, während ICKE (2000) einen Mittelwert von $268 \mathrm{~g} \mathrm{~cm}^{-2} \mathrm{~d}^{-1}$ angibt. In der vorliegenden Arbeit wurden im Mittel Saftflussdichten von $133 \mathrm{~g} \mathrm{~cm}^{-2} \mathrm{~d}^{-1}$ an Wurzeln der organischen Auflage gemessen.

Die Schattenbaumart Buche weist eine hohe Dürreempfindlichkeit auf (ELLENBERG, 1996); eine gute Wasserversorgung während der Vegetationsperiode ist also wichtig. Für die Buche liegen meist Daten für die Jahresbestandestranspiration vor, die zwischen $178 \mathrm{~mm}$ und 272 mm variieren (Angaben nach KOCH, 2002). ROBERTS \& ROSIER (1994) dagegen geben eine Bestandestranspiration von $393 \mathrm{~mm}$ für die Buchen in einem Buchen-Eschenwald an. LADEFOGED (1963) konnte an einem Strahlungstag mit guter Wasserversorgung eine maximale Transpirationsrate von $1.41 \mathrm{~d}^{-1} \mathrm{~m}^{-2}$ messen, die deutlich höher als für Bergahorn war. Entlang eines Niederschlagsgradienten gibt SCHIPKA (2002) als maximale Werte der Tagestranspiration von Buchenwäldern Werte zwischen $4.8 \mathrm{~mm} \mathrm{~d}^{-1}$ und $8.6 \mathrm{~mm} \mathrm{~d}^{-1}$ an. Eine wesentliche trockenstress-bedingte Beeinträchtigung der Transpiration der Bestände konnte an einem niederschlagsarmen Standort im Mitteldeutschen Trockengebiet nicht festgestellt werden. LEUSCHNER et al. (2001a) sprechen der Buche eine größere Trockenheitsempfindlichkeit als der Traubeneiche zu, was sich in geringeren Stammzuwächsen, höheren Feinwurzelproduktionsraten bei Trockenheit und stärkeren Schwankungen des Blatt-Wasserpotentials äußert.

Im Bestand im Hainich wurden von HöLSCHER et al. (2004) $152 \mathrm{~g} \mathrm{~cm}^{-2} \mathrm{~d}^{-1}$ als mittlere Stamm-Saftflussdichte gemessen. Die Wurzel-Saftflussdichte war mit $337.8 \mathrm{~g} \mathrm{~cm}^{-2} \mathrm{~d}^{-1}$ (diese Arbeit) sehr viel höher.

Für die Buche liegen Messungen aus dem Mischbestand in der Lüneburger Heide vor. Die dort an Strahlungstagen gemessene Stamm-Saftflussdichte beträgt $500 \mathrm{~g} \mathrm{~cm}^{-2} \mathrm{~d}^{-1}$, die WurzelSaftflussdichte in einer gut wasserversorgten organischen Auflage $1425 \mathrm{~g} \mathrm{~cm}^{-2} \mathrm{~d}^{-1}$ (CONERS, 2001). Über die Vegetationsperiode 1999 hatten die Buchenwurzeln im Mittel eine Saftflussdichte von $448 \mathrm{~g} \mathrm{~cm}^{-2} \mathrm{~d}^{-1}$ (ICKE, 2000), in der vorliegenden Arbeit von $342 \mathrm{~g} \mathrm{~cm}^{-2}$ $\mathrm{d}^{-1}$. Untersuchungen von BURK (mündl. Mitteilung) in einem Mischbestand im Ziegelrodaer Forst (Sachsen-Anhalt) ergaben deutlich geringere Tageswerte der Saftflussdichte $\left(87 \mathrm{~g} \mathrm{~cm}^{-2}\right.$ $\mathrm{d}^{-1}$ ). Ein Grund für diese sehr niedrigen Werte könnte in dem außergewöhnlich trockenen und heißen August des zu Grunde liegenden Messjahres 2003 zu sehen sein, während dem der Saftfluss fast zum Erliegen kam.

Die standortspezifischen Unterschiede bei Eiche und Buche werden in Kap. 5.3 diskutiert.

Ein Vergleich der Wurzel-Saftflussdichten mit parallel von HÖLSCHER et al. (2004) aufgenommenen Stamm-Saftflussdichten zeigt eine in den Wurzeln effektivere Wasserleitung: pro $\mathrm{cm}^{2}$ leitendes Gewebe kann dort oftmals mehr als die doppelte Menge Wasser transportiert werden (Abb. 5.2).

Für Bergahorn, Hainbuche und Buche konnte ein direkter Zusammenhang zwischen der über die Wurzeln aufgenommenen und der im Xylem des Stammes weitergeleiteten Wassermenge gefunden werden $(r=0.78,0.58$ und $0.64 ; p<0.05)$. Für Esche und Linde konnte keine Korrela- 


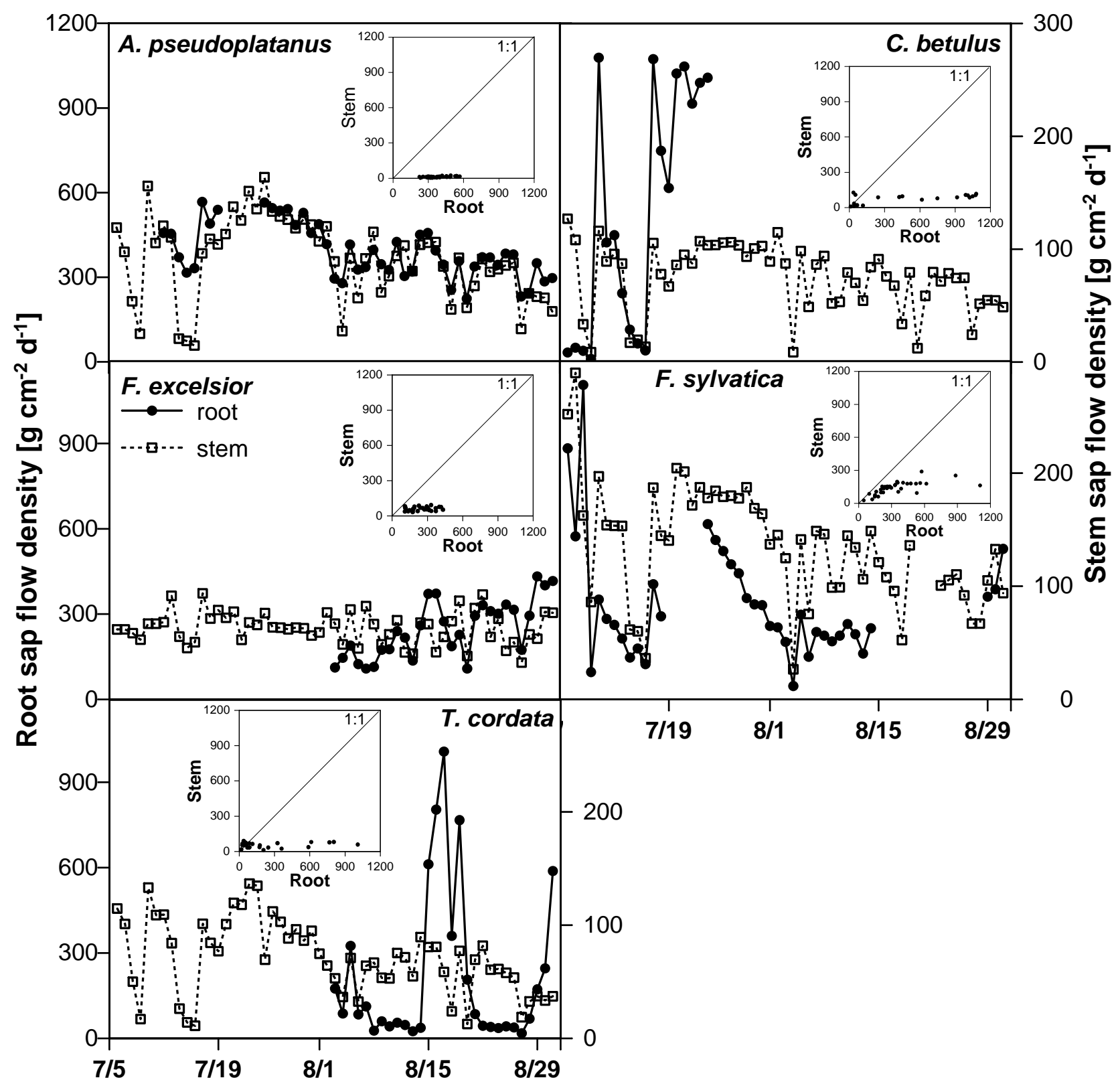

Abb. 5.2: Tageswerte der Wurzel- und Stamm-Saftflussdichten von fünf Baumarten auf den Untersuchungsflächen im Nationalpark Hainich im Zeitraum 6.7.-31.8.2001. Aufgetragen sind die Tageswerte gemittelt aus Messungen an jeweils 10 Wurzeln pro Baumart bzw. von jeweils fünf Individuen (HÖLSCHER, KOCH mündl. Mitteilung). Zur besseren Übersichtlichkeit wurden die Standardfehler nicht aufgetragen. Die Achsen für Wurzel- und Stamm-Saftflussdichte sind unterschiedlich skaliert. In den Inserts sind die Saftflussdichten von Stamm und Wurzel direkt gegenübergestellt. 
tion der Saftflussdichten festgestellt werden ( $\mathrm{r}=0.2$ und $\mathrm{r}=0.15, \mathrm{p}>0.05)$. Auch fehlt bei beiden Baumarten ein gleichsinniger Verlauf der Saftflussdichten von Wurzel und Stamm über den betrachteten Zeitraum. Dies stimmt überein mit der geringen Abhängigkeit der Wasseraufnahme der Esche von Umgebungsparametern wie Strahlung, VPD oder Bodenfeuchte sowohl auf Wurzel- als auch auf Stammebene (HÖLSCHER et al., 2004). Die Winterlinde dagegen wiesen in der Stamm-Saftflussdichte durchaus eine Einflussnahme durch die genannten Parameter auf. Bei dieser Art lässt sich die geringe Interaktion der Flüsse auf Wurzel- und Stammebene nicht schlüssig erklären.

Zwischen dem Stamm- und Wurzelsaftfluss der Eiche wurde dagegen eine gute Übereinstimmung gefunden, wie Untersuchungen an Traubeneichen in der Lüneburger Heide zeigten, bei denen ein Korrelationskoeffizient von 0.7 ermittelt wurde (KORN, 1999).

Vergleiche zwischen Stamm- und Wurzelsaftfluss wurden von verschiedenen Autoren gezogen. So konnten z.B. LOTT et al. (1996), GREEN et al. (1997) und CABIBEL \& DO (1991a) synchron laufende Saftflussraten in Stamm und Grobwurzeln von Grevillea robusta bzw. Malus spec. nachweisen. Bei einer Verschlechterung der Wasserversorgung berichten einige Autoren von Abweichungen von diesem Synchronismus. CABIBEL \& DO (1991a) stellten eine Verschiebung der Wasseraufnahme in trockenem Boden um 12 Stunden gegenüber dem Stammfluss fest. BURGESS et al. (2000) konnten in trockenen Bodenbereichen ebenfalls die Entkopplung des Wurzelsaftflusses von dem Transpirationsstrom messen. Da es jedoch nicht zu einer Einschränkung der Transpiration kam und der Stamm-Saftfluss weiterhin aufrechterhalten wurde, muss eine zumindest vorübergehende Wasserspeicherung im Stamm bzw. Wassernachleitung für die Transpiration aus dem Stamm in Betracht gezogen werden.

Unabhängig von dem Synchronismus des Wurzel- und Stammsaftflusses war die Saftflussdichte der Wurzeln aller Baumarten um das doppelte (Buche), im Extremfall der Hainbuche um das fünffache höher als die Stamm-Saftflussdichte.

ZIMMERMANN \& BROWN (1971) berichten von Unterschieden in der Geschwindigkeit des Saftflusses entlang der Stammachse. Sie beschreiben für ringporige Gehölze wie Esche und Eiche höhere Flussgeschwindigkeiten im basalen Stammbereich als im Kronenbereich. Bei der zerstreutporige Birke dagegen steigt die Flussgeschwindigkeit mit der Stammhöhe an. Die Autoren erklären den anatomischen Unterschieden der leitenden Querschnittsflächen von Ring- und Zerstreutporern.

Durch die Bestimmung des tatsächlich hydroaktiven Splintholzes anhand von Bohrkernen wurde eine Unterschätzung der Saftflussdichte im Stamm der untersuchten Baumarten ausgeschlossen (HÖLSCHER et al., 2004).

Angaben über Durchmesser der Xylemgefäße im Stamm einiger Arten sind bei ZIMMERMANN \& BROWN (1971) zu finden, jedoch ohne Angabe des Alters und des Durchmessers der untersuchten Stämme. Im Stamm der Esche wurden in Brusthöhe Xylemgefäße mit Durchmessern zwischen 120 und $350 \mu \mathrm{m}$ gefunden. Diese sind damit weitlumiger als die Gefäße der in der vorliegenden Arbeit untersuchten Schwachwurzeln der Esche (5-120 $\mu \mathrm{m})$. Bergahorn $(30-110 \mu \mathrm{m})$, Hainbuche $(16-80 \mu \mathrm{m})$ und Buche $(16-80 \mu \mathrm{m})$ haben als zerstreutporige Baumarten geringere Gefäßdurchmesser im Stamm (ZIMMERMANN \& BROWN, 1971). Die- 
se liegen in einer ähnlichen Größenordnung wie die Gefäßdurchmesser der 3-4 mm starken Wurzeln der jeweiligen Baumart aus der vorliegenden Untersuchung (Bergahorn: 10-114 $\mu \mathrm{m}$, Hainbuche: 5-128 $\mu \mathrm{m}$, Buche: 10-176 $\mu \mathrm{m}$ ). Die Gefäße der Wurzeln Unterschiede zwischen Stamm und Wurzeln in der Gefäßweite mit deutlich größeren Gefäßlumina der Wurzeln beschreiben ZIMMERMANN \& TYREE (2002) für z.B. Acer rubrum und MARTINEZ-VILALTA et al. (2002) für neun mediterrane Baumarten. Mit einer größeren Gefäßweite einher geht eine höhere hydraulische Leitfähigkeit des Xylems MARTINEZ-VILALTA et al. (2002), ZIMMERMANN \& TYREE (2002) und eine höhere Saftflussgeschwindigkeit, so dass mehr Wasser transportiert werden kann. Dies wird zusätzlich durch längere Gefäße in den Wurzeln gefördert, da Gefäßdurchmesser und -länge positiv miteinander korreliert sind (ZIMMERMANN \& JEJE, 1981). Diese Faktoren begünstigen eine erhöhte Saftflussdichte der Wurzeln. Nach ZIMMERMANN \& TYREE (2002) ist die Abnahme der Tracheenweite in acropetaler Richtung eine Anpassung an die erhöhte Emboliegefahr, die sich aus einer Zunahme der Wasserpotentialdifferenz mit zunehmender Baumhöhe ergibt. Größere Gefäßdurchmesser in Wurzeln gewährleisten dort einen schnelleren Wassertransport bei höherer hydraulischer Leitfähigkeit als im Stamm.

Durch die im Vergleich zum Stamm hohe Saftflussdichte in den Wurzeln kann eine stetige Wassernachlieferung für den Stamm gewährleistet werden.

Eine Besonderheit des entkoppelten Saftflusses von Stamm und Wurzel stellt der von vielen Autoren beschriebene ,hydraulic lift“ dar (z.B. VAN BAVEL \& BAKER, 1985, CALDWELL \& RICHARDS, 1989, MOREIRA et al., 2003). Dieser beschreibt die Umkehrung des Wassertransportprozesses, indem Wasser aus feuchten Bodenschichten durch die Wurzeln zu trockenen Bodenbereichen transportiert wird. Eine Voraussetzung dafür ist das Vorhandensein eines inversen Potentialgradienten. Neben dem meist beschriebenen Transport aus tiefen Bodenschichten an oberflächennahe, gibt es einen ,inverse hydraulic lift“", bei dem Wasser von oberen Bodenhorizonten in tiefere Lagen transportiert wird (BURGESS et al., 1998, SCHULZE et al., 1998). Bei den Saftflussmessungen der vorliegenden Arbeit konnten keine Hinweise auf diese Vorgänge gefunden werden. gefunden werden.

Für die querschnittsbezogenen Flussraten in Schwachwurzeln wurden im Hainich signifikante Artunterschiede festgestellt. Hohe Raten ergaben sich für Hainbuche, Stieleiche und Buche, während Bergahorn, Winterlinde und Esche niedrige Saftflussdichten hatten aufwiesen.

In einer gemeinsamen Betrachtung aller Baumarten konnte ein positiver Zusammenhang zwischen der Saftflussdichte der Wurzeln und der potentiell aufnehmenden Wurzeloberfläche gezeigt werden (Abb. 5.3).

Baumarten mit einer durchschnittlich geringeren Wurzeloberfläche pro Schwachwurzelstrang wie Esche und Linde hatten geringe Saftflussdichten der Messwurzeln. 


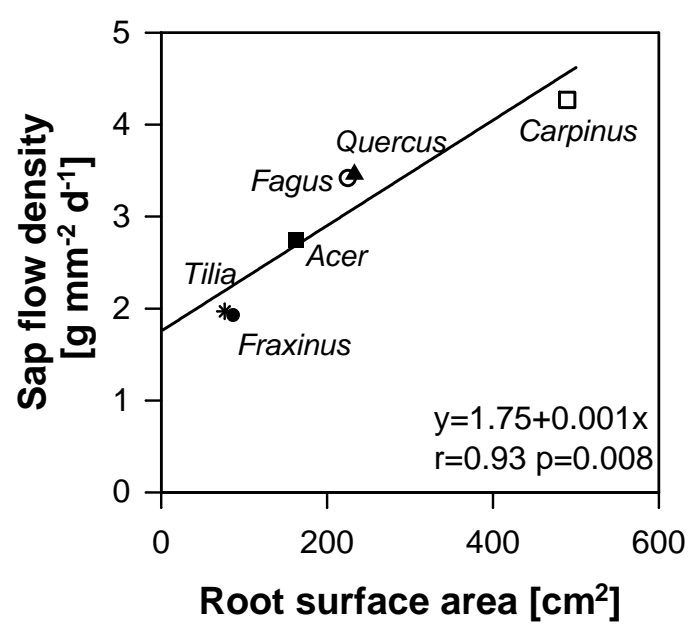

Abb. 5.3: Beziehung zwischen der Saftflussdichte und der Wurzeloberfläche der Messwurzeln der sechs Baumarten im Nationalpark Hainich. Die Saftflussdichte wurde in den Vegetationsperioden 2000 und 2001 an 8-15 Wurzeln (Durchmesser 2.9-4.1 mm) pro Baumart mit der Miniatursaftflussmethode ermittelt. Die Wurzeln wurden nach Abschluss der Messungen geerntet und die Oberfläche von der Messstelle bis zu den Wurzelspitzen ermittelt. Aufgetragen sind jeweils die Mittelwerte.

\subsubsection{Die Bedeutung biotischer und abiotischer Faktoren für die Wurzel-Wasseraufnahme verschiedener Baumarten}

\section{Der Einfluss der abiotischen Faktoren auf die Baumarten}

Wie in Kapitel 5.1.1 dargelegt wurde, sind Strahlung und VPD die treibenden Kräfte für den Wassertransport durch eine Pflanze. In zahlreichen Studien konnte eine solche Abhängigkeit der Transpirationsrate bzw. der Stamm-Saftflussdichte belegt werden, wobei sowohl lineare (OREN et al., 1999, BACKES, 1996) als auch nicht-lineare, z.B. asymptotische (MILLER et al., 1980, SENOCK \& LEUSCHNER, 1999), logarithmische (HÖLSCHER et al., 2004, KOCH, 2002) oder parabelförmige (PATAKI et al., 2000) Antwortkurven ermittelt wurden. Daher ist zu erwarten, dass diese beiden atmosphärischen Faktoren einen großen Einfluss auf die Wasseraufnahme der Bäume haben.

Unterschiedliche Abhängigkeiten des Stammsaftflusses verschiedener Baumarten vom VPD wies HÖLSCHER et al. (2004) für Bäume des selben Bestandes im Hainich nach. In Übereinstimmung mit den vorliegenden Ergebnissen konnte für die Stamm-Saftflussdichte der Eschen keine Beziehung mit dem VPD aufgestellt werden, während Bergahorn, Hainbuche, Winterlinde und Buche $\left(\mathrm{R}^{2}=0.86-0.68\right)$ sehr stark beeinflusst wurden. Die Korrelation zwischen der Stamm-Saftflussdichte und dem VPD wurde hier am besten durch eine logarithmische Funktion beschrieben, im Gegensatz zu den Saftflussdichten der Wurzeln. 
Übereinstimmend mit diesen Ergebnissen für die Esche konnten COCHARD et al. (1997) Transpirationsraten messen, die im Verlaufe eines Tagesganges weitgehend unabhängig vom VPD waren. Im Gegensatz dazu bestand bei Eschen-Jungwuchs in einem Eschen-BergahornMischbestand eine enge Korrelation der Saftflussraten mit dem VPD und der Strahlung (STÖHR \& LÖSCH, 2004). Im Modell konnten bis zu 75\% der Varianz mit Änderungen des Strahlungsangebotes begründet werden; der Einfluss des VPD war etwas geringer. Ein ZweifaktorenModell aus Strahlung und VPD erlaubte eine Erklärung von 88\% der Varianz.

BACKES (1996) fand für die Xylemsaftflussraten von Traubeneiche, Buche, Birke und Kiefer jeweils signifikante lineare Beziehungen zu der Strahlung und dem VPD, die zwischen verschiedenen Messjahren und den Baumarten variierten.

OREN \& PATAKI (2001) untersuchten einen Bestand mit Quercus alba und Acer rubrum. Dort traten Unterschiede zwischen den Arten auf. Hier wies die Eiche jeweils eine leicht geringere Abhängigkeit vom Strahlungsangebot und VPD auf als der Ahorn. Die Varianz der Bestandestranspiration war zu 59\% von der Strahlung und nur zu 22\% von dem VPD abhängig.

Die Abhängigkeit des Wurzelsaftflusses von den Umweltfaktoren Strahlung, VPD und Bodenfeuchte untersuchte CONERS (2001) vergleichend für Buche, Traubeneiche und Fichte in der Lüneburger Heide. Er konnte für über $80 \%$ der Buchen- und Eichenwurzeln das VPD als wichtige Einflussgröße ermitteln. Die Globalstrahlung und der Bodenwassergehalt wurden für 40\% der Wurzeln als beeinflussender Faktor der Wurzel-Wasseraufnahme angesehen. Die Fichtenwurzeln zeigten eine geringere Abhängigkeit vom VPD.

Diese Untersuchungen zeigen eine Abhängigkeit des Saftflusses von den betrachteten Umweltfaktoren. Für die Wurzel-Wasseraufnahme der sechs in der vorliegenden Arbeit untersuchten Baumarten konnte eine lineare Abhängigkeit bestätigt werden. Die Wurzeln zeigten demnach mit steigendem VPD bzw. steigender Netto-Strahlung eine gesteigerte Wasseraufnahme. Somit wurden die atmosphärischen Signale über den Stamm an die Wurzeln weitergegeben. Dies äußerte sich in synchronen Tagesgängen von Wurzel- und Stammsaftfluss, wie es beispielhaft in Abb. 5.4 für die Buche dargestellt ist (Daten Stammsaftfluss von KOCH, 2002). Für einen Großteil der Wurzeln von Esche und Winterlinde bildeten die untersuchten Umweltfaktoren jedoch nicht die Haupteinflussgrößen für die Wasseraufnahme. Diese zeigten in der Regressionsanalyse keine Abhängigkeit von der Netto-Strahlung oder dem VPD. Der Wurzelsaftfluss dieser beiden Baumarten war über die Vegetationsperiode ebenfalls nicht parallel zum Stammsaftfluss. Die Wasseraufnahme dieser Wurzeln unterliegt anderen Steuergrößen. Hierzu zählen die hydraulische Leitfähigkeit und die Wasserpotentialdifferenz.

\section{Die axiale hydraulische Leitfähigkeit der Wurzeln verschiedener Baumarten}

Da eine hohe Aufnahme-Effizienz der Wurzeln eine wichtige Voraussetzung für die Wasserversorgung einer Pflanze ist, muss die hydraulische Leitfähigkeit der Wurzeln hoch sein (STEUDLE, 1994). Nach der allgemeinen Flussgleichung (Gl. 5.1) ist demnach der Widerstand, der dieser Wasseraufnahme entgegensteht, bzw. dessen reziproker Wert, die Leitfähigkeit, eine wichtige Größe zur Beschreibung der Wasseraufnahme. 


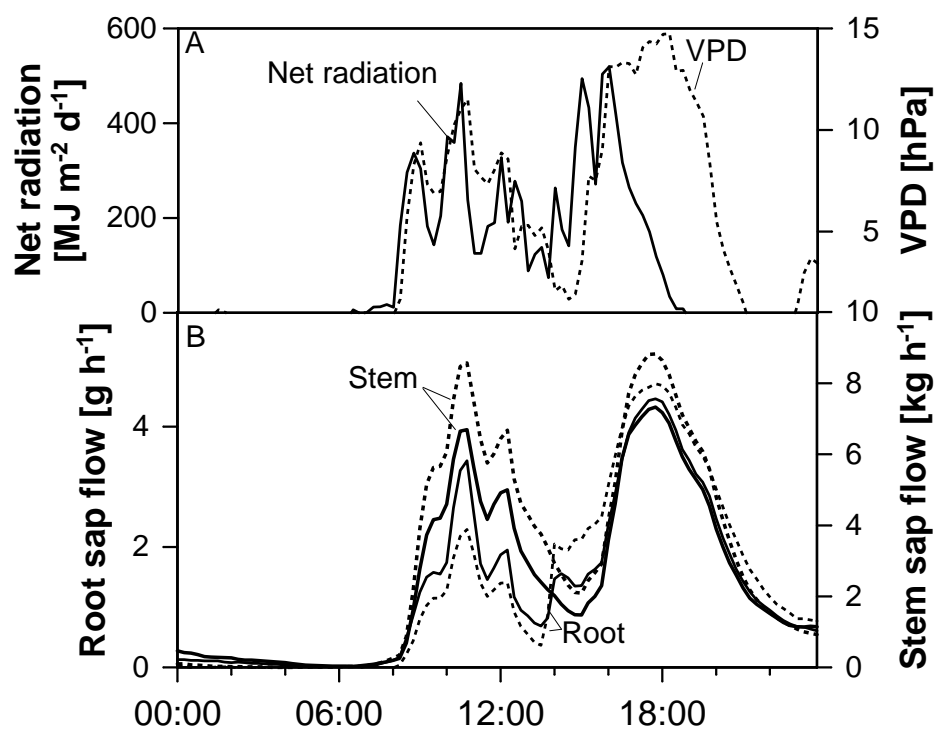

Abb. 5.4: A Tagesgang der Strahlungsbilanz und des Wasserdampfsättigungsdefizits am 09.08.2001, aufgezeichnet auf einer Freifläche in direkter Nachbarschaft des untersuchten Bestandes. B Tagesgänge der Saftflussraten in zwei Wurzeln (Durchmesser 3-4 mm) und zwei Stämme der Buche am 09.08.2001 im Nationalpark Hainich. Die Stamm-Saftflussraten der Buche wurden von $\mathrm{KOCH}(2002)$ gemessen.

Nach einer von SPERRY et al. (1988) vorgestellten Methode kann die maximale hydraulische Leitfähigkeit eines Wurzel- oder Zweigsegmentes unter Laborbedingungen ermittelt werden. Damit wird jedoch allein die axiale Leitfähigkeit beschrieben, radiale Leitfähigkeiten, die für die Wasseraufnahme über die Wurzel eine wichtige Rolle spielen (STEUDLE, 1994), werden nicht berücksichtigt.

Mit Ausnahme des Bergahorns waren die Unterschiede in der axialen Leitfähigkeit zwischen den in der vorliegenden Arbeit untersuchten Baumarten gering. Die Wurzeln des Bergahorns wiesen eine vielfach höhere Leitfähigkeit auf. Da eine hohe intraspezifische Variabilität auftrat, konnte dieser Unterschied nicht statistisch bestätigt werden. So wiesen einzelne Wurzeln des Bergahorns eine maximale axiale Leitfähigkeit in der gleichen Größenordnung der anderen Baumarten auf.

ZIMMERMANN \& TYREE (2002) konnten für Spezies von Acer, Thuja und Schefflera eine Zunahme der hydraulischen Leitfähigkeit von Stammsegmenten mit dem Segment-Durchmesser nachweisen, da mit zunehmendem Stammdurchmesser die Anzahl und/oder die Größe der leitenden Xylemelemente zunahm. Zu unterscheiden ist hier zwischen der Zunahme der Anzahl und der Zunahme der Größe der Xylemelemente, da der Durchmesser mit der vierten Potenz zur Zunahme der Leitfähigkeit beiträgt. Daher ist es für einen Vergleich von Segmenten mit unterschiedlichen Durchmessern angebracht, die spezifische Leitfähigkeit zu berechnen, die sich auf die Querschnittsfläche des Segmentes bezieht.

Die Berechnung der spezifischen Leitfähigkeit bestätigte die höhere axiale Leitfähigkeit der 
Bergahorn-Wurzeln (Abb. 4.33), da für die Untersuchung Wurzeln ähnlichen Durchmessers ausgewählt wurden. In dem von ZIMMERMANN \& TYREE (2002) angesprochenen Parameter Gefäßdichte unterschieden sich die Bergahornwurzeln nicht von den anderen Baumarten. Im Gegensatz zu der sehr hohen axialen Leitfähigkeit wiesen die Wurzeln des Bergahorns englumigere Gefäße auf als die anderen Baumarten. Die Gefäßlänge kann als beeinflussende Größe eine Rolle spielen, da die Tracheen eine begrenzte Länge haben und von einer nicht-perforierten Endwand abgeschlossen werden (JURZITZA, 1987), die den Wassertransport einschränkt. SPERRY et al. (1988) geben für Zweige von Acer saccharum eine maximale Gefäßlänge von $15 \mathrm{~cm}$ an. In der Wurzel nimmt die Gefäßlänge generell stark zu (ZIMMERMANN \& TYREE, 2002), so dass in dem untersuchten Segment von ca. 5 cm Länge offene Gefäßenden bei allen Baumarten zu finden waren.

LARCHER (1994) gibt für die Wurzelhölzer sommergrüner Laubbäume die spezifische Wasserleitfähigkeit mit 0.02-0.15 $\mathrm{m}^{2} \mathrm{MPa}^{-1} \mathrm{~s}^{-1}$ an. An dem oberen Ende dieses Bereiches lassen sich die spezifischen Leitfähigkeiten von Buche, Stieleiche, Esche, Winterlinde und Hainbuche einordnen, die des Bergahorns liegt höher.

Von LÖSCH (2001) werden die spezifischen Leitfähigkeiten der Zweige verschiedener Pflanzenarten angegeben, die jedoch mit maximal $0.0087 \mathrm{~m}^{2} \mathrm{MPa}^{-1} \mathrm{~s}^{-1}$ wesentlich geringer sind als die Wurzelleitfähigkeit.

An mediterranen Baumarten fanden MARTINEZ-VILALTA et al. (2003) unter Trockenstress eine negative Beziehung zwischen den aufsummierten Tageswerten des Saftflusses und der spezifischen Leitfähigkeit. Quercus ilex schränkte den Saftfluss sehr stark ein, wies jedoch gleichzeitig die höchste spezifische Wurzelleitfähigkeit auf $\left(60.1 \cdot 10^{-4} \mathrm{~m}^{2} \mathrm{MPa}^{-1} \mathrm{~s}^{-1}\right)$. Im Gegensatz dazu verminderte sich die Saftflussrate von Phyllirea latifolia, einer trockentoleranten Art, nur wenig. Die spezifische Leitfähigkeit der Wurzel war mit $18.9 \cdot 10^{-4} \mathrm{~m}^{2} \mathrm{MPa}^{-1} \mathrm{~s}^{-1}$ um ein Drittel geringer als bei der Eiche. Insgesamt waren die dort gemessenen Leitfähigkeiten um ein Vielfaches geringer als in den mitteleuropäischen Baumarten.

Ein positiver Zusammenhang zwischen der spezifischen Leitfähigkeit und der mittleren Saftflussdichte der sechs Baumarten bzw. der oberflächenbezogenen Wasseraufnahmerate ergab sich in der vorliegenden Arbeit nicht (Abb. 5.5). Die Hainbuche mit der geringsten axialen Leitfähigkeit wies die höchsten Saftflussdichten auf, während der Bergahorn trotz der sehr hohen axialen Leitfähigkeit nur eine mittlere Wasseraufnahmerate hatte.

Ein Zusammenhang mit der Trockentoleranz der Arten, wie er von PATAKI et al. (2000), LEMOINE et al. (2001) und von MARTINEZ-VILALTA et al. (2003) dargestellt wird, soll in Kapitel 5.2.3 diskutiert werden.

In der vorliegenden Arbeit wurde die theoretische Leitfähigkeit der Wurzeln angegeben, die sich nach dem Gesetz von Hagen-Poiseuille aus Gefäßlumina berechnen lässt. Signifikante Unterschiede zwischen den Baumarten ergaben sich nicht. Tendenziell wiesen Buche und Stieleiche die größten theoretischen Leitfähigkeiten auf; die Wurzeln des Bergahorns und der Esche die geringste, was den Ergebnissen der experimentellen Untersuchung widerspricht. LÖSCH (2001) gibt an, dass die berechneten Leitfähigkeiten oft von den empirisch ermittelten Leitfähigkeiten abweichen und diese überschätzen. So beträgt die empirisch ermittelte Leit- 

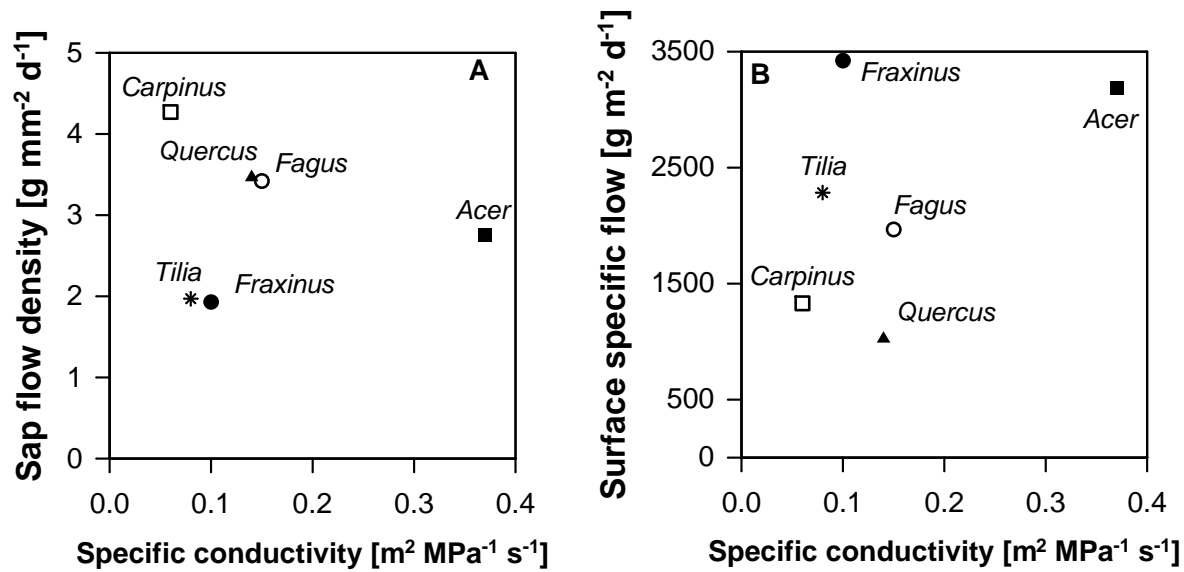

Abb. 5.5: Beziehung zwischen der spezifischen Leitfähigkeit $\left(\mathrm{k}_{m}\right.$ bezogen auf die Querschnittsfläche der Segmente) und der mittleren Saftflussdichte (A) bzw. der oberflächenspezifischen Wasseraufnahmerate (B) der Wurzeln von sechs Baumarten im Hainich. Die Leitfähigkeiten wurden mit der Durchflussmethode nach SPERRY et al. (1988) gemessen. Dargestellt sind die Mittelwerte und von jeweils 4-8 Messungen pro Baumart. Die Saftflussraten wurden in den Vegetationsperioden 2000 und 2001 an 8-15 Wurzeln pro Baumart mit der Miniatursaftflussmethode ermittelt.

fähigkeit von Eichenwurzeln 84\%, die der Buchenwurzeln sogar nur 37.5\% der theoretischen Leitfähigkeit. Auch der Bergahorn erreicht nur 38.0\% der theoretisch möglichen Leitfähigkeit (ZIMMERMANN \& TYREE, 2002). Für die Eschenwurzeln der vorliegenden Arbeit betrug die spezifische axiale Leitfähigkeit noch $86.7 \%$ der theoretischen. Weitaus mehr überschätzt wurden die theoretischen Leitfähigkeiten der Winterlinde und der Hainbuche, deren spezifischen Leitfähigkeit bei $24.6 \%$ bzw. $23.2 \%$ der theoretischen lag. Die experimentell ermittelte maximale axiale Leitfähigkeit der Eichenwurzeln betrug nur $38.6 \%$ der berechneten, die der Buchenwurzeln in nahezu Übereinstimmung mit dem Literaturwert nur 41.8\%. Dagegen war die theoretische Leitfähigkeit des Bergahorns sogar 2.5fach geringer als die gemessene Leitfähigkeit, so dass eher ein Fehler in der Messung der maximalen axialen Leitfähigkeit zu vermuten ist. Die von SPERRY et al. (1988) angegebenen Fehlerquellen beziehen sich meist auf eine unterschätzte axiale Leitfähigkeit, können also diese Diskrepanz nicht erklären.

Tatsächlich kann die Berechnung der theoretischen Leitfähigkeit fehlerbehaftet sein. Denn bei dieser Berechnung wird von einer idealen Kapillare ausgegangen, der die Gefäße in der Wurzel jedoch nicht entsprechen, da sie meist nicht ideal kreisrund sind. Fehler, die aus der Durchmesserermittlung hervorgehen, gehen in der 4. Potenz in die Werte der Leitfähigkeit ein. In der vorliegenden Untersuchung wurde nicht der gesamte Querschnitt der Wurzel anatomisch untersucht, sondern die Anzahl der Xylemgefäße eines Ausschnittes auf die gesamte Xylemfläche hochgerechnet. Bei dieser Hochrechnung können aufgetretene Fehler ebenfalls nochmals potenziert werden. Nach LEWIS \& BOOSE (1995) geht der größte Fehler in der Berechnung nach dem Gesetzt von Hagen-Poiseuille aus der Überschätzung des Gefäßdurch- 
messers hervor, denn bei vielen Angiospermen sind die Gefäßquerschnitte elliptisch. Dies war auch in den Wurzeln der hier untersuchten Baumarten der Fall, wurde jedoch bei der Berechnung berücksichtigt.

\section{Die hydraulische Leitfähigkeit $\operatorname{Lp}_{r}$ der Wurzeln verschiedener Baumarten}

Während bei den bisher besprochenen gemessenen und theoretisch berechneten hydraulischen Leitfähigkeiten allein die axialen Leitungscharakteristika der Wurzeln eingehen, wird die hydraulische Leitfähigkeit der Wurzel jedoch entscheidend von der radialen Leitfähigkeit mitbestimmt, die in der Wurzel oft der limitierende Faktor der Wasseraufnahme ist (ADEOYE \& RAWLINS, 1981, STEUdLE, 1994, PASSIOURA, 1988). Daher wurde aus in situ-Messungen im Bestand die hydraulische Leitfähigkeit der Wurzel $\left(\mathrm{Lp}_{r}\right)$ ermittelt, die sich aus den axialen und den radialen Anteilen der Leitfähigkeit zusammensetzt. In der vorliegenden Arbeit beinhaltet $\mathrm{Lp}_{r}$ zusätzlich die Leitfähigkeit der Rhizosphäre. Dies wird bedingt durch die Berechnung von $\mathrm{Lp}_{r}$ aus der Wasseraufnahmerate und der Potentialdifferenz zwischen Boden und Wurzel. Um allein die Leitfähigkeit der Wurzel zu berechnen, müsste die Potentialdifferenz zwischen Wurzeloberfläche und Wurzelxylem eingesetzt werden (SMIT et al., 2000).

In der Wurzel kann man davon ausgehen, dass die radiale Leitfähigkeit einen großen Anteil an $\mathrm{Lp}_{r}$ ausmacht, da im sekundären Xylem dicotyler Pflanzen nur geringe Transportwiderstände auftreten (PASSIOURA, 1988, MELCHIOR \& STEUDLE, 1993). Sieht man von Verletzungen oder Cavitation ab, wird der axiale Widerstand demgegenüber klein. Eine Ausnahme bildet die Wurzelspitzenregion, in der die Leitgefäße in einem primären Zustand vorliegen und die axiale Wasserleitung durch Querwände behindert wird (MELCHIOR \& STEUDLE, 1993).

In der vorliegenden Arbeit betrug die hydraulische Leitfähigkeit $\mathrm{Lp}_{r}$ der Wurzeln zwischen 3.8 und $27.6 \cdot 10^{-8} \mathrm{~m} \mathrm{MPa}^{-1} \mathrm{~s}^{-1}$ (für Eiche bzw. Winterlinde (Tab. 5.2)). Hier zeigten sich deutliche Unterschiede zwischen den Baumarten. Vor allem fiel die Winterlinde mit einer sehr viel höheren hydraulischen Leitfähigkeit auf.

Die meisten in der Literatur angegebenen $\mathrm{Lp}_{r}$-Werte wurden im Labor mit der Wurzeldrucksonde ermittelt. Dennoch finden sich recht gute Übereinstimmungen zwischen diesen und den aus in situ-Messungen berechneten Werten, wie bereits von CONERS (2001) festgestellt wurde.

STEUDLE \& MESHCHERYAKOV (1996) fanden für Schwachwurzeln der Stieleiche mit der Wurzeldrucksonde etwas niedrigere Werte, die zwischen 0.77 und $3.1 \cdot 10^{-8} \mathrm{~m} \mathrm{MPa}^{-1} \mathrm{~s}^{-1}$ lagen. CONERS (2001) gibt für Traubeneichen-Wurzeln Maximalwerte von $1.70 \cdot 10^{-8} \mathrm{~m}$ $\mathrm{MPa}^{-1} \mathrm{~s}^{-1}$ an, die nochmals etwas geringer sind, als die von STEUDLE \& MESHCHERYAKOV (1996) gemessenen Werte. Die Wurzeln der Buchen aus dem Hainich hatten eine hydraulische Leitfähigkeit von $4.7 \cdot 10^{-8} \mathrm{~m} \mathrm{MPa}^{-1} \mathrm{~s}^{-1}$, während von CONERS (2001) maximal $3.22 \cdot 10^{-8}$ $\mathrm{m} \mathrm{MPa}^{-1} \mathrm{~s}^{-1}$ gemessen wurden. STEUDLE \& HEYDT (1997) wiesen mit der Wurzeldrucksonde Werte zwischen 0.35 und $1.6 \cdot 10^{-8} \mathrm{~m} \mathrm{MPa}^{-1} \mathrm{~s}^{-1}$ nach. An Wurzeln von Picea abies maßen RÜDINGER et al. (1994) im Mittel eine hydraulische Leitfähigkeit von $6.4 \cdot 10^{-8} \mathrm{~m} \mathrm{MPa}^{-1}$ $\mathrm{s}^{-1}$, einzelne Wurzeln wiesen maximale Leitfähigkeiten von $29 \cdot 10^{-8} \mathrm{~m} \mathrm{MPa}^{-1} \mathrm{~s}^{-1}$ auf. Hy- 
draulische Leitfähigkeiten in der Größenordnung der Wurzeln aus dem Hainich wurden z.B. von SANDS ET AL. (1982) (zitiert nach STEUDLE \& HEYDT, 1997) an Pinus taeda-Wurzeln gemessen. Junge Wurzeln erreichten bis zu $20 \cdot 10^{-8} \mathrm{~m} \mathrm{MPa}^{-1} \mathrm{~s}^{-1}$, ältere Wurzeln noch $7.6 \cdot 10^{-8} \mathrm{~m} \mathrm{MPa}^{-1} \mathrm{~s}^{-1}$. SMITH \& ROBERTS (2003) maßen an 1-4 mm starken Wurzeln von Grevillea robusta $\mathrm{Lp}_{r}$-Werte von $12 \cdot 10^{-8} \mathrm{~m} \mathrm{MPa}^{-1} \mathrm{~s}^{-1}$.

RINCON et al. (2003) konnten für Wurzeln von Glycine max keine Beziehung zwischen der hydraulischen Leitfähigkeit und der theoretischen axialen Leitfähigkeit feststellen, woraus der Schluss gezogen werden kann, dass die Hauptkomponente der Wurzelleitfähigkeit im radialen Anteil liegt.

Dies konnte ebenfalls für die Variabilität der hydraulischen Leitfähigkeit zwischen den verschiedenen Baumarten in der vorliegenden Arbeit festgestellt werden. Weder zwischen theoretischer $\left(\mathrm{k}_{S}\right.$ theo $)$ noch gemessener axialer Leitfähigkeit $\left(\mathrm{k}_{m}\right)$ und der gemessenen hydraulischen Leitfähigkeit $\mathrm{Lp}_{r}$ konnte eine statistisch signifikante Beziehung gefunden werden $\left(\mathrm{R}^{2}=0.02\right.$, $\mathrm{p}=0.77$ bzw. $\mathrm{R}^{2}=0.05, \mathrm{p}=0.73$ ). Ein enger linearer Zusammenhang zwischen der Wasseraufnahmerate und der hydraulischen Leitfähigkeit $\mathrm{Lp}_{r}$ wurde nicht gefunden, so dass ein dominierender Einfluss der hydraulischen Wurzelleitfähigkeit, und der darin eingeschlossenen Rhizosphären-Leitfähigkeit auf die Höhe der Wasseraufnahmerate, nicht gegeben ist.

Eine Erklärung für die intra- und interspezifische Variabilität der Leitfähigkeiten von Baumwurzeln bieten STEUDLE (1994) und STEUDLE \& HEYDT (1997) mit dem ,composite transport model of the root" an. Anhand dieses Modells kann eine Steigerung der hydraulischen Leitfähigkeit der Wurzel $\mathrm{Lp}_{r}$ bei erhöhter Wasseraufnahme erklärt werden. Je nach den Erfordernissen, d.h. je nach dem Wasserbedarf des Sprosses, kann das Verhältnis zwischen dem apoplastischen und dem zellulären Wasserfluss variiert werden. Daraus ergibt sich eine Abhängigkeit der hydraulischen Leitfähigkeit von der Wurzelanatomie, da die Ausprägung eines Caspary-Streifens und die Einlagerung von Suberinlamellen in die Zellen der Endodermis bzw. des Periderms Barrieren gegen den apoplastischen Wassertransport bilden.

Die hydraulische Leitfähigkeit der Wurzeln kann sich demnach an den Wasserbedarf der oberirdischen Pflanzenteile, in diesem Fall des Stammes und der Krone, anpassen und ist vom Wasserdurchsatz des Baumes abhängig.

Unterschiede im Grad der Suberinisierung der Wurzeln krautiger Pflanzen und der Wurzeln von Bäumen führen zu Differenzen der hydraulischen Leitfähigkeit. Da Wurzeln von (Alt-) Bäumen meist in einem höheren Maße suberinisiert sind, ist die radiale hydraulische Leitfähigkeit geringer. Durch einen unterschiedlichen Suberinisierungsgrad kann es zu Artunterschieden in der Leitfähigkeit kommen (STEUDLE \& HEYDT, 1997).

Unter diesem Gesichtspunkt untersuchten LEUSCHNER et al. (2003) die Suberin- und Ligningehalte der Feinwurzeln von Fichte, Buche und Traubeneiche. Zwar wurden signifikante Unterschiede zwischen den drei Baumarten gefunden, die Unterschiede in den ebenfalls untersuchten radialen Leitfähigkeiten waren jedoch vergleichsweise gering, so dass der Suberingehalt allein keine Erklärung für die differierenden Leitfähigkeiten bot. 
Aquaporine haben eine wichtige Bedeutung, wenn durch einen hohen Grad der Suberinisierung einer Wurzel der apoplastische Wasserfluss weitgehend unterbrochen ist. In diesem Fall kann man davon ausgehen, dass die Aquaporine den einzigen Mechanismus für den Wassertransport in der Wurzel bilden (STEUDLE \& PETERSON, 1998). Dementsprechend fanden HENZLER et al. (1999) eine Abhängigkeit der hydraulischen Leitfähigkeit in Wurzeln der krautigen Lotus japonica von der Expression der Aquaporine im Tagesrhythmus. Demnach würde eine artspezifische Ausprägung von Aquaporinen auch artspezifische Unterschiede in den Leitfähigkeiten und Wasseraufnahmeraten zur Folge haben. Allerdings gibt es noch keine Studien, die das Vorkommen von Aquaporinen in den Wurzeln verschiedener Baumarten vergleichend betrachten. Aufgrund der Vielzahl an Formen, in denen Aquaporine in pflanzlichen Geweben auftreten können, ist das Verständnis der genauen Funktion in Bezug auf die hydraulische Leitfähigkeit der Pflanze bisher noch unvollständig (JAVOT \& MAUREL, 2002).

\section{Die Wasseraufnahme durch die Feinwurzeln}

Untersuchungen an Wurzeln krautiger Pflanzen zufolge, sind die Hauptbarrieren für die Wasseraufnahme in der Exo- oder Endodermis zu sehen (SANDERSON, 1983, MELCHIOR \& STEUdLE, 1993, MCKENZIE \& PETERSON, 1995a, ZimMERMANN \& STEUdLE, 1998, RIEGER \& LITVIN, 2003). Angiospermenwurzeln stoßen mit dem Einsetzen des sekundären Dickenwachstums die primäre Endodermis ab. Durch perikline Teilungen des nach innen an die primäre Endodermis angrenzenden Perikambiums, wird das Periderm als sekundäres Abschlussgewebe gebildet. Durch Einlagerung von Suberin in die Zellen des Periderms wird die Permeabilität für Wasser weitgehend herabgesetzt. Daher wird häufig die Wurzelspitzenregion als Zone der Wasseraufnahme genannt (z.B. MELCHIOR \& STEUdLE, 1993). VON GUTTENBERG (1968) kommt zu dem Schluss, dass nicht direkt die äußerste Wurzelspitze für die Wasseraufnahme verantwortlich ist, da in der meristematischen Zone und in der Streckungszone die Wasserleitung durch dichtgelagerte Zellen erschwert würde. Erst in der Wurzelhaarzone befinden sich Rhizodermis, primäre Endodermis und die Leitelemente fertig ausgebildet für einen raschen Wassertransport. In der anschließenden Region der Wurzel kommt es durch Einlagerung von Suberinlamellen wiederum zur Beeinträchtigung der Wasseraufnahme. VON GUTTENBERG (1968) führt an, dass bei dicotylen Angiospermen durch die Peridermbildung die Zone der raschen Wasseraufnahme schon frühzeitig beendet wird.

Um zu klären, ob die Baumarten Unterschiede in der Ausprägung des Periderms aufweisen, wurden $5 \mathrm{~mm}$ hinter der mykorrhizierten Wurzelspitze Wurzelquerschnitte angefertigt und lichtmikroskopisch untersucht. Dabei konnte festgestellt werden, dass bei allen untersuchten Arten bereits direkt hinter der Wurzelspitze schon die Abstoßung der Endodermis vollzogen war und 3-4 Peridermzellschichten ausdifferenziert waren. Nach der vorgestellten Theorie müsste demnach die Wasserversorgung der Bäume ausschließlich über die Wurzelspitzen erfolgen, während der restliche Teil der Wurzel nur zu Transportzwecken dient.

In der Anzahl der Peridermzelllagen unterschieden sich die Baumarten nur wenig. Jedoch hatten Esche und Linde entlang des untersuchten Wurzelstranges eine dickere Schicht des sekundären Abschlussgewebes entwickelt als die anderen vier Baumarten (Abb. 4.16). 
Nach MCKenZIE \& PeTERSON (1995b) treten bei Wurzeln von Pinus banksiana und Eucalyptus pilularis erst in einer Entfernung von ca. $10 \mathrm{~cm}$ bzw. $60 \mathrm{~cm}$ von der Wurzelspitze die ersten Zellen einer Korkschicht, das sich entwickelnde Periderm, auf. Untersuchungen von MAPFUMO \& ASPINALL (1994) zeigten ebenso für junge Wurzeln von Weinstöcken erst nach mehr als $50 \mathrm{~cm}$ Entfernung von der Wurzelspitze eine beginnende Abstoßung des Cortex. Dagegen konnte ICKE (2000) bereits wenige mm hinter der Wurzelspitze von Buchen- und Traubeneichenwurzeln keine Endodermis mehr nachweisen.

Aufgrund dieser Ergebnisse ist es demnach schwer, den genauen Ort der Wasseraufnahme zu bestimmen.

Für die Bestimmung der oberflächenspezifischen Wasseraufnahme wurde daher in der vorliegenden Arbeit neben der Gesamtwurzeloberfläche auch die Feinstwurzeloberfläche $(<1 \mathrm{~mm}$ im Durchmesser) als Bezugsgröße für die Saftflussrate gewählt (Abb. 4.24).

Trotz der signifikant unterschiedlichen Gesamtwurzeloberflächen war der relative Anteil an Feinstwurzeln an den untersuchten Wurzelsträngen für alle Baumarten gleich hoch. Daher ergab sich für eine nur auf die Feinstwurzeln beschränkte Wasseraufnahme eine nur geringe Abweichung von der oberflächenspezifischen Aufnahmerate im Verhältnis der Baumarten untereinander. Stellt man die Wasseraufnahmeraten der Feinstwurzeln den Peridermstärken in den Feinstwurzeln (hier $5 \mathrm{~mm}$ hinter der Wurzelspitze) gegenüber (Abb. 5.6), lässt sich kein signifikanter Zusammenhang erkennen. So hat die Esche trotz einer starken Peridermschicht eine hohe Wasseraufnahmerate über die Feinstwurzeln, während die Hainbuche die geringste Wasseraufnahmerate bei geringer ausgeprägtem Abschlussgewebe aufweist.

Diese Ergebnisse legen den Schluss nahe, dass auch ältere, ausdifferenzierte Wurzelsegmente einen Beitrag zur Wasseraufnahme leisten.

ADDOMS (1946) und KRAMER (1946) konnten an suberinisierten Baumwurzeln, die ein Periderm aufwiesen, den Eintritt von Wasser durch die Korkschicht feststellen. KRAMER \& BULLOCK (1966) fanden ebenfalls eine beträchtliche Wasseraufnahme durch suberinisierte Wurzelabschnitte. Nach ihren Berechnungen wird lediglich 2.4\% des Wassers durch Wurzelspitzen aufgenommen, 23\% über mykorrhizierte Wurzeln und 75\% über suberinisierte Wurzeln. VON GUTTENBERG (1968) stellt die Theorie auf, dass durch eine hohe Saugkraft des Sprosses, also eine hohe Wasserpotentialdifferenz bei starker Transpiration, sich die Zone der Wasseraufnahme zugunsten der basalen Anteile der Wurzel verschiebt. Dies setzt einen höheren Einfluss der Wasserpotentialdifferenz gegenüber der radialen Wurzelleitfähigkeit voraus. Neuere Untersuchungen zur Wasseraufnahme über Grobwurzeln liegen von LINDENMAIR \& MATZNER (2001) vor, die die Wasseraufnahme von intakten Grobwurzelsegmenten von Fichten im Bestand untersuchten. Die Hochrechnung der Wasseraufnahme auf das gesamte Grobwurzelsystem ergab eine Aufnahmeleistung von 12\% der täglichen Transpiration. Die Wurzeln nahmen bis zu 0.001-0.025 $\mathrm{g} \mathrm{cm}^{-2} \mathrm{~d}^{-1}$ Wasser auf. Dies ist deutlich geringer als die oberflächebezogene Wasseraufnahmerate der Feinwurzeln in der vorliegenden Untersuchung. Deren Aufnahmeraten lagen im Mittel zwischen 0.20 und $0.34 \mathrm{~g} \mathrm{~cm}^{-2} \mathrm{~d}^{-1}$ und damit bis zu 340fach höher als die der Grobwurzelsegmente. In einer weiteren Untersuchung stellten 


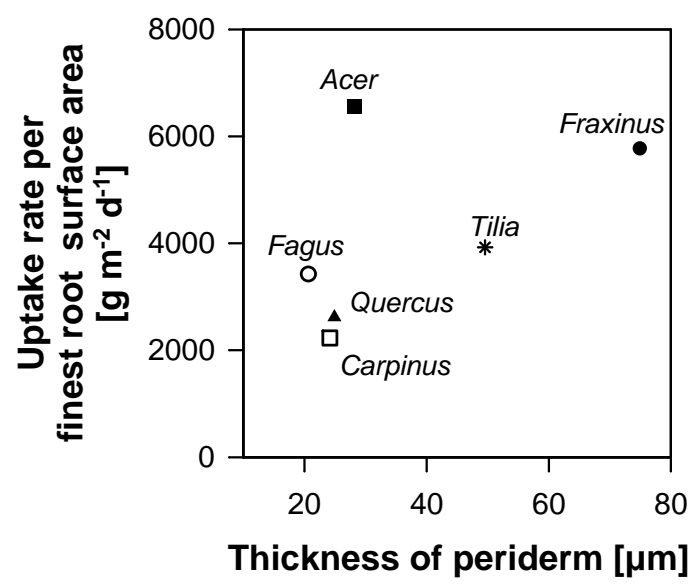

Abb. 5.6: Beziehung zwischen der Peridermstärke in $5 \mathrm{~mm}$ Abstand von der Wurzelspitze und der oberflächenspezifischen Wasseraufnahmerate der Feinstwurzeln. Dargestellt sind die Mittelwerte der Peridermstärke von 3 Wurzelenden pro Baumart und die Mittelwerte der oberflächenspezifischen Wasseraufnahmerate von 10-15 Wurzeln pro Baumart aus den Vegetationsperioden 2000 und 2001. Als Bezugsgröße der Wasseraufnahmerate diente die Oberfläche der Feinstwurzeln (Durchmesser $<1 \mathrm{~mm}$ ).

LINDENMAIR \& MATZNER (2003) an Grobwurzelsegmente (Durchmesser 1.8 bis $7.2 \mathrm{~cm}$ ) von Buchen und Eichen oberflächenspezifische Aufnahmeraten bis zu $0.009 \mathrm{~g} \mathrm{~cm}^{-2} \mathrm{~d}^{-1}$ fest. Experimente von MACFALL et al. (1991) an Pinus taeda-Sämlingen bestätigten ebenfalls eine Wasseraufnahme über Wurzeln mit sekundärem Dickenwachstum.

Allerdings macht die Feinwurzeloberfläche den größten Anteil an der Gesamtwurzeloberfläche aus, so dass zu erwarten ist, dass tatsächlich die Wasseraufnahme vorwiegend über die Fein- und Feinstwurzeln stattfindet, auch wenn dort bereits ein Periderm ausgebildet ist.

Die in der vorliegenden Arbeit untersuchten Wurzelstränge waren mykorrhiziert. Der Grad der Mykorrhizierung wurde nicht bestimmt, doch konnten zwei Arten der Mykorrhiza-Infektion unterschieden werden. Die Wurzeln der Winterlinde, Hainbuche, Stieleiche und Buche waren ektomykorrhiziert, während Bergahorn und Esche eine VA-Mykorrhiza aufwiesen.

Einen Einfluss der Mykorrhizierung der Wurzel bewerten viele Autoren positiv für die Pflanze. Für ektomykorrhizierte Wurzeln basiert dieser positive Effekt auf einem Schutz der Wurzel oder der Wurzelspitze durch den Pilzmantel vor der Austrocknung (GEORGE \& MARSCHNER, 1996. SMITH \& READ, 1997) oder der Änderung der hydraulischen Leitfähigkeit der Wurzel (NARDINI et al., 2000, MUSHIN \& ZWIAZEK, 2002). STEUDLE \& HEYDT (1997) konnten nur eine geringe Beeinflussung der hydraulischen Leitfähigkeit der Wurzeln von Buchensämlingen beobachten. Die von ihnen festgestellten Effekte einer Ektomykorrhizierung beruhen auf einer verbesserten Phosphat-Aufnahme, was von NARDINI et al. (2000) bestätigt wird.

Die Untersuchungen zum Effekt einer VA-Mykorrhizierung auf den Wasserhaushalt der Pflan- 
zen weisen auf eine verbesserte Austrocknungsresistenz der Wurzeln und zusätzlich eine erhöhte Wasseraufnahme hin (GEORGE et al., 1992, RUIZ-LOZANO \& AZCON, 1995). Bei VA-mykorrhizierten Wurzeln beruhen die positiven Effekte der Mykorrhizierung auf einer erhöhten Nährstoffaufnahme und insbesondere einer besseren Phosphatversorgung (GEORGE et al., 1992, SMITH \& READ, 1997). MUSHIN \& ZWIAZEK (2002) konnten an Wurzeln von inokulierten Ulmen eine Steigerung der hydraulischen Leitfähigkeit feststellen.

Es kann festgehalten werden, dass sich eine Mykorrhizierung der Wurzeln positiv auf den Baum auswirkt. In welcher Weise jedoch eine Steigerung der Wasseraufnahme erreicht wird ist noch ungeklärt. STEUDLE \& HEYDT (1997) gehen von einer effektiven Vergrößerung der aufnehmenden Oberfläche durch die Hyphen der Ektomykorrhiza aus. In einer Vergrößerung der Wurzeldichte und damit der Wurzeloberfläche bei gleichzeitig verminderter hydraulischer Wurzelleitfähigkeit sehen NARDINI et al. (2000) einen positiven Effekt infolge einer Ektomykorrhizierung. Das Gegenteilige postulieren GEORGE et al. (1992) für VA-mykorrhizierte Wurzeln, die nach ihren Untersuchungen vor allem an krautigen Pflanzen kürzer, dicker und weniger verzweigt sind als nicht-mykorrhizierte Wurzeln. Unterschiede in der Wurzelmorphologie zwischen ekto- und VA-mykorrhizierten Wurzeln konnten in der vorliegenden Untersuchung nicht bestätigt werden. Die kürzesten und stärksten vermessenen Wurzelstränge wiesen die ektomykorrhizierte Buche und der VA-mykorrhizierte Bergahorn auf. Auch unterschieden sich auf verschiedene Arten mykorrhizierte Feinwurzeln nicht systematisch im Verzweigungsgrad voneinander (siehe Tab. 3.1). Dies gilt ebenfalls für die Höhe der Saftflussdichte und für die gemessenen hydraulischen Leitfähigkeiten $\mathrm{Lp}_{r}$ und $\mathrm{k}_{m}$; diese lassen keine Unterscheidung zwischen ekto- und VA-mykorrhizierten Arten zu.

\subsubsection{Die Bedeutung der unterirdischen Bestandesstruktur für die Wasseraufnahme}

Eine hohe Wachstumsrate und die Durchdringung eines großen Bodenvolumens durch Baumwurzeln erhöhen die Möglichkeit, Wasserressourcen zu erschließen und damit einen stabilen Wasserhaushalt aufrecht zu erhalten (PERSSON, 2000).

Ein flaches, ausgedehntes Wurzelsystem mit einer hohen Feinwurzeldichte nahe der Bodenoberfläche ist von Vorteil, um bei einer Durchfeuchtung des Oberbodens eine schnelle Wasseraufnahme zur ermöglichen, wie GREEN \& CLOTHIER (1995) für Apfelbäume feststellten. Die Feinwurzelverteilung spiegelt damit die potentielle Wasseraufnahmekapazität wieder (GREEN \& ClOTHIER, 1995). Ein großes Wurzelsystem kann nach TESKEY et al.(1985) als eine Anpassung an Austrocknungsereignisse gewertet werden. Durch ein solches überdimensioniertes Wurzelsystem kann der Rhizosphärenwiderstand ausgeglichen werden, der bei geringen Bodenmatrixpotentialen ansteigt (vgl. auch RAMBAL, 1984). Allerdings weisen THORBURN \& EHLERINGER (1995) darauf hin, dass das Vorkommen von Wurzeln nicht zwingend mit der Aktivität dieser Wurzeln verbunden ist.

Einen Einfluss der Größe des Wurzelsystems auf die Wasserentnahme aus dem Boden konnten FORT et al. (1998) an Birken- und Eichenjungwuchs ermitteln. Die höhere Feinwurzelmasse 
der Birken ging einher mit einer höheren Wasserentnahme aus dem Boden. Tatsächlich kann dies auch für die Baumarten im Hainich festgestellt werden (Abb. 5.7A). Mit einer steigenden Feinwurzeldichte nahm die Bestandeswasseraufnahme zu. Dagegen ergab sich keine signifikante Korrelation zwischen der Saftflussdichte einzelner Wurzeln und der Feinwurzeldichte. Jedoch kann die Tendenz beobachtet werden, dass Baumarten mit einer geringen mittleren Saftflussdichte eine höhere Feinwurzeldichte aufweisen (Abb. 5.7B).

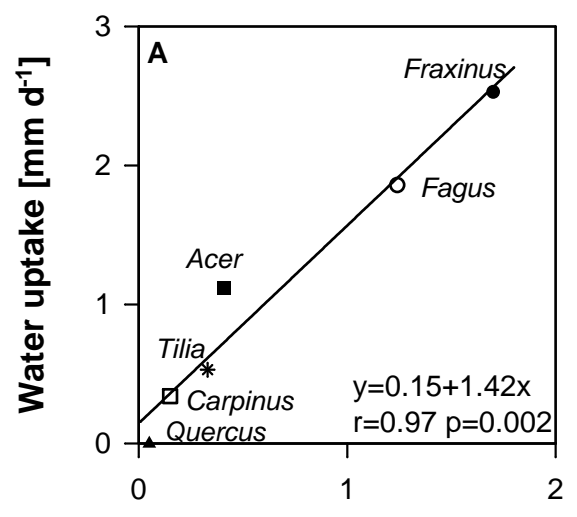

Fine root density [g d.m. L-1]

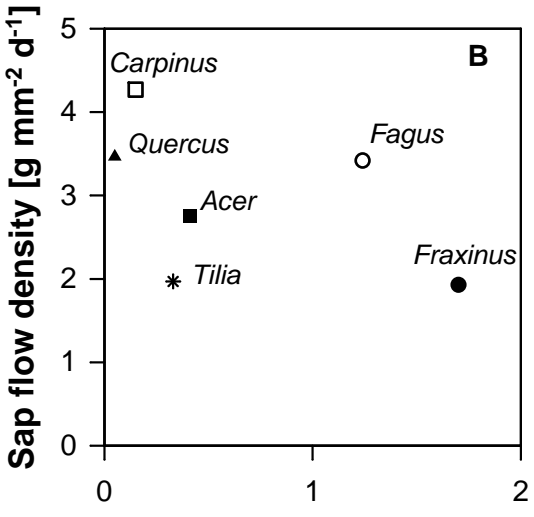

Fine root density [g d.m. L-1]

Abb. 5.7: Beziehung zwischen der Feinwurzeldichte und der Bestandeswasseraufnahme (A) bzw. der Saftflussdichte (B) der sechs Baumarten im Nationalpark Hainich. Dargestellt sind die Mittelwerte der Feinwurzeldichte im Bestand (Daten der Buche von $\mathrm{KOCH}(2002)$ ), und die mittlere Bestandeswasseraufnahme in den Vegetationsperioden 2000 und 2001 sowie die gemittelten Tageswerte der Saftflussdichte aus 10-18 Wurzeln pro Baumart.

Es wird deutlich, dass sich bei der Esche die niedrige Wasseraufnahmerate einzelner Wurzeln durch ein großflächiges Wurzelsystem relativiert. Dadurch erzielt sie hohe Bestandeswasseraufnahmeraten. Darin geht die weiter vorn angegebene positive Beziehung zwischen der Saftflussdichte und der Oberfläche der Wurzelstranges ein. Am Beispiel der Esche lässt sich zeigen, dass diese eine nur geringe Saftflussdichte hat. Gleichzeitig wiesen die untersuchten Wurzelstränge eine geringe Wurzeloberfläche auf. In Verbindung mit einer hohen Feinwurzeldichte kann für die Esche daher auf Bestandesebene eine hohe Wasseraufnahme bestimmt werden.

Von KOCH (2002) liegen für den benachbarten Buchenwald Daten der Bestandestranspiration aus der Vegetationsperiode 2001 vor. Im Mittel hatte der Buchenwald eine Transpirationsrate von $1.18 \mathrm{~mm} \mathrm{~d}^{-1}$. Die aus dem Bestandes-RAI und den Wurzelsaftflussmessungen in diesem Buchenwald berechnete Bestandeswasseraufnahme liegt bei $1.86 \mathrm{~mm} \mathrm{~d}^{-1}$. Diese beiden Angaben liegen in der gleichen Größenordnung. Somit kann davon ausgegangen werden, dass die gemessenen Wurzelsaftflussraten die Wasseraufnahme recht gut wiedergeben.

Eine Beeinflussung der Wasseraufnahmeraten ist durch eine unterschiedliche Erschließung des Bodens durch das Wurzelsystem der verschiedenen Baumarten möglich. So weisen z.B. MANNING \& BARBOUR (1988), KÖSTLER et al. (1968) und JACKSON et al. (1996) darauf 
hin, dass Baumarten mit einem tief reichenden Wurzelsystem Vorteile in der Wasserversorgung bei einer Austrocknung des Oberbodens gegenüber flachwurzelnden Arten haben.

Die vorliegenden Ergebnisse zur Grobwurzelverteilung im Mischbestand im Hainich zeigten eine vollständige Erschließung des Bodens im Profil bis in eine Tiefe von $50 \mathrm{~cm}$. Eine tiefere Beprobung war durch das dort anstehende Ausgangsgestein nicht möglich. Der überwiegende Anteil der Grobwurzeln befand sich in einer Bodentiefe bis $20 \mathrm{~cm}$. So kann für den Hainich aufgrund dieser Ergebnisse keine Einteilung in flach- oder tiefwurzelnde Baumarten vorgenommen werden. Nach KUTSCHERA \& LICHTENEGGER (2002) unterscheiden sich die sechs Baumarten hinsichtlich ihrer mittleren Durchwurzelungstiefe kaum voneinander, sie reichen von 120-130 cm für Hainbuche und Linde, bis zu $150 \mathrm{~cm}$ für Esche und Eiche. Diese Angaben gelten für sandige Lehmböden. Die in der vorliegenden Arbeit untersuchten Bäume stocken jedoch auf lehmigem Ton, der ein schnelles, weites Vordringen der Wurzeln behindern kann. Baumarten, deren Wurzeln eine höhere mechanische Energie besitzen, können den Boden leichter durchdringen als Wurzeln von Baumarten mit geringer mechanischer Energie. $\mathrm{Zu}$ ersteren zählen Stieleiche, Hainbuche und Esche, während dichtgelagerte Lehmböden bei der Buche, der Winterlinde und besonders dem Bergahorn zu einer Verflachung des Wurzelsystems führen (KÖSTLER et al., 1968).

Eine Konzentrierung der Grobwurzeln in den oberen $20 \mathrm{~cm}$ des Bodens konnten SCHMID \& KAZDA (2001), BREDA et al. (1995) und JOHN et al. (2001) bestätigen, die verschiedene Laub- und Nadelbaumarten in Misch- und Reinbeständen untersuchten. KOCH (2002) nahm die Grobwurzelverteilung in einem Buchenbestand, der benachbart zu dem in der vorliegenden Arbeit betrachteten Mischbestand lag, auf. Dort wurde ein Verteilungsschwerpunkt in der Bodentiefe bis $20 \mathrm{~cm}$ festgestellt. Auf der Mischwaldfläche wurde eine Bestandesgrobwurzeldichte von 105.7 Wurzeln $\mathrm{m}^{-2}$ ermittelt, die im Buchenreinbestand mit 60.9 Wurzeln $\mathrm{m}^{-2}$ (KOCH, 2002) deutlich geringer war.

Die signifikant größten Grobwurzeldichten in jeder Tiefe wurden von der Esche erreicht. Grob- und Schwachwurzeln der Stieleiche konnten nur an einer Probestelle gefunden werden. Die relativen Häufigkeiten korrelierten sehr gut mit der Stammdichte der jeweiligen Arten.

Der Hauptanteil der Feinwurzeln wird meist in den obersten Bodenhorizonten gefunden (z.B. BÜTTNER \& LEUSCHNER, 1994, BREDA et al., 1995, HERTEL, 1999). Die Feinwurzeldichte des Mischwaldes im Hainich wurde in der vorliegenden Arbeit in einer Bodentiefe von 0$10 \mathrm{~cm}$ und 10-20 cm ermittelt. Schon in dieser vertikalen Stufung nahm der Bestandeswert der Feinwurzeldichte von 2.92 auf $0.92 \mathrm{~g} \mathrm{~L}^{-1}$ signifikant ab. $\mathrm{KOCH}$ (2002) gibt für den benachbarten Buchenbestand eine Feinwurzeldichte von $1.24 \mathrm{~g} \mathrm{~L}^{-1}$ in $0-10 \mathrm{~cm}$ bzw. $1.06 \mathrm{~g} \mathrm{~L}^{-1}$ in 10-20 cm Bodentiefe an.

In einer Übersicht über die Literaturangaben der Feinwurzelbiomasse aus 60 verschiedenen Waldbeständen gemäßigter Breiten geben LEUSCHNER \& HERTEL (2003) einen Mittelwert von $482 \mathrm{~g} \mathrm{~m}^{-2}$ für Laubwälder an. Die Feinwurzelbiomassen der einzelnen Bestände liegen im Bereich zwischen 69 und $1017 \mathrm{~g} \mathrm{~m}^{-2}$. Ähnlich hoch ist der von ihnen ermittelte Wert für Buchenbestände, der bei $470 \mathrm{~g} \mathrm{~m}^{-2}$ liegt. Die Feinwurzelbiomasse des Mischbestandes, der in der vorliegenden Arbeit untersucht wurde, ist mit $384.9 \mathrm{~g} \mathrm{~m}^{-2}$ in den oberen $20 \mathrm{~cm}$ des Mi- 
neralbodens etwas geringer als der Durchschnitt. Laubwaldbestände aus der vorher genannten Übersicht, die hinsichtlich des Niederschlags und des $\mathrm{pH}$-Wertes des Bodens vergleichbar mit dem Mischbestand aus der vorliegenden Arbeit sind, weisen ähnlich hohe Feinwurzelbiomassen auf.

REWALD (2003) untersuchte das Feinwurzelsystem in einem Traubeneichen-Hainbuchen-Mischwald im Ziegelrodaer Forst (Sachsen-Anhalt). Für den oberen Mineralbodenhorizont $(0-10 \mathrm{~cm})$ gibt er eine Bestandesfeinwurzelbiomasse von $122 \mathrm{~g} \mathrm{~m}^{-2}$ an.

Eine weitere Untersuchung der Feinwurzeln im Mischwald im Hainich führte MEINEN(2004) durch. Für vier Untersuchungsflächen benachbart zu der in der vorliegenden Arbeit untersuchten Fläche gibt sie Bestandesfeinwurzeldichten von $2.04-2.71 \mathrm{~g} \mathrm{l}^{-1}$ an. Damit liegen die Ergebnisse für die Feinwurzeldichte der vorliegenden Arbeit mit $2.92 \mathrm{~g}^{-1}$ in der gleichen Größenordnung.

Die Feinwurzeldichte eines Linden-Ahorn-Waldes auf Basalt betrug lediglich $0.59 \mathrm{~g} \mathrm{l}^{-1}$ (HÖLSCHER et al., 2002). Dieser Bestand kann jedoch als Sonderstandort betrachtet werden, da der Skelettanteil 57\% des Bodenvolumens ausmachte. An Stellen mit Feinboden ohne hohe Skelettfraktion wurde eine sehr hohe Feinwurzeldichte von $6.75 \mathrm{~g} \mathrm{l}^{-1}$ ermittelt.

Es kann also festgehalten werden, dass der Mischwaldbestand im Hainich ein sehr gut durchwurzelter Bestand mit einer hohen Feinwurzelbiomasse ist, sich damit jedoch nicht von vergleichbaren Laubwaldbeständen unterscheidet.

Die Überlappung der Wurzelsysteme ist hoch. In über $40 \%$ der Probestellen wurden Feinwurzeln von vier Baumarten gefunden, in jeweils 2\% der Fälle konnte nur eine Art bzw. sechs Arten (von 11 vorkommenden Baumarten) nachgewiesen werden. In dem von REWALD (2003) untersuchten Mischbestand aus vier Baumarten war der obere Mineralboden zu 100\% durchwurzelt, in 50\% der Probestellen wurden Feinwurzeln zweier Arten gefunden. HöLSCHER et al. (2002) konnten dagegen in einem skelettreichen Mischbestand aus sechs Baumarten eine räumliche Trennung der Wurzelsysteme aufzeigen, da in 62\% der Proben nur Wurzeln einer Baumart gefunden wurden. In einem Traubeneichen-Buchenmischbestand überlappten die Wurzelsysteme vollständig, wobei die Buche fast immer eine deutlich höhere Feinwurzeldichte hatte als die Eiche (CONERS et al., 1998, LEUSCHNER et al., 2001b).

Aus den ermittelten Feinwurzelbiomassen wurde der Wurzeloberflächen-Index (root area index, RAI) berechnet. Dieser beschreibt die den Bäumen zur Aufnahme von Wasser und Nährstoffen zur Verfügung stehende Feinwurzeloberfläche, die mit steigendem RAI zunimmt.

Der Bestandes-RAI (kumuliert aus den RAI der einzelnen Baumarten) lag für den hier untersuchten Mischwald bei $12.7 \mathrm{~m}^{2} \mathrm{~m}^{-2}$ (in 0-10 $\mathrm{cm}$ Tiefe). Den signifikant größten Anteil hatte wiederum die Esche $\left(7.4 \mathrm{~m}^{2} \mathrm{~m}^{-2}\right)$, während die Buche nur einen RAI von $0.16 \mathrm{~m}^{2} \mathrm{~m}^{-2}$ aufwies. Der RAI-Wert für die Buche im oberen Mineralboden im benachbarten Buchenreinbestand lag bei $4.4 \mathrm{~m}^{2} \mathrm{~m}^{-2}$ (KOCH, 2002). HERTEL (1999) ermittelte für Buchenbestände RAIWerte zwischen 3.1 und $9.1 \mathrm{~m}^{2} \mathrm{~m}^{-2}$. LEUSCHNER et al. (2001b) geben den RAI bis in $0.60 \mathrm{~m}$ Tiefe eines Buchen-Traubeneichen-Mischbestandes mit 9.52 (Buche) bzw. $3.43 \mathrm{~m}^{2} \mathrm{~m}^{-2}$ (Eiche) an. Einen im Vergleich zu diesen relativ niedrigen RAI-Werten hatte der Mischwald im Ziegelrodaer Forst mit $4.5 \mathrm{~m}^{2} \mathrm{~m}^{-2}$ (REWALD, 2003). 


\subsubsection{Veränderung der Wasseraufnahme während natürlich auftretender Trockenperioden}

Für den Wurzelsaftfluss aller in dieser Arbeit untersuchten Baumarten erwies sich der Bodenwassergehalt über den gesamten Messzeitraum lediglich als untergeordneter Faktor. Nur bei wenigen Wurzeln blieb im Modell der multiplen Regression der Parameter Bodenwassergehalt erhalten. Lediglich für den Bergahorn konnte für die Hälfte der untersuchten Wurzeln $42 \%$ der Varianz durch Schwankungen im Bodenwassergehalt erklärt werden.

Der Wassergehalt des Bodens gewinnt an Bedeutung für die Wasseraufnahme, wenn Austrocknungsereignisse auftreten. Nach Beobachtungen von z.B. OREN \& PATAKI (2001), LEMOINE et al. (2001), MARTINEZ-VILALTA et al. (2003), AASAMAA et al. (2004) gibt es zwei unterschiedliche Anpassungsstrategien der Baumarten an Trockenheit. Die Autoren unterscheiden zum einen Bäume, die bei beginnender Austrocknung des Bodens sofort ihre Wasseraufnahme einschränken. Bei diesen Arten verringert sich die stomatäre Leitfähigkeit, um eine Absenkung des Wasserpotentials und Cavitationen der wasserleitenden Xylemgefäße zu vermeiden. Diese Reaktionen von Pflanzen werden als ,,avoidance“-Mechanismen bezeichnet (nach LEVITT, 1956 AUs LÖSCH, 2001, LUDLOW, 1989). Zum anderen werden Baumarten unterschieden, die eine hohe stomatäre Leitfähigkeit beibehalten, wodurch das Wasserpotential erniedrigt wird. Dadurch kann bei diesen Arten eine gute Wasseraufnahme auch bei Trockenheit gewährleistet werden. Diese Baumarten ertragen Stress, dementsprechend wird von „tolerance“-Mechanismen gesprochen (nach LEVITT,1956 AUS LÖSCH, 2001, LUDLOW, 1989). Eine solche Unterteilung in Arten mit „tolerance“- und „,avoidance“-Strategie kann für die Baumarten der vorliegenden Untersuchung unternommen werden.

Während Austrocknungsperioden mit abnehmender Bodenwasserverfügbarkeit wurde die Wasseraufnahme über Wurzeln von Winterlinde, Buche und Bergahorn um mehr als die Hälfte gesenkt (67-73\%). Bei der Hainbuche konnte ebenfalls eine tendenziell starke Abnahme der Saftflussdichte festgestellt werden. Bei Stieleiche und Esche konnte eine Reduzierung der Saftflussdichte beobachtet werden, die jedoch deutlich geringer war (25-28\%).

Die multiple Regressionsanalyse zeigte eine wachsende Bedeutung des Bodenwassergehaltes während der Austrocknung (Tab. 4.9). Für alle Baumarten stieg der durch den Bodenwassergehalt erklärbare Anteil der Varianz an, während der Einfluss der Strahlung und des VPD abnahm. Besonders deutlich wurde dies bei der Buche: die Höhe der Saftflussdichte jeder untersuchten Wurzel wurde etwa zur Hälfte von der Bodenfeuchte bestimmt. Relativ unbeeinflusst blieb die Esche, nur 50\% der untersuchten Wurzeln konnte ein beeinflussender Faktor zugeschrieben werden, so dass die Wasseraufnahme der Esche während der Austrocknungsperiode in noch geringerem Maße von Umweltfaktoren beeinflusst wurde als über die gesamte Vegetationsperiode. Von den hier betrachteten Umgebungsparametern hatte allein der Bodenwassergehalt einen Einfluss auf die Höhe der Wasseraufnahmerate. Eine Steuerung der Wasseraufnahme muss demnach in erster Linie über physiologische Größen erfolgen. Zwar konnte keine Beziehung zwischen der Wurzel-Saftflussdichte und dem Wurzel-Wasserpotential gefunden werden, doch wurde für alle Arten eine - zumindest tendenzielle - Korrelation zwi- 
schen Wurzel-Saftflussdichte und Wasserpotentialdifferenz gefunden. Diese Wasserpotentialdifferenz stellt nach der allgemeinen Flussgleichung (G1. 5.1) einen Hauptfaktor für den Fluss des Wassers durch die Pflanze dar. Da die Saftflussdichte der Esche keine direkte Beeinflussung durch die Umweltfaktoren Strahlung, VPD oder Bodenwassergehalt erfährt, ist ein Zurücktreten dieser Effekte hinter den Wasserpotentialdifferenz möglich.

Direkt mit den Wurzel-Saftflussdichten vergleichbar sind die Ergebnisse aus dem Hainich von HÖLSCHER et al. (2004). Für Bergahorn, Hainbuche, Buche und Linde wurden hier mit abnehmender Bodenfeuchte signifikante Abnahmen in der Stamm-Saftflussdichte gemessen. Die Reduzierung der Flussdichte war am höchsten bei der Winterlinde (44\%), gefolgt von Buche (39\%), Bergahorn (37\%) und Hainbuche, die mit 31\% die geringste Abnahme der Flussdichte hatte. Eine Beeinflussung der Stamm-Saftflussdichte der Esche wurde nicht festgestellt. Hier kann eine Differenzierung zwischen zerstreutporigen und ringporigen Arten erfolgen. Die zerstreutporigen Baumarten Winterlinde, Buche, Bergahorn und Hainbuche weisen eine Abhängigkeit der Stamm-Saftflussdichte vom Bodenwassergehalt auf, die ringporige Esche jedoch nicht.

Weitere Studien weisen ebenfalls auf eine Änderung der Abhängigkeit der Transpiration und Saftflussrate von Umweltparametern bei einer sinkenden Bodenwasserverfügbarkeit hin.

In einem Quercus alba-Acer rubrum-Bestand sank mit abnehmendem Bodenwassergehalt der Einfluss der Strahlung und des VPD auf die Stamm-Saftflussdichte. Bei guter Wasserverfügbarkeit wurden bis zu 84\% der Varianz der Stamm-Saftflussdichte des Ahorns und bis zu 82\% bei der Eiche durch die Strahlung erklärt, in ähnlichem Maße auch durch das VPD. Während der Austrocknung des Bodens lag der Einfluss der Strahlung nur noch bei 31\%, eine Abhängigkeit vom VPD bestand nicht mehr (OREN \& PATAKI, 2001). Eine Abnahme des Einflusses von Strahlung und VPD während einer Trockenperiode fanden STÖHR \& LÖSCH (2004) an Eschen.

Eine lineare Abhängigkeit der Stamm-Saftflussdichte vom Bodenwassergehalt konnten PATAKI et al. (2000) für Baumarten eines subalpinen Bestandes zeigen. Bei einem konstanten Bodenwassergehalt ergab sich eine Beziehung zwischen dem Saftfluss und dem VPD, nicht jedoch bei sinkendem Bodenwassergehalt.

Eine Limitierung der Wasseraufnahme von Grevillea robusta-Bäumen in Kenia wird laut HoWARD et al. (1997) eher durch eine verminderte Bodenfeuchte als durch mikroklimatische Bedingungen hervorgerufen. Durch Entlaubung der Bäume wurde die transpirierende Oberfläche und damit der Transpirationssog verringert, was die Menge des Saftflusses kaum beeinflusste. Daraus wurde auf eine überwiegende Abhängigkeit von der Bodenwasserverfügbarkeit geschlossen.

Untersuchungen von TESKEY et al. (1985), ONG \& KHAN (1993), GREEN \& ClOTHIER (1999) und MORENO et al. (1996) weisen darauf hin, dass bei einer partiellen Austrocknung des Bodens Wurzeln in feuchten Bodenhorizonten die Versorgung des Baumes mit Wasser übernehmen. Die Bäume konnten den Ort der Wasseraufnahme mit sich ändernder Wasserver- 
fügbarkeit verlagern. Dadurch ist es ihnen möglich, Defizite in der Wasserversorgung durch Wurzeln trockener Horizonte zu kompensieren. Dies geschieht, indem in den feuchten Wurzeln die Saftflussrate in dem Maße zunimmt, wie sie in den trockenen Wurzeln abnimmt, so dass keine Auswirkung auf die Gesamt-Transpirationsleistung erkennbar wird.

Die Wiederbewässerungsexperimente an Eichen und Buchen im Hainich der vorliegenden Arbeit konnten diese Ergebnisse allerdings nicht bestätigen. Während der Phase der Austrocknung nahm der Saftfluss in allen Wurzeln einer Baumart relativ gleichmäßig ab. Nach der Bewässerung einiger Wurzelregionen um den Stammfuß nahm der Saftfluss in den bewässerten Wurzeln wieder zu, die nicht-bewässerten Wurzeln zeigten jedoch keine stärkere Verminderung der Wasseraufnahmerate als aufgrund der fortschreitenden Austrocknung zu erwarten war.

MORENO et al. (1996) stellten fest, dass bei oberflächlich verlaufenden Grobwurzeln nach einer Austrocknungsphase durch eine Wiederbewässerung keine Steigerung der Saftflussrate erreicht wurde, da die Wurzeln irreversibel cavitiert waren. Dies konnte anhand der eigenen Wiederbewässerungsexperiment nicht bestätigt werden, da immer eine unmittelbare Steigerung der Wasseraufnahme der Feinwurzeln nach der Bewässerung erfolgte.

Dem entsprechen Messungen von CRUIZIAT et al. (2002) an Zweigen von Eichen, die nachwiesen, dass erst durch eine mehrmonatige Trockenheit eine den Baum nachhaltig beeinflussende Anzahl von Embolien entstehen.

In einer weiteren Untersuchung wurde in einem benachbarten Buchenwald im Nationalpark Hainich die Wasseraufnahmerate von Buchengrobwurzeln (Durchmesser 7.1-18.9 mm) gemessen (KOCH, 2002). Der Mittelwert der Grobwurzel-Saftflussdichte lag bei $2.64 \mathrm{~g} \mathrm{~mm}^{-2}$ $\mathrm{d}^{-1}$. Im Vergleich dazu lagen die an den Feinwurzeln gemessenen Saftflussdichten mit $3.07 \mathrm{~g}$ $\mathrm{mm}^{-2} \mathrm{~d}^{-1}$ im Mittel über denselben Zeitraum nur leicht höher. In Abb. 5.8 sind die jeweiligen Tagesmittelwerte der Saftflussdichten der Grob- und Feinwurzeln über einen Zeitraum von 24 Tagen im Sommer 2001 aufgetragen. 


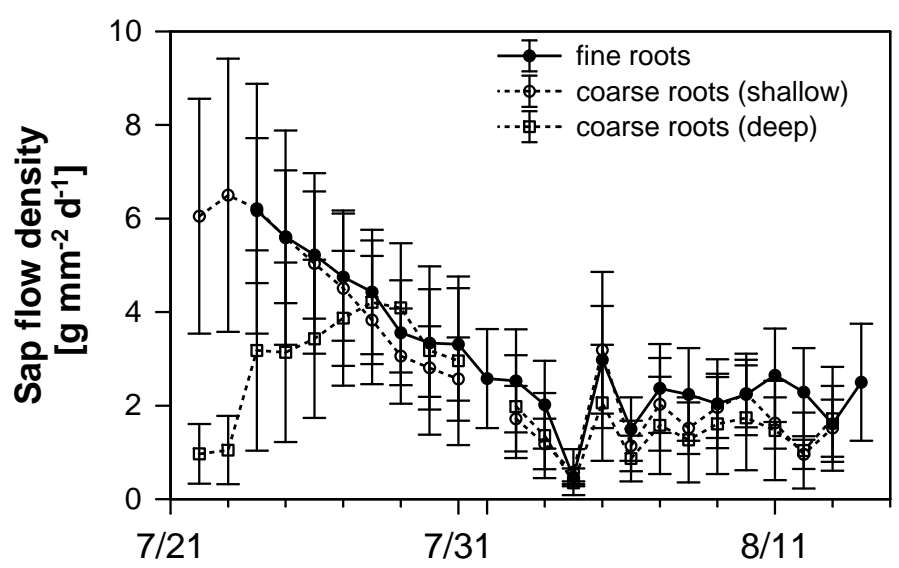

Abb. 5.8: Saftflussdichten von Grob- und Feinwurzeln der Buche auf der Untersuchungsfläche Buchenwald im Nationalpark Hainich im Zeitraum vom 22.7.-14.8.2001. Die GrobwurzelSaftflussdichte wurde an oberflächlich (bis $10 \mathrm{~cm}$ Bodentiefe; shallow) und tief liegenden Wurzeln (30-50 cm Bodentiefe; deep) gemessen. Die Saftflussdichten der Feinwurzeln wurden gemessen mit dem Miniatur-Saftflusssystem nach Senock \& Ham, die Werte der Grobwurzeln wurden von KOCH (2002) über eine Konstant-Temperaturdifferenz-Methode nach CERMAK et al. (1973) bestimmt. Aufgetragen sind die Tageswerte gemittelt aus Messungen an jeweils 10 Wurzeln mit einem Durchmesser von 3-4 mm bzw. 5 Wurzeln mit einem Durchmesser von 7-19 mm sowie die Standardfehler.

Die aufgetragene Zeitspanne entspricht der in Kapitel 4.2.5 vorgestellten Austrocknungsperiode mit einer starken Abnahme des Bodenwassergehaltes. Zwischen den oberflächennah lokalisierten Grob- und Feinwurzeln konnten keine Unterschiede in der Höhe der Saftflussdichte festgestellt werden. Tiefliegende Wurzeln hatten jedoch sehr viel geringere Saftflussdichten. Mit sinkendem Bodenwassergehalt nahm zunächst die Saftflussdichte in den tiefen Grobwurzeln zu, während an den oberflächlich verlaufenden Wurzeln eine Abnahme der Saftflussdichten gemessen wurde. Die abnehmende Wasseraufnahme der oberflächennahen Wurzeln konnte durch in tieferen und besser wasserversorgten Bodenschichten liegende Wurzeln kompensiert werden $(\mathrm{KOCH}, 2002)$. Mit fortdauernder Trockenheit war dies nicht mehr möglich, da die Bodenmatrixpotentiale in dieser Bodentiefe auf sehr niedrige Werte sanken ( $\overline{\mathrm{KOCH}}$, 2002) und damit die Wasseraufnahme dort erschwerte.

\section{Absenkung des Wasserpotentials während der Austrocknungsperiode}

Ein Großteil der in der Literatur angegebenen Wasserpotentialdaten von Bäumen stammt aus Messungen an oberirdischen Pflanzenorganen, nur wenige Untersuchungen beziehen sich auf Wurzeln. In Tab. 5.2 sind Literaturwerte der Blatt- und Wurzel-Wasserpotentiale verschiedener Arten angegeben. Die Werte stellen die Tagesminima der Wasserpotentiale dar; die Angaben des Blatt-Wasserpotentials beziehen sich auf Blätter aus der Sonnenkrone von Altbäumen. 
Tab. 5.2: Vergleich der von verschiedenen Autoren gemessenen MinimumWasserpotentiale $\left(\Psi_{\text {min }}\right)$ in Blättern der Sonnenkrone und in Wurzeln, jeweils gemessen an Altbäumen; sowie die hydraulische Leitfähigkeit $\left(\mathrm{Lp}_{r}\right)$ der Wurzeln verschiedener Baumarten.

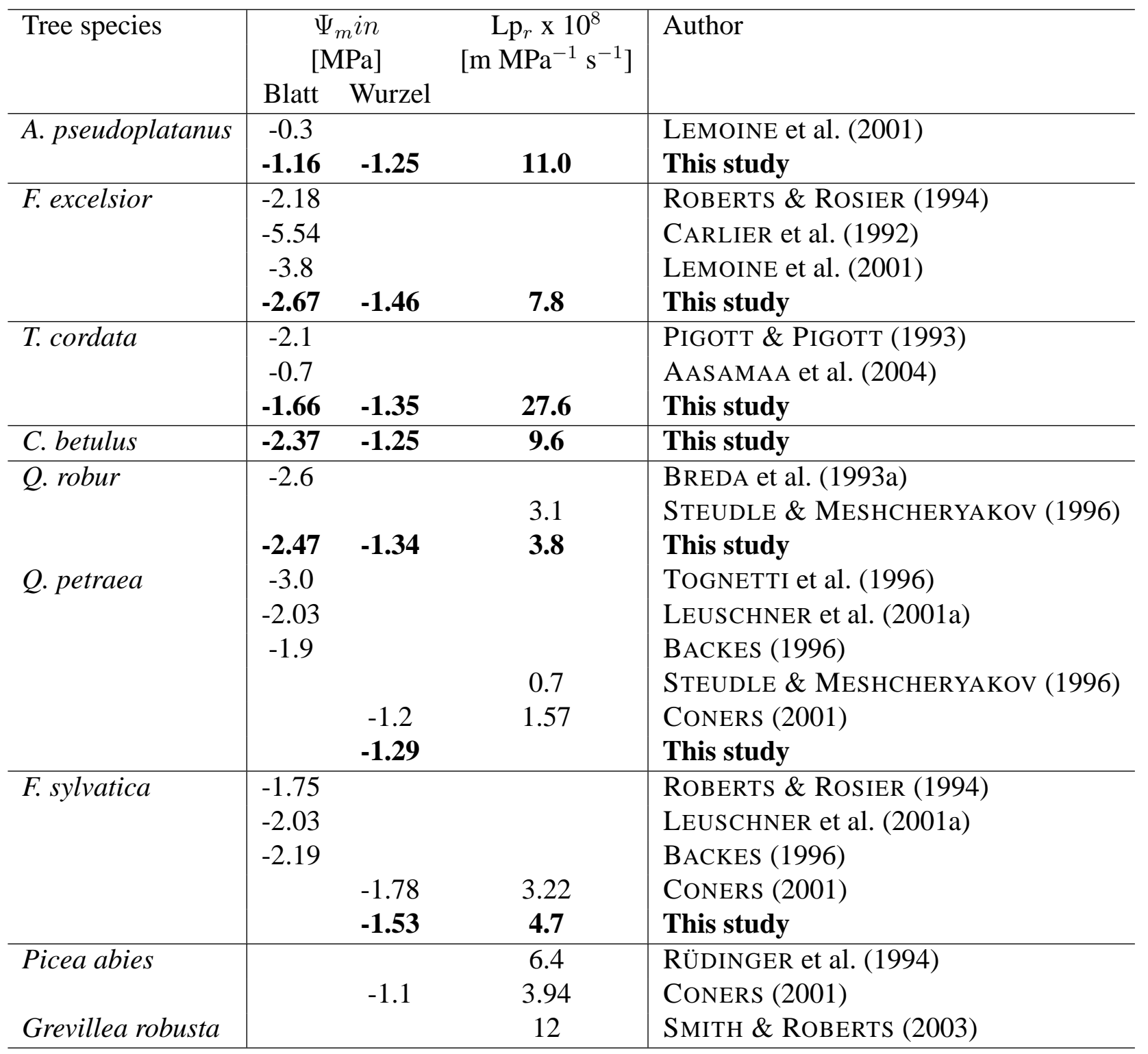


Alle sechs Baumarten im Hainich zeigten bei synchroner Messung im Mischbestand eine Absenkung ihrer Blatt- und Wurzel-Wasserpotentiale mit der Zunahme der Transpirationsbelastung und die darauf folgende die Erholung der Potentiale auf das Ausgangsniveau. Die Esche senkte sowohl ihr Wurzel- als auch das Blatt-Wasserpotential am meisten ab (um 1.04 bzw. 1.54 MPa). Sie wies mit -2.67 MPa das niedrigste Blatt-Wasserpotential auf. Während die Unterschiede zwischen den Wurzel-Wasserpotentialen der einzelnen Arten in der Regel nicht signifikant waren, hatten die Blätter der Esche meist das signifikant niedrigste Wasserpotential und die Blätter des Bergahorns das höchste. Dementsprechend erfuhren der Bergahorn, gefolgt von Winterlinde und Hainbuche die geringsten Absenkungen des Wasserpotentials bei Trockenheit.

Die Tagesminima der Blatt-Wasserpotentiale des Bergahorns stimmen recht gut mit den Literaturwerten überein. So fanden KHALIL \& GRACE (1992) an Bergahorn-Jungpflanzen unter Trockenstress Wasserpotentiale bis -1.15 MPa. Die von LEMOINE et al. (2001) in einem Auenbestand gemessenen Minimumwerte lagen mit -0.3 MPa deutlich höher. Die von SCHMITT (1999) untersuchten Bergahorne erreichten bei -0.49 MPa ihr Minimum. SCHMITT (1999) fand für Bergahorn-Jungwuchs Tagesminima der Blatt-Wasserpotentiale, die im Verlauf der Vegetationsperiode nahezu konstant waren; sie erfuhren eine maximale Absenkung von 0.2 MPa und lagen signifikant höher als Esche, Buche und Sommerlinde.

In der vorliegenden Untersuchung fällt auf, dass an den meisten Messtagen das Blatt-Wasserpotential des Bergahorns höher lag als das Wurzel-Wasserpotential. Die Wurzel-Wasserpotentiale konnten durch Messungen mit einem Psychrometer bestätigt werden. Die Messungen mit dem Wescor-Psychrometer (Messkammer C-52) ergaben bei der linearen Regression eine signifikante Übereinstimmung mit den parallel erfolgten Messungen mit der Druckkammer (Abb. 5.9), wobei die vom Psychrometer gelieferten Werte meist negativer waren als die Werte der Druckkammer (vgl. CAMPBEll \& CAMPBELL, 1974, TuRnER et al., 1984).

Da die gemessenen Blatt-Wasserpotentiale gut mit den Literaturwerten übereinstimmen, ist es fraglich, welche Messungen fehlerbehaftet sind. Bei der Messung mit der Druckkammer ergeben sich Fehlermöglichkeiten. So konnte VON WILLERT et al.(1995) z.B. an Jungtrieben von Taxus baccata nachweisen, dass sich das Wasserpotential-Gleichgewicht zwischen Mesophyllzellen und Xylem erst langsam einstellte und ein konstanter Wert erst nach mehrmaligen Messungen erreicht wurde. Somit würde das Wasserpotential mit der ersten Ablesung überschätzt. Für Sonnenblumenblätter unter leichtem Trockenstress konnte ein solcher Gradient über das Blatt nachgewiesen werden; dies gilt folglich für stark transpirierende große Blätter. Ein Anzeichen dafür, dass dies ebenfalls auf die Bergahornblätter zutreffen könnte, ist das gegenüber dem Wurzel-Wasserpotential signifikant negativere Blatt-Wasserpotential Ende September. $\mathrm{Zu}$ diesem Zeitpunkt waren die Bäume aufgrund vorangegangener Regenfälle keinerlei Trockenheit mehr ausgesetzt.

Bei der weiteren Betrachtung der Potentialgradienten wird im Fall des Bergahorns lediglich auf einen Messtag zurückgegriffen, an dem das Blatt-Wasserpotential stärker negative Werte aufwies als das Wurzel-Wasserpotential. 


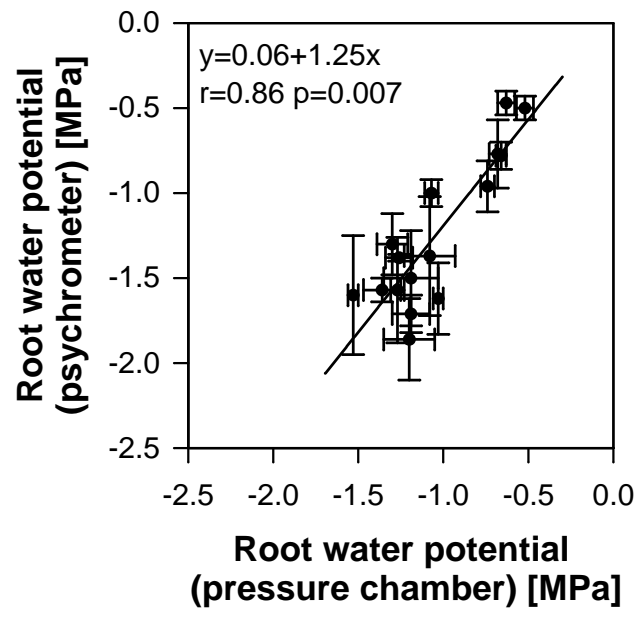

Abb. 5.9: Beziehung zwischen dem mit der Druckkammer-Methode nach Scholander gemessenen Wurzel-Wasserpotential und dem mit Psychrometern (Messkammer C-52) gemessenen Wurzel-Wasserpotential. Angegeben sind die Mittelwerte und Standardfehler der im Nationalpark Hainich gemessenen Tagesminima der Wasserpotentiale beider Methoden.

Die im Tagesverlauf erreichten Minimum-Wasserpotentiale der Esche sind sehr variabel und standortsabhängig, wie z.B. CARLIER et al.(1992) angeben. Von ihnen wurden Blatt-Wasserpotentiale auf flachgründigen Standorten bis $-5.54 \mathrm{MPa}$ gemessen, gleichzeitig dazu lag in einem Auwald das Minimum bei -1.94 MPa. MARIGO et al. (2000) stellten für Somit kann der Esche eine außergewöhnliche Toleranz gegen Trockenheit zugeschrieben werden (MARIGO et al., 2000), was sich in einer sehr guten Regenerationsfähigkeit nach einer Austrocknung zeigt (WIERSUM \& HARMANNY, 1983).

Vergleichende Messungen vom LEMOINE et al. (2001) an Esche und Bergahorn bzw. Acer opalus, der den Bergahorn auf trockenen Standorten ablöst, zeigten für die Esche stets niedrigere Wasserpotentiale. Gleichzeitig war die hydraulische Leitfähigkeit der Blattstiele des Ahorns höher. Dies deckt sich mit den Ergebnissen der vorliegenden Arbeit. Im Hainich waren die Wasserpotentiale der Esche deutlich negativer als die des Bergahorns bei einer gegen Ende der Trockenperiode höheren hydraulischen Leitfähigkeit der Bergahornwurzeln.

Die Winterlinde nimmt bezüglich der Wasserpotentiale eine Mittelstellung ein, allerdings ist der Potentialgradient zwischen Blatt und Wurzeln weniger steil als bei Esche, Hainbuche und Eiche. In der Literatur finden sich nur wenige Angaben zur Winterlinde. AASAMAA et al. (2004) geben als Wasserpotential von Wipfeltrieben -0.5 MPa bzw. -0.7 MPa unter Trockenstress in den frühen Morgenstunden an. Diese Werte sind deutlich höher als die hier präsentierten Werte, entsprechen allerdings dem predawn-Wasserpotential, das SCHMITT (1999) für Blätter des Sommerlinden-Jungwuchses mit -0.83 MPa angibt. Das von ihr gemessene Minimumwasserpotential liegt mit $-1.71 \mathrm{MPa}$ in der gleichen Größenordnung wie das der Winterlinden im Hainich. PIGOTT \& PIGOTT (1993) konnten ein etwas niedrigeres Wasserpotential (-2.1 MPa) während einer Trockenperiode messen. 
Für die Hainbuche konnten keine Literaturangaben über Wasserpotentiale gefunden werden. Im Vergleich zu Buche, Stieleiche, Winterlinde, Esche und Bergahorn lagen die WurzelWasserpotentiale meist höher. Der Potentialgradient zwischen Blatt und Wurzel war von allen Arten am wenigsten stark ausgeprägt.

Das Blatt-Wasserpotential der Stieleiche erreichte mit der Esche vergleichbare Tagesminima. Die Wurzel-Wasserpotentiale waren weitgehend mit denen der Esche identisch. Die an den Blättern gemessenen -2.47 MPa decken sich sehr gut mit Werten von BREDA et al. (1993a), die ein Tagesminimum-Wasserpotential von -2.6 MPa angeben. Die an Blättern aus der Sonnenkrone von Traubeneichen gemessenen Wasserpotentiale liegen in derselben Größenordung wie die der Stieleiche. Im Vergleich zur Esche erreichte die Eiche jedoch nicht deren niedrige Extremwerte der Wasserpotentiale und wies nicht dieselbe Amplitude auf.

Die Buche erreichte im Sommer 2001 das am stärksten negative Wurzel-Wasserpotential der sechs untersuchten Arten (-1.53 MPa). CONERS (2001) konnte an den Wurzeln der Buche ein sehr niedriges Wasserpotential bestimmen, das mit $-1.78 \mathrm{MPa}$ unter den hier aufgeführten Baumarten das niedrigste ist. Die Literaturangaben sprechen dafür, dass die Buche ihr Blatt-Wasserpotential ähnlich weit absenken kann wie die Eiche. In einer Untersuchung von ROBERTS \& ROSIER (1994) wurden die Blatt-Wasserpotentiale von Esche und Buche gemessen. Hier zeigte sich, dass die Buche ihr Wasserpotential nicht so weit absenken kann wie die Esche (-2.18 MPa gegenüber -1.75 MPa). Vergleichbar mit den in der vorliegenden Arbeit erhobenen Daten ist die maximale Differenz zwischen Werten bei einer geringen TranspirationsBeanspruchung und den saisonalen Minima-Werten. Die Esche erreichte eine maximale Absenkung um 1.74 MPa (Hainich: Blätter 1.52, Wurzeln 1.04 MPa), die Buche um 0.45 MPa (Hainich: Wurzeln $0.93 \mathrm{MPa}$ ).

Eine eindeutige Beziehung zwischen der Wasseraufnahme und dem Wurzel-Wasserpotential, wie sie nach der allgemeinen Flussgleichung zu erwarten wäre, konnte nicht nachgewiesen werden. Mit den vorliegenden Ergebnissen können lediglich Tendenzen einer Beziehung zwischen Wasserpotential und Saftfluss gezeigt werden (Abb. 4.28). Nur für die Winterlinde und die Buche konnten mit sinkendem Wurzel-Wasserpotential erhöhte Saftflussdichten gemessen werden. Für Bergahorn, Esche und Hainbuche war kein Zusammenhang dieser beiden Parameter erkennbar. Damit wird das Wasserpotential als Einflussfaktor auf die Wasseraufnahme von anderen Faktoren überlagert. Eine positive Beziehung zwischen Wasserpotential und Saftflussdichte deutete sich für die Stieleiche an. Bei der Betrachtung des Wasserpotentialgradienten zwischen Blatt und Wurzel kann ein meist nur tendenzieller Zusammenhang mit der Wurzel-Saftflussdichte festgestellt werden. Die Daten der linearen Regression sind in Tab. 5.3 aufgeführt. Für die Eiche lässt sich ein Zusammenhang der Saftflussdichte mit der Wasserpotentialdifferenz nicht feststellen, hier wird das Wasserpotential als Einflussgröße von anderen Faktoren überlagert. 
Tab. 5.3: Lineare Regression zwischen der Wurzel-Saftflussdichte und dem Wasserpotentialgradienten Blatt-Wurzel. Dargestellt ist die Anzahl der in die Regression aufgenommen Messtermine (n), der Korrelationskoeffizient (r) sowie der y-Achsenabschnitt (a) und die Steigung der Regressionsgeraden (b) mit der Gleichung $\mathrm{y}=\mathrm{a}+\mathrm{bx}$ und die Irrtumswahrscheinlichkeit (p). In die Berechnung der linearen Regression gingen die mittleren Tageswerte der Wurzel-Saftflussdichte ein sowie die Differenz aus dem parallel ermitteltem Blatt- und Wurzel-Wasserpotential der jeweiligen Baumart auf der Untersuchungsfläche im Nationalpark Hainich im Verlauf der Vegetationsperiode 2001.

\begin{tabular}{lccccc}
\hline & $\mathrm{n}$ & $\mathrm{r}$ & $\mathrm{a}$ & $\mathrm{b}$ & $\mathrm{p}$ \\
\hline A. pseudoplatanus & 4 & 0.86 & -1.46 & 0.29 & 0.14 \\
F. excelsior & 4 & 0.96 & 0.99 & 0.11 & 0.04 \\
T. cordata & 4 & 0.83 & -0.12 & 0.36 & 0.17 \\
C. betulus & 3 & 0.91 & 0.14 & 0.08 & 0.28 \\
Q. robur & 5 & -0.32 & 1.32 & -0.18 & 0.61 \\
\hline
\end{tabular}

\section{Wassernutzungsstrategien verschiedener Baumarten bei Bodenaustrocknung}

Bei der Erstellung von Empfindlichkeitskurven (,vulnerability curves“) wird durch das Anlegen eines Druckes auf ein Pflanzensegment die Reduzierung der hydraulischen Leitfähigkeit erreicht. Mit ansteigendem Druck nimmt die Leitfähigkeit durch entstehende Cavitationen ab, die durch das Eintreten von Gas- oder Luftblasen durch die Tüpfel in benachbarte Xylemgefäße ausgelöst werden. Mit dieser Methode kann das Auftreten von Cavitationen unter hohen Xylemspannungen simuliert werden (SPERRY \& SALIENDRA, 1994). Ergebnisse aus Studien mit dieser Methode lassen darauf schließen, dass das Wurzelxylem empfindlicher gegen Cavitation ist als das Xylem des Sprosses (HACKE \& SAUTER, 1996, HACKE et al., 2000b). Daher werden Wurzeln als „Achillesferse“ oder Sicherung des Baumes für den Wassertransport gedeutet, da cavitierte Wurzeln unter geringerem Ressourcenverbrauch eher ersetzt werden können als Gefäße im Stamm. Eine Embolie in Wurzeln ist reversibler als im Stamm (ALDER et al., 1996), da bei einer Wiederdurchfeuchtung des Bodens die Xylemspannung nachlässt und das cavitierte Gefäß wieder befüllt werden kann. Zwar gibt es nach SPERRY \& SALIENDRA (1994) eine Beziehung zwischen dem Gefäßvolumen und der Anfälligkeit für Cavitationen; diese war jedoch beim Vergleich verschiedener Taxa nicht zu erkennen. Die Autoren geben für Schwachwurzeln von Betula occidentalis eine mittlere Cavitationsspannung von $0.66 \pm 0.27 \mathrm{MPa}$ an, bei der die Leitfähigkeit um etwa $50 \%$ eingeschränkt war. Die in der vorliegenden Arbeit gemessenen Wurzel-Wasserpotentiale unterschritten diesen Wert während mehrerer Wochen deutlich. Lediglich zu Beginn und zum Ende der Messperiode konnten höhere Wasserpotentiale gemessen werden. Alle Baumarten zeigten in dieser Trockenperiode ebenfalls eine Reduzierung der hydraulischen Leitfähigkeit (Tab.4.10).

Buche, Bergahorn und Linde erfuhren die größten Abnahmen der Leitfähigkeit mit zunehmen- 
der Bodenaustrocknung. Die Stieleiche verlor über 50\% der Wurzelleitfähigkeit, lediglich die Esche zeigte eine nur geringe Einschränkung. Die Verluste der Leitfähigkeit der Bergahornwurzeln waren zunächst gering, während Eichen- und Buchenwurzeln einer schnellen Reduzierung um bis zu 70\% unterlagen. Allerdings konnte bei der Eiche im Anschluss eine erneute Steigerung der hydraulischen Wurzelleitfähigkeit festgestellt werden.

In die hydraulischen Leitfähigkeit $\mathrm{Lp}_{r}$ der Wurzel geht ebenfalls die Leitfähigkeit der Rhizosphäre ein. Mit der Austrocknung des Bodens nimmt auch die Leitfähigkeit des Bodens ab. Durch Schrumpfungsprozesse sowohl des Bodens als auch der Wurzel kann sich der Kontakt zwischen Boden bzw. Bodenlösung und Wurzel verschlechtern (BOYER, 1985, SCHACHTSCHABEL et al., 1992, HUCK et al., 1970), wodurch sich der Widerstand in der Rhizosphäre erhöht und in diesem Bereich zum limitierenden Faktor für den Wassertransport werden kann (STIRZAKER \& PASSIOURA, 1996, B BRATAUD et al., 1995). Inwieweit sich diese RhizosphärenLeitfähigkeit auf unterschiedliche Baumarten auswirkt, wird noch diskutiert. Nach SPERRY et al. (1998) und HACKE et al. (2000a) resultieren Unterschiede in der Leitfähigkeit der Rhizosphäre in erster Linie aus unterschiedlichen Bodenarten.

Im Zusammenhang mit der Anpassung an Bodentrockenheit werden „Kosten-Nutzen-Rechnungen" (trade-off's) diskutiert; zugunsten eines besseren Cavitationsschutzes wird die hydraulische Leitfähigkeit heruntergesetzt. Die Gefahr einer Cavitation ist in englumigen Gefäßen geringer als in weitlumigen, jedoch können englumige Gefäße Wasser weitaus weniger effizient leiten als Gefäße mit einem weiten Durchmesser („efficiency versus safety dilemma“ ZIMMERMANN \& TYREE, 2002). Zwischen der Gefäßweite und der gemessenen hydraulischen Leitfähigkeit konnte in der vorliegenden Arbeit keine Beziehung gefunden werden (Abb. 5.10). Die Unterschiede in den Gefäßgrößen bzw. der Gefäßverteilung zwischen den sechs Baumarten sind zu gering, um die voneinander abweichenden hydraulischen Wurzelleitfähigkeiten erklären zu können.

HACKE et al. (2000b) konnten demgegenüber für verschiedene Straucharten sowohl intra- als auch interspezifisch eine Beziehung zwischen dem Gefäßdurchmesser und der Cavitationsresistenz aufstellen. In Verbindung mit dem Wasserpotential-Minimum der Arten zeigte sich eine lineare Korrelation mit der Empfindlichkeit gegen Cavitationen. Arten, die ihr Wasserpotential weit absenkten, waren weniger empfindlich als Arten mit einem höheren Wasserpotential, deren Cavitationsschwelle höher lag. COCHARD et al. (1997) konnten dieselbe Beobachtung an Zweigen und Blattrhachiden von Eschen machen und berichten über identische Ergebnisse für Buchen (COCHARD et al., 1999). Für Wurzeln verschiedener mediterraner Baumarten (MARTINEZ-VILALTA et al., 2002) sowie für Stiel- und Traubeneichen (BREDA et al., 1993a, AUSSENAC \& LEVY, 1983) konnte eine Beziehung zwischen der Wasserpotentialabsenkung und der Cavitationsempfindlichkeit aufgestellt werden.

In diesem „trade-off“ liegen die Unterschiede zwischen trockenheitstoleranten und -empfindlichen Baumarten begründet. Eine geringe Wurzelleitfähigkeit gilt als Preis dafür, dass eine trockenheitstolerante Baumart in der Lage ist, sehr negative Wasserpotentiale zu ertragen, ihre Wasseraufnahme nicht wesentlich einschränken zu müssen und unempfindlicher gegen Cavitationen der Xylemgefäße zu sein (LEMOINE et al., 2001, ZIMMERMANN \& TYREE, 


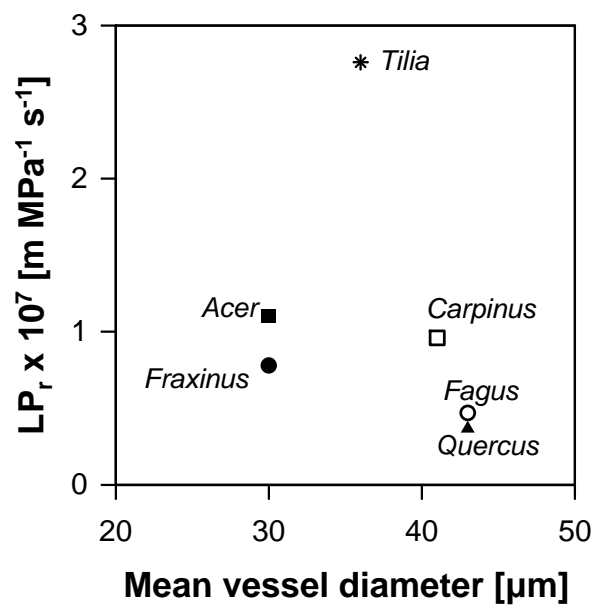

Abb. 5.10: Beziehung zwischen dem mittleren Gefäßdurchmesser und der hydraulischen Wurzel-Leitfähigkeit $\mathrm{Lp}_{r}$ der sechs Baumarten im Nationalpark Hainich. Dargestellt ist der mittlere Gefäßdurchmesser im Wurzelquerschnitt (Durchmesser 3-4 mm), lichtmikroskopisch ermittelt an 10-15 Wurzeln pro Baumart, an denen zuvor Saftflussmessungen stattfanden. Die hydraulische Leitfähigkeit wurde aus in situ-Messungen an drei Messterminen gemittelt.

2002). Diese These wird ebenfalls von NARDINI et al. (2003) vertreten, die eine signifikante Abhängigkeit der hydraulischen Wurzelleitfähigkeit vom Blatt-Wasserpotential an Fraxinus ornus feststellten. Daraus schließen sie auf einen großen Einfluss dieser Wurzelleitfähigkeit auf die gesamte hydraulische Architektur der Pflanze und auf die Trockenstresstoleranz der Baumart.

Im Vergleich der beiden Baumarten Populus tremuloides und Abies lasiocarpa zeigten PATAKI et al. (2000) Unterschiede in der Reaktion auf eine Bodenaustrocknung. Die trockenheitsempfindliche Baumart Abies lasiocarpa hatte eine geringe Stammsaftflussraten in Verbindung mit einem nur wenig negativen Blatt-Wasserpotential. Populus tremuloides konnte dagegen bei geringen Bodenwassergehalten eine hohe Saftflussrate aufrechterhalten, senkte dafür jedoch das Blatt-Wasserpotential sehr stark ab. Darauf gründet sich die Definition für eine Trockentoleranz; die Aufrechterhaltung des Saftflusses unter trockenen, ungünstigen Bedingungen. Dies bestätigen MARTINEZ-VILALTA et al. (2003) durch Untersuchungen des Saftflusses an mediterranen Baumarten.

LEMOINE et al. (2001) folgern aus Untersuchungen an Esche und Ahorn, dass es in trockenen Habitaten wichtiger ist, Trockenheit tolerieren zu können, als schnell Wasser zu transportieren. Dies setzt voraus, dass auf Kosten der hydraulischen Leitfähigkeit die Cavitationsresistenz optimiert wird. Im Vergleich der trockenheitstoleranten Esche mit dem trockenheitsempfindlichen Bergahorn in ihrer Studie zeigte sich dementsprechend eine eingeschränkte hydraulische Leitfähigkeit an Zweigsegmenten von Eschen trockener Standorte. Gleichzeitig wiesen die Eschen mit -2.2 MPa niedrigere Blatt-Wasserpotentiale auf als die Bergahorne (-0.3 MPa). Der Bergahorn der trockenen Standorte wies dagegen, in Übereinstimmung mit Ergebnis- 
sen von KHALIL \& GRACE (1992), höhere Blatt-Wasserpotentiale auf als die Esche und als Bergahorn-Individuen feuchter Standorte.

Die Anpassung der Winterlinde an Trockenheit untersuchten AASAMAA et al. (2004) im Kronenbereich. Die Winterlinde weist nach ihren Ergebnissen ein verhältnismäßig hohes Wasserpotential bei einer starken Einschränkung der Blattleitfähigkeit auf. Damit wird die Winterlinde als nicht-trockentolerante Baumart eingestuft.

Fasst man die Unterschiede zwischen den sechs hier betrachteten Baumarten hinsichtlich der Wurzel-Wasserpotentiale, der hydraulischen Leitfähigkeiten und der Wasseraufnahmeraten zusammen (Tab. 5.4), werden Unterschiede in den Wassernutzungsstrategie deutlich.

Tab. 5.4: Bewertung der Parameter Wasserpotential, hydraulische Leitfähigkeit und Wasseraufnahmeraten der Wurzeln im Vergleich der sechs Baumarten im Nationalpark Hainich.

+++ groß/hoch; ++ mittelmäßig; + gering; nd Daten liegen nicht vor.

\begin{tabular}{|c|c|c|c|c|c|c|}
\hline & \multicolumn{2}{|c|}{ Wurzel-Wasserpotential } & \multicolumn{2}{|c|}{ Leitfähigkeit } & \multicolumn{2}{|c|}{ Saftflussdichte } \\
\hline & Minimum & $\begin{array}{c}\text { Absenkung bei } \\
\text { Trockenheit }\end{array}$ & axial & $\mathrm{Lp}_{r}$ & gesamt & $\begin{array}{l}\text { Reduzierung bei } \\
\text { Trockenheit }\end{array}$ \\
\hline A. pseudoplatanus & +++ & + & +++ & +++ & ++ & +++ \\
\hline F. excelsior & + & +++ & + & + & + & + \\
\hline T. cordata & ++ & + & ++ & +++ & + & +++ \\
\hline C. betulus & + & + & + & ++ & +++ & nd \\
\hline Q. robur & ++ & ++ & ++ & ++ & +++ & + \\
\hline F. sylvatica & + & +++ & +++ & + & +++ & +++ \\
\hline
\end{tabular}

Die zuvor (Kapitel 5.2) als trockenheitsempfindlich beschriebenen Baumarten Bergahorn und Buche zeigten unterschiedliche Reaktionen in ihrer Wurzel-Wasseraufnahme auf die Austrocknungsperiode. Der Bergahorn erhielt ein hohes Wurzel-Wasserpotential durch eine nur geringe Absenkung über die Austrocknungsperiode. Die Buche dagegen hatte zeitweise das am stärksten negative Wurzel-Wasserpotential der hier untersuchten Baumarten. Mit zunehmender Bodenaustrocknung sank das Wasserpotential im selben Maße ab wie z.B. bei der trockenheitstoleranten Esche. In der hydraulischen Leitfähigkeit zeigten diese beiden Baumarten ebenfalls Unterschiede. Während die Wurzelleitfähigkeit des Bergahorns wie für trockenheitsempfindliche Baumarten zu erwarten hoch war, hatte die Buche eine vergleichsweise geringe Leitfähigkeit. Beiden Baumarten gemein ist die für trockenheitsempfindliche Baumarten postulierte starke Reduzierung der Wasseraufnahme während einer Phase mit geringer Bodenwasserverfügbarkeit. Somit kann der Bergahorn in Übereinstimmung mit LEMOINE et al. (2001) nach den hier betrachteten Parametern als trockenheitsempfindlich eingestuft werden. Die Buche dagegen zeigte mit einer geringen Wurzelleitfähigkeit, im Vergleich mit den anderen Arten, und einem sehr niedrigen Wasserpotential Reaktionen einer Toleranz-Strategie. 
Für die Hainbuche liegen mehr Hinweise in der Literatur auf eine nur wenig trockenheitsempfindliche Strategie vor. Im Bereich der Wurzel-Wasseraufnahme hatte sie, verglichen mit den anderen Baumarten, ein nicht sehr negatives Wurzel-Wasserpotential, welches während der Austrocknungsperiode nur wenig abgesenkt wurde. Die axiale Leitfähigkeit war sehr gering, die Wurzelleitfähigkeit lag niedriger als beim Bergahorn. Die Reduzierung der WurzelWasseraufnahme während einer Phase mit sinkendem Bodenwassergehalt konnte auf Grund fehlender Daten nicht sicher beschrieben werden. Während der Austrocknungsperiode verringerte die Hainbuche tendenziell sehr stark die Wurzelsaftflussrate. Anhand weiterer niederschlagsfreier Tage während des Untersuchungszeitraums ließ sich auf eine geringe Reduzierung der hohen Saftflussrate schließen.

Esche, Linde und Eiche werden als trockenheitstolerante Baumarten angesehen, die sich nach einer Trockenphase wieder schnell erholen. Dafür sprechen die im Vergleich niedrigen Wurzel-Wasserpotentiale dieser drei Arten. Esche und Eiche schränkten die Höhe der Wasseraufnahmerate in der Periode mit abnehmendem Bodenwassergehalt nur wenig ein, bei einer gleichzeitig geringen Wurzelleitfähigkeit. Dagegen waren die Wasseraufnahmeraten der Lindenwurzeln während der Austrocknungsphase ähnlich stark eingeschränkt wie die der Buchen- und Bergahornwurzeln. Eine hohe Leitfähigkeit wird nach der Theorie eher bei dürreempfindlichen Baumarten erwartet.

Beobachtungen von FRECH (mündl. Mitteilung) aus dem extrem warmen und trockenen Sommer 2003 unterstützen die Einordnung der Esche als trockentolerante Baumart. Bei der Buche und der Hainbuche setzte auf Grund der Sommertrockenheit schon früh der Blattfall ein. Der Blattabwurf beschränkte sich bei der Linde auf die Schattenblätter. Die Esche dagegen zeigte keine vorzeitige Blattseneszenz oder Blattabwurf. Lediglich eine stark abnehmende Turgeszenz der Blätter konnte beobachtet werden. 


\subsection{Wurzelwasseraufnahme von Eiche und Buche auf unterschiedlichen Böden}

In der vorliegenden Arbeit wurden vergleichende Messungen der Wurzelwasseraufnahmeraten von Buche und Eiche im Nationalpark Hainich und in der Lüneburger Heide durchgeführt. Der Bestand im Hainich ist ein aus elf Baumarten zusammengesetzter Mischwald, der auf einer tonreichen Terrafusca-Braunerde über mittlerem Muschelkalk stockt, die Bodenart ist ein lehmiger Ton bis schluffiger Lehm. Die organische Auflage besteht aus einer dünnen Streuschicht. Die Buchenwurzeln wurden in einem benachbarten Buchenwald mit derselben Bodenbeschaffenheit untersucht, kleinräumig waren hier Lößauflagerungen zu finden. Die Messungen in der Lüneburger Heide fanden in einem Eichen-Buchen-Mischwald auf saurer Braunerde mit einer organischen Auflage aus rohhumusartigem Moder statt. Dort findet man als Bodenart einen Mittelsand vor.

Die in der Lüneburger Heide gemessenen Saftflussdichten und oberflächenspezifischen Wasseraufnahmeraten waren geringer als im Hainich. In der anatomischen Struktur der Wurzeln ließen sich keine Unterschiede zwischen den beiden Standorten feststellen. ICKE (2000) untersuchte die Anatomie des Abschlussgewebes vergleichbarer Buchen- und Traubeneichenwurzeln aus der Lüneburger Heide. Es konnten keine Unterschiede zu den Wurzeln aus dem Hainich aufgezeigt werden.

Die Transpirationsbeanspruchung beider Standorte in Form von VPD und Nettostrahlung war in den beiden Untersuchungsgebieten ähnlich. Ein Indikator hierfür sind die identischen Wurzel-Wasserpotentiale in den beiden Beständen.

Für beide Standorte wurde aus den Boden-Matrixpotentialen und dem volumetrischen Bodenwassergehalt die pF-Kurve erstellt (Abb. 5.11), die zur Charakterisierung des Wasserhaushaltes eines Bodens herangezogen werden kann (SCHACHTSCHABEL et al., 1992).

Im Hainich wurde die Bodenfeuchte in den Bodentiefen 5, 15 und $40 \mathrm{~cm}$ aufgenommen, in der Lüneburger Heide in 5 und $30 \mathrm{~cm}$. Dargestellt sind Werte aus je zwei Desorptionsphasen, wodurch ein Hysterese-Effekt vermieden wird. Alle Kurven mit Ausnahme der Bodentiefe $5 \mathrm{~cm}$ im Hainich zeigen einen engen linearen Zusammenhang zwischen dem Bodenwassergehalt und dem Boden-Matrixpotential. Der sandige Mineralboden in der Lüneburger Heide zeigt über einen weiten Bereich mit sinkendem Bodenwassergehalt geringere $\mathrm{pF}$-Werte der BodenMatrixpotential als der lehmige Boden im Hainich. Schon mit gering niedrigerem Bodenwassergehalt nehmen die pF-Werte stark zu. Dies bedeutet, dass das Wasser in den Feinporen fester gebunden ist. Dadurch nimmt mit zunehmender Austrocknung der Nachleitwiderstand in einem tonigen Boden zu (LARCHER, 1994).

Dieser Widerstand wirkt sich auf den Widerstand der Rhizosphäre bzw. auf den Übergangswiderstand an der Grenzfläche Boden-Wurzel (soil-root-interface) aus. Mit einem verminderten Bodenwassergehalt und der Schrumpfung des Bodens geht der direkte Kontakt zwischen Wurzel und Boden bzw. dem Kapillarwasser verloren (BOYER, 1985, SCHACHTSCHABEL et al., 1992), wodurch die Wasseraufnahme behindert wird. Die Höhe und der Einfluss dieses Über- 


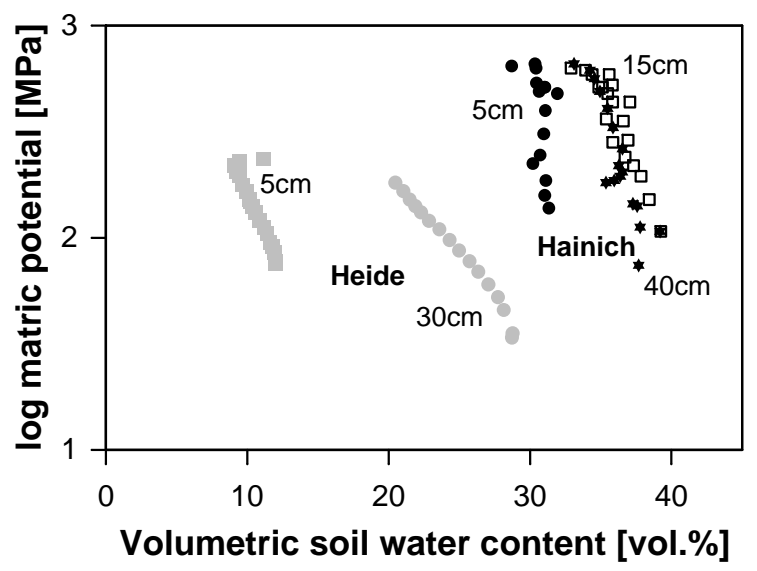

Abb. 5.11: Feld-pF-Kurven der Untersuchungsflächen im Nationalpark Hainich und der Lüneburger Heide, erstellt aus Messungen des volumetrischen Bodenwassergehaltes mittels TDR und des Boden-Matrixpotentials mittel Tensiometern. Im Hainich wurde in den Bodentiefen 5,15 und $40 \mathrm{~cm}$ gemessen, in der Lüneburger Heide in 5 und $30 \mathrm{~cm}$ (Daten aus dem Jahr 1998 KORN, 1999). Dargestellt sind Werte aus je zwei Desorptionsphasen zur Vermeidung des Hysterese-Effektes.

gangswiderstandes auf die Wasseraufnahme wird noch diskutiert. BARATAUD et al. (1995) entwickelten ein Modell, dass diesen Übergang als limitierenden Faktor für der Wasseraufnahme in trockenen Böden quantifiziert.

Nach SPERRY et al. (1998, 2002) und HACKE et al. (2000a) ist ein limitierender Einfluss der Rhizosphäre auf die Wasseraufnahme allerdings eher in Böden mit einer groben Textur zu finden. Sie berechneten für Bäume in sandigen Böden eine geringere oberflächenbezogene Wasseraufnahmerate (als Rhizosphären-Flussdichte bezeichnet), als für Bäume in feinporigen Böden. Diese geringe Rhizosphären-Flussdichte resultiert in erster Linie aus einem erhöhten Wurzel-Blattflächen-Verhältnis. Das auf den Sandböden sehr viel tiefreichendere Wurzelsystem, einhergehend mit einer Verschiebung der Wasseraufnahme in tiefere Bodenschichten bei Trockenheit, wird als wichtige Anpassung an die Austrocknung des Oberbodens angesehen (SPERRY et al., 2002, RAMBAL, 1984, JACKSON et al., 1996).

In der Lüneburger Heide ist eine mächtige und gutdurchwurzelte organische Auflage vorhanden. Dadurch kann das Wurzelsystem der Eichen und Buchen dieses Standortes in Auflageund Mineralboden-Wurzeln getrennt werden. Die organische Auflage trägt entscheidend zur Wasserversorgung der Bäume bei (LEUSCHNER, 1998, CONERS, 2001). Bei der Austrocknung des Bodens übernehmen die Wurzeln der organischen Auflage die Wasserversorgung der Bäume, während über die Wurzeln im Mineralboden nur eine geringe Menge Wasser aufgenommen wird (CONERS, 2001). Dies konnte in der vorliegenden Arbeit ebenfalls beobachtet werden. Die Saftflussdichte der Wurzeln aus der organischen Auflage war signifikant höher als die Saftflussdichte der Mineralboden-Wurzeln.

Die Oberfläche der untersuchten Wurzelstränge aus der organischen Auflage war etwa doppelt 
so groß wie die der Mineralboden-Wurzeln. Dies resultierte aus einer größeren Oberfläche der Feinwurzeln dieser Wurzelstränge. Ein Grund für diese bessere Ausbildung des Feinwurzelsystems in der organischen Auflage kann in der besseren Versorgung mit Nährstoffen gegenüber dem nährstoffarmen sandigen Mineralboden gesehen werden. Diese Theorie unterstützen z.B. Pregitzer et al. (1993) und LEUSCHNER et al. (2004).

Im Hainich war nur eine geringe $\mathrm{O}_{L}$-Schicht der Auflage vorhanden. Diese kann aufgrund fehlender Durchwurzelung nicht zur Wasserversorgung der Bäume beitragen, der Wasserbedarf muss aus dem Mineralboden gedeckt werden. Dementsprechend sind die Unterschiede in der Saftflussdichte der Wurzeln (meist $\mathrm{A}_{h}$-Horizont) des Hainich zu den Auflagen-Wurzeln der Lüneburger Heide geringer als zu den Mineralboden-Wurzeln. Die großen Unterschiede in der oberflächenspezifischen Wasseraufnahmerate zwischen den beiden Standorten resultierten aus einer vielfach größeren Feinst- und Feinwurzeloberfläche der Wurzeln aus der organischen Auflage in der Lüneburger Heide.

Daraus lässt sich schlussfolgern, dass die Wasseraufnahmeleistung der Wurzeln von der Lokalisierung in einer Bodenschicht abhängig ist sowie von der Ausprägung einer organischen Auflage. CONERS (2001) konnte für Mineralboden-Wurzeln der Buche in einem Bestand mit einer geringmächtigen Auflage höhere oberflächespezifische Wasseraufnahmeraten nachweisen als für Auflagen-Wurzeln desselben Bestandes.

Da sich die Wurzel-Wasserpotentiale zwischen den beiden Standorten nicht unterschieden, konnten bei vergleichbaren Bodenmatrixpotentialen ähnliche Potentialdifferenzen zwischen Wurzel und Boden festgestellt werden. Im Vergleich der hydraulischen Leitfähigkeit $\mathrm{Lp}_{r}$ der Wurzeln im Hainich und der Lüneburger Heide, konnten für die Wurzeln aus dem Hainich höhere Werte festgestellt werden (Daten der Baumarten aus der Lüneburger Heide von CONERS, 2001). Dies spricht für einen erhöhten Rhizosphären-Widerstand in der Lüneburger Heide. sprechen für einen erhöhten Widerstand im radialen Anteil der Wassertransportweges in der Wurzel oder in der Rhizosphäre.

Im Allgemeinen wird der Traubeneiche eine bessere Anpassung an geringe Wasserverfügbarkeit und erhöhte Transpirationsbeanspruchung zugesprochen als der Stieleiche (z.B. ELLENBERG, 1996, AAS, 1998). BREDA et al. (1993a) verglichen Q. petraea und Q. robur hinsichtlich physiologischer Reaktionen auf Trockenstress. Sie konnten unter natürlichen Bedingungen keine Unterschiede zwischen den beiden Eichenarten feststellen. Sowohl die Stammsaftflussdichte als auch die stomatäre Leitfähigkeit und die predawn-Wasserpotentiale wiesen keine signifikanten Artunterschiede auf.

$\mathrm{Da}$ in der vorliegenden Untersuchung keine Unterschiede in dem Wurzel-Wasserpotential zwischen diesen beiden Eichenarten aufgetreten sind, kann davon ausgegangen werden, dass die unterschiedlichen Wasseraufnahmeraten und hydraulischen Leitfähigkeiten von Stiel- und Traubeneiche nicht durch Artunterschiede hervorgerufen wurden. 


\section{Zusammenfassung}

In der vorliegenden Arbeit wurde die Wasseraufnahme der Baumarten Bergahorn, Esche, Winterlinde, Hainbuche, Stieleiche und Buche untersucht. Während der Vegetationsperioden 2000 und 2001 wurden an jeweils 20 Wurzeln (Durchmesser 3-4 mm) pro Baumart Sensoren installiert, mit denen nach der Miniatur-Saftflussmessmethode die Wasseraufnahmerate aufgezeichnet werden konnte. Nach Abschluss der Messungen wurden die Wurzelstränge geerntet und die Wurzeloberfläche sowie die Verteilung dieser auf Durchmesserklassen bestimmt.

Die Untersuchung fand in einem aus elf Baumarten zusammengesetzten Mischwald und einem benachbarten Buchenwald im Nationalpark Hainich (Thüringen) statt. Die Esche wies die höchsten Stamm- und Feinwurzeldichten im Mischbestand auf, gefolgt von Bergahorn und Linde. Buche und Stieleiche waren nur mit wenigen Individuen und einer geringen Feinwurzeldichte vertreten.

Unterschiede in der Wurzel-Wasseraufnahme zwischen den sechs Baumarten waren signifikant. Bergahorn, Esche und Winterlinde hatten in den beiden Untersuchungsjahren die niedrigsten Saftflussdichten. Um einen Faktor 1.5 bis 2 höhere Saftflussdichten wurden an Wurzeln der Hainbuche, der Stieleiche und der Buche gemessen.

In derselben Reihenfolge, Hainbuche $>$ Stieleiche $>$ Buche $>$ Bergahorn $>$ Esche $>$ Winterlinde, nahm die Größe der Oberfläche der untersuchten Wurzelstränge ab. Eschen- und Lindenwurzeln hatten sechsfach kleinere Wurzeloberflächen als die Hainbuche. Zwischen der Größe der Wurzeloberfläche und der Höhe der Saftflussdichte konnte ein linearer Zusammenhang festgestellt werden.

Dadurch ergaben sich die höchsten oberflächenspezifischen Wasseraufnahmeraten für die Wurzeln der Esche. Ähnlich hohe Aufnahmeraten pro Wurzeloberfläche hatten Bergahornwurzeln. Die geringsten oberflächespezifischen Aufnahmeraten schließlich hatten Buche und Stieleiche, deren Wurzeln nur ein Drittel der Wassermenge pro $\mathrm{cm}^{2}$ Wurzeloberfläche wie die Esche aufnahmen.

An Feinst- und Feinwurzeln konnte für alle Baumarten die Ausbildung einer Peridermschicht als sekundäres Abschlussgewebe nachgewiesen werden. Wurzeln der sechs Baumarten hatten schon in einem Abstand von $0.5 \mathrm{~cm}$ zur Wurzelspitze ein Periderm, das aus bis zu vier Zelllagen aufgebaut war. Entlang der Wurzelachse nahm die Dicke der Peridermschicht zu. Diese Zunahme war am stärksten bei Eschenwurzeln und am wenigsten an Wurzeln des Bergahorns zu beobachten.

Die Saftflussdichte der Wurzeln aller sechs Baumarten wies eine Abhängigkeit von der NettoStrahlung und dem VPD der Luft auf. Ein Einfluss des Bodenwassergehaltes auf die Saftflussdichte konnte für alle Baumarten nur während einer Austrocknungsperiode festgestellt werden. Hainbuche, Buche und Stieleiche hatten positiv mit Netto-Strahlung und VPD korrelierte 
Saftflussdichten. Die Abhängigkeit der Saftflussdichten der Bergahorn-, besonders jedoch der Eschen- und Lindenwurzeln von diesen Faktoren war nur gering gegeben.

Die hydraulische Leitfähigkeit der Wurzeln $\left(\mathrm{Lp}_{r}\right)$ der Winterlinde war dreifach höher als die der fünf anderen Baumarten. Buchen- und Stieleichenwurzeln hatten die niedrigsten $\mathrm{Lp}_{r^{-}}$ Werte im Untersuchungszeitraum. Ein linearer Zusammenhang mit der Höhe der Saftflussdichte war nicht gegeben.

Während zweier Austrocknungsperioden in den Vegetationsperioden 2000 und 2001 konnte eine unterschiedliche Reaktion der Baumarten auf die Austrocknung des Oberbodens festgestellt werden. Esche und Stieleiche behielten während dieser Austrocknungsperiode hohe Wasseraufnahmeraten bei. Bergahorn, Winterlinde und Buche schränkten dagegen die Wasseraufnahme stark ein.

Eine starke Absenkung der Blatt- und Wurzel-Wasserpotentiale mit zunehmender Bodenaustrocknung erfuhren Wurzeln der Esche, der Stieleiche und der Buche. Die Wasserpotentiale der Bergahorn-, Winterlinden- und Hainbuchenwurzeln wurden in geringerem Maße reduziert.

In einem Traubeneichen-Buchen-Mischbestand in der Lüneburger Heide wurden die Wasseraufnahmeraten von Traubeneiche und Buche auf sandigem Boden vergleichend zum lehmigen Boden im Hainich untersucht.

In der Lüneburger Heide konnten in der mächtigen und gut durchwurzelten organischen Auflage zweifache höhere Saftflussdichten und größere Wurzeloberflächen gemessen werden als im Mineralboden. Die Konzentrierung der Wasseraufnahme über ein reichverzweigtes Feinwurzelsystem in der gut nährstoffversorgten organischen Auflage stellt die Wasserversorgung der Bäume in dem grobporigen Substrat sicher.

Die organische Auflage bestand im Hainich aus einer dünnen $\mathrm{O}_{L}-$ Schicht, die kaum durchwurzelt war. Der Wasser- und Nährstoffbedarf der Bäume muss aus dem Mineralboden gedeckt werden. Die Buchen- und Eichenwurzeln im Hainich wiesen entsprechend ähnlich hohe Saftflussdichten auf wie die Wurzeln der organischen Auflage der Lüneburger Heide. In dem nährstoffreichen, feinporigen Boden des Hainich hatten die Wurzelstränge geringere Oberflächen als in der Lüneburger Heide, dadurch aber bis zu siebenfach höhere oberflächenspezifische Wasseraufnahmeraten. 


\section{Literaturverzeichnis}

AAS, G. (1998): Morphologische und ökologische Variation mitteleuropäischer QuercusArten: ein Beitrag zum Verständnis der Biodiversität. IHW-Verlag, Libri botanici 19, Eching, $221 \mathrm{~S}$.

AasamaA, K., Sõber, A., Hartung, W., Ninnemets, U. (2004): Drought acclimation of two deciduous tree species of different layers in a temperate forest canopy. Trees 18: 93-101.

AdDOMS, R. M. (1946): Entrance of water into suberized roots of trees. Plant Physiology 46: 109-111.

AdeOYE, K., RAwlins, S. (1981): Split-root technique for measuring root water potential. Plant Physiology 68: 44-47.

Alder, N. N., Sperry, J. S., Pockman, W. T. (1996): Root and stem xylem embolism, stomatal conductance and leaf turgor in Acer gradidentatum populations along a soil moisture gradient. Oecologia 105: 293-301.

Asche, N. (1995): Die Esche. Allgemeine Forstzeitung 20: 1087-1089.

Aussenac, G., Levy, G. (1983): Influence of soil drying on the plant water relations and growth of pendunculate oak (Quercus pendunculata Ehrl.) and ash (Fraxinus excelsior L.). Annals of Forest Science 40: 251-263.

BACKES, K. (1996): Der Wasserhaushalt vier verschiedener Baumarten der Heide-WaldSukzession. Cuvillier-Verlag, Göttingen, 134 S.

BAKER, J., VAN BAVEL, C. (1987): Measurements of mass flow of water in the stems of herbaceous plants. Plant, Cell and Environment 10: 777-782.

Barataud, F., Moyne, C., Breda, N., Granier, A. (1995): Soil water dynamics in an oak stand. II. A model of the soil-root network compared with experimental data. Plant and Soil 172: 29-43.

BÖHM, W. (1979): Methods of studying root systems. Springer Verlag, Berlin Heidelberg New York, $188 \mathrm{~S}$.

Boyer, J. S. (1985): Water transport. Annual Review of Plant Biology 36: 473-516.

Breda, N., Cochard, H., Dreyer, E., Granier, A. (1993a): Field comparison of transpiration, stomatal conductance and vulnerability to cavitation of Quercus petraea and Quercus robur under water stress. Annals of Forest Science 50: 571-582. 
Breda, N., Cochard, H., Dreyer, E., Granier, A. (1993b): Water transfer in a mature oak stand (Quercus petraea): seasonal evolution and effects of a severe drought. Canadian Journal of Forest Research 23: 1136-1143.

Breda, N., Granier, A., Barataud, F., Moyne, C. (1995): Soil water dynamics in an oak stand I. Soil moisture, water potentials and water uptake by roots. Plant and Soil 172: $17-27$.

Brockmann, W. G., Eckstein, D., Aniol, R. W. (1987): Dendroklimatologische Untersuchungen zur Bedeutung des Produktionsfaktors Wasser für das Baumwachstum. Forstwiss.Cbl. 106: 340-354.

BÜTTNER, V., LEUSCHNER, C. (1994): Spatial and temporal patterns of fine root abundance in a mixed oak-beech forest. Forest Ecology and Management 70: 11-21.

Burgess, S. O., Adams, M. A., Bleby, T. M. (2000): Measurement of sap flow in roots of woody plants: a commentary. Tree Physiology 20: 909-913.

Burgess, S. O., Adams, M. A., Turner, N. C., Ong, C. K. (1998): The redistribution of soil water by tree root systems. Oecologia 115: 306-311.

CABIBEL, B., Do, F. (1991a): Mesures thermiques des flux de sève et comportement hydrique des arbres. II Evolution dans le temps des flux des sève et comportement hydrique des arbres en présence ou non d'une irrigation localisée. Agronomie 11: 757-766.

CABiBel, B., Do, F. (1991b): Mesures thermiques des flux des sève dans les troncs et les racines et fonctionnement hydrique des arbres. I Analyse théorique des erreurs sur la mesure des flux et validation des mesures en présence de gradients thermiques extérieurs. Agronomie 11: 669-678.

CAldwell, M. M., RichaRds, J. H. (1989): Hydraulic lift: water efflux from upper roots improves effectiveness of water uptake by deep roots. Oecologia 79: 1-5.

CAmpbell, G. S., CAMPBell, M. D. (1974): Evaluation of a thermocouple hygrometer for measuring leaf water potential in situ. Agronomy Journal 66: 24-27.

Carlier, G., Peltier, J.-P., Gielly, L. (1992): Comportement hydrique du frêne (Fraxinus excelsior L.) dans une formation montagnarde mesoxerophile. Annals of Forest Science 49: 207-223.

Cermak, J., Demil, Penka, M. (1973): A new method of sap flow rate determination in trees. Biologia Plantarum 15: 171-178.

Chrispeels, M. J., Maurel, C. (1994): Aquaporins: The molecular basis of facilitated water movement through living plant cells? Plant Physiology 105: 9-13. 
Cochard, H., Lemoine, D., Dreyer, E. (1999): The effects of acclimation to sunlight on the xylem vulnerability to embolism in Fagus sylvatica L. Plant, Cell and Environment 22: 101-108.

Cochard, H., Pfeiffer, M., Le Gall, K., Granier, A. (1997): Developmental control of xylem hydraulic resistances and vulnerability to embolism in Fraxinus excelsior L.: impacts on water relations. Journal of Experimental Botany 48: 655-663.

CONERS, H. (2001): Wasseraufnahme und artspezifische hydraulische Eigenschaften der Feinwurzeln von Buche, Eiche und Fichte: In situ-Messungen an Altbäumen. Dissertation, Albrecht-von-Haller-Institut für Pflanzenwissenschaften, Universität Göttingen.

Coners, H., Hertel, D., Leuschner, C. (1998): Horizontal- und Vertikalstruktur des Grob- und Feinwurzelsystems von konkurrierenden Buchen und Eichen in einem Mischbestand. Verhandlungen der Gesellschaft für Ökologie 28: 435-440.

CONERS, H., LEUSCHNER, C. (2002): In situ water absorption by tree fine roots measured in real time using miniature sap-flow gauges. Functional Ecology 16: 696-703.

Cruiziat, P., Cochard, H., Ameglio, T. (2002): Hydraulic architecture of trees: main concepts and results. Annals of Forest Science 59: 723-752.

EllenberG, H. (1996): Vegetation Mitteleuropas und der Alpen in ökologischer, dynamischer und historischer Sicht. 5 Aufl., Eugen Ulmer Verlag, Stuttgart, 1095 S.

Fort, C., Muller, F., Label, P., Granier, A., Dreyer, E. (1998): Stomatal conductance, growth and root signaling in Betula pendula seedlings subjected to partial soil drying. Tree Physiology 18: 769-776.

George, E., Häussler, K., Kothari, S. K., Li, X.-L., Marschner, H. (1992): Contribution of mycorrhizal hyphae to nutrient and water uptake of plants. In READ, D. J., Lewis, D. H., Fitter, A. H., Alexander, I. J. (Hg.), Mycorrhizas in Ecosystems, Kap. 5, CAB International, Wallingford, S. 42-47.

George, E., Marschner, H. (1996): Nutrient and water uptake by roots of forest trees. Zeitschrift für Pflanzenernährung und Bodenkunde 159: 11-21.

Green, S. R., Clothier, B. E. (1995): Root water uptake by kiwifruit vines following partial wetting of the root zone. Plant and Soil 173: 317-328.

Green, S. R., Clothier, B. E. (1999): The root zone dynamics of water uptake by a mature apple tree. Plant and Soil 206: 61-77.

Green, S. R., Clothier, B. E., McLeod, D. J. (1997): The response of sap flow in apple roots to localised irrigation. Agricultural water management 33: 63-78. 
Green, S. R., Vogeler, I., Clothier, B. E., Mills, T. M., Van Den Dijssel, C. (2003): Modeling water uptake by a mature apple tree. Australian Journal of Soil Research 41: 365-380.

Gulder, H.-J. (2002): Standortansprüche und Wurzelwerk der Esche. In SCHMIDT, O. (Hg.), Beiträge zur Esche, Bayrische Landesanstalt für Wald und Forstwirtschaft, Freising, S. 50-52.

Hacke, U. G., SAUter, J. J. (1996): Xylem dysfunction during winter and recovery of hydraulic conductivity in diffuse-porous and ring-porous trees. Oecologia 105: 435-439.

Hacke, U. G., Sperry, J. S., Ewers, B. E., Ellsworth, D. S., Schäfer, K. V. R., Oren, R. (2000a): Influence of soil porosity on water use in Pinus taeda. Oecologia 124: 495-505.

Hacke, U. G., Sperry, J. S., Pittermann, J. (2000b): Drought experience and cavitation resistance in six shrubs from the Great Basin, Utah. Basic and applied Ecology 1: 31-41.

Henzler, T., Waterhouse, R. N., Smyth, A. J., Carvajal, M., Cooke, D. T., Schäffner, A. R., Steudle, E., Clarkson, D. T. (1999): Diurnal variations in hydraulic conductivity and root pressure can be correlated with the expression of putative aquaporins in the roots of Lotus japonicus. Planta 210: 50-60.

Hertel, D. (1999): Das Feinwurzelsystem von Rein- und Mischbeständen der Rotbuche: Struktur, Dynamik und interspezifische Konkurrenz. Dissertationes Botanica Bd. 317, Berlin Stuttgart, $190 \mathrm{~S}$.

Hölscher, D., Hertel, D., Leuschner, C., Hottkowitz, M. (2002): Tree species diversity and soil patchiness in a temporate broad-leaved forest with limited rooting space. Flora 197: 118-125.

Hölscher, D., Koch, O., Korn, S., Leuschner, C. (2004): Sap flux of five co-occurring tree species in a temperate broad-leaved forest during seasonal drought. Trees in press.

Howard, S. B., Ong, C. K., BlaCk, C. R., Khan, A. A. H. (1997): Using sap flow gauges to quantify water uptake by tree roots from beneath the crop rooting zone in agroforestry systems. Agroforestry Systems 35: 15-29.

Huck, M. G., Klepper, B., TAYlor, H. M. (1970): Diurnal variations in root diameter. Plant Physiology 45: 529-530.

Hultine, K. R., Cable, W. L., Burgess, S. O., Williams, D. G. (2003): Hydraulic redistribution by deep roots of a Chihuahuan desert phreatophyte. Tree Physiology 23: 353360 . 
ICKE, R. (2000): Ökophysiologische und anatomische Untersuchungen zur Wasseraufnahme von Buchen- und Eichenfeinwurzeln in einem Mischbestand in der Lüneburger Heide. Diplomarbeit, FG Pflanzenökologie und Ökosystemforschung, Universität - GH Kassel.

Jackson, R. B., Canadell, J., Ehleringer, J. R., Mooney, H. A., Sala, O. E., SCHUlzE, E.-D. (1996): A global analysis of root distribution for terrestrial biomes. Oecologia 108: 389-411.

Javot, H., Maurel, C. (2002): The role of aquaporins in root water uptake. Annals of Botany 90: 301-313.

John, B., PANDEY, H. N., TRIPATHI, R. S. (2001): Vertical distribution and seasonal changes of fine and coarse root mass in Pinus kesiya Royle Es.Gordon forest of three different ages. Acta oecologia 22: 293-300.

JurzitzA, G. (1987): Anatomie der Samenpflanzen. Thieme Verlag, Stuttgart, 293 S.

KAnG, S., Hu, X., Jerie, P., Zhang, J. (2003): The effects of partial root zone drying on root, trunk sap flow and water balance in an irrigated pear (Pyrus communis) orchard. Journal of Hydrology 280: 192-206.

Khalil, A. A. M., Grace, J. (1992): Acclimation to drought in Acer pseudoplatanus L. (Sycamore) seedlings. Journal of Experimental Botany 43: 1591-1602.

Klaus, S., Reisinger, E. (1995): Der Hainich - ein Weltnaturerbe. In Landschaftspflege und Naturschutz in Thüringen - Sonderheft, Thüringer Landesanstalt für Umwelt, Jena, S. 32 .

KocH, O. (2002): Wasserumsatz eines Buchenbestandes im Hainich. Diplomarbeit, Albrechtvon-Haller-Institut für Pflanzenwissenschaften, Universität Göttingen.

KORN, S. (1999): Untersuchungen zu den Mechanismen der Wasseraufnahme von Eichenfeinwurzeln in einem Altbestand. Diplomarbeit, FG Pflanzenökologie und Ökosystemforschung, Universität - GH Kassel.

Kramer, H., AKÇA, A. (1987): Leitfaden für Dendrometrie und Bestandesinventur. J.D. Sauerländers Verlag, Frankfurt a. M., 266 S.

KRAMER, P. J. (1946): Absorption of water through suberized roots of trees. Plant Physiology 21: 37-41.

KrAmer, P. J., Bullock, H. C. (1966): Seasonal variations in the properties of suberized and unsuberized roots of trees in relation to the absorption of water. American Journal of Botany 53: 200-204. 
KÖstler, J. N., BrÜCKner, E., BibelRiether, H. (1968): Die Wurzeln der Waldbäume. Verlag Paul Parey, Hamburg, 284 S.

KutscherA, L., LichtenEGger, E. (2002): Wurzelatlas mitteleuropäischer Waldbäume und Sträucher. Leopold Stocker Verlag, Graz, 604 S.

LADEFOGED, K. (1963): Transpiration of forest trees in closed stands. Physiologia Plantarum 16: 378-414.

LARChER, W. (1994): Ökophysiologie der Pflanzen. 5 Aufl., Verlag Eugen Ulmer, Stuttgart, $394 \mathrm{~S}$.

LAZARESCU, D., FidAnOF, F. (1968): Forschungen in bezug auf die Verdunstung bei der Linde (Cercetari privind transpiratia la tei). Revista Padurilor (zitiert in AFZ) 10: 515-518.

Leibundgut, H. (1991): Unsere Waldbäume. 2 Aufl., Verlag Paul Haupt, Bern, 172 S.

Lemoine, D., Peltier, J.-P., Marigo, G. (2001): Comparative studies of the water relations and the hydraulic characteristics in Fraxinus excelsior, Acer pseudoplatanus and A. opalus trees under soil water contrasted conditions. Annals of Forest Science 58: 723-731.

LEUSCHNER, C. (1994a): Forest dynamics on sandy soils of the Lueneburg Heath (northwestern Germany). Phytocoenologia 22: 289-324.

LeUsCHNER, C. (1994b): Walddynamik in der Lüneburger Heide: Ursachen, Mechanismen und die Rolle der Ressourcen. unveröff. Habilitationsschrift, Universität Göttingen.

LEUSCHNER, C. (1998): Water extraction by tree fine roots in the forest floor of a temperate Fagus-Quercus forest. Annals of Forest Science 55: 141-157.

Leuschner, C., Backes, K., Hertel, D., Schipka, F., Schmitt, U., Terborg, O., Runge, M. (2001a): Drought responses at leaf, stem and fine root levels of competitive Fagus sylvatica L. and Quercus petraea (Matt.) Liebl. trees in dry and wet years. Forest Ecology and Management 149: 33-46.

Leuschner, C., Coners, H., ICKe, R. (2004): In situ measurement of fine root water absorption in three temperate tree species. II. Species differences and differential activity of superficial and deep reaching roots. Tree Physiology submitted? .

Leuschner, C., Coners, H., Icke, R., Hartmann, K., Effinger, N. D., Schreiber, L. (2003): Chemical composition of the periderm in relation to in situ water absorption rates of oak, beech and spruce fine roots. Annals of Forest Science 60: 763-772.

Leuschner, C., Hertel, D. (2003): Fine root biomass of temperate forests in relation to soil acidity and fertility, climate, age and species. Progress in Botany 64: 405-438. 
Leuschner, C., Hertel, D., Coners, H., BütTner, V. (2001b): Root competition between beech and oak: a hypothesis. Oecologia 126: 276-284.

LEWIS, A. M., Boose, E. R. (1995): Estimating volume flow rates through xylem conduits. American Journal of Botany 82: 1112-1116.

Lindenmair, J., Matzner, E. (2001): Bedeutung verschiedener Wurzelzonen für die Ionen- und Wasseraufnahme von Altfichten. In Grundlagen zur nachhaltigen Entwicklung von Ökosystemen bei veränderter Umwelt - BITÖK Forschungsbericht 1998-2000, Kap. A9, Bayreuther Forum Ökologie Bd. 84/2001, Bayreuth, S. 155-165.

Lindenmair, J., Matzner, E. (2003): Bedeutung verholzter Wurzelzonen für die Ionenund Wasseraufnahme von Fichte, Buche und Eiche. In Grundlagen zur nachhaltigen Entwicklung von Ökosystemen bei veränderter Umwelt - BITÖK Forschungsbericht 2002, Kap. A9, Bayreuther Forum Ökologie Bd. 101, Bayreuth, S. 41-48.

LotT, J. E., Khan, A. A. H., Ong, C. K., Black, C. R. (1996): Sap flow measurements of lateral tree roots in agroforstry systems. Tree Physiology 16: 995-1001.

LÖSCH, R. (2001): Wasserhaushalt der Pflanzen. Quelle \& Meyer Verlag, Wiebelsheim, 595 $\mathrm{S}$.

LudlOw, M. M. (1989): Strategies of response to water stress. In KREEB, K. H., Richter, H., Hinckley, T. M. (Hg.), Structural and functional response to environmental stresses: water shortage, SPB Academic Publishing, The Hague, The Netherlands, S. 269-281.

MacFall, J. S., Johnson, G. A., Kramer, P. J. (1991): Comparative water uptake by roots of different ages in seedlings of loblolly pine (Pinus taeda L.). New Phytologist 119: $551-560$.

MANning, S. J., BARbour, M. G. (1988): Root systems, spatial patterns, and competition for soil moisture between two desert subshrubs. American Journal of Botany 75: 885-893.

Mapfumo, E., Aspinall, D. (1994): Anatomical changes of grapevine (Vitis vinifera L. cv. Shiraz) roots related to radial resistance to water movement. Aust. Journal of Plant Physiology 21: 437-447.

Marigo, G., Peltier, J.-P., Girel, J., Pautou, G. (2000): Success in the demographic expansion of Fraxinus excelsior L. Trees 15: 1-13.

Martinez-Vilalta, J., Mangiron, M., Ogaya, R., Sauret, M., Serrano, L., PeNUElAS, J., PinOL, J. (2003): Sap flow of three co-occuring Mediterranean woody species under varying atmospheric and soil water conditions. Tree Physiology 23: 747-758.

Martinez-Vilalta, J., Prat, E., Oliveras, I., Pinol, J. (2002): Xylem hydraulic properties of roots and stems of nine Mediterranean wood species. Oecologia 133: 19-29. 
McKenzie, B. E., Peterson, C. A. (1995a): Root browning in Pinus banksiana Lamb. and Eucalyptus pilularis Sm. 1. Anatomy and permeability of the white and tannin zones. Botanica Acta 108: 127-137.

McKenzie, B. E., Peterson, C. A. (1995b): Root browning in Pinus banksiana Lamb. and Eucalyptus pilularis Sm. 2. Anatomy and permeability of the cork zone. Botanica Acta 108: 138-143.

Meinen, C. (2004): Der Einfluss der Baumartenzusammensetzung auf die Verjüngung von Carpinus betulus, Fagus sylvatica, Fraxinus excelsior und Tilia cordata in artenreichen Mischwaldbeständen im Nationalpark Hainich. Diplomarbeit, Albrecht-von-Haller-Institut für Pflanzenwissenschaften, Universität Göttingen.

Melchior, W., Steudle, E. (1993): Water transport in onion (Allium cepa L.) roots - Changes of axial and radial hydraulic conductivity during root development. Plant Physiology 101: $1305-1315$.

Milburn, J. A. (1996): Sap ascent in vascular plants: challengers to the cohesion-tension theory ignore the significance of immature xylem and the recycling of Münch water. Annals of Botany 78: 399-407.

Miller, D. R., Vavrina, C. A., Christensen, T. W. (1980): Measurement of sap flow and transpiration in ring-porous oaks using a heat pulse velocity technique. Forest Science 26: 485-494.

MÖNNINGHOFF, W. (1998): Nationalpark Hainich. VEBU, Berlin, 168 S.

Moreira, M. Z., Scholz, F. G., Bucci, S. J., Sternberg, L. S., Goldstein, G., MEINZER, F. C., FrAnCO, A. C. (2003): Hydraulic lift in a neotropical savanna. Functional Ecology 17: 573-581.

Moreno, F., Fernandez, E., Clothier, B. E., Green, S. R. (1996): Transpiration and root water uptake by olive trees. Plant and Soil 184: 85-96.

Mushin, T. M., ZwIAZEK, J. J. (2002): Ectomycorrhizas increase apoplastic water transport and root hydraulic conductivity in Ulmus americana seedlings. New Phytologist 153: 153158.

NADEZHDina, N., CERMAK, J. (2000): Responses of sap flow rate along tree stem and coarse root radii to changes of water supply. In STOKES, A. (Hg.), The supporting roots of trees and woody plants: Form, Function and Physiology, Kluwer Academic Publisher, Netherlands, S. 227-238.

NamVar, K., Spethman, W. (1986): Die heimischen Waldbaumarten der Gattung „Tilia“ (Linde). Allgemeine Forstzeitung 3: 42-45. 
Nardini, A., Salleo, S., Trifilo, P., Lo Gullo, M. A. (2003): Water relations and hydraulic characteristics of three woody species co-occurring in the same habitat. Annals of Forest Science 60: 297-305.

Nardini, A., Salleo, S., Tyree, M. T., Vertovec, M. (2000): Influence of the ectomycorrhizas formed by Tuber melanosporum Vitt. on hydraulic conductance and water relations of Quercus ilex L. seedlings. Annals of Forest Science 57: 305-312.

NNYAMAH, J. U., BLACK, T. A. (1977): Rates and patterns of water uptake in a Douglas Fir forest. Soil Sci. Soc. Am. J. 41: 972-979.

ONG, C. K., KHAN, A. A. H. (1993): The direct measurement of water uptake by individual tree roots. Agroforestry Today 5: 2-5.

OREN, R., PATAKI, D. (2001): Transpiration in response to variation in microclimate and soil moisture in southeastern deciduous forests. Oecologia 127: 549-559.

Oren, R., Phillips, N., Ewers, B. E., Pataki, D., Megonigal, J. P. (1999): Sap-fluxscaled transpiration responses to light, vapor pressure deficit, and leaf area reduction in a flooded Taxodium distichum stand. Tree Physiology 19: 337-347.

PASsiourA, J. B. (1988): Water transport in and to roots. Annual Review of Plant Biology 39: 245-265.

Pataki, D., Oren, R., Smith, W. K. (2000): Sap flux of co-occurring species in a western subalpine forest during seasonal soil drought. Ecology 81: 2557-2566.

Persson, H. (2000): Adaptive tactics and characteristics of tree fine roots. In STOKes, A. (Hg.), The supporting roots of trees and woody plants: Form, Function and Physiology, Kluwer Academic Publishers, Netherlands, S. 337-346.

PigotT, C. D. (1991): Tilia cordata Miller. Journal of Ecology 79: 1147-1207.

Pigott, C. D., PigotT, S. (1993): Water as a determinant of the distribution of trees at the boundary of the Mediterranean zone. Journal of Ecology 81: 557-566.

Pregitzer, K. S., Hendrik, R. L., Fogel, R. (1993): The demography of fine roots in response to patches of water and nitrogen. New Phytologist 125: 575-580.

RAMBAL, S. (1984): Water balance and pattern of root water uptake by a Quercus coccifera L. evergreen scrub. Oecologia 62: 18-25.

Rüdinger, M., Hallgren, S. W., Steudle, E., Schulze, E.-D. (1994): Hydraulic and osmotic properties of spruce roots. Journal of Experimental Botany 45: 1413-1425. 
REWALD, B. (2003): Konkurrenz zwischen vier verschiedenen Baumarten in einem Eichenmischbestand im Mitteldeutschen Trockengebiet. Diplomarbeit, Albrecht-von-HallerInstitut für Pflanzenwissenschaften, Universität Göttingen.

RÖHRIG, E., Gussone, H. A. (1990): Waldbau auf ökologischer Grundlage: Baumartenwahl, Bestandesbegründung und Bestandespflege, Bd. 2. 6 Aufl., Parey, Hamburg, 314 S.

Rieger, M., Litvin, P. (2003): Root system hydraulic conductivity in species with contrasting root anatomy. Journal of Experimental Botany 331: 201-209.

Rincon, C. A., Raper, C. D., Patterson, R. P. (2003): Genotypic differences in root anatomy affecting water movement through roots of soybean. International Journal of Plant Sciences 164: 543-551.

Roberts, J., Rosier, P. T. W. (1994): Comparative estimates of transpiration of ash and beech forest at a chalk site in southern Britain. Journal of Hydrology 162: 229-245.

Ruiz-Lozano, J. M., AzCon, R. (1995): Hyphal contribution to water uptake in mycorrhizal plants as affected by the fungal species and water status. Physiologia Plantarum 95: $472-478$.

Rust, S., SAVILL, P. S. (2000): The root systems of Fraxinus excelsior and Fagus sylvatica and their competitive relationships. Forestry 73: 499-508.

SAKURATANI, T. (1981): A heat balance method for measuring water flux in the stem of intact plants. J.Agr.Met. 37: 9-17.

SANDERSON, J. (1983): Water uptake by different regions of the Barley root. Pathways of radial flow in relation to development pf the endodermis. Journal of Experimental Botany 34: $240-253$.

Schachtschabel, P., Blume, H.-P., Brümmer, G., Hartge, K.-H., Schwertmann, U. (1992): Lehrbuch der Bodenkunde. 13 Aufl., Ferdinand Enke Verlag, Stuttgart, 491 S.

SCHIPKA, F. (2002): Blattwasserzustand und Wasserumsatz von vier Buchenwäldern entlang eines Niederschlagsgradienten in Mitteldeutschland. Dissertation, Albrecht-von-HallerInstitut für Pflanzenwissenschaften, Universität Göttingen.

SCHMID, I., KAZDA, M. (2001): Vertical distribution and radial growth of coarse roots in pure and mixed stands of Fagus sylvatica and Picea abies. Canadian Journal of Forest Research 31: 539-548.

SCHMITT, S. (1999): Vergleichende Untersuchung zum Trockenstress an den Baumarten Buche, Bergahorn, Sommerlinde und Esche in einem jungen Mischbestand. Diplomarbeit, FG Pflanzenökologie und Ökosystemforschung, Universität - GH Kassel. 
Scholander, P. F., Hammel, H. T., Bradstreet, E. D., Hemmingen, E. A. (1965): Sap pressure in vascular plants. Science 148: 339-346.

Schulze, E.-D., Caldwell, M. M., Canadell, J., Mooney, H. A., Jackson, R. B., Parson, D., Scholes, R., SAla, O. E., Trimborn, P. (1998): Downward flux of water through roots (i.e. inverse hydraulic lift) in dry Kalahari sands. Oecologia 115: 460-462.

SENOCK, R. S., HAM, J. M. (1993): Heat balance sap flow gauge for small diameter stems. Plant, Cell and Environment 16: 593-601.

SENOCK, R. S., Leuschner, C. (1999): Water flux dynamics in small diameter roots of a fast growing tropical tree. Plant and Soil 208: 57-71.

Smit, A. L., Bengough, A. G., Engels, C., Van Noordwijk, M., Pellerin, S., VAN DE GeiJn, S. C. (2000): Root methods. A handbook. Springer-Verlag, Berlin, 587 S.

Smith, D. M., RoberTs, J. (2003): Hydraulic conductivities of competing root systems of Grevillea robusta and maize in agroforestry. Plant and Soil 251: 343-349.

Smith, S. E., READ, D. J. (1997): Mycorrhizal symbiosis. 2 Aufl., Academic Press, London, $605 \mathrm{~S}$.

Sperry, J. S., Adler, F. R., CAmpbell, G. S., Comstock, J. P. (1998): Limitation of plant water use by rhizosphere and xylem conductance: results from a model. Plant, Cell and Environment 21: 347-359.

Sperry, J. S., Donnelly, J. R., Tyree, M. T. (1988): A method for measuring hydraulic conductivity and embolism in xylem. Plant, Cell and Environment 11: 35-40.

Sperry, J. S., Hacke, U. G., Oren, R., Comstock, J. P. (2002): Water deficits and hydraulic limits to leaf water supply. Plant, Cell and Environment 25: 251-263.

SPERRY, J. S., SALIENDRA, N. Z. (1994): Intra- and inter-plant variation in xylem cavitation in Betula occidentalis. Plant, Cell and Environment 17: 1233-1241.

Spethman, W., Namvar, K. (1985): Der Bergahorn und die Gattung Acer. Allgemeine Forstzeitung 42: 1126-1129.

SteinberG, S. L., VAn BAVEl, C. H. M., McFarland, M. J. (1990): Improved sap flow gauge for woody and herbaceous plants. Agronomy Journal 82: 851-854.

STEudLE, E. (1994): Water transport across roots. Plant and Soil 167: 79-90.

STEudLE, E. (1995): Trees under tension. Nature 378: 663-664. 
Steudle, E., Heydt, H. (1997): Water transport across tree roots. In EsCHRICH, W., ZIEGLER, H. (Hg.), Trees - Contribution to modern tree physiology, Backhuys Publishers, Leiden, NL, S. 239-255.

Steudle, E., Meshcheryakov, A. B. (1996): Hydraulic and osmotic properties of oak roots. Journal of Experimental Botany 47: 387-401.

Steudle, E., Peterson, C. A. (1998): How does water get through roots? Journal of Experimental Botany 49: 775-788.

STÖHR, A., LÖSCH, R. (2004): Xylem sap flow and drought stress of Fraxinus excelsior saplings. Tree Physiology 24: 169-180.

STIRZAKer, R. J., PASSiOURA, J. B. (1996): The water relations of the root-soil interface. Plant, Cell and Environment 19: 201-208.

Teskey, R. O., Grier, C. C., Hinckley, T. M. (1985): Relation between root system size and water inflow capacity of Abies amabilis growing in a subalpine forest. Canadian Journal of Forest Research 15: 669-672.

Thorburn, P. J., Ehleringer, J. R. (1995): Root water uptake of field-growing plants indicated by measurements of natural-abundance deuterium. Plant and Soil 177: 225-233.

Tognetti, R., Raschi, A., Beres, C., Fenyvesi, A., Ridder, H.-W. (1996): Comparison of sap flow, cavitation and water status of Quercus petraea and Quercus cerris trees with special reference to computer tomography. Plant, Cell and Environment 19: 928-938.

TÜRK, W. (1996): Die Hainbuche in der realen und der potentiellen Vegetation Mitteleuropas unter besonderer Berücksichtigung Bayerns. In SCHMIDT, O. (Hg.), Beiträge zur Hainbuche, Kap. 4, Bayrische Landesanstalt für Wald und Forstwirtschaft, Freising, S. 17-24.

Turner, N. C., Spurway, R. A., Schulze, E.-D. (1984): Comparison of water potentials measured by in situ psychrometry and pressure chamber in morphologically different species. Plant Physiology 74: 316-319.

Tyerman, S. D., Niemietz, C. M., Bramley, H. (2002): Plant aquaporins: multifunctional water and solute channels with expanding roles. Plant, Cell and Environment 25: 173-194.

VAN BAVEL, C., BAKER, J. (1985): Water transfer by plant roots from wet to dry soil. Naturwissenschaften 72: 606-607.

VIEWEG, G. H., ZIEGLER, H. (1960): Thermoelektrische Registrierung der Geschwindigkeit des Transpirationsstromes I. Deutsche Botanische Ges. 73: 221-226. 
Von Guttenberg, H. (1968): Der primäre Bau der Angiospermenwurzel, Bd. VIII Teil 5 aus: Handbuch der Pflanzenanatomie. 2 Aufl., Gebrüder Borntraeger, Berlin, 472 S.

Von Willert, D. J., Matyssek, R., Herppich, W. (1995): Experimentelle Pflanzenökologie. Georg Thieme Verlag, Stuttgart, 344 S.

WeGner, L. H., Zimmermann, U. (1998): Simultaneous recording of xylem pressure and trans-root potential in roots of intact glycophyts by using a novel xylem pressure probe technique. Plant, Cell and Environment 21: 849-865.

WeISER, F. (1995): Beitrag zur Existenz von Ökotypen bei Gemeiner Esche (Fraxinus excelsior L.). Forstarchiv 66: 251-257.

WEYKAM, S. (1991): Feinwurzeluntersuchungen in einem Eichen-Buchen-Mischwald der Lüneburger Heide. Diplomarbeit, Systematisch-Geobotanisches Institut, Universität Göttingen.

Wiersum, L. K., Harmanny, K. (1983): Changes in the water-permeability of roots of some trees during drought stress and recovery, as related to problems of growth in urban environment. Plant and Soil 75: 443-448.

Zimmermann, H. M., STeudle, E. (1998): Apoplastic transport across young maize roots: effect of the exodermis. Planta 206: 7-19.

Zimmermann, M. H., Brown, C. L. (1971): Trees - Structure and Function. Springer Verlag, New York, 336 S.

Zimmermann, M. H., JeJe, A. A. (1981): Vessel-length distribution in stems of some American woody plants. Canadian Journal of Botany 59: 1882-1892.

Zimmermann, M. H., Tyree, M. T. (2002): Xylem Structure and the ascent of sap. 2 Aufl., Springer Verlag, Berlin, $283 \mathrm{~S}$.

Zimmermann, U., Schneider, H., Wegner, L. H., Wagner, H.-J., Szimtenings, M., HaAse, A., Bentrup, F.-W. (2002): What are the driving forces for water lifting in the xylem conduit? Physiologia Plantarum 114: 327-335. 


\section{Abbildungsverzeichnis}

2.1 A Mittlere Monatsniederschläge der Jahre 1990-2000. B Vergleich der Monatsniederschläge Mai-September der Messzeiträume und des langjährigen Mittels ........................ 7

4.1 Relative Häufigkeit des gleichzeitigen Vorkommens verschiedener Baumarten in den Wurzelproben . . . . . . . . . . . . . . . . . 27

$4.2 \quad$ Feinwurzeldichte in Beziehung zum Abstand zum nächsten Baumstamm . . . 32

4.3 Relative Häufigkeit des Vorkommens von Grobwurzeln verschiedener Baumarten in $0-50 \mathrm{~cm}$ Tiefe $\ldots \ldots \ldots \ldots . \ldots \ldots 33$

4.4 Grobwurzeldichte der Mischwaldfläche im Nationalpark Hainich . . . . . . . 34

4.5 Grobwurzeldichte in Beziehung zum Abstand zum nächsten Baumstamm . . 35

4.6 Grobwurzeldichte in den untersuchten Tiefenstufen auf der Mischwaldfläche im Nationalpark Hainich . . . . . . . . . . . . . . . . . . . . . 36

4.7 Kalibrierung der Saftflusssensoren gegen gravimetrisch gemessenen Wasseraufnahme aus einem Reservoir . . . . . . . . . . . . . . . . . . . . 37

$4.8 \quad$ Gesamtwurzeloberfläche von sechs Baumarten auf der Untersuchungsfläche

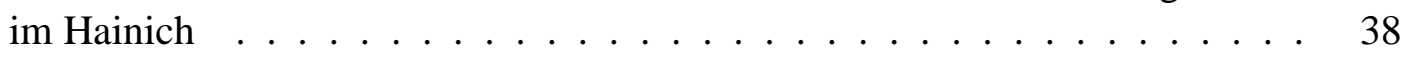

$4.9 \quad$ Verteilung der Wurzeloberfläche auf drei Durchmesserklassen . . . . . . . . 39

4.10 Abhängigkeit der Wurzeloberfläche in verschiedenen Durchmesserklassen von der Gesamtwurzeloberfläche des jeweiligen Wurzelstranges . . . . . . . . . . 40

4.11 Abhängigkeit des Wurzeldurchmessers von der Entfernung zum Wurzelende. 41

4.12 Leitflächen der Wurzeln der sechs Baumarten im Hainich . . . . . . . . . . . 42

4.13 Anzahl der Gefäße pro $\mathrm{mm}^{2}$ Xylemquerschnittsfläche der sechs untersuchten

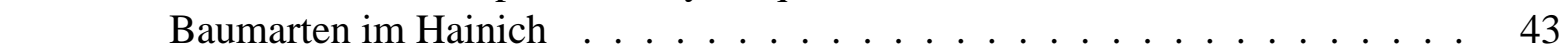

4.14 Häufigkeitsverteilung von Xylemgefäßen in Querschnitten von Wurzeln sechs verschiedener Baumarten . . . . . . . . . . . . . . . . 44

4.15 Wurzeldurchmesser in der Wurzelspitzenregion der sechs Baumarten im Hainich 45

4.16 Stärke des Periderms in der Wurzelspitzenregion der sechs Baumarten im Hai-

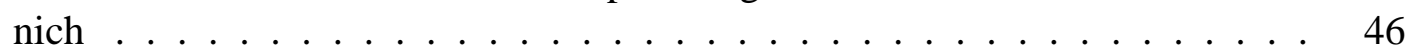

4.17 Anzahl der Zelllagen des Periderms in der Wurzelspitzenregion der sechs Baumarten im Hainich . . . . . . . . . . . . . . . . 46

4.18 Strahlungsbilanz und Wasserdampfsättigungsdefizit der Luft während der Vegetationsperioden 2000 und $2001 \mathrm{im} \mathrm{Hainich} \ldots$. . . . . . . . . . . . 48

4.19 Volumetrischer Bodenwassergehalt in drei Bodentiefen im Hainich . . . . . . 49

4.20 Gemittelte Tageswerte der Saftflussdichten im Hainich . . . . . . . . . . . . 50

4.21 Tageswerte der Saftflussdichten von sechs Baumarten im Hainich im Verlauf der Vegetationsperioden 2000 und 2001 . . . . . . . . . . . . . . . . 51 
Abbildungsverzeichnis

4.22 Tageswerte der oberflächenspezifischen Saftflussraten von sechs Baumarten im Hainich im Verlauf der Vegetationsperioden 2000 und 2001 . . . . . . . . 55

4.23 Oberflächenspezifische Wasseraufnahmeraten der sechs Baumarten im Hainich 56

4.24 Wasseraufnahmeraten der sechs Baumarten im Hainich bezogen auf die Feinst-

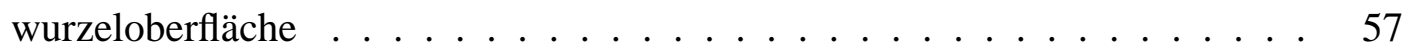

4.25 Strahlungsbilanz, VPD und Bodenwassergehalte während zweier Austrock-

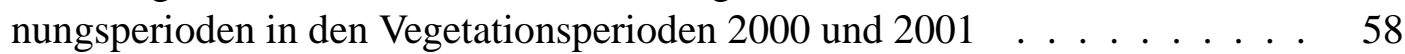

4.26 Tageswerte der Saftflussdichten der sechs Baumarten im Hainich während zweier Austrocknungsperioden . . . . . . . . . . . . . . . . 59

4.27 Wurzel-Wasserpotentiale der sechs Baumarten im Hainich . . . . . . . . . . 62

4.28 Abhängigkeit der Saftflussdichte vom Wurzel-Wasserpotential der sechs Baumarten im Hainich . . . . . . . . . . . . . . . . . . 64

4.29 Blatt- und Wurzel-Wasserpotentiale der sechs Baumarten im Hainich . . . . . 65

4.30 Theoretische hydraulische Leitfähigkeit $\mathrm{k}_{\text {Stheo }}$ der Wurzeln der untersuchten Baumarten im Hainich und Heide . . . . . . . . . . . . . . . 67

4.31 Hydraulische Leitfähigkeit $\mathrm{Lp}_{r}$ der Wurzeln der untersuchten Baumarten im Nationalpark Hainich . . . . . . . . . . . . . . . . . . . 68

4.32 Maximale hydraulische Leitfähigkeit $\mathrm{k}_{m}$ von 3-4 mm starken Wurzeln der untersuchten Baumarten in Hainich . . . . . . . . . . . . . . . . . 70

4.33 Spezifische Leitfähigkeit der Wurzeln von sechs Baumarten im Hainich . . . 70

4.34 Mittlere Saftflussdichten und oberflächenspezifische Saftflussraten von Buche

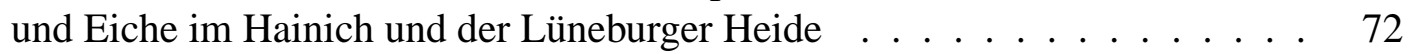

4.35 Gesamtwurzeloberfläche von Buche und Eiche in der Lüneburger Heide und im Hainich . . . . . . . . . . . . . . . . . . . . . . 74

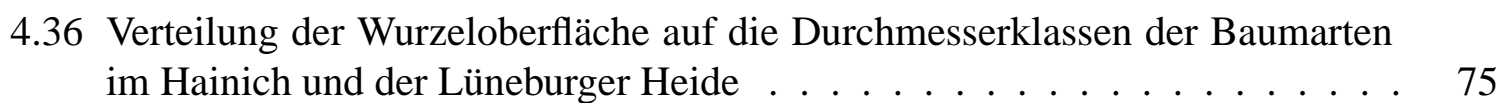

4.37 Leitflächen der Wurzelquerschnitte von Eiche und Buche aus Hainich und Lüneburger Heide . . . . . . . . . . . . . . . 76

4.38 Anzahl der Xylemgefäße im Wurzelquerschnitt von Buchen und Eichen im Hainich und der Lüneburger Heide . . . . . . . . . . . . . . . . . . . . 77

4.39 Häufigkeitsverteilung der Xylemgefäße in Wurzelquerschnitt von Eiche und Buche aus dem Hainich und der Lüneburger Heide . . . . . . . . . . . . . 78

4.40 Strahlungsbilanz und VPD im Hainich und der Lüneburger Heide . . . . . . 79

4.41 Bodenwassergehalte im Hainich und der Lüneburger Heide . . . . . . . . . . 80

4.42 Wurzel-Wasserpotentiale von Eiche und Buche aus dem Hainich und der Lüneburger Heide . . . . . . . . . . . . . . . . . . 81

4.43 Abhängigkeit der Saftflussdichte vom Wurzel-Wasserpotential von Eiche und Buche im Hainich und der Lüneburger Heide . . . . . . . . . . . . . . . 82

4.44 Tagesgänge der Saftflussdichte nach Bewässerungsversuchen an Wurzeln der Stieleiche im Hainich . . . . . . . . . . . . . . . . . . . . 84

4.45 Tagesgänge der Saftflussdichte nach Bewässerungsversuchen an Wurzeln der Buche im Hainich . . . . . . . . . . . . . . . . . . 85 
5.1 Beziehung zwischen dem Wurzeldurchmesser und der maximalen stündlichen Saftflussdichte aus Literaturwerten . . . . . . . . . . . . . . . . . . 90

5.2 Wurzel- und Stamm-Saftflussdichten von fünf Baumarten im Hainich . . . . 95

5.3 Beziehung zwischen der Saftflussdichte und der Wurzeloberfläche der Messwurzeln der sechs Baumarten im Nationalpark Hainich . . . . . . . . . . . . 98

5.4 Tagesgänge der Saftflussraten in zwei Wurzeln und zwei Stämmen der Buche im Hainich . . . . . . . . . . . . . . . . . . . 100

5.5 Beziehung zwischen der Wasseraufnahmerate und der spezifischen Leitfähigkeit der Wurzeln von sechs Baumarten im Hainich . . . . . . . . . . . . . . . 102

5.6 Beziehung zwischen der Peridermstärke und der oberflächenspezifischen Wasseraufnahmerate der Feinstwurzeln . . . . . . . . . . . . . . . . . 107

5.7 Beziehung zwischen der Feinwurzeldichte und der Bestandeswasseraufnahme bzw. der Saftflussdichte der sechs Baumarten . . . . . . . . . . . . . . . . . 109

5.8 Saftflussdichten von Fein- und Grobwurzeln der Buche im Hainich vom 22.7.$14.8 .2001 \ldots \ldots \ldots \ldots \ldots \ldots \ldots 115$

5.9 Beziehung zwischen Wurzel-Wasserpotentialen gemessen mit der DruckkammerMethode nach Scholander und Psychrometern . . . . . . . . . . . . . . . . . 118

5.10 Beziehung zwischen dem mittleren Gefäßdurchmesser und der hydraulischen Wurzel-Leitfähigkeit der sechs Baumarten im Nationalpark Hainich . . . . . 122

5.11 Feld-pF-Kurven der Untersuchungsflächen im Nationalpark Hainich und der Lüneburger Heide . . . . . . . . . . . . . . . . . . . . . . 126 


\section{Tabellenverzeichnis}

2.1 Bestandesstrukturdaten Hainich $\ldots \ldots \ldots \ldots$

2.2 Bestandesstrukturdaten Lüneburger Heide $\ldots \ldots \ldots \ldots \ldots \ldots \ldots$

$3.1 \quad$ Merkmale zur Unterscheidung der Wurzeln von neun Baumarten . . . . . . . 16

3.2 Einteilung der Grobwurzeln in Durchmesserklassen $\ldots \ldots \ldots \ldots$. . . . . 17

$4.1 \quad$ Feinwurzelbiomasse im Hainich $\ldots \ldots \ldots \ldots$

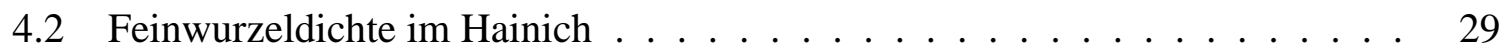

4.3 Spezifische Feinwurzeloberfläche im Hainich $\ldots \ldots \ldots$

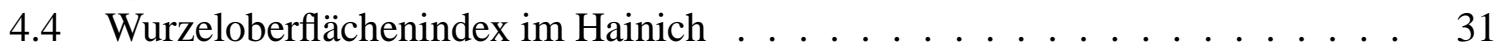

4.5 Relativer Anteil der Baumarten an der Feinwurzeldichte und der Stammdichte 33

4.6 Variationskoeffizienten der Saftflussdichte innerhalb der sechs Baumarten im Hainich . . . . . . . . . . . . . . . . . . 52

4.7 Korrelationskoeffizienten zur Abhängigkeit der Saftflussdichte der Wurzeln von Strahlung, VPD und Bodenfeuchte . . . . . . . . . . . . . 53

4.8 Ergebnisse der multiplen Regression mit Variablenselektion für sechs Baumarten 54

4.9 Ergebnisse der multiplen Regression mit Variablenselektion für sechs Baumarten während einer Austrocknungsperiode $\ldots \ldots \ldots \ldots$. . . . . . 6

4.10 Hydraulische Leitfähigkeit $\mathrm{Lp}_{r}$ der sechs Baumarten im Hainich an verschiedenen Tagen im Verlauf der Vegetationsperiode $2001 \ldots \ldots$. . . . . . . . . 69

4.11 Hochrechnung auf die Bestandeswasseraufnahme im Hainich . . . . . . . . 71

4.12 Korrelationskoeffizienten der Abhängigkeit der Saftflussdichte der Wurzeln von Strahlung, VPD und Bodenfeuchte $\ldots \ldots \ldots \ldots \ldots$

5.1 Vergleich der von verschiedenen Autoren gemessenen maximalen Wurzel-

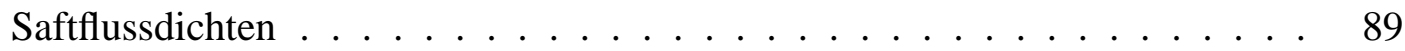

5.2 Minimum-Wasserpotential und hydraulische Leitfähigkeit verschiedener Baum-

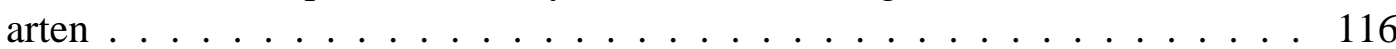

5.3 Lineare Regression zwischen der Wurzel-Saftflussdichte und dem Wasserpotentialgradienten Blatt-Wurzel $\ldots \ldots \ldots \ldots \ldots \ldots \ldots$

5.4 Bewertung verschiedener Parameter der sechs Baumarten . . . . . . . . . 123

A.1 Gleichungen der Häufigkeitsverteilung der Xylemgefäße . . . . . . . . . . II

A.2 $\quad$ Saftflussdichten der sechs Baumarten $\ldots \ldots \ldots \ldots \ldots \ldots$ II

A.3 Oberflächenspezifische Wasseraufnahmeraten der sechs Baumarten. . . . . . . III

A.4 Oberflächenspezifische Wasseraufnahmeraten der Feinstwurzeln . . . . . . . III

A.5 $\quad$ Saftflussdichten der Wurzeln aus der Lüneburger Heide $\ldots \ldots \ldots \ldots \ldots$. . . . IV 
A.6 Oberflächenspezifische Wasseraufnahmeraten der Wurzeln aus der Lüneburger Heide $\ldots \ldots \ldots \ldots \ldots \ldots \ldots \ldots \ldots \ldots$ IV

A.7 Korrelationskoeffizienten signifikanter Korrelationen zwischen Saftflussdichte und Umweltfaktoren $\mathrm{A} \ldots \ldots \ldots$. . . . . . . . . . . . . .

A.8 Korrelationskoeffizienten signifikanter Korrelationen zwischen Saftflussdichte und Umweltfaktoren B . . . . . . . . . . . . . . . . . . . . . . . VI

A.9 Korrelationskoeffizienten signifikanter Korrelationen zwischen Saftflussdichte und Umweltfaktoren $\mathrm{C}$. . . . . . . . . . . . . . . . . . . . . . . . VII

A.10 Korrelationskoeffizienten signifikanter Korrelationen zwischen Saftflussdichte und Umweltfaktoren D 


\section{Abkürzungsverzeichnis}

\begin{tabular}{|c|c|}
\hline ANOVA & Varianzanalyse für balancierte Stichproben \\
\hline BHU & Brusthöhenumfang [m] \\
\hline d.m. & dry matter, Trockenmasse $[\mathrm{g}]$ \\
\hline GLM & Varianzanalyse für unbalancierte Stichproben \\
\hline $\mathrm{k}_{m}$ & axiale hydraulische Leitfähigkeit $\left[\mathrm{m}^{4} \mathrm{MPa}^{-1} \mathrm{~s}^{-1}\right]$ \\
\hline $\mathrm{k}_{\text {Stheo }}$ & theoretische axiale Leitfähigkeit $\left[\mathrm{m}^{2} \mathrm{MPa}^{-1} \mathrm{~s}^{-1}\right]$ \\
\hline LAI & leaf area index, Blattflächenindex $\left[\mathrm{m}^{2} \mathrm{~m}^{-2}\right]$ \\
\hline $\mathrm{Lp}_{r}$ & hydraulische Leitfähigkeit der Wurzel $\left[\mathrm{m} \mathrm{MPa}^{-1} \mathrm{~s}^{-1}\right]$ \\
\hline MESZ & mitteleuropäische Sommerzeit \\
\hline $\min$ & Mineralboden \\
\hline $\mathrm{n}$ & Probenumfang \\
\hline org & organische Auflage \\
\hline $\mathrm{p}$ & Irrtumswahrscheinlichkeit \\
\hline $\mathrm{r}$ & Korrelationskoeffizient \\
\hline $\mathrm{R}^{2}$ & Bestimmtheitsmaß \\
\hline RAI & root area index, (Fein-)Wurzeloberflächenindex $\left[\mathrm{m}^{2} \mathrm{~m}^{-2}\right]$ \\
\hline SE & standard error, Standardfehler \\
\hline SPAC & soil plant atmosphere continuum \\
\hline SRA & specific root area, spezifische (Fein-)Wurzeloberfläche $\left[\mathrm{cm}^{2} \mathrm{~g}^{-1}\right]$ \\
\hline ssp. & subspecies, Unterart \\
\hline TDR & time domain reflectrometry, zur Bestimmung des Bodenwassergehalts \\
\hline VA-Myk. & vesikulär-arbusculäre Mykorrhiza \\
\hline VPD & vapour pressure deficit, Wasserdampfsättigungsdefizit der Luft [hPa] \\
\hline$\Delta \Psi ; \Psi_{\min }$ & Wasserpotentialgradient; Minimum-Wasserpotential [MPa] \\
\hline$\Theta$ & Bodenwassergehalt [vol.\%] \\
\hline
\end{tabular}


A Anhang 
Tab. A.1: Gleichungen der Verteilungskurven zur Häufigkeitsverteilung von Xylemgefäßen im Wurzelquerschnitt der sechs Baumarten im Hainich und der zwei Baumarten der Lüneburger Heide. Die Kurven werden beschrieben durch eine Gleichung des Typs $y=a+b \cdot e^{-\left(\frac{x-c}{d}\right)^{2}}$. Angegeben sind die Parameter der Gleichung, sowie der Korrelationskoeffizient $r$ und die Irrtumswahrscheinlichkeit $\mathrm{p}(\mathrm{n}=36)$.

\begin{tabular}{l|cccc|cc}
\hline Baumart & $\mathrm{a}$ & $\mathrm{b}$ & $\mathrm{c}$ & $\mathrm{d}$ & $\mathrm{r}$ & $\mathrm{p}$ \\
\hline Bergahorn & $-6.37 \cdot 10^{-16}$ & 20.47 & 5.12 & 3.28 & 0.94 & $\leq 0.001$ \\
Esche & $1.80 \cdot 10^{-16}$ & 20.50 & 4.83 & 3.27 & 0.95 & $\leq 0.001$ \\
Winterlinde & 2.16 & 18.98 & 5.27 & 3.43 & 0.96 & $\leq 0.001$ \\
Hainbuche & $3.95 \cdot 10^{-16}$ & 9.86 & 7.00 & 7.72 & 0.89 & $\leq 0.001$ \\
Stieleiche & $-1.48 \cdot 10^{-15}$ & 13.00 & 6.31 & 7.99 & 0.87 & $\leq 0.001$ \\
Buche & 0.80 & 14.71 & 8.16 & 5.82 & 0.89 & $\leq 0.001$ \\
\hline Traubeneiche & & & & & & \\
- org. Auflage & $1.37 \cdot 10^{-16}$ & 14.81 & 7.48 & 7.69 & 0.83 & $\leq 0.001$ \\
$\quad$ - Mineralboden & $-1.55 \cdot 10^{-16}$ & 13.95 & 7.70 & 6.59 & 0.87 & $\leq 0.001$ \\
Buche & & & & & & \\
$\quad$ - org. Auflage & $-5.36 \cdot 10^{-16}$ & 22.44 & 6.47 & 5.12 & 0.81 & $\leq 0.001$ \\
- Mineralboden & $2.98 \cdot 10^{-16}$ & 23.26 & 6.94 & 4.80 & 0.90 & $\leq 0.001$ \\
\hline
\end{tabular}

Tab. A.2: Saftflussdichten der sechs Baumarten, gemittelt über die Vegetationsperioden 2000 und 2001. $\mathrm{n}_{d}$ - Anzahl der Tage; $\mathrm{n}_{r}$ - Anzahl der Messwurzeln; $\bar{x}$ - Mittelwert mit Standardfehler; $\mathrm{x}_{0.75}, \mathrm{x}_{0.25}$ - oberes und unteres Quartil; max, min - Maximal- und Minimalwerte; VK Variationskoeffizient.

\begin{tabular}{l|ccccccccc}
\hline & \multicolumn{8}{|c}{ Saftflussdichte $\left[\mathrm{g} \mathrm{mm}^{-2} \mathrm{~d}^{-1}\right]$} \\
& $\mathrm{n}_{d}$ & $\mathrm{n}_{r}$ & $\bar{x} \pm \mathrm{se}$ & Median & $\mathrm{x}_{0.75}$ & $\mathrm{x}_{0.25}$ & $\max$ & $\min$ & $\mathrm{VK}$ \\
\hline Bergahorn & 489 & 18 & $2.75 \pm 0.21$ & 1.05 & 2.70 & 0.47 & 21.75 & 0.02 & 167.84 \\
Esche & 396 & 21 & $1.93 \pm 0.11$ & 1.40 & 2.40 & 0.67 & 20.08 & 0.02 & 111.31 \\
Winterlinde & 588 & 20 & $1.97 \pm 0.11$ & 1.03 & 2.46 & 0.49 & 16.82 & 0.02 & 131.29 \\
Hainbuche & 231 & 16 & $4.27 \pm 0.31$ & 2.19 & 6.11 & 1.00 & 24.80 & 0.02 & 110.28 \\
Stieleiche & 759 & 18 & $3.49 \pm 0.15$ & 1.88 & 4.91 & 0.85 & 26.82 & 0.01 & 114.82 \\
Buche & 663 & 19 & $3.42 \pm 0.14$ & 2.34 & 4.48 & 1.05 & 22.16 & 0.02 & 109.31 \\
\hline
\end{tabular}


Tab. A.3: Oberflächenspezifische Wasseraufnahmeraten der sechs Baumarten, gemittelt über die Vegetationsperioden 2000 und 2001. $\mathrm{n}_{d}$ - Anzahl der Tage; $\mathrm{n}_{r}$ - Anzahl der Messwurzeln; $\bar{x}$ - Mittelwert mit Standardfehler; $\mathrm{x}_{0.75}, \mathrm{x}_{0.25}$ - oberes und unteres Quartil; max, min - Maximalund Minimalwerte; VK - Variationskoeffizient.

\begin{tabular}{l|ccccccccc}
\hline & \multicolumn{7}{|c}{ Oberflächenspezifische Wasseraufnahmerate $\left[\mathrm{g} \mathrm{m}^{-2} \mathrm{~d}^{-1}\right]$} \\
& $\mathrm{n}_{d}$ & $\mathrm{n}_{r}$ & $\bar{x} \pm \mathrm{se}$ & Median & $\mathrm{x}_{0.75}$ & $\mathrm{x}_{0.25}$ & $\mathrm{max}$ & $\mathrm{min}$ & $\mathrm{VK}$ \\
\hline Bergahorn & 286 & 10 & $3189.1 \pm 425.7$ & 838.4 & 2278.5 & 225.9 & 55360.0 & 17.8 & 225.7 \\
Esche & 298 & 15 & $3423.3 \pm 275.3$ & 1973.1 & 4092.3 & 1055.3 & 24630.0 & 34.1 & 138.8 \\
Winterlinde & 380 & 12 & $2284.7 \pm 116.8$ & 1467.9 & 3147.9 & 727.6 & 1618.00 & 24.5 & 99.6 \\
Hainbuche & 177 & 10 & $1330.9 \pm 113.7$ & 760.1 & 1612.7 & 433.6 & 7130.0 & 6.4 & 113.7 \\
Stieleiche & 469 & 12 & $1041.3 \pm 44.0$ & 762.6 & 1513.7 & 327.8 & 8650.0 & 10.3 & 91.6 \\
Buche & 413 & 13 & $1967.2 \pm 144.9$ & 903.9 & 2219.6 & 459.5 & 25400.0 & 4.8 & 149.7 \\
\hline
\end{tabular}

Tab. A.4: Oberflächenspezifische Wasseraufnahmerate der Feinstwurzeln $(<1 \mathrm{~mm})$ der sechs Baumarten, gemittelt über die Vegetationsperioden 2000 und 2001. $\mathrm{n}_{d}$ - Anzahl der Tage; $\mathrm{n}_{r}$ - Anzahl der Messwurzeln; $\bar{x}$ - Mittelwert mit Standardfehler; $\mathrm{x}_{0.75}, \mathrm{x}_{0.25}$ - oberes und unteres Quartil; max, min - Maximal- und Minimalwerte; VK - Variationskoeffizient.

\begin{tabular}{l|ccccccccc}
\hline & \multicolumn{6}{|c}{ Oberflächenspezifische Wasseraufnahmerate der Feinstwurzeln[g m $\left.{ }^{-2} \mathrm{~d}^{-1}\right]$} \\
& $\mathrm{n}_{d}$ & $\mathrm{n}_{r}$ & $\bar{x} \pm \mathrm{se}$ & Median & $\mathrm{x}_{0.75}$ & $\mathrm{x}_{0.25}$ & $\max$ & $\min$ & $\mathrm{VK}$ \\
\hline Bergahorn & 286 & 10 & $6551.9 \pm 930.5$ & 1290.3 & 3855.3 & 310.1 & 120141.0 & 25.3 & 240.2 \\
Esche & 298 & 15 & $5777.1 \pm 417.6$ & 3499.1 & 7139.1 & 1750.5 & 60722.0 & 71.1 & 124.8 \\
Winterlinde & 380 & 12 & $3924.7 \pm 223.1$ & 2322.8 & 5195.0 & 1170.2 & 30272.0 & 44.7 & 110.8 \\
Hainbuche & 177 & 10 & $2231.0 \pm 178.8$ & 1298.8 & 2858.2 & 682.4 & 12701.0 & 8.3 & 106.6 \\
Stieleiche & 469 & 12 & $2658.5 \pm 204.7$ & 1301.1 & 2648.9 & 529.3 & 49220.0 & 13.9 & 166.8 \\
Buche & 413 & 13 & $3426.8 \pm 287.2$ & 1433.8 & 3291.1 & 705.8 & 46205.0 & 7.4 & 170.3 \\
\hline
\end{tabular}


Tab. A.5: Saftflussdichten von Eichen- und Buchenwurzeln, gemittelt über die Monate August und September 2001 im Hainich und der Lüneburger Heide. $\mathrm{n}_{d}$ - Anzahl der Tage, $\mathrm{n}_{r}$ - Anzahl der Messwurzeln, $\bar{x}$ - Mittelwert mit Standardfehler, $\mathrm{x}_{0.75}, \mathrm{x}_{0.25}$ - oberes und unteres Quartil, max, min - Maximal- und Minimalwerte, VK - Variationskoeffizient.

\begin{tabular}{l|ccccccccc}
\hline & \multicolumn{8}{|c}{ Saftflussdichte $\left[\mathrm{g} \mathrm{mm}^{-2} \mathrm{~d}^{-1}\right]$} \\
& $\mathrm{n}_{d}$ & $\mathrm{n}_{r}$ & $\bar{x} \pm \mathrm{se}$ & Median & $\mathrm{x}_{0.75}$ & $\mathrm{x}_{0.25}$ & $\max$ & $\min$ & $\mathrm{VK}$ \\
\hline Stieleiche & 153 & 9 & $2.18 \pm 0.24$ & 21.87 & 2.47 & 1.25 & 0.55 & 0.10 & 137.91 \\
Buche & 238 & 9 & $3.56 \pm 0.30$ & 22.16 & 4.53 & 1.97 & 0.95 & 0.08 & 130.99 \\
Traubeneiche & & & & & & & & & \\
org. Auflage & 70 & 6 & $1.58 \pm 0.12$ & 5.39 & 2.26 & 1.48 & 0.72 & 0.37 & 61.97 \\
Mineralboden & 27 & 3 & $0.68 \pm 0.06$ & 1.29 & 0.94 & 0.68 & 0.44 & 0.09 & 46.76 \\
Buche & & & & & & & & & \\
org. Auflage & 105 & 8 & $2.12 \pm 0.24$ & 17.31 & 2.44 & 1.43 & 0.73 & 0.15 & 116.71 \\
Mineralboden & 14 & 2 & $1.01 \pm 0.18$ & 2.63 & 1.40 & 0.80 & 0.49 & 0.20 & 66.94 \\
\hline
\end{tabular}

Tab. A.6: Oberflächenspezifische Wasseraufnahmerte von Eichen- und Buchenwurzeln aus dem Hainich und der Lüneburger Heide, gemittelt über die Monate August und September 2001. In der Lüneburger Heide wurde zwischen Wurzeln der organischen Auflage (org) und dem Mineralboden (min) unterschieden. $\mathrm{n}_{d}$ - Anzahl der Tage, $\mathrm{n}_{r}$ - Anzahl der Messwurzeln, $\bar{x}-$ Mittelwert mit Standardfehler, $\mathrm{x}_{0.75}, \mathrm{x}_{0.25}$ - oberes und unteres Quartil, max, min - Maximalund Minimalwerte, VK - Variationskoeffizient.

\begin{tabular}{l|ccccccccc}
\hline & \multicolumn{7}{|c}{ Oberflächenspezifischen Wassaufnahmerate $\left[\mathrm{g} \mathrm{m}^{-2} \mathrm{~d}^{-1}\right]$} \\
& $\mathrm{n}_{d}$ & $\mathrm{n}_{r}$ & $\bar{x} \pm \mathrm{se}$ & Median & $\mathrm{x}_{0.75}$ & $\mathrm{x}_{0.25}$ & max & min & VK \\
\hline Eiche & 73 & 9 & $784.80 \pm 79.92$ & 3931.10 & 1088.80 & 573.74 & 309.08 & 36.27 & 87.01 \\
Buche & 153 & 9 & $1969.30 \pm 285.76$ & 25414.70 & 1461.00 & 729.07 & 314.41 & 60.76 & 179.49 \\
Traubeneiche \\
- org & 70 & 6 & $211.80 \pm 27.87$ & 1082.70 & 273.50 & 114.66 & 58.34 & 15.80 & 110.07 \\
- min & 24 & 2 & $117.20 \pm 13.53$ & 317.30 & 145.30 & 106.90 & 70.53 & 18.43 & 56.61 \\
Buche & & & & & & & & & \\
- org & 81 & 7 & $261.40 \pm 36.77$ & 2224.60 & 295.50 & 165.30 & 96.16 & 16.06 & 126.58 \\
- min & 14 & 2 & $331.10 \pm 74.81$ & 1042.90 & 349.00 & 238.51 & 195.24 & 44.22 & 84.54 \\
\hline
\end{tabular}


Tab. A.7: Korrelationskoeffizienten und Irrtumswahrscheinlichkeiten (kursiv) der signifikanten Korrelationen $(\mathrm{p}<0.05)$ zwischen der Saftflussdichte einzelner Wurzeln und den Parametern Strahlungsbilanz (Q), Wasserdampfsättigungsdefizit der Luft (VPD) und volumetrischer Bodenwassergehalt $(\theta)$.

\begin{tabular}{|c|c|c|c|c|c|c|c|}
\hline Bergahorn & $Q$ & VPD & $\Theta$ & Esche & $Q$ & VPD & $\Theta$ \\
\hline BAh1.1 & $\begin{aligned} & 0.75 \\
\leq & 0.0001\end{aligned}$ & $\begin{array}{c}0.75 \\
\leq 0.0001\end{array}$ & & Es5.1 & $\begin{array}{c}0.68 \\
0.0029\end{array}$ & $\begin{array}{c}0.82 \\
\leq 0.0001\end{array}$ & \\
\hline BAh1.2 & $\begin{array}{c}0.67 \\
\leq 0.0001\end{array}$ & $\begin{array}{c}0.70 \\
\leq 0.0001\end{array}$ & & Es5.2 & $\begin{array}{c}0.69 \\
0.0022\end{array}$ & $\begin{array}{c}0.83 \\
\leq 0.0001\end{array}$ & \\
\hline BAh1.3 & & & $\begin{array}{c}0.61 \\
\leq 0.0001\end{array}$ & Es5.7 & $\begin{array}{c}0.86 \\
0.0013\end{array}$ & $\begin{array}{l}0.77 \\
0.01\end{array}$ & \\
\hline BAh1.4 & & & $\begin{array}{c}0.46 \\
0.0013\end{array}$ & Es5.6 & & & $\begin{array}{l}0.55 \\
0.041\end{array}$ \\
\hline BAh1.6 & & & $\begin{array}{c}0.66 \\
\leq 0.0001\end{array}$ & Es5.9 & $\begin{array}{c}0.66 \\
0.0036\end{array}$ & $\begin{array}{c}0.63 \\
0.0063\end{array}$ & \\
\hline BAh1.7 & $\begin{array}{c}0.38 \\
0.046\end{array}$ & $\begin{array}{l}0.36 \\
0.01\end{array}$ & & Es3.3 & $\begin{array}{c}0.58 \\
0.0005\end{array}$ & $\begin{array}{c}0.62 \\
0.0001\end{array}$ & \\
\hline BAh1.10 & $\begin{array}{c}0.42 \\
0.032\end{array}$ & $\begin{array}{c}0.50 \\
0.003\end{array}$ & & Es3.4 & $\begin{array}{l}0.38 \\
0.03\end{array}$ & & \\
\hline BAh2.6 & $\begin{array}{c}0.85 \\
0.0034\end{array}$ & $\begin{array}{c}0.84 \\
0.005\end{array}$ & $\begin{array}{l}0.78 \\
0.07\end{array}$ & $\begin{array}{l}\text { Es3.6 } \\
\text { Es3.9 }\end{array}$ & $\begin{array}{c}0.47 \\
0.03 \\
0.67 \\
\leq 0.0001\end{array}$ & $\begin{aligned} & 0.86 \\
\leq & 0.0001\end{aligned}$ & \\
\hline
\end{tabular}


Tab. A.8: Korrelationskoeffizienten und Irrtumswahrscheinlichkeiten (kursiv) der signifikanten Korrelationen $(\mathrm{p}<0.05)$ zwischen der Saftflussdichte einzelner Wurzeln und den Parametern Strahlungsbilanz (Q), Wasserdampfsättigungsdefizit der Luft (VPD) und volumetrischer Bodenwassergehalt $(\theta)$.

\begin{tabular}{|c|c|c|c|c|c|c|c|}
\hline Winterlinde & $\mathrm{Q}$ & VPD & $\Theta$ & Hainbuche & $\mathrm{Q}$ & VPD & $\Theta$ \\
\hline \multirow[t]{2}{*}{$\mathrm{Li} 2.4$} & & 0.52 & & Hbu6.7 & 0.54 & 0.76 & \\
\hline & & 0.0018 & & & 0.038 & 0.001 & \\
\hline \multirow[t]{2}{*}{ Li2. 6} & & & 0.40 & HBu6.10 & 0.55 & 0.72 & \\
\hline & & & 0.0227 & & 0.015 & 0.004 & \\
\hline \multirow[t]{2}{*}{$\mathrm{Li} 2.10$} & 0.44 & 0.57 & & HBu4.1 & 0.66 & 0.73 & \\
\hline & 0.01 & $\leq 0.0001$ & & & 0.014 & 0.004 & \\
\hline \multirow[t]{2}{*}{$\mathrm{Li} 4.1$} & 0.45 & & & $\mathrm{HBu} 4.2$ & 0.62 & 0.78 & \\
\hline & 0.018 & & & & 0.03 & 0.0026 & \\
\hline \multirow[t]{2}{*}{$\mathrm{Li} 4.2$} & 0.44 & & & $\mathrm{HBu} 4.4$ & & 0.76 & \\
\hline & 0.02 & & & & & 0.0024 & \\
\hline \multirow[t]{2}{*}{$\mathrm{Li} 4.5$} & & 0.69 & & $\mathrm{HBu} 4.7$ & & 0.73 & \\
\hline & & 0.0015 & & & & 0.015 & \\
\hline \multirow[t]{2}{*}{ Li4.7 } & 0.80 & 0.79 & & & & & \\
\hline & $\leq 0.0001$ & $\leq 0.0001$ & & & & & \\
\hline \multirow[t]{2}{*}{$\mathrm{Li} 4.8$} & 0.49 & & 0.51 & & & & \\
\hline & 0.0075 & & 0.04 & & & & \\
\hline \multirow[t]{2}{*}{ Li4.10 } & 0.52 & 0.43 & 0.72 & & & & \\
\hline & 0.0049 & 0.023 & 0.001 & & & & \\
\hline
\end{tabular}


Tab. A.9: Korrelationskoeffizienten und Irrtumswahrscheinlichkeiten (kursiv) der signifikanten Korrelationen $(\mathrm{p}<0.05)$ zwischen der Saftflussdichte einzelner Wurzeln und den Parametern Strahlungsbilanz (Q), Wasserdampfsättigungsdefizit der Luft (VPD) und volumetrischer Bodenwassergehalt $(\theta)$.

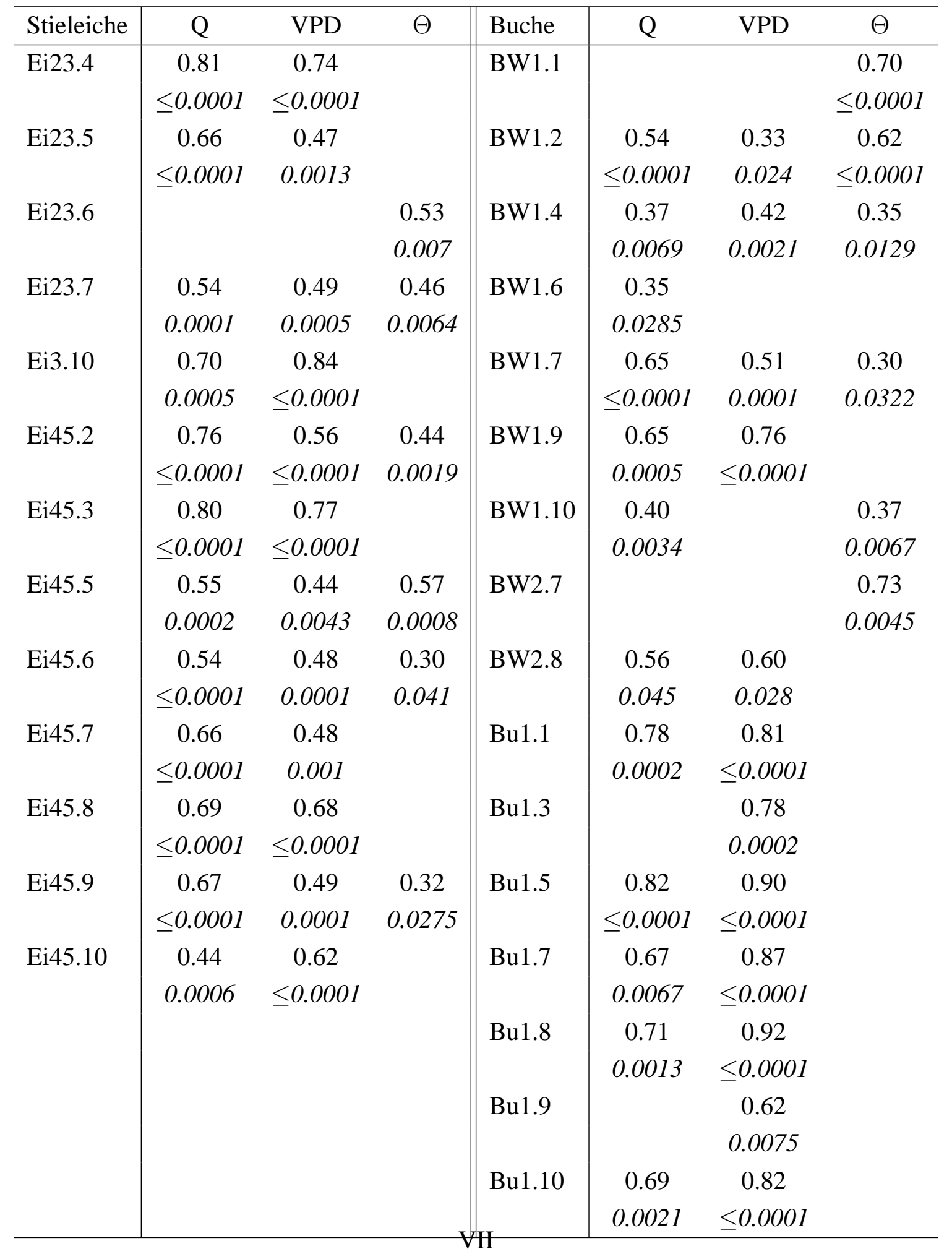


Tab. A.10: Korrelationskoeffizienten und Irrtumswahrscheinlichkeiten (kursiv) der signifikanten Korrelationen $(\mathrm{p}<0.05)$ zwischen der Saftflussdichte einzelner Wurzeln und den Parametern Strahlungsbilanz $(\mathrm{Q})$, Wasserdampfsättigungsdefizit der Luft (VPD) und volumetrischer Bodenwassergehalt $(\theta)$.

\begin{tabular}{l|ccc||l|lll}
\hline Traubeneiche & Q & VPD & $\Theta$ & Buche & Q & VPD & $\Theta$ \\
\hline Hei1.1 & 0.71 & 0.58 & 0.69 & Hei1.6 & 0.87 & 0.72 & \\
Hei1.2 & $\leq 0.0001$ & 0.002 & 0.001 & & 0.001 & 0.019 & \\
& & & 0.80 & Hei1.7 & 0.58 & 0.64 & 0.72 \\
Hei1.3 & & & $\leq 0.0001$ & & 0.0004 & 0.0001 & $\leq 0.0001$ \\
& & & 0.67 & Hei1.9 & 0.87 & 0.70 & \\
Hei1.4 & & & 0.003 & & $\leq 0.0001$ & 0.0004 & \\
& 0.78 & 0.65 & & Hei1.10 & 0.65 & 0.60 & 0.52 \\
Hei2.1 & 0.001 & 0.012 & & & 0.0002 & 0.0008 & 0.021 \\
& 0.65 & 0.87 & & Hei2.6 & 0.59 & 0.80 & \\
Hei2.2 & 0.022 & 0.0003 & & & 0.042 & 0.002 & \\
& 0.64 & 0.90 & & Hei2.7 & 0.59 & 0.79 & \\
Hei2.3 & 0.026 & $\leq 0.0001$ & & & 0.045 & 0.002 & \\
& 0.76 & 0.97 & & Hei2.9 & & & 0.89 \\
Hei2.4 & 0.004 & $\leq 0.0001$ & & & & & 0.019 \\
& 0.63 & 0.78 & & Hei2.10 & 0.66 & 0.93 & \\
\hline
\end{tabular}

